\title{
WestVirginiaUniversity
}

THE RESEARCH REPOSITORY @ WVU

Graduate Theses, Dissertations, and Problem Reports

2000

\section{Enhanced design for oxy -fuel fired batch tanks using CFD methods}

Guosheng Kang

West Virginia University

Follow this and additional works at: https://researchrepository.wvu.edu/etd

\section{Recommended Citation}

Kang, Guosheng, "Enhanced design for oxy -fuel fired batch tanks using CFD methods" (2000). Graduate Theses, Dissertations, and Problem Reports. 3179.

https://researchrepository.wvu.edu/etd/3179

This Dissertation is protected by copyright and/or related rights. It has been brought to you by the The Research Repository @ WVU with permission from the rights-holder(s). You are free to use this Dissertation in any way that is permitted by the copyright and related rights legislation that applies to your use. For other uses you must obtain permission from the rights-holder(s) directly, unless additional rights are indicated by a Creative Commons license in the record and/ or on the work itself. This Dissertation has been accepted for inclusion in WVU Graduate Theses, Dissertations, and Problem Reports collection by an authorized administrator of The Research Repository @ WVU.

For more information, please contact researchrepository@mail.wvu.edu. 


\title{
ENHANCED DESIGN FOR OXY-FUEL FIRED BATCH TANKS USING CFD METHODS
}

\author{
Guosheng Kang \\ DISSERTATION \\ Submitted to the College of Engineering and Mineral Resources \\ at West Virginia University \\ in partial fulfillment of the requirements for the degree of \\ Doctor of Philosophy in Mechanical Engineering \\ Mechanical and Aerospace Engineering Department
}

Ismail Celik, Ph.D.

Nigel Clark, Ph.D.

Gary Morris, Ph.D.

Victor Mucino, Ph.D.

Carl Rotter, Ph.D.

John E. Sneckenberger, Ph.D., Chair

Morgantown, West Virginia

2000

Keywords: Glass Melting, Batch Tank, Oxy-Fuel, Computational Fluid Dynamics Copyright 2000 Guosheng Kang 


\title{
ABSTRACT \\ Enhanced Design for Oxy-Fuel Fired Batch Tanks Using CFD Methods
}

\author{
Guosheng Kang
}

\begin{abstract}
Oxy-fuel firing is more energy efficient and environment friendly than conventional air-fuel firing and its application for glass melting has begun since 1990 . This technology has been advanced for continuous glass melting furnaces based on continued research and application experiences accumulation, while its application in batch tanks is experiencing a transition period. Batch tanks are commonly used by the hand and art glass companies. Compared to continuous furnaces, a batch tank has smaller size and higher operation temperature. The four primary concerns in the application of oxy-fuel firing in batch tanks are (1) The high flame temperature of oxyfuel firing may overheat the batch tank refractory; because of batch tank's size, both flame length and width are critical factors for batch tank design. (2) Flame length and width as well as flame temperature depend on burner design, therefore, research on oxyfuel burner performances is indispensable for enhanced batch tank design. (3) Proper burner placement in batch tank makes better heat transfer to glass while avoiding overheating refractory. (4) $\mathrm{NO}_{\mathrm{x}}$ formation in an oxy-fuel fired batch tank is sensitive to the nitrogen content in both fuel and oxygen supply, and to oxygen fuel mixing pattern as well as tank geometry. The $\mathrm{NO}_{\mathrm{x}}$ emissions need to be predicted for enhancement of burner design, burner placement, and tank geometry design as well as settings of operation parameters.

This research focused on the above four primary concerns of oxy-fuel firing and specified the primary aspects of an oxy-fuel batch tank design. The physical and chemical processes of the combustion and heat transfer were analyzed and modeled using computational fluid dynamics (CFD) methods. Based on the modeling of the geometry, the turbulence, the chemical reaction, the radiation, the $\mathrm{NO}_{\mathrm{x}}$ formation, and the soot formation, these specified aspects of most concern in batch tank design were simulated using commercial CFD software FLUENT.

Oxy-fuel flame features and the burner-tank compatibility as well as the $\mathrm{NO}_{\mathrm{x}}$ emissions were simulated. First, the commonly used traditional coaxial burners with a wide range of jet velocities were systematically studied and fuel-oxygen velocities were optimized, which provides a guidance of burner selection and operating condition setting for small and medium batch tanks. Second, flat flame burners were studied for medium and large batch tanks. It is found that flat flame has better flame coverage over glass surface and better overall temperature distribution, which enhances heat transfer to glass while lessens superstructure refractory corrosion and reduces $\mathrm{NO}_{\mathrm{x}}$ emissions. The effect of buoyancy on flame propagation can be counteracted by calculated direction setting of the flat flame burner. Third, burner placement in batch tank was investigated to ensure an appropriate match between the oxy-fuel burner(s) and a batch tank. The results of this research provide an overall understanding of the batch tank design and operation, and will help in dissemination of oxy-fuel firing technology in the hand glass industry.
\end{abstract}


This dissertation is dedicated to the hand glass industry 


\section{ACKNOWLEDGMENTS}

I am very grateful for having this great opportunity to work for the hand glass industry, where science and art are combined.

I would like to thank my research advisor Dr. John E. Sneckenberger for his guidance, support and patience as well as providing opportunities for my frequent exposure in real world engineering with dozens of industrial companies, without which this research project would not be a contribution to the hand glass industry.

I would like to thank all of my committee members, Dr. Ismail Celik, Dr. Nigel Clark, Dr. Gary Morris, Dr. Victor Mucino, Dr. Carl Rotter, and Dr. John E. Sneckenberger for their invaluable support and contributions through this research project. Special thanks are also due to all faculty and staff in the Mechanical and Aerospace Engineering Department for their assistance to my academic study and dissertation research.

It has been my privilege to be associated with the Projects With Industry (PWI) Program at West Virginia University. Many research ideas that reflect the concerns of the hand glass companies were inspired during the on-site work with glass plant managers and operation engineers. I would like to acknowledge the support from West Virginia Development Office and the Energy Efficiency Program whose manager is Jeff Herholdt. The support made the visits to glass companies and the research activities happen. I would like to thank Harry Fontana at L.E. Smith Glass Company, Don Coe at AGA Gas Inc., Daniel Ertl at Maxon Corporation for their help from the view of real world engineering. Many other people in several additional glass companies and glass services contributed to this research, although their names could not be listed here.

Finally, I would like to thank my wife Qing, whose love and support have made it possible for me to accomplish this task. 


\section{TABLE OF CONTENT}

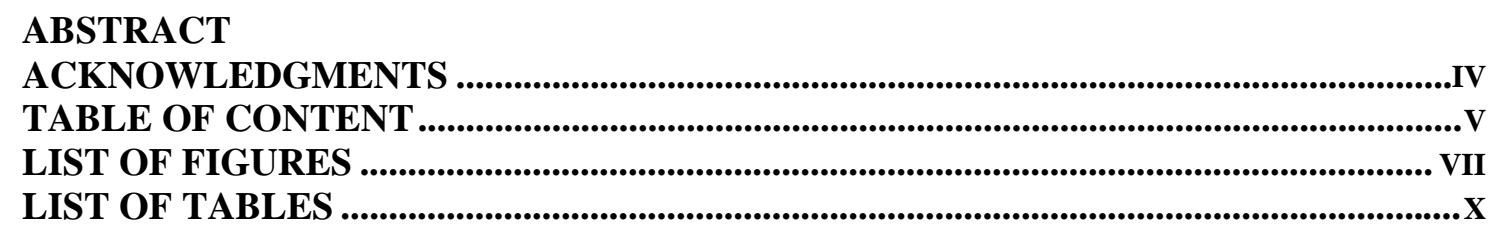

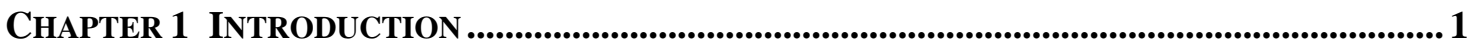

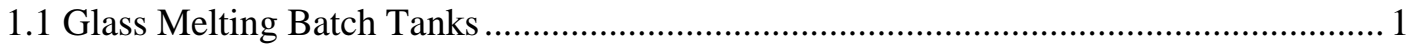

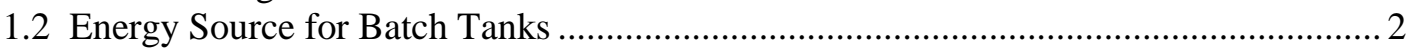

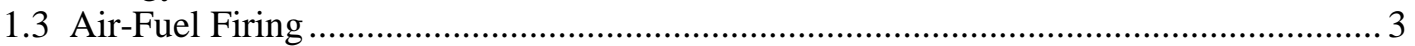

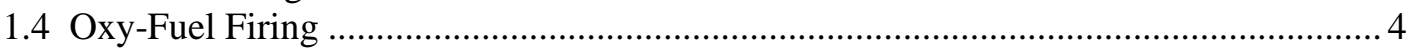

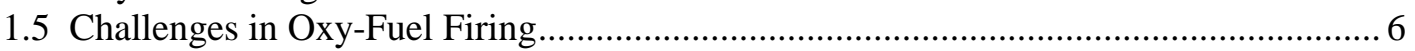

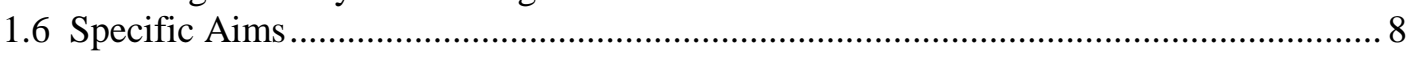

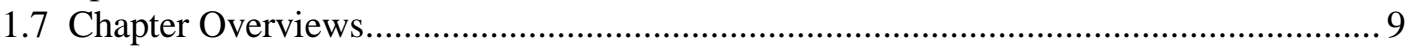

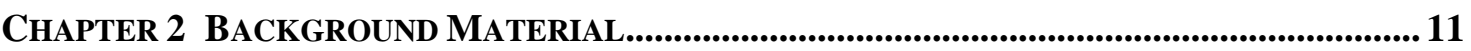

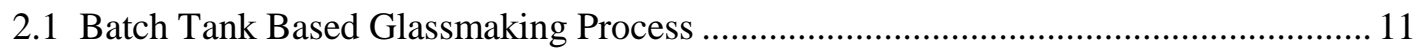

2.2 Energy Consumption for Glass Melting Process ........................................................ 13

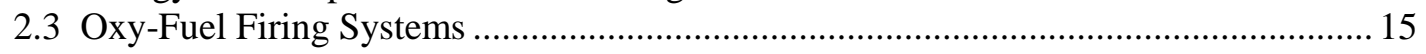

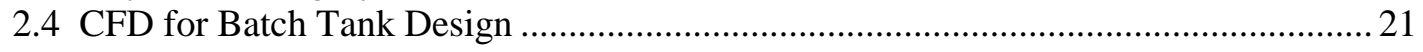

Chapter 3 Analysis of Combustion AND Heat TranSFer.......................................26

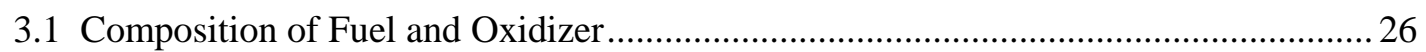

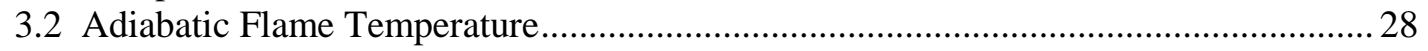

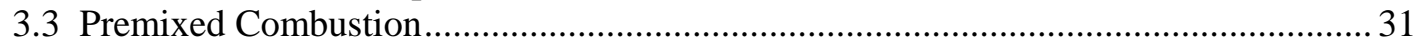

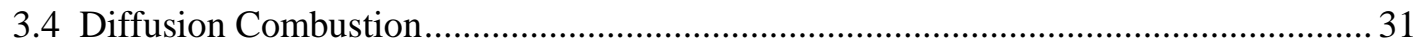

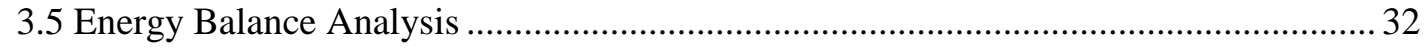

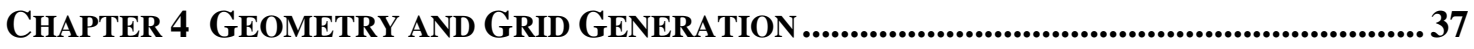

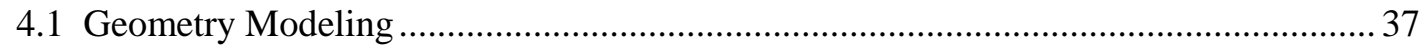

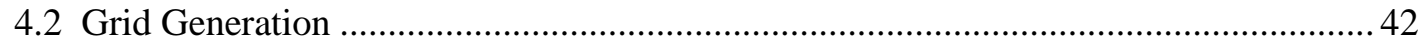

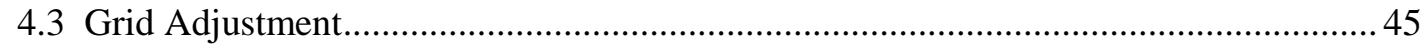

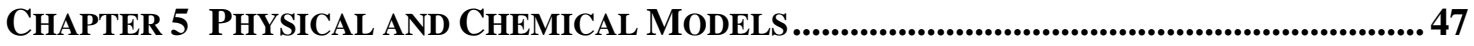

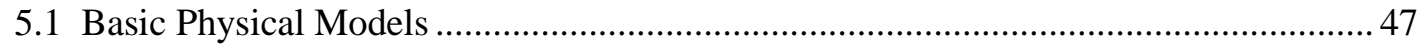

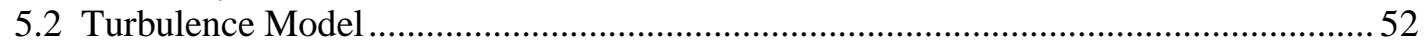

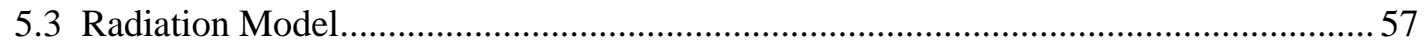

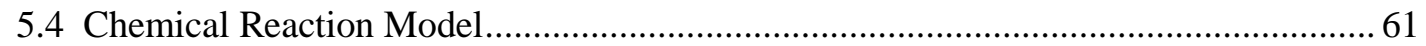

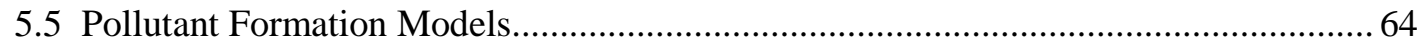

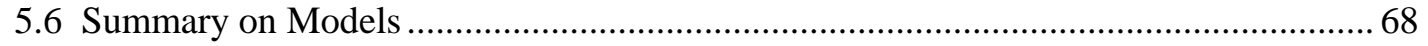

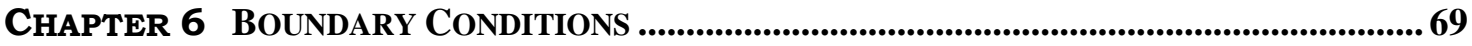

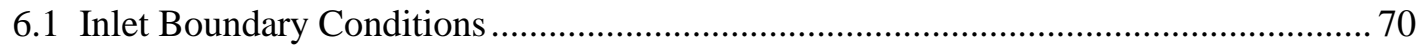

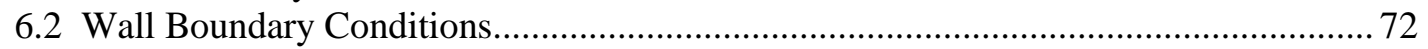

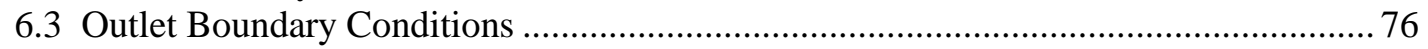

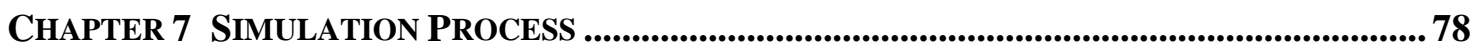

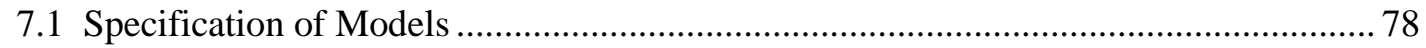




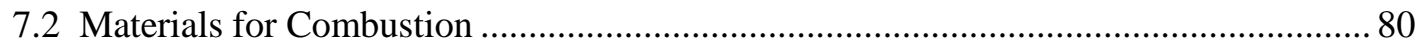

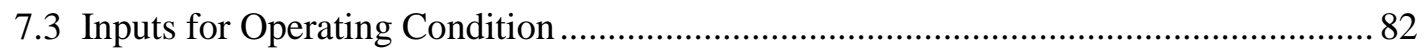

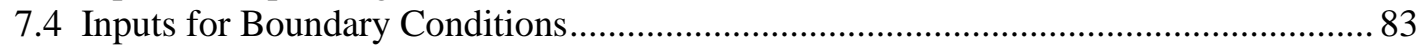

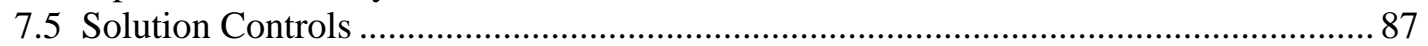

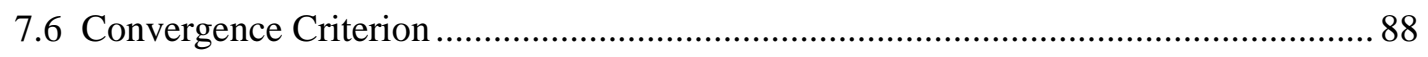

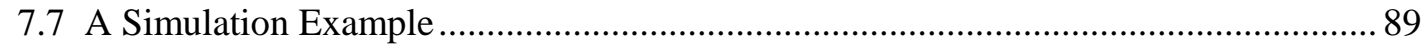

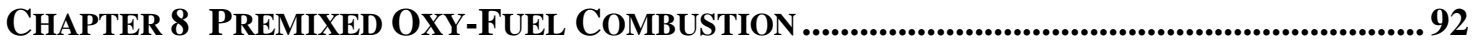

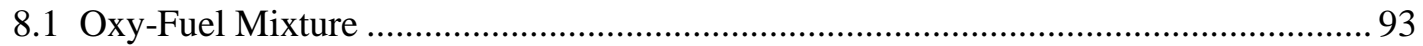

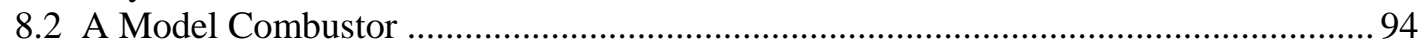

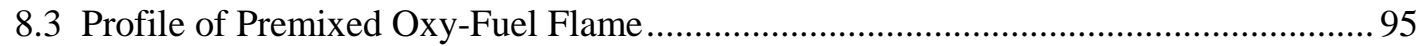

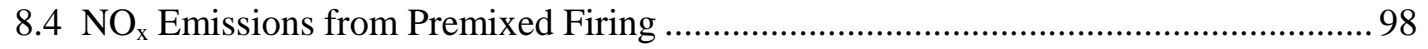

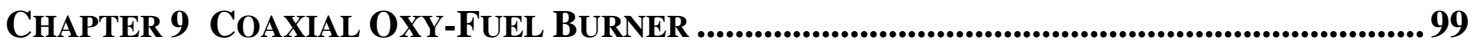

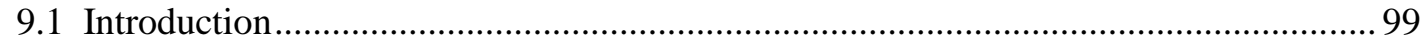

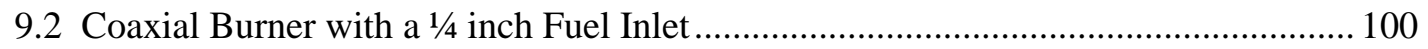

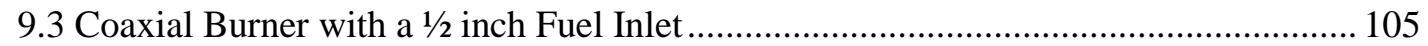

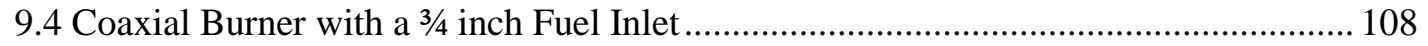

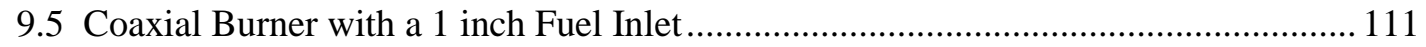

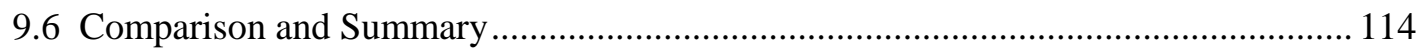

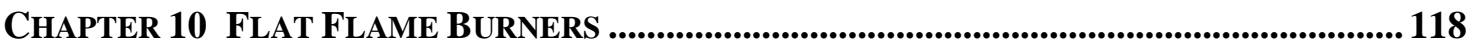

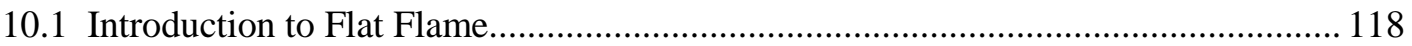

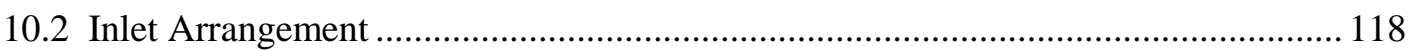

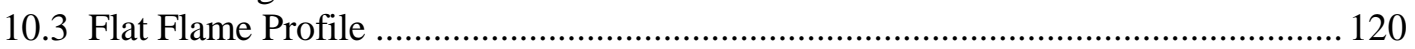

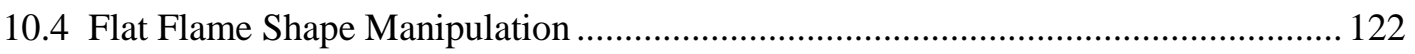

Chapter 11 BuRner Placement ANd Batch Tank Design............................................ 124

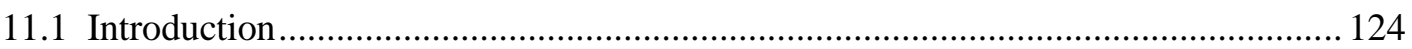

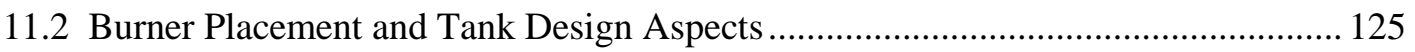

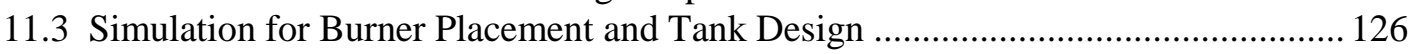

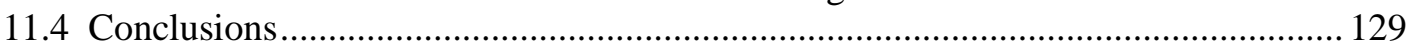

ChaPTER 12 SUMMARY, CONTRIBUtIONS AND FUTURE WORK......................................... 130

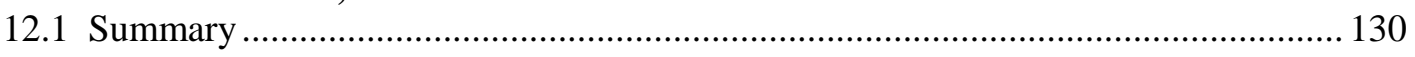

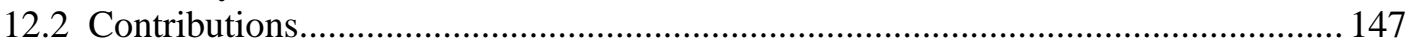

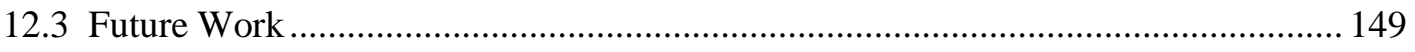

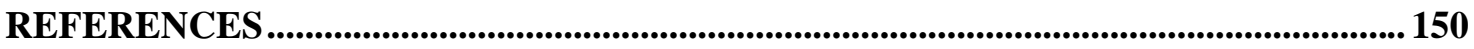




\section{LIST OF FIGURES}

Figure 1.1 Basic structure of a batch tank ........................................................................... 2

Figure 1.2 Glass melting process of a typical batch tank ..................................................... 3

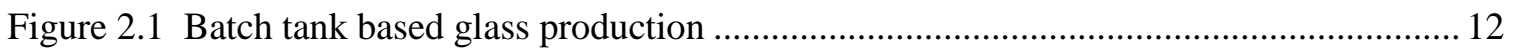

Figure 2.2 History of batch melting in an air-fuel batch tank................................................ 14

Figure 2.3 A batch tank for view factor calculation .............................................................. 19

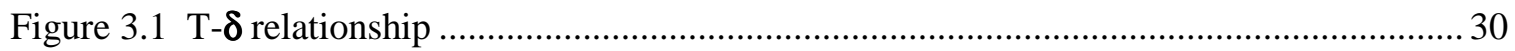

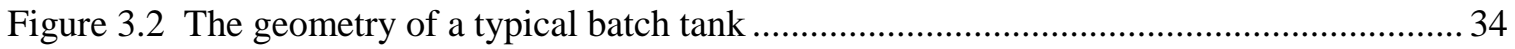

Figure 4.1 A cylindrical oxy-fuel combustor (burner is not shown) ......................................... 38

Figure 4.2 Axisymmetric geometry of a cylindrical combustor ................................................. 38

Figure 4.3 Rectangular batch tank (crown removed) ................................................................ 39

Figure 4.4 Hexagonal batch tank (crown removed) ................................................................. 39

Figure 4.5 Geometry of computation domain for a batch tank ................................................ 41

Figure 4.6 Geometry of a batch tank prepared to structured gird generation .............................. 41

Figure 4.7 Structured grid of 2-D axis-symmetric plane for a cylindrical combustor................. 43

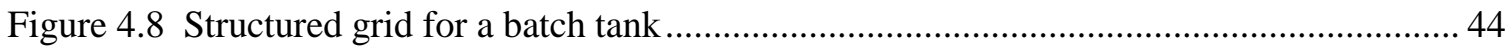

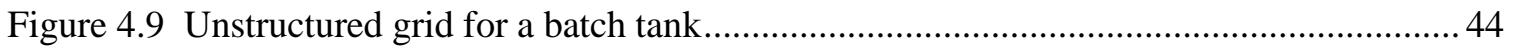

Figure 4.10 Solution based grid adaption. Left: before adaption; Right: after adaption ............. 46

Figure 5.1 Temperature contours of coaxial burner flame using different turbulence models..... 56

Figure 5.2 Temperature profiles predicted with three different radiation models ....................... 60

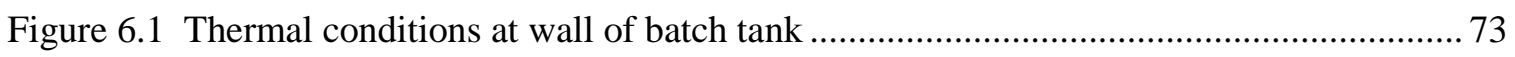

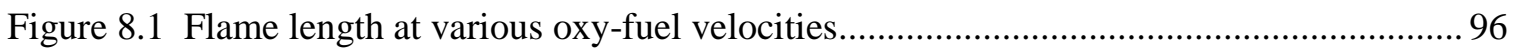

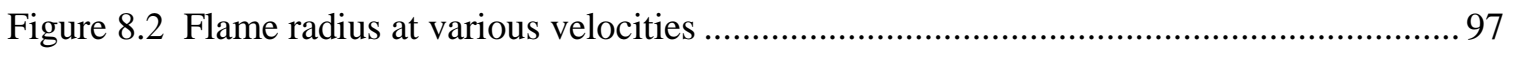

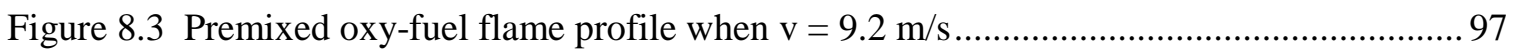

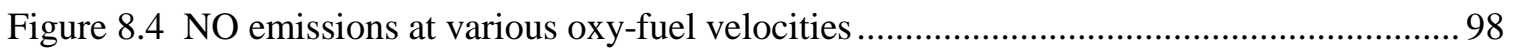


Figure 9.1 Coaxial burner schematic

Figure 9.2 Flame length and flame width of a coaxial burner with $1 / 4$ inch fuel inlet................. 102

Figure 9.3 Peak temperature and $\mathrm{NO}_{\mathrm{x}}$ emission of a coaxial burner with $1 / 4$ inch fuel inlet....... 103

Figure 9.4 A coaxial burner with $1 / 4$ inch fuel inlet runs at two fuel consumption rates ............. 104

Figure 9.5 Flame length and flame width of a coaxial burner with $1 / 2$ inch fuel inlet................. 106

Figure 9.6 Peak temperature and $\mathrm{NO}_{\mathrm{x}}$ emission of a coaxial burner with $\frac{1}{2} 2$ inch fuel inlet ....... 107

Figure 9.7 Flame length and flame width of a coaxial burner with $3 / 4$ inch fuel inlet ................ 109

Figure 9.8 Peak temperature and $\mathrm{NO}_{\mathrm{x}}$ emission of a coaxial burner with $3 / 4$ inch fuel inlet ....... 110

Figure 9.9 Flame length and flame width of a coaxial burner with 1 inch fuel inlet.................. 112

Figure 9.10 Peak temperature and $\mathrm{NO}_{\mathrm{x}}$ emission of a coaxial burner with 1 inch fuel inlet ...... 113

Figure 9.11 Flame shape of a coaxial burner with 1 inch fuel inlet, $V_{\text {oxygen }}=4.2 \mathrm{~m} / \mathrm{s} \ldots \ldots \ldots \ldots . . .114$

Figure 9.12 Flame profile comparison among burners with $1 / 4,1 / 2,3 / 4$, and 1 inch fuel inlet ....... 115

Figure 9.13 Wall temperature distribution along axial direction .......................................... 116

Figure 10.1 Fuel and oxygen inlets of a flat flame burner................................................ 119

Figure 10.2 Temperature contour on two orthogonal planes................................................ 121

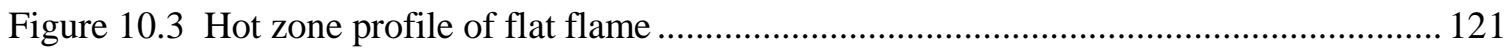

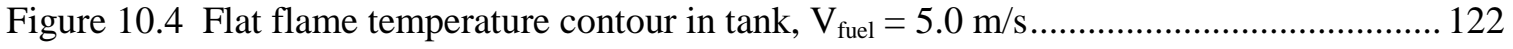

Figure 10.5 Flat flame profile and temperature distribution in tank, $\mathrm{V}_{\text {fuel }}=5.0 \mathrm{~m} / \mathrm{s} \ldots \ldots \ldots \ldots \ldots \ldots \ldots$

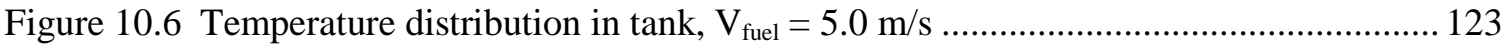

Figure 11.1 Schematic of burner placement in a batch tank .............................................. 125

Table 11.1 Parameters of burner and tank and operating condition ...................................... 126

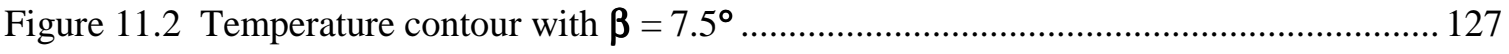

Figure 11.3 Temperature contour for extended tank and redirected burner ............................. 128

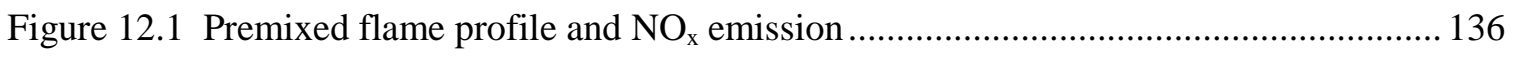

Figure 12.2 Flame length and flame width of a coaxial burner with $1 / 4$ inch fuel inlet.............. 137

Figure 12.3 Peak temperature and $\mathrm{NO}_{\mathrm{x}}$ emission of a coaxial burner with $1 / 4$ inch fuel inlet..... 138 
Figure 12.4 Flame length and flame width of a coaxial burner with $1 / 2$ inch fuel inlet ............... 139

Figure 12.5 Peak temperature and $\mathrm{NO}_{\mathrm{x}}$ emission of a coaxial burner with $1 / 2$ inch fuel inlet..... 140

Figure 12.6 Flame length and flame width of a coaxial burner with $3 / 4$ inch fuel inlet.............. 141

Figure 12.7 Peak temperature and $\mathrm{NO}_{\mathrm{x}}$ emission of a coaxial burner with $3 / 4$ inch fuel inlet..... 142

Figure 12.8 Flame length and flame width of a coaxial burner with 1 inch fuel inlet............... 143

Figure 12.9 Peak temperature and $\mathrm{NO}_{\mathrm{x}}$ emission of a coaxial burner with 1 inch fuel inlet...... 144

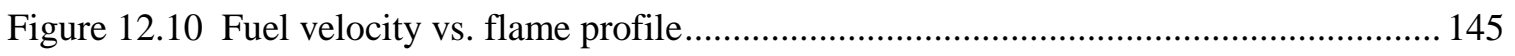

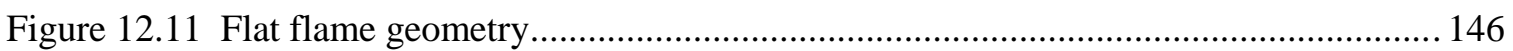




\section{LIST OF TABLES}

Table 1.1 Comparison of volatile components in exhaust for two firings ................................... 8

Table 3.1 Components of some commercial natural gases distribution in US cities ...................2 27

Table 3.2 Ideal Gas Properties of Carbon Dioxide and Water [38] ............................................ 30

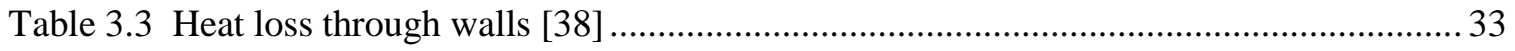

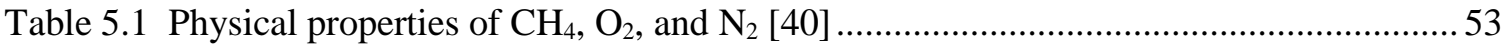

Table 5.2 Assessment Results of Radiation Models ................................................................... 60

Table 5.3 Physical Models and Chemical Reaction Models for a Batch Tank............................. 68

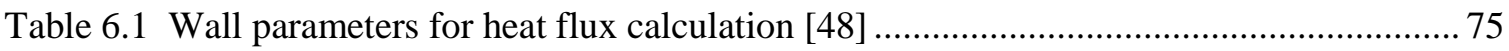

Table 6.2 Heat flux through walls of a typical batch tank ...................................................... 75

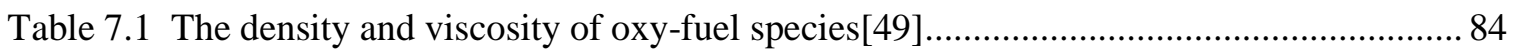

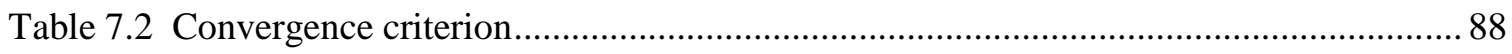

Table 8.1 Composition of the oxy-fuel mixture at given oxygen purity................................... 94

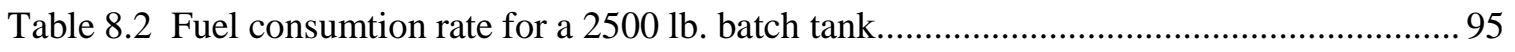

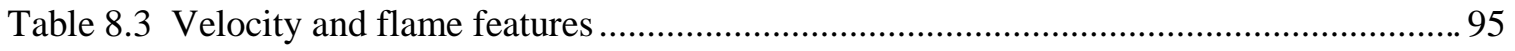

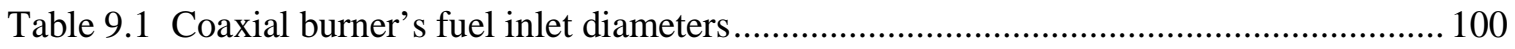

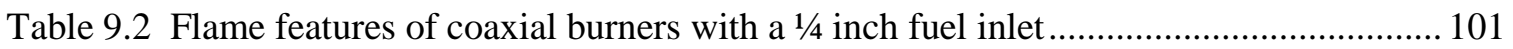

Table 9.3 Flame features of coaxial burners with a $1 / 2$ inch fuel inlet ....................................... 105

Table 9.4 Flame features of coaxial burners with a $3 / 4$ inch fuel inlet ....................................... 108

Table 9.5 Flame features of coaxial burners with a 1 inch fuel inlet....................................... 111 


\section{Chapter 1 Introduction}

\subsection{Glass Melting Batch Tanks}

To illustrate physical glass melting in batch tanks and their functions, the concept of a glass melter should be introduced first. A glass melter is a chamber in which fuel combusts with oxidant above the batch materials and ensures heat transfer to batch materials. Batch materials are raw materials for glass forming. For example, a typical batch composition for soda-lime glass consists of $76 \% \mathrm{SiO}_{2}, 8 \% \mathrm{CaO}$, and $16 \% \mathrm{NaCO}_{3}$ [1]. In the glass industry, the classification of melter types is based on the handling of material in its passage through the melters. Two principal types are in existence, which are the continuous furnaces and batch tanks. In a continuous furnace, the charged raw material moves while it is being heated up to molten state in a certain melting rate without interruption. While a batch tank is defined as a glass-containing vessel made from refractory mainly used for the melting of batch for colored glass, crystal glass and special glasses [2]. A batch tank is refilled with batch materials periodically and its melting period may vary from several hours up to a couple of days. If a batch tank is refilled with batch materials daily, with melting usually done at night and glass production the following day, then it is called as a day tank, although sometimes, the production may last less or more than one day. Batch tanks are widely used in medium and small glass companies, especially in hand glass companies, in which art glass, stained glass, tableware glass, marbles, etc. are produced.

Batch tanks often have melting capacities of several hundred pounds to several thousand pounds; most of them fall in the range of 500 to 4000 pounds. Correspondingly, the inside size of base of a batch tank varies roughly from 10 to 70 square feet. Some batch tanks may have smaller or larger capacity and size, which may be beyond these ranges. The melting period of 
most batch tanks is usually 10 to 24 hours; but occasionally some big batch tanks, for example, an 8000-pound batch tank, may need up to 36 hours for melting process.

Figure 1.1 illustrates the structure of a typical batch tank, which has length L, width W and superstructure height $\mathrm{H}$. One sidewall and one end wall have been removed and the crown has been partially cut for better view.

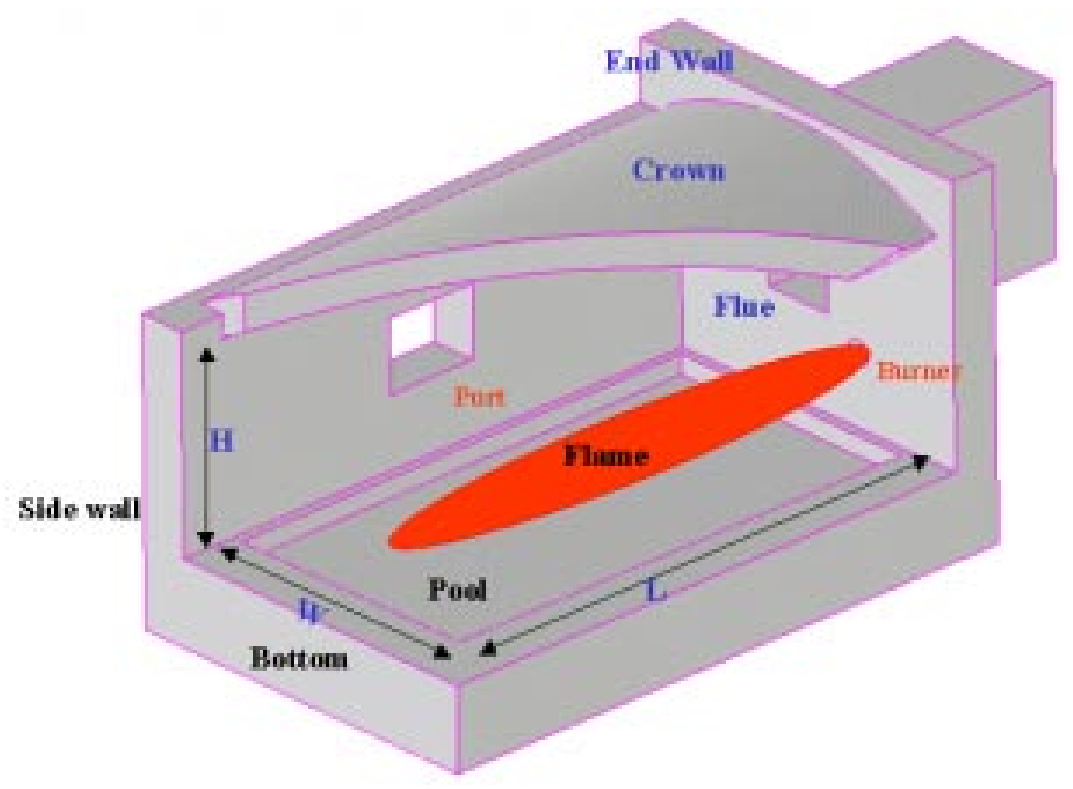

Figure 1.1 Basic structure of a batch tank

\subsection{Energy Source for Batch Tanks}

Although both gas fuel and oil fuel as well as electricity are utilized as energy sources for glass melting process, gas fuels are used by most of batch tanks and hydrocarbons are the most commonly used fuel. Correspondingly, the oxidizer is either ambient air or oxygen separated from air. The air-fuel combustion is well known and still widely used in the glass industry. When oxygen takes the place of air, then the combustion is called oxy-fuel firing. Currently, both air-fuel firing and oxy-fuel firing are served in the glass industry. Nevertheless, the trend is that the conventional air-fuel is being replaced by oxy-fuel firing [3]. 


\subsection{Air-Fuel Firing}

In the glass industry, air-fuel combustion is the traditional firing technology used to melt the batch materials in the melter for glassmaking. When fuels, typically hydrocarbon fuels such as natural gas, combust with air, heat is released and combustion products include carbon dioxide, water vapor, and some other trace species are generated. The schematic of glass melting process in a typical batch tank is illustrated in Figure 1.2.

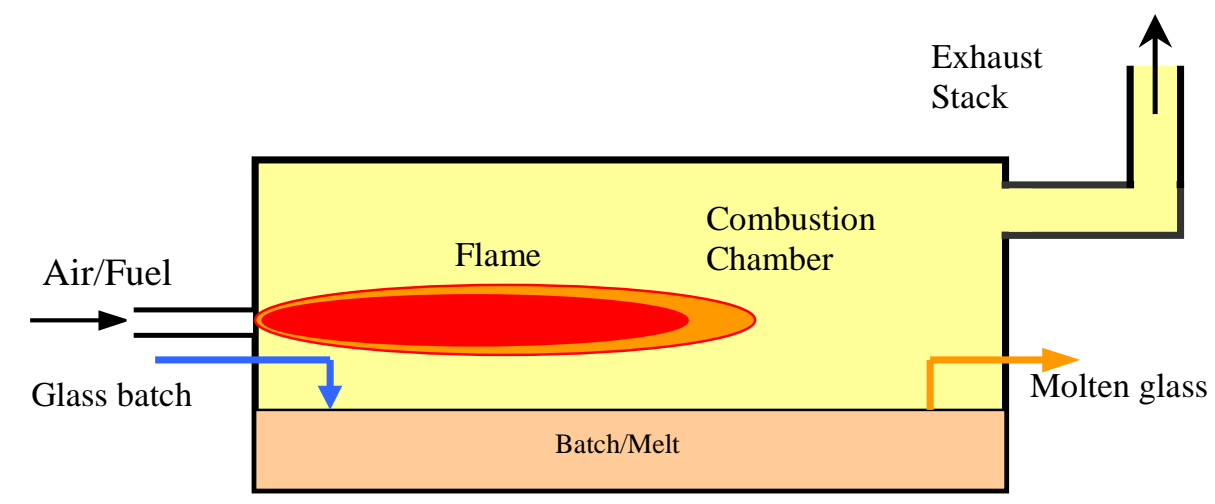

Figure 1.2 Glass melting process of a typical batch tank

The primary energy loss is due to heat loss through tank walls and heat escaping with exhaust gases. When a batch tank is in operation, the temperature of the inner surface of the tank wall is often in the range of 1400 to $1600^{\circ} \mathrm{C}$; and the outer surface temperature of the melter wall is up to $400^{\circ} \mathrm{C}$ if not insulated [4]. Guosheng Kang and John E. Sneckenberger measured the inner surface temperatures of the superstructure refractory of an oxy-fuel tank in operation with an IR remote temperature-sensing device. These temperatures varied from $1329^{\circ} \mathrm{C}$ to $1770^{\circ} \mathrm{C}$, but the temperature of most parts of the superstructure was around $1600^{\circ} \mathrm{C}$. They also measured the outer surface temperatures, which were around $290^{\circ} \mathrm{C}$ to $310^{\circ} \mathrm{C}$ without insulation and $110^{\circ} \mathrm{C}$ to $120^{\circ} \mathrm{C}$ with insulation. Such a high temperature difference causes significant heat loss through 
melter walls. The other primary energy loss is due to the existence of nitrogen in air, which provides no contribution to the combustion reaction, but does absorb a great amount of heat when it goes through the combustion chamber and releases heat to surrounding through the exhaust stack.

The nitrogen is also a source for enabling nitrous oxides $\left(\mathrm{NO}_{\mathrm{x}}\right)$ to form at high temperature (somewhat above $1600^{\circ} \mathrm{C}$ ) [5]. $\mathrm{NO}_{\mathrm{x}}$ formation is the most serious emission problem in today's glass industry, and the U.S. Environment Protection Agency (EPA) has stringent regulations on $\mathrm{NO}_{\mathrm{x}}$ emission. As part of the Clean Air Act Amendments, the U.S. EPA has enacted new regulations aimed at reducing $\mathrm{NO}_{\mathrm{x}}$ emissions from major stationary source [6]. According to the Act Amendments, three levels of $\mathrm{NO}_{\mathrm{x}}$ control could be required depending on the geographical location and the status of the melter, with each level being more costly and entailing more risk. These three levels are: (1) Reasonable Available Control Technology (RACT) is defined as being generally available within the industry, and economically achievable with a low level of risk. U.S. EPA expects RACT to reduce $\mathrm{NO}_{\mathrm{x}}$ emission by 40 60\%; (2) Best Available Control Technology (BACT) could involve additional technical risk by requiring assessment of control system from a similar industry. In 1998, the South Coast Air Quality Management District is requiring the glass industry to meet BACT threshold of less than $2 \mathrm{lbs}$. of $\mathrm{NO}_{\mathrm{x}}$ per ton of glass produced [7]; and (3) Lowest Achievable Emission Rate (LAER) is the most stringent level of control. From the view of environment protection, the application of oxy-fuel firing is a mandated choice for the glass industry.

In summary, air-fuel firing is a well developed and widely used technology in the glass industry. Its primary disadvantages are low energy efficiency and high $\mathrm{NO}_{\mathrm{x}}$ emissions.

\subsection{Oxy-Fuel Firing}

The use of oxygen in a glass melter is not a new concept; many glass companies have experiences of boosting or enriching with oxygen over the last 20 to 30 years. However, these 
experiences usually relate to solving problems during difficulties with a regenerator or recuperator or in times of massive pull requirements for short-term solutions. In the $1990 \mathrm{~s}$, the advancement of air separation technology makes it more feasible to switch air-fuel firing to oxyfuel firing so as to enhance energy efficiency and meet the EPA regulations of emissions [8]. Instead of using air, oxygen with a purity of over $94 \%$ is used for oxy-fuel firing; thus, energy efficiency is enhanced, and, because of the very limited nitrogen involved in the combustion process and a better control over temperature distribution, $\mathrm{NO}_{\mathrm{x}}$ emission is greatly reduced $[9,10$, 11]. As a result, more than 350 continuous melters have been converted to oxy-fuel firing in 1990 's and more than $20 \%$ of U.S. glass production now uses the oxy-fuel firing process [12].

The oxy-fuel technology for glass melting has been developing for the glass industry since 1990. In the summer of 1991, the first conversion of a large container furnace to oxy-fuel firing was completed by Gallo Glass Company in Modesto, CA. Since then, there has been an increasing adoption of the oxy-fuel process in all glass product segments, including the float glass manufacturing section. Pilkington Libbey-Owens-Ford (LOF) put an oxy-fuel melting system into use in the summer of 1998, which is the first oxy-fuel system used in float process in glass industry [13]. Float process was developed by the UK firm Pilkington Brothers, which is a method for the production of high-quality sheet glass whereby a ribbon of molten glass is fed across a bath of heated liquid, usually molten tin, in a carefully controlled atmosphere.

Today, a fully optimized oxy-fuel melting system should include the following five main parts: (1) Added oxygen supply facility. (2) Specialized burners for oxy-fuel firing. (3) Modified tank design and construction, including tank geometry design, refractory selection and installation practices. (4) Extended $\mathrm{NO}_{\mathrm{x}}$ and particulate emissions measurement and control. (5) Enhanced furnace operating controls and maintenance [14]. Ongoing efforts for further development for all five of these system parts will lead to more conversions. Although significant contributions have already been made in both basic research and industrial practice, for using oxy-fuel firing as a newly developed technology, many challenges and opportunities still exist in the glass industry. 
Furthermore, in the past, most of these efforts were aimed at providing better design, construction and operation for continuous furnace.

As a result, batch tanks have just borrowed the technology from that which has been put into use in continuous furnaces. This research focuses specially on batch tanks to help the hand glass industry with batch tank oriented oxy-fuel firing technology.

\subsection{Challenges in Oxy-Fuel Firing}

The conversion to oxy-fuel firing has brought two prominent benefits for the glass industry. The first benefit is that natural gas consumption is decreased. In practice, fuel savings of $20 \%$ have been realized using oxy-fuel firing [8,9]. L.E. Smith Glass Company in Mount Pleasant, PA even reached $40 \%$ saving. The second benefit is that $\mathrm{NO}_{\mathrm{x}}$ and particulate emissions are greatly reduced. It has been widely reported that $\mathrm{NO}_{\mathrm{x}}$ emissions in continuous furnaces can be reduced by $70 \%$ from baseline air-fuel conditions, and the reduction of particulate emission in the exhaust gases is up to $50 \%$.

Besides these two prominent benefits, oxy-fuel fired batch tanks have three typical advantages. (1) The tank structure can be more compact. With oxy-fuel firing, recuperators and/or regenerators used in air-fuel fired tanks are no longer needed, and the new tank is more compact and much easier for technical management. (2) The melting rate is increased. Oxy-fuel firing provides higher process temperature and higher concentration of water vapor and carbon dioxide in the combustion chamber. Water vapor and carbon dioxide absorb and emit heat, thus improving the heat transfer and temperature uniformity [15]. Hence, the melting rate is increased and thus the melting efficiency is improved. (3) The glass quality is improved due to the improved heat transfer to batch materials. Oxy-fuel firing provides better control over glass quality; particularly the ability to reduce the incidence of cords (an inclusion of glass of a different composition) or stones (crystalline inclusion) [9]. 
While oxy-fuel firing has brought various benefits and advantages to the glass industry, many new issues have been identified with the implementation and use of this technology. These issues have been observed in both continuous furnaces and batch tanks. The primary concerns are related to the following aspects:

(1). Oxy-fuel burners

The burner is the heart of the tank; the flame shape plays an important role in the heat transfer to both the glass and the refractory. The flame shape depends on the burner structure and oxy/fuel flow rate. Therefore, optimization of the burner design and burner arrangement should enhance energy efficiency, improve glass melt quality, and lessen the temperature effect on corrosion of superstructure refractory.

\section{(2). Tank geometry}

When commercial oxygen is used as oxidizer, the volume of the combustion chamber can be reduced. In addition, oxy-fuel flame has different features such as flame temperature, flame length and flame width. Therefore, the geometry of the tank needs to be changed. The geometry design depends on the melting requirement and also the burner selected for the tank.

\section{(3). Superstructure refractory corrosion}

There are two types of wear and damage of refractory in a batch tank; one type is the corrosion of superstructure caused by high temperature volatile gas flow, and the other type is the wear of refractory in glass-contact region, which is caused by glass flow. After converting to oxy-fuel firing, the higher flame temperature and the improved heat radiation improve the melting quality, but causes a higher crown temperature and increases the release of sodium hydroxide $(\mathrm{NaOH})$ from glass melt. Meanwhile, due to nitrogen having been removed from the combustion system, the oxy-fuel firing yields a higher concentration of water vapor (more than 3 times higher than that in air-fuel firing). This leads to aggravated attack of water vapor and sodium hydroxide on the superstructure refractory. Table 1 gives a comparison of the concentration of various components in exhaust between air-fuel firing and oxy-fuel firing [16]. 
The corrosion of superstructure and the wear of glass-contact walls require much maintenance or cause premature failure [4].

Table 1.1 Comparison of volatile components in exhaust for two firings

\begin{tabular}{|l|c|c|}
\hline Component & Oxy-Fuel & Air-Fuel \\
\hline $\mathrm{N}_{2}$ (\% vol.) & 13 & 68 \\
\hline $\mathrm{O}_{2}(\%$ vol. $)$ & 3 & 2 \\
\hline $\mathrm{H}_{2} \mathrm{O}(\%$ vol. $)$ & 54 & 18 \\
\hline $\mathrm{CO}_{2}(\%$ vol. $)$ & 31 & 12 \\
\hline $\mathrm{NaOH}(\mathrm{ppm})$ & 210 & 60 \\
\hline
\end{tabular}

(4). $\mathrm{NO}_{\mathrm{x}}$ formation

$\mathrm{NO}_{\mathrm{x}}$ formation is one of the primary problems for environmental protection in the glass industry. The main mechanism underlying $\mathrm{NO}_{\mathrm{x}}$ formation in the glass melting process is the thermal mechanism. The burner type and the tank geometry together determine the $\mathrm{NO}_{\mathrm{x}}$ emissions from the batch tank. With oxy-fuel firing, the flame temperature increases significantly, which makes $\mathrm{NO}_{\mathrm{x}}$ formation more sensitive to any nitrogen, such as that associated with the oxygen purity. Don Coe of AGA Gas Inc. in Cleveland, $\mathrm{OH}$, tested and measured that using $93.0 \%$ oxygen yields two times more $\mathrm{NO}_{\mathrm{x}}$ than the emission from using $99.99 \%$ oxygen [17]. In addition, operating pressure within the combustion chamber becomes a factor of $\mathrm{NO}_{\mathrm{x}}$ formation, because a negative pressure will lead ambient air entering the combustion chamber through any possible leakage. With such a leakage, the nitrogen contained in the leakage air becomes a significant source for $\mathrm{NO}_{\mathrm{x}}$ formation.

\subsection{Specific Aims}

The overall goal of this research was to better understand the factors affecting the behavior of oxy-fuel burners and oxy-fuel fired batch tanks. To reach this goal, the emphases of this research were focused on: 
(1) Modeling of the physical and chemical processes of the combustion and heat transfer in batch tanks as well as the pollutant emissions. Oxy-fuel reacting flow differs from air-fuel reacting flow in almost all aspects of the physical and chemical processes. The geometry model, the turbulent model, the radiation model, the chemical reaction model, the $\mathrm{NO}_{\mathrm{x}}$ formation model, and the soot formation model, etc., were specified and tested for batch tank combustion simulation.

(2) Specifying primary factors of oxy-fuel burners. Premixed oxy-fuel burner was considered as an aid for diffusion burner investigation. In diffusion burner study, both coaxial burner and flat flame burner were considered. The velocities of the fuel and the oxygen, and the velocity difference between the fuel and the oxygen were studied.

(3) Identifying operating and boundary conditions that will be utilized in simulation. They were obtained on the basis of both theoretical analysis and real engineering practice.

(4) Simulating all primary concerns in batch tank design. Burner behavior, batch tank design, burner placement in batch tank, and $\mathrm{NO}_{\mathrm{x}}$ emissions were investigated using the specified models.

\subsection{Chapter Overviews}

Chapter 2 introduces the background of glassmaking in batch tanks, the physical systems involves in batch tank operation, and the batch tank structure; identifies primary design aspects for oxy-fuel fired batch tanks, and summarizes oxy-fuel firing technology features and the previous CFD works done in the field of continuous furnaces and batch tanks.

Chapter 3 theoretically analyzes the oxy-fuel combustion and heat transfer in a typical batch tank. The adiabatic flame temperature, heat flux across tank walls, and the energy balance were discussed. It serves for the setting of basic physical and chemical reaction models, turbulence model, and radiation model as well as boundary conditions. 
Chapter 4 introduces the geometry modeling for a cylindrical model combustor and a batch tank, and the grid generation for them.

Chapter 5 deals with physical models and chemical reaction models for the combustion and heat transfer modeling and some physical properties required as inputs for solving the governing equations.

Chapter 6 provides the operating and boundary conditions for the simulation of a typical batch tank.

Chapter 7 introduces the simulation process, which includes geometry modeling of a typical batch tank and grid generation procedure for it; sets all needed models and inputs, and convergence criterion.

Chapter 8 presents simulation results for premixed flame. Premixed oxy-fuel combustion is not recommended for engineering practice in batch tanks, but the insight gained from the simulation helps the design of diffusion burners.

Chapter 9 presents two-dimensional and three-dimensional simulation results for coaxial jet burners. Four distinct fuel inlet diameters were set and corresponding oxygen velocities were identified so as to yield proper flame profile.

Chapter 10 presents investigation on flat flame formation, which is for future use in hand glass industry. The effect of buoyancy on flat flame propagation and the remedy method were discussed.

Chapter 11 presents investigation of the burner placement in a batch tank, and the burnertank compatibility, which provides an iterative design method for batch tank design enhancement.

Chapter 12 summarizes the objectives and contributions of this research and the future work that may be extended from this research. 


\section{Chapter 2 Background Material}

\subsection{Batch Tank Based Glassmaking Process}

Glass is a material made by cooling certain molten compounds in a way in which it does not crystallize. Glass viscosity at ambient temperature is so high that for all practical purposes it is solid. Materials having the ability to cool without crystallizing are rare, silica compounds being the most common. Essentially all glasses of commercial importance are based on silica.

Glass furnaces carry out certain chemical reactions at extremely high temperature in the melting process. Although the furnace geometry, firing pattern, and specific temperature vary depending on the type of glass produced, all glass furnaces operate at temperatures where $\mathrm{NO}_{\mathrm{x}}$ formation can take place. Therefore, energy efficiency and $\mathrm{NO}_{\mathrm{x}}$ emissions are the primary concerns in the glass industry.

\subsubsection{Glass Formation}

Despite differences in the final products, all glass is produced by first combining dry ingredients into what is known as a batch. In the fired tank, melting causes chemical reactions to take place between the batch ingredients. The main reactions involved in soda-lime glass formation can be summarized as follows:

$$
\begin{aligned}
& \mathrm{Na}_{2} \mathrm{CO}_{3}+a \mathrm{SiO}_{2} \rightarrow \mathrm{Na}_{2} \cdot a \cdot \mathrm{SiO}_{2}+\mathrm{CO}_{2} \\
& \mathrm{CaCO}_{3}+b \mathrm{SiO}_{2} \rightarrow \mathrm{CaO} \cdot b \cdot \mathrm{SiO}_{2}+\mathrm{CO}_{2} \\
& \mathrm{Na}_{2} \mathrm{SO}_{3}+c \mathrm{SiO}_{2} \rightarrow \mathrm{Na}_{2} \mathrm{O} \cdot c \cdot \mathrm{SiO}_{2}+\mathrm{SO}_{2}
\end{aligned}
$$

Some other ingredients will be added to the batch depending on the functional requirements of the final product. For example, a variety of metal oxidizers are commonly used to form colored glass, and lead is added for crystal glass. When those non-basic ingredients are 
added into the batch, the combustion is usually required to proceed at excess air or oxygen for the completion of oxidization.

Once the batch materials have been properly melted, in which chemical reactions of glass formation have been finished. Then the glass melt can be brought out of the tank to form glassware using various techniques, such as blowing, pressing, etc.

\subsubsection{Glassmaking}

Handmade glassware is made of fined glass melt gathered from batch tanks. The melt is generally composition homogeneous, stone and bubble free viscous fluid with desired viscosity. The detailed information about glassmaking is beyond the scope of this research. Thus a brief introduction of the production of handmade glass is shown schematically in Figure 2.1.

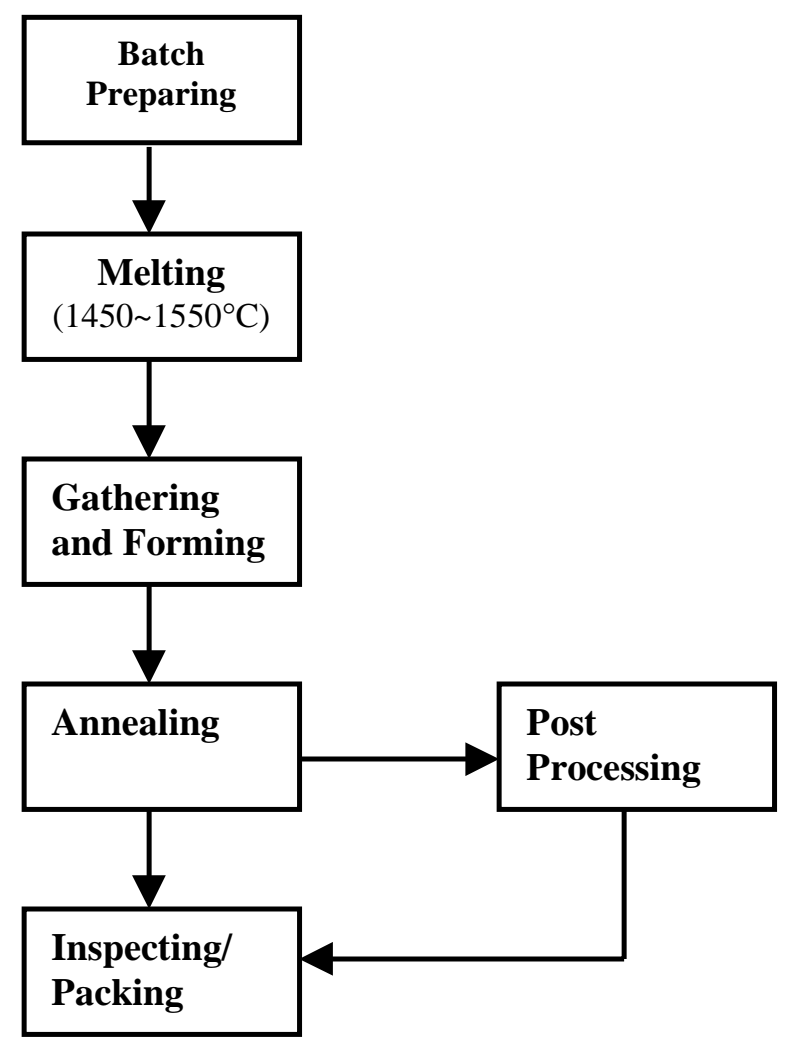

Figure 2.1 Batch tank based glass production 


\subsection{Energy Consumption for Glass Melting Process}

The heat for the reactions of glass formation mentioned in Section 2.1 is usually supplied by flames fired over the batch materials or the progressively developed glass melt. Heat is transferred primarily by radiation from the flame to the surface of the melt. The configuration of the batch tank is generally a rectangular space with a curved roof.

Generally, the energy input in air-fuel fired batch tanks is around 100,000 BTUs of gas per hour for each cubic foot of glass. Soda-lime glass weighs 150 pounds per cubic foot, thus 670 BTUs per hour for each pound of glass is needed. For example, a 2500-pound batch tank needs 1,600 MBTUs per hour if it is air-fuel fired. When using oxy-fuel, this amount of energy requirement may reduce to less than 800 MBTUs per hour.

Cullet (broken glass) is sometimes used in batch tank melting. Cullet may consist of internally recycled glass from waste in downstream operations, or it may be externally recycled from glass returned in recycle operations. Because the chemical reactions necessary to form glass have already taken place in the cullet, about half the energy is needed to melt cullet compared to virgin batch ingredients.

In the melting tank, the batch components and cullet react to form glass. Because of heat transfer limitations, a glass batch tank is generally designed for 1.5 to $2.2 \mathrm{~m}^{2}$ of melting area per ton of glass produced. The depth of the glass melt is usually 10 inches to 20 inches. To make sure the melt become homogeneous and free of bubbles, the melt needs "fining" before glassware making. The "fining" takes place in the same tank, but with a higher temperature.

The heat absorption rate in the glass forming process varies along the melting history. An indirect measurement of heat transfer to glass in an air-fuel fired batch tank has been conducted by our partner at Brooke Glass Company, WV. The measurement of the crown temperature at the center point of the crown varies from the beginning and over more than twothird of the total melting period. The temperature-melting time curve shows that the melting occurs primarily in the first 10 hours, within which the first three hours the batch absorbs heat at 
peak rate. Two reasons may cause such a phenomena: during the first couple of hours when the batch is at a lower temperature, the heat is primarily used for increasing the internal energy of the basic materials; later the heat is primarily used for generating chemical reactions during glass formation. Figure 2.2 shows a record of crown temperature vs. time during batch melting.

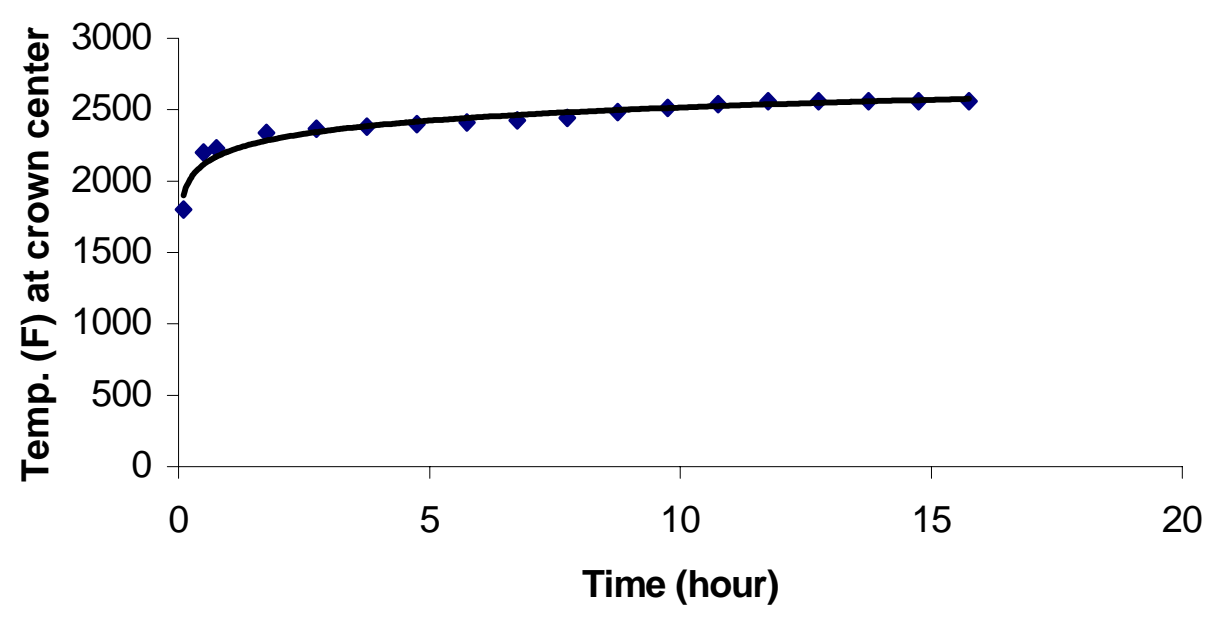

Figure 2.2 History of batch melting in an air-fuel batch tank

The theoretical energy requirements for glass (per ton of glass produced) can be approximated as follows:
Stoichiometric chemical reactions requirements:
$0.58 \times 10^{6} \mathrm{Btu}$
Sensible heat bringing batch to $2800^{\circ} \mathrm{F}$ :
$1.55 \times 10^{6} \mathrm{Btu}$
Total
$2.13 \times 10^{6} \mathrm{Btu}$.

But because of the low thermal efficiency of the melting tanks, more than $6 \times 10^{6}$ Btu is required in practice to produce a ton of glass. Of this total, about $40 \%$ of the total goes to heating the batch material and for the thermodynamic heat of the glass forming reactions. Roughly, about $30 \%$ of the total heat is lost through the tank walls, and $30 \%$ is carried away with the exhaust 
through the stack. Small batch tanks may consume more energy; thus their energy efficiency may be lower than $40 \%$.

In engineering practice, the energy requirement for the production of each ton of glass in a continuous furnace requires 4 to 8 MMBTU; a batch tank has a higher energy comsumption rate, which is usually 6 to 12 MMBTU per ton of glass.

\subsection{Oxy-Fuel Firing Systems}

Physically, the operation of a batch tank or a group of batch tanks in a glass plant involves several sub-systems, such as the gas supply systems, the raw material mixer and feeder, the burners, the combustion tank, and the control system. Gas supply systems ensure that the fuel and oxygen are steadily and safely transported to the tank under certain requirements. One or more burners mix fuel with oxidizer and make combustion happen within a desired flame region. The tank is where combustion occurs and heat is transferred to glass, while the heat loss through walls is limited, and the heat loss through the exhaust is lessened. The control system deals with all the primary factors of the tank's operation, such as gas pressure, oxy-fuel ratio, combustion temperature, internal tank pressure, key species concentration, and automatic shut off for safety.

This section focuses on the fuel and oxygen supply systems and burners as well as batch tanks. Feeder systems and control systems are beyond the scope of this research, which is a topic of further research.

\subsubsection{Natural Gas Supply}

Natural gas is introduced to a glass plant via a pipeline. The gas is usually dry gas due to dehydration made in gas well. The composition and heating value of natural gas are presented in Chapter 3. The supply pressure of natural gas is around 60 psig (74.70 psia). Operation of burners needs a minimum of 25 psig gas pressure at the burners. After all regulation and control, a pressure of 35 psig is preferred at the burner. The natural gas pressure at a burner can be regulated. 


\subsubsection{Oxygen Supply}

Sufficient supply of oxygen with an acceptable purity is the economic prerequisite for conversion to oxy-fuel firing. There are several technologies for separating oxygen from air. For example, the 140-year-old Cryogenic Separation technology is still in use today; Selective Chemical Adsorption has been worked on since the Second World War; and the 30-year-old Vacuum Swing Adsorption (VSA) or Vacuum Pressure Swing Adsorption (VPSA) is currently showing lots of improvements in efficiency [18]. In addition, Paramagnetic and Solid Electrolyte Separations are newly developed technologies in recent years.

Due to economic reasons nowadays, only three ways of oxygen supply are acceptable for the glass industry. The first way is to supply oxygen using an On-Site Plant Supply via Molecular Sieve Adsorption System, which can supply oxygen with a purity of 92 94\% in the cost of $\$ 20$ to $\$ 40$ per ton. The second way is On-Site Plant Supply via a Cryogenic Distillation, which can supply oxygen with a purity of 90 98\%. The cost of this kind of oxygen supply depends on the local cost of electricity and the oxygen consumption scale of the glass plant. The third way is to supply oxygen by an On-Site Bulk Liquid Oxygen System filled by off-site supplier, which can supply oxygen with a purity of over $94 \%$ and up to $99.5 \%$. But the production from the third way is less than 5 tons per day (TPD); thus, it can be chosen for oxygen requirements of less than 5 TPD [19].

Cost is the driver in choosing the supply method. The first two methods are most glass company's choice in case they build up the on-site oxygen supply system other than purchase oxygen from supplier.

Currently, new oxygen supply methods, such as Chemical Absorption of Oxygen [20], which uses organometallic complex to absorb oxygen from air and release pure oxygen, and Paramagnetic Oxygen Separation [21], are still under development. They can not be put into commercial use in the very near future. 
When a glass company plans to convert its air-fuel fired tank to an oxy-fuel fired one, or plans to build a new oxy-fuel fired tank, oxygen supply considerations must be take into account, but it is mainly a decision based on economic and environmental reasons more than a technological choice.

\subsubsection{Burners}

The development of specialized oxy-fuel burners plays an important role in the improvement of oxy-fuel firing system. However, a decade ago, in the 1980s when oxygen boosting was being used to increase production in recuperative tanks, the burners used in the oxygen boosting process were borrowed from the metals industry [22]. Currently, three types of oxy-fuel burners are available for glass melting processes; they are coaxial (tube-in-tube) burners, flat flame burners and oscillating burners.

(1) Coaxial Burner: Conventional oxy-fuel burner designs have introduced oxygen around a central jet of fuel, a configuration referred as a coaxial (or "tube-in-tube") burner. The flame characteristics from these burners are determined by oxygen and fuel velocities as well as nozzle and burner block configuration. The advantages of coaxial burner are its simplicity and convenience for operation; the disadvantages are that its round flame has insufficient coverage over glass surface and its high flame temperature when use oxy-fuel firing.

(2) Flat Flame Burner: By 1990, specialized burners were developed to physically replace the existing coaxial air-fuel burners. An example of these burners is the oxy-fuel fired adjustable flat flame burner, which spreads its flame significantly over the melting surface and is approximately two to three times the square foot coverage of the conventionally shaped oxy-fuel burner. In 1993, BOC's Flat Jet ${ }^{\mathrm{TM}}$ was first introduced for use by glass industry [14].

(3) Oscillating Burner: In 1997, the Institute of Gas Technology in Des Plains, IL, and Air Liquid America Corp. in Countryside, IL, developed the oscillating combustion technology to reduce $\mathrm{NO}_{\mathrm{x}}$ emissions [23]. It is reported that this kind of burner generate alternative fuel rich 
and fuel lean flames to lower flame temperature and increase soot formation, thus improve heat transfer and reduce $\mathrm{NO}_{\mathrm{x}}$ emissions.

The basic consideration of burner design is the flame profile and the flame temperature distribution, the soot formation and the $\mathrm{NO}_{\mathrm{x}}$ formation are two important factors for the burner behavior. For a redesigned batch tank, its glass melt capacity determines the heat that needs to be provided by one or more burners. Thus, the total heat supply depends on the burner type, the number of burners, and the overall thermal efficiency of the tank. The soot formation is a factor for improvement of radiation heat transfer. If the burner design is good enough, a fractional amount of natural gas will be pyrolyzed when it enters the combustion chamber.

In the past, burners were considered an afterthought in glass furnace design. Today, new burner technologies for both conventional air-fuel and oxy-fuel applications continue to be developed and assist glass companies to lower production costs and pollution rates. One of the primary efforts in burner development is to develop specialized burners for a batch tank. The application of computational fluid dynamics (CFD) simulation is a new tool for burner design optimization.

\subsubsection{Tank Body}

Construction of a batch tank is another topic that is beyond the scope of this research. In this research, only those aspects of batch tank construction related to combustion chamber size and boundary conditions are of concern, which are the sizes and thermal properties of the tank walls, the tank crown, and the tank exhaust.

\section{(1) Refractory Walls}

The body of a batch tank can be functionally divided into two parts. One part is the combustion chamber, which is a space between crown and glass surface and surrounded by the tank's superstructure; the other is the glass melting place, where raw batch materials turn to glass melt ready for glassmaking. The heat needed for glass melting comes from the chemical 
reactions of the oxy-fuel combustion that occurs in the combustion chamber. The tank body strongly influences the melting process.

\section{(2) Crown}

Each batch tank consists of several side walls and a single crown. The crown is a curved wall that is opposite to the glass surface plane; it plays an important role in heat radiation to the glass. Figure 2.3 shows a batch tank, which is used to illustrate the calculation of view factors. The length, the width, and the superstructure height are 2.50 meters, 1.74 meters, and 0.68 meters, respectively. The glass surface plane, the crown and the four side walls were all marked with a name for view factor calculation. $A_{1}$ is the glass surface plane, $A_{2}$ is the crown, $A_{3}$ and $A_{4}$ are a pair of side wall, $\mathrm{A}_{5}$ and $\mathrm{A}_{6}$ are a pair of end walls as shown.

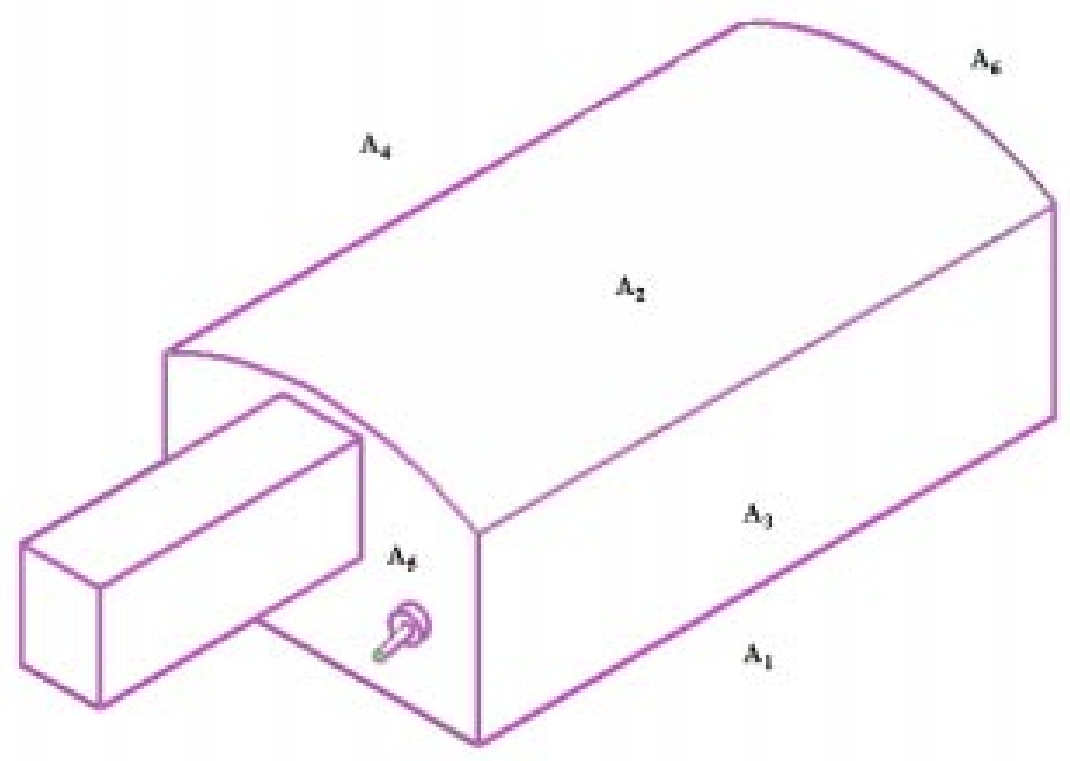

Figure 2.3 A batch tank for view factor calculation

The view factor indicates radiation heat exchange between surfaces. To analyze the geometry's effect on radiation, the $6 \times 6$ Matrix A of view factors can be expressed as shown in equation 2-1. 


$$
A=\left(\begin{array}{llllll}
F_{11} & F_{12} & F_{13} & F_{14} & F_{15} & F_{16} \\
F_{21} & F_{22} & F_{23} & F_{24} & F_{25} & F_{26} \\
F_{31} & F_{32} & F_{33} & F_{34} & F_{35} & F_{36} \\
F_{41} & F_{42} & F_{43} & F_{44} & F_{45} & F_{46} \\
F_{51} & F_{52} & F_{53} & F_{54} & F_{55} & F_{56} \\
F_{61} & F_{62} & F_{63} & F_{64} & F_{65} & F_{66}
\end{array}\right)
$$

There are 36 view factors, but the number of unknowns can be reduced considering three additional conditions: the symmetric feature of the geometry, the reciprocity, and the summation rule. And finally these unknowns were solved and all the view factors are listed in Matrix B.

$$
\mathrm{B}=\left(\begin{array}{llllll}
\mathrm{F}_{11}=0.000 & \mathrm{~F}_{12}=0.540 & \mathrm{~F}_{13}=0.130 & \mathrm{~F}_{14}=0.130 & \mathrm{~F}_{15}=0.100 & \mathrm{~F}_{16}=0.100 \\
\mathrm{~F}_{21}=0.516 & \mathrm{~F}_{22}=0.031 & \mathrm{~F}_{23}=0.130 & \mathrm{~F}_{24}=0.130 & \mathrm{~F}_{25}=0.096 & \mathrm{~F}_{26}=0.096 \\
\mathrm{~F}_{31}=0.333 & \mathrm{~F}_{32}=0.348 & \mathrm{~F}_{33}=0.000 & \mathrm{~F}_{34}=0.140 & \mathrm{~F}_{35}=0.140 & \mathrm{~F}_{36}=0.140 \\
\mathrm{~F}_{41}=0.333 & \mathrm{~F}_{42}=0.348 & \mathrm{~F}_{43}=0.140 & \mathrm{~F}_{44}=0.000 & \mathrm{~F}_{45}=0.140 & \mathrm{~F}_{46}=0.140 \\
\mathrm{~F}_{51}=0.333 & \mathrm{~F}_{52}=0.258 & \mathrm{~F}_{53}=0.140 & \mathrm{~F}_{54}=0.140 & \mathrm{~F}_{55}=0.000 & \mathrm{~F}_{56}=0.130 \\
\mathrm{~F}_{61}=0.333 & \mathrm{~F}_{62}=0.258 & \mathrm{~F}_{63}=0.140 & \mathrm{~F}_{64}=0.140 & \mathrm{~F}_{65}=0.130 & \mathrm{~F}_{66}=0.000
\end{array}\right)
$$

The calculated view factors show that, among the side walls and crown, the crown inner surface has the greatest view factor to glass surfaces, which means the radiation heat exchange between the crown and the glass surface is most significant. To enhance heat transfer to glass via surface radiation, there are two ways using geometry design: properly lower the crown height and use refractory with better emissivity such as fused silica bricks.

\section{(3) Exhaust}

Exhaust exit size is often called flue size, which is an important aspect in batch tank design. When oxy-fuel is applied to a batch tank, a positive pressure is required as one of the critic measures for $\mathrm{NO}_{\mathrm{x}}$ emissions control. This positive pressure is potentially the driven force that will open the seams of the tank if the flue size is not big enough. 
In an air-fuel fired batch tank, an empirical principle for flue size design has been developed by batch tank designers and constructors, which is 1 square inch for every 10,000 BTUs or 6.45 square centimeters for every $2520 \mathrm{kcal}$ of energy input [24]. However, for oxy-fuel firing, for the same energy input, the volume of the combustion products only takes $30 \%$ percent of that of air-fuel firing. Therefore, the principle for flue size design can be modified as: 1 square inch for every 3,000 BTUs or 2 square centimeters for every $2600 \mathrm{kcal}$ of energy input. For example, a batch tank with 2500 pounds melting capacity requires 600 MBTU each hour. According to the modified principle, the flue size should be 60 square inches $\left(0.165 \mathrm{~m}^{2}\right)$. In practice, the opening of flue is designed a little bit bigger than this estimated size, and a block of refractory is put on the top of the stack in order to adjust the flue opening corresponding the sensor indicated internal pressure.

\subsection{CFD for Batch Tank Design}

\subsubsection{Benefits of CFD in Glass Industry}

Today, many of the energy related or environmental issues can not possibly be confronted without detailed knowledge of the fluid flow dynamics. In the glass industry, all the fluid flows that interest researchers and engineers are turbulent flows except the molten glass flow. Therefore, a solid grasp of fluid turbulence inside the combustion chamber can allow engineers to improve the energy efficiency, reduce formation of the harmful species, and control their impact on the refractory and environment. These insights are guiding the design of tanks including burner design to improve the performance and efficiency. However, prototype testing of new burner combustion technologies is not feasible for gathering the needed knowledge for three reasons. First, both the full-scale and small-scale experiments are cost-prohibitive; Second, it is always risky to perform small-scale experiments because of the scaling problem; and Third, both full-scale and small-scale experiments under some conditions are often impossible. Therefore, the ability to numerically predict the combustion process provides a viable alternative 
to physical prototyping in the exploration of new burner combustion technologies and new tank design.

The development of the modern computers and related technologies provide such ability. With computers and computational fluid dynamics (CFD) codes, it is possible for engineers to gain valuable insights into turbulent flow, combustion and heat transfer phenomenon. In the 1990s, workstations and high-end PCs became readily available. Most researchers use workstations for CFD development and applications. The trend is such that in the $21^{\text {st }}$ century, the high-end PCs will be more cost effective for common applications of CFD in industry.

The gas flow inside the glass tank is complicated. But compared to the flow associated with the airplane, it is possibly much simpler. In addition, since a batch tank is smaller in size, the grid size is less than half a million, and for most batch tanks the grid size is less than 200 thousand. Therefore, it is both technically and economically practical to introduce CFD modeling and simulation to the batch tank design for the hand glass industry. CFD will be particularly useful for the prediction of the spatial and temporal distributions of temperature, pressure, heat transfer, velocity, and concentration of concerned species in the combustion chamber, which are needed for better understanding of both batch tank construction and operation, as well as glass processing.

\subsubsection{CFD Modeling in Glass Industry}

Mathematical modeling of a glass furnace began and was developed in the 1980s. For instance, R. R. McConnel and R. E. Goodson [25] tried to improve energy efficiency via modeling glass furnaces. H. Mase and K. Oda [26] modeled the melting process of a glass tank furnace with batch in 1980. F. Simonis, H. De Waal and R. C. G. Beerkens [27] predicted the influence of operation parameters on the behavior of a glass furnace by simulation in 1986. In addition, a three dimensional numerical modeling of an industrial glass furnace was done by $\mathrm{M}$. G. Carvalho, et al [28] in 1988. Of course, all the furnaces modeled in the 1980s were air-fuel 
fired, and the modeling in 1980's were still in the earlier stage compared to the prospect of CFD modeling and simulation for industrial processes in 1990s.

Since the early 1990s, when oxy-fuel firing was introduced to the glass industry as described in Chapter 1, many attributes of a glass batch tank have changed. To meet the operation requirements of oxy-fuel firing, a second wave of modeling for oxy-fuel firing furnaces has been progressed and reported each year at The Conference on Glass Problems since 1990. Examples are "Model-based evaluation of oxy-fuel glass-melting furnace performance" and "Design modeling of glass furnace oxy-fuel conversion using three-dimensional combustion models" [29].

A physical-mathematical model for a glass-melting furnace includes several sub-models, such as the combustion chamber model, the glass melt model, the batch-melting region model, and the glass tank/combustion chamber coupling algorithm [30]. Some of these sub-models have been built up for design assistance, and some other more advanced sub-models are still being conceived or researched. For example, The OIT Times issued by the Office of Industrial Technologies (OIT) of US Department of Energy (DOE) reported that DOE funded an R\&D project titled "Development and Validation of Coupled Combustion Space/Glass Bath Furnace Simulation" in 1999 [31]. Sub-models that deal with refractory corrosion and other phenomena are also under consideration.

To use CFD to analyze the oxy-fuel combustion process, one must first formulate a mathematical model with which to simulate the physical process. Some simplification is necessary in the consideration of the geometry setup. Benjamin Jurcik and Carol Schnepper [32] studied the effects of geometric approximation of furnace crown; they used a series of steps instead of Body Fitted Coordinate (BFC) curves in their geometry. After comparing the results, they concluded that the approximation is accurate enough with saved calculating time. To set a proper geometry, the physical and chemical attributes of the furnace in operation must be understood; otherwise, an approximation may lead to errors beyond tolerance. 


\subsubsection{CFD Codes and Typical Modeling Aspects}

CFD modeling and simulation helps to understand and quantify the interactive physicochemical processes which take place during glass production. CFD can be used to model every phase of the glass process, including the melters, furnaces and refiners, the glass flow and heat transfer in the forehearths and spout bowls, the forming, stretching and drawing of glass, glass blowing, and fiber production. The insight gained with flow modeling can improve both product and process designs, ultimately boosting productivity, and reducing production costs and pollutant emissions. Phillip Burnside [33]remarked that "The models serve as a basis for more geometrically complex analyses that will allow us to optimize process improvements before time and money are spent on experimental testing”.

A number of commercial CFD software products or non-commercial CFD codes are available for the tasks mentioned above. For example, FLUENT released by Fluent Inc. and CFX provided by AEA Technology Inc. are two typical commercial CFD software products have been widely used by many researchers and engineers. Also, there are some non-commercial codes developed by governmental laboratories for research and some in-house codes developed by industrial companies for their services for the glass industry and other relevant industries. It is reported that US DOE Sandia National Laboratory developed a CFD code named GOMA for glass flow and formation simulation; the Air Liquid America Corp. developed an in-house code known as Athena for combustion modeling; TNO in Netherlands developed their own CFD code TNT-GTN. FLUENT is fully capable to handle modeling and simulation for almost all design aspects for batch tanks with an acceptable accuracy. Glass Services Ltd. In Czech Republic is extending its modeling and simulation services to glass companies in USA and other countries.

CFD modeling and simulation has now become involved in almost all aspects of the glassmaking process. Those process segments include combustion, pollutant formation, melters, air bubbles, electric boosting, batch melting, refiners, bubble tracking, forehearths, spout bowls, 
sheet formation, product forming (augers), sheet drawing, fiber drawing, annular tube drawing, glass blowing, gob formation, coating, and molding filling [34]. 


\section{Chapter 3 Analysis of Combustion and Heat Transfer}

In an oxy-fuel fired glass melting batch tank, the combustion is maintained by continuous supply of natural gas and oxygen. The combustion depends on several factors, such as the composition of natural gas, the oxygen purity, the oxygen/fuel ratio, and the mixing pattern of the natural gas and the oxygen. A burner that introduces oxy-fuel into the combustion chamber determines the mixing pattern.

A theoretical analysis of the oxy-fuel combustion process in a typical batch tank will be necessary for understanding the combustion and heat transfer process, for quantifying some key parameters, and for specifying physical models and chemical models as well as for setting boundary conditions. Finally, the theoretical analysis and the engineering data are both important for verification and interpretation of the CFD simulation results.

\subsection{Composition of Fuel and Oxidizer}

In oxy-fuel firing for glass melting, the fuel is usually the natural gas and the oxidizer is the industrial oxygen. The heating value (HV) of the natural gas depends on the composition of the natural gas. Besides, the nitrogen contained in both the natural gas supply and oxygen supply is a source of thermal $\mathrm{NO}_{\mathrm{x}}$ formation in the combustion process.

\subsubsection{Natural Gas}

Natural gas is provided to glass plant via a pipeline. The natural gas is usually dry gas due to dehydration made in gas well. The composition of natural gas varies from supply to supply. Generally, it consists of several different hydrocarbons, with the major constituent being methane and a small amount of other gases. Table 3.1 gives the composition of natural gases in several cities, as well as their higher heating values (HHV). 
Table 3.1 Components of some commercial natural gases distribution in US cities

\begin{tabular}{|l|l|l|l|l|l|l|l|l|l|l|}
\hline & $\mathrm{CH}_{4}$ & $\mathrm{C}_{2} \mathrm{H}_{6}$ & $\mathrm{C}_{3} \mathrm{H}_{8}$ & $\mathrm{C}_{4} \mathrm{H}_{10}$ & $\mathrm{C}_{5} \mathrm{H}_{12}$ & $\mathrm{C}_{\mathrm{x}} \mathrm{H}_{\mathrm{y}}$ & $\mathrm{CO}_{2}$ & $\mathrm{~N}_{2}$ & $\mathrm{He}$ & $\begin{array}{l}\mathrm{HHV} \\
\text { (Btu/cf.) }\end{array}$ \\
\cline { 2 - 10 } Cleveland, OH & 93.30 & 3.49 & 0.68 & 0.18 & 0.04 & --- & 1.80 & --- & 0.50 & 1,037 \\
Detroit, MI & 89.92 & 4.21 & 1.34 & 0.34 & 0.090 & 0.01 & 0.59 & 3.30 & 0.20 & 1,016 \\
Los Angeles, CA & 86.50 & 8.00 & 1.90 & 0.30 & .10 & 0.10 & 0.50 & 2.60 & --- & 1,086 \\
Milwaukee, WI & 89.01 & 5.19 & 1.89 & 0.66 & 0.44 & 0.02 & --- & 2.73 & 0.06 & 1,052 \\
New York, NY & 94.52 & 3.29 & 0.73 & 0.26 & 0.10 & 0.09 & 0.70 & 0.31 & -- & 1,049 \\
San Francisco, CA & 88.69 & 7.01 & 1.93 & 0.28 & 0.03 & --- & 0.62 & 1.43 & 0.01 & 1,086 \\
Washington, DC & 95.15 & 2.84 & 0.63 & 0.24 & 0.05 & 0.05 & 0.62 & 0.42 & --- & 1,042 \\
\hline
\end{tabular}

Source: American Gas Association [35]

There are two main concerns about natural gases; one is the heating value and the other is the nitrogen content. If an average value is taken from Table 3.1, then in this analysis, the higher heating value (HHV) of natural gas is assumed as $1030 \mathrm{Btu} / \mathrm{ft}^{3}$; the lower heating value (LHV) of most natural gas in USA is around $935 \mathrm{Btu} / \mathrm{ft}^{3}[36]$.

For the nitrogen content, Table 3.1 shows that it may be as low as $0.31 \%$, and as high as 3.3\%. The effect of this amount nitrogen on $\mathrm{NO}_{\mathrm{x}}$ formation in air-fuel combustion is insignificant because it is a minor nitrogen source compared to the nitrogen from the air supply. However, in oxy-fuel combustion, the nitrogen contained in natural gas can be significant, and its effect to $\mathrm{NO}_{\mathrm{x}}$ formation should definitely be taken into consideration.

According to Don Coe [17] at AGA Gas Inc., the nitrogen content in natural gas supplies in $\mathrm{OH}, \mathrm{PA}$ and $\mathrm{WV}$ can be assumed as $1 \%$ for combustion analysis.

In this research, both the fuel and the oxygen are modeled as binary system. The fuel is the mixture of $\mathrm{CH}_{4}$ and $\mathrm{N}_{2}$ only; the oxidizer is a mixture of $\mathrm{O}_{2}$ and $\mathrm{N}_{2}$ only. The actual natural gas may have different combustion characteristics.

\subsubsection{Oxygen}

Industrial oxygen is separated from ambient air. Strictly speaking it is a mixture other than $100 \%$ pure substance. Among the co-existed composition components, nitrogen is of most concern. Oxygen and nitrogen are the main constitutions of industrial oxygen; the other constitutions can be neglected. 
Assuming that industrial oxygen is a binary mixture of oxygen and nitrogen, then the mass fraction of oxygen must be above 92\%. Otherwise, the balance nitrogen will be too sensitive for $\mathrm{NO}_{\mathrm{x}}$ formation and thus ruin the emissions control effort of using oxy-fuel. For stricter requirement, $99.99 \%$ oxygen may be the option, but the cost is dramatically increased.

As described in Chapter 2, there are three ways to supply oxygen to a glass melting batch tank. However, the level of oxygen consumption in most handmade glass companies is such that bulk oxygen supply is the only choice. This type of industrial oxygen supply usually has a purity of $97 \%$ or even $99.99 \%$, which is suitable for batch tank operation on both economical and technological basis.

\subsection{Adiabatic Flame Temperature}

Natural gas-oxygen combustion can be modeled using an adiabatic, constant-pressure process to specify the upper limit of the flame temperature, that is, the adiabatic flame temperature. In this section, the calculations are based on the following seven assumptions: (1) Fuel is $100 \%$ methane $\left(\mathrm{CH}_{4}\right)$ and oxidizer is $100 \%$ oxygen $\left(\mathrm{O}_{2}\right)$. (2) Fuel and oxygen are stoichiometically premixed at $298 \mathrm{~K}$ and 1 atm. (3) Combustion is adiabatic and occurs at constant pressure. (4) Chemical reaction is non-dissociated and complete. (5) One step global reaction represents the complex multiple step reactions. (6) Shaft work is assumed zero. (7) Kinetic energy is small compared with the enthalpy [37].

Based on the above assumptions, the energy conservation equation is simply expressed as

$$
h_{r}=h_{p}
$$

where

$$
\begin{aligned}
& h_{r} \text { is the enthalpy of reactants, and } \\
& h_{p} \text { is the enthalpy of products. }
\end{aligned}
$$

Using the one-step global reaction model, the complete chemical reaction can be expressed as 


$$
\mathrm{CH}_{4}+2 \mathrm{O}_{2} \rightarrow \mathrm{CO}_{2}+2 \mathrm{H}_{2} \mathrm{O}
$$

Thus, Equation (3-1) becomes

$1\left[\left(\hat{h}_{s}+\Delta \hat{h}^{\circ}\right)\right]_{\mathrm{CH}_{4}}+2\left[\left(\hat{h}_{s}+\Delta \hat{h}^{\circ}\right)\right]_{O_{2}}=1\left[\left(\hat{h}_{s}+\Delta \hat{h}^{\circ}\right)\right]_{\mathrm{CO}_{2}}+2\left[\left(\hat{h}_{s}+\Delta \hat{h}^{\circ}\right)\right]_{\mathrm{H}_{2} \mathrm{O}}$

where $\quad \hat{h}_{s}$ is sensible enthalpy at $\mathrm{T}(\mathrm{K})$ and $\Delta \hat{h}^{\circ}$ is enthalpy of formation

The enthalpy of formation of $\mathrm{O}_{2}$ is $0 \mathrm{~kJ} / \mathrm{kmol}$; the enthalpy of formation of $\mathrm{CH}_{4}, \mathrm{O}_{2}, \mathrm{CO}_{2}$ and $\mathrm{H}_{2} \mathrm{O}$ are $-74,850 \mathrm{~kJ} / \mathrm{kmol}, 0 \mathrm{~kJ} / \mathrm{kmol},-393,520 \mathrm{~kJ} / \mathrm{kmol}$, and $-241,820 \mathrm{~kJ} / \mathrm{kmol}$, respectively . Then Equation (3-3) becomes

$$
(0-74,850)=\left(\bar{h}_{\mathrm{SOO}_{2}}-393,520\right)+2\left(\bar{h}_{\mathrm{s}_{2} \mathrm{O}}-241,820\right)
$$

Then, by guessing a series of temperatures within the range of $1900 \mathrm{~K}$ to $3250 \mathrm{~K}$ and using enthalpy data listed in Table 3.2 [38], the difference between left hand side (LHS) and right hand side (RHS) of Equation 3-4, that is $\delta=$ LHS-RHS, is calculated as shown in Equation 3-5.

$$
\begin{aligned}
& \delta=(0-74,850)-\left(\bar{h}_{\mathrm{SO}_{2}}-393,520\right)-2\left(\bar{h}_{\mathrm{SH}_{2} \mathrm{O}}-241,820\right) \\
& \delta=-\bar{h}_{\mathrm{SCO}_{2}}-2 \bar{h}_{\mathrm{sH}_{2} \mathrm{O}}+802310
\end{aligned}
$$

The T- $\delta$ relationship is almost linear; thus the adiabatic temperature can be approximately by extrapolating the developed linear equation

$$
\delta=-169.68 \mathrm{~T}+876593
$$

That is, letting $\delta=0$ yields $\mathrm{T}_{\mathrm{ad}}=5120 \mathrm{~K}$.

Thus, the adiabatic flame temperature of stoichiometric mixture of methane-oxygen combustion system is estimated as $5120 \mathrm{~K}$. Assuming the approximation by extrapolation is 
accurate enough, then the maximum flame temperatures derived from CFD simulations should be below this value of $5120 \mathrm{~K}$.

Table 3.2 Ideal Gas Properties of Carbon Dioxide and Water [38]

\begin{tabular}{|c|c|c|c|c|c|}
\hline \multicolumn{2}{|c|}{$\begin{array}{l}\text { Enthalpy of Formation } \\
(\mathrm{kJ} / \mathrm{kmol})\end{array}$} & \multirow[t]{2}{*}{$\begin{array}{l}\text { Guessed T } \\
\text { (K) }\end{array}$} & \multicolumn{2}{|c|}{$\begin{array}{c}\text { Sensible Enthalpy } \\
(\mathrm{kJ} / \mathrm{kmol})\end{array}$} & \multirow[t]{2}{*}{$\begin{array}{c}\delta \\
(\mathrm{kJ} / \mathrm{kmol})\end{array}$} \\
\hline $\mathrm{CO}_{2}$ & $\mathrm{H}_{2} \mathrm{O}$ & & $\mathrm{CO}_{2}$ & $\mathrm{H}_{2} \mathrm{O}$ & \\
\hline \multirow[t]{20}{*}{-393520} & \multirow[t]{20}{*}{-241820} & 1900 & 94793 & 77517 & 552483 \\
\hline & & 2000 & 100804 & 82593 & 536320 \\
\hline & & 2100 & 106864 & 87735 & 519976 \\
\hline & & 2200 & 112939 & 92940 & 503491 \\
\hline & & 2300 & 119035 & 98199 & 486877 \\
\hline & & 2400 & 125152 & 103508 & 470142 \\
\hline & & 2500 & 131290 & 108868 & 453284 \\
\hline & & 2600 & 137449 & 114273 & 436315 \\
\hline & & 2700 & 143620 & 119717 & 419256 \\
\hline & & 2750 & 146713 & 122453 & 410691 \\
\hline & & 2800 & 149808 & 125198 & 402106 \\
\hline & & 2850 & 152908 & 127952 & 393498 \\
\hline & & 2900 & 156009 & 130717 & 384867 \\
\hline & & 2950 & 159117 & 133486 & 376221 \\
\hline & & 3000 & 162226 & 136264 & 367556 \\
\hline & & 3050 & 165341 & 139051 & 358867 \\
\hline & & 3100 & 168456 & 141846 & 350162 \\
\hline & & 3150 & 171576 & 144648 & 341438 \\
\hline & & 3200 & 174695 & 147457 & 332701 \\
\hline & & 3250 & 177822 & 150272 & 323944 \\
\hline
\end{tabular}

Then the T- $\delta$ relationship was obtained and is shown in Figure 3.1.

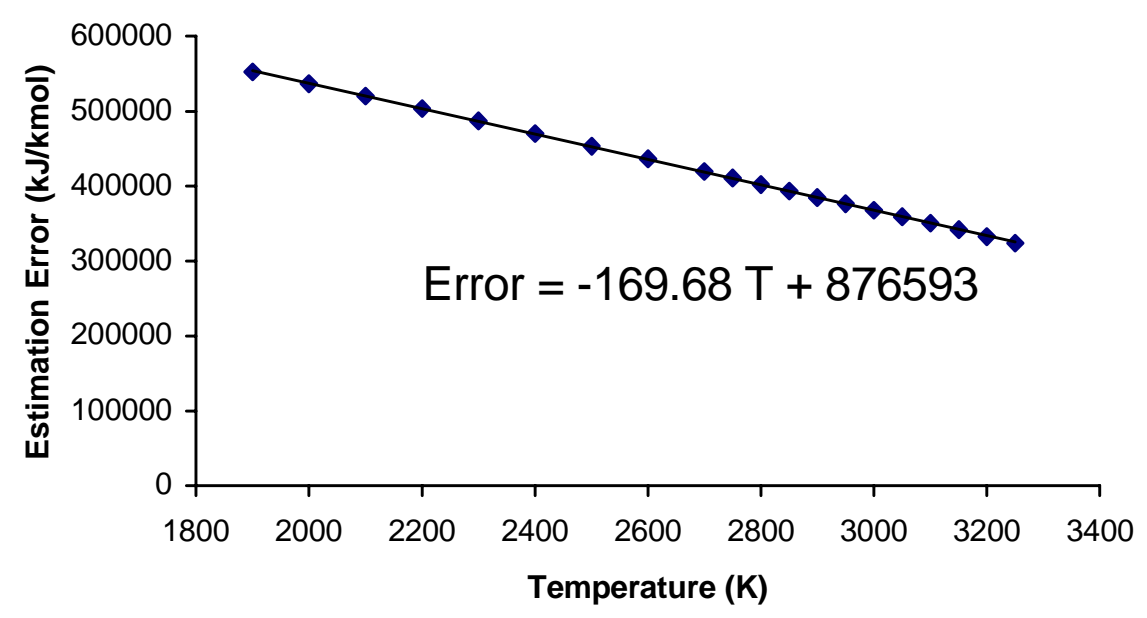

Figure 3.1 $T-\delta$ relationship 
This temperature is surely over estimated even for perfectly premixed combustion because of the assumptions as stated at the beginning of this section. For diffusion flame combustion, because the mixing pattern becomes a limiting factor of the chemical reaction, the "mixed-is-burned" assumption is added. More reduction should be taken into account from this calculated constant pressure, adiabatic flame temperature. As a result, $5000 \mathrm{~K}$ is set as the upper limit throughout all the simulation in this research.

\subsection{Premixed Combustion}

Premixed oxy-fuel flames arise from the combustion of gaseous natural gas and oxygen which are perfectly mixed prior to combustion. Glass melting batch tanks require intensive energy input; thus if premixed flames are used, they must be turbulent premixed flames. Turbulent flow increases the flame propagation, and there is no evidence that the turbulence substantially alters the chemistry.

Premixed oxy-fuel combustion has two disadvantages. First, safety issue arises due to flashback. Second, assuming the safety is guaranteed, the high flame temperature may still damage the burner tunnel refractory and/or the tank walls if the flame is not properly manipulated.

Although premixed oxy-fuel combustion in a glass melting process is not often seen in practice, it still is worthy to explore the potential of using it. After all, modeling of such a process and simulation for a premixed combustion on a computer will provide understanding of oxy-fuel firing without any safety problem.

\subsection{Diffusion Combustion}

Diffusion flames take place when the sources of fuel and oxidizer are physically separated so that the energy release rate is primarily controlled by the mixing process. In the hand glass industry, in which natural gas and air or oxygen burner systems are used, diffusion 
flames occur with natural gas flowing in one inlet and the oxidizer, air or oxygen, flowing in the other inlet.

The character of a diffusion flame changes with the fuel and oxygen inlet velocities. With the low inlet velocity (laminar flow) the mixing rate is slow and the flame is long and smooth. The laminar flame length increases linearly with increasing flow velocity up to a point where the flame becomes turbulent. Chemical kinetics plays a primary role within the laminar region. In the glass industry, the use of laminar flames are limited to other aspects of glassware production, such as glassware edge finishing and Lehr heating. In a glass melting batch tank where intensive energy is needed for the glass melting, diffusion flames are definitely necessary. The rate of burning is limited by the mixing rate because the chemical reactions are typically faster than the mixing rate. The flame length decreases with more rapid turbulent mixing. The turbulent flame length is proportional to the inlet size.

The issue is that this principle for flame length prediction is too general even for coaxial burners. The dependence of burner flame size on the natural gas velocity and the oxygen velocity is still basically unknown for the hand glass industry. In addition, diffusion combustion through non-coaxial burners such as flat flame burners is of concern in today's glass industry.

\subsection{Energy Balance Analysis}

An overall estimation of the energy balance for a batch tank is presented in this section. A 2500-pound batch tank is taken for the illustration of the energy balance analysis.

\subsubsection{Total Energy Input}

The natural gas consumption in such a batch tank is $600 \mathrm{SCFH}$, or $0.2133 \times 10^{-3} \mathrm{kmol} / \mathrm{s}$ at standard state $(298 \mathrm{~K}, 1 \mathrm{~atm})$. The enthalpy of combustion of methane is $50,019 \mathrm{~kJ} / \mathrm{kg}=800304$ $\mathrm{kJ} / \mathrm{kmol}$; therefore, the total energy input is $170700 \mathrm{~W}$ or $162 \mathrm{Btu} / \mathrm{s}$. Some of this amount of energy is used to melt the glass, while some of the energy is conducted through the crown, walls, 
and bottom of the tank to the surrounding, and the rest of the energy goes out with the exhaust through the stack.

\subsubsection{Heat loss through tank walls}

For a given tank geometry and refractory material properties, the heat loss through tank wall can be roughly estimated. The 2500-pound batch tank can be designed as a rectangular tank, whose length, width, and superstructure height are 1.80 meters, 1.20 meters, and 0.70 meters, respectively. The geometry of such a batch tank and two cut views as well as one cross section are shown in Figure 3.2.

The area of each tank surface, the thickness and heat conductivity of each wall are needed for heat loss calculation. The surface area of each wall, the wall thickness, heat conductivity, and the temperature difference across the wall, as well as the heat loss through each wall are listed in Table 3.3.

Table 3.3 Heat loss through walls [38]

\begin{tabular}{|l|l|c|c|c|c|c|}
\hline $\begin{array}{l}\text { Wall Type } \\
\text { \& Quantity }\end{array}$ & Material & $\begin{array}{c}\text { Thickness } \\
\Delta \mathrm{x}(\mathrm{m})\end{array}$ & $\begin{array}{c}\text { Area } \\
\mathrm{A}\left(\mathrm{m}^{2}\right)\end{array}$ & $\begin{array}{c}\boldsymbol{k} \\
(\mathrm{W} / \mathrm{m}-\mathrm{K})\end{array}$ & $\begin{array}{c}\Delta \mathbf{T} \\
(\mathrm{K})\end{array}$ & $\begin{array}{c}\text { Heat Loss } \\
\mathrm{dQ} / \mathrm{dt}(\mathrm{W})\end{array}$ \\
\hline Crown (1) & Silica & 0.23 & 2.27 & 1.73 & 1300 & 22200 \\
\hline Breast wall (2) & Mullite & 0.30 & 1.26 & 1.73 & 1300 & 9450 \\
\hline End wall (2) & Mullite & 0.23 & 0.97 & 1.73 & 1300 & 9480 \\
\hline Side wall (2) & AZS & 0.30 & 0.36 & 1.22 & 1300 & 1910 \\
\hline Bottom (1) & Flux block & 0.40 & 2.16 & 1.49 & 1300 & 8720 \\
\hline
\end{tabular}

The total heat loss (with insulation $)=22200+2 \times 9450+2 \times 9480+2 \times 1910+8720=$ $72600 \mathrm{~W}$ (or $68.8 \mathrm{BTU} / \mathrm{s})$.

\subsubsection{Heat for Glass Melting and Formation}

The energy for glass melting contributes to two aspects. First, it heats up the batch material from room temperature to the temperature at which glass formation occurs; then it provides the energy for the progress of glass formation. 


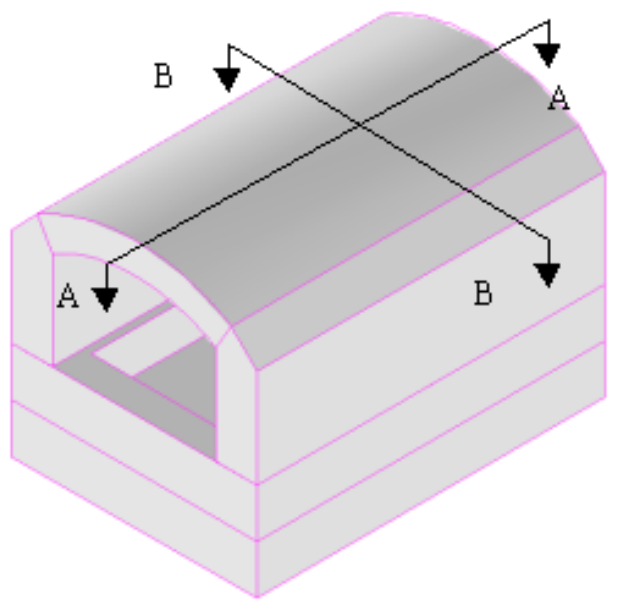

(a) 2500-pound batch tank

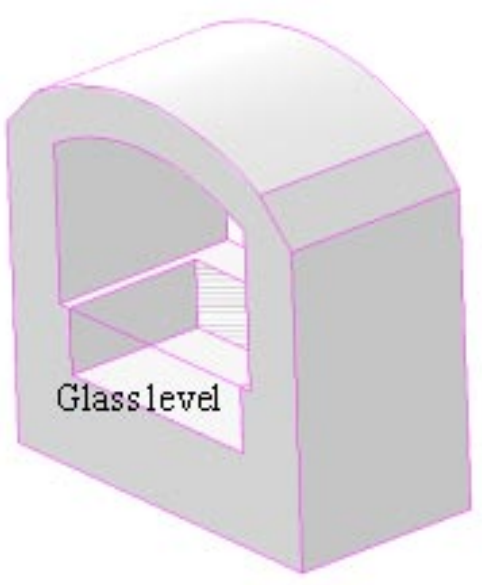

(c) Cut view $\mathrm{B}$

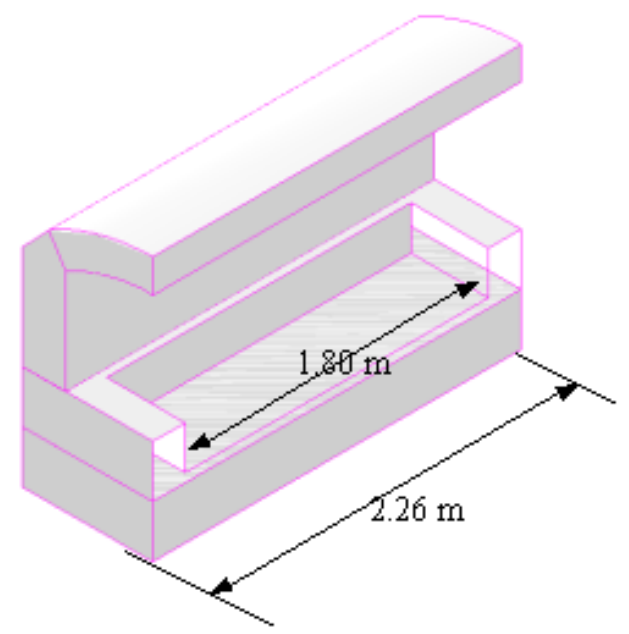

(b) Cut view A

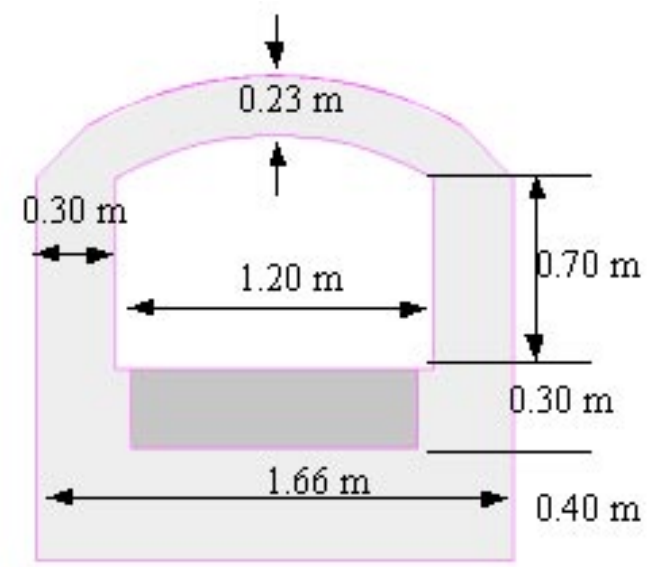

(d) View B (Cross-section)

Figure 3.2 The geometry of a typical batch tank 
The energy used to heat up the soda-lime batch material can be estimated as that energy needed to heat up soda-lime glass. The specific heat for soda-lime-silicate glass is $c_{p}=840 \mathrm{~J} / \mathrm{kg}$ $\mathrm{K}$ [1], the glass in the tank is $1200 \mathrm{~kg}$, the temperature difference is $\mathrm{T}_{\text {end }}-\mathrm{T}_{\text {start }}=1720 \mathrm{~K}-300 \mathrm{~K}=$ $1420 \mathrm{~K}$. Therefore, $\Delta \mathrm{Q}=\mathrm{m} c_{p}\left(\mathrm{~T}_{\text {end }}-\mathrm{T}_{\text {start }}\right)=(1200 \mathrm{~kg})(840 \mathrm{~J} / \mathrm{kg}-\mathrm{K})(1420 \mathrm{~K})=1431360000 \mathrm{~J}=$ $1431360 \mathrm{~kJ}$. Generally, the melting time is 12 hours $=43200$ seconds. Thus the internal energy increment is $33.1 \mathrm{~kJ} / \mathrm{s}=33100 \mathrm{~W}$ or $31 \mathrm{BTU} / \mathrm{s}$.

The energy for glass formation can be estimated based on glass formation chemistry. Stoichiometric chemical reactions requires $0.58 \times 10^{6}$ Btu per ton of glass. The glass amount is 1.25 ton, therefore, a total of $0.725 \times 10^{6} \mathrm{BTU}$ is needed. Assuming 12 hours reaction period, then the energy for chemical reactions of glass formation is $16.8 \mathrm{BTU} / \mathrm{s}$ or $17700 \mathrm{~W}$.

Adding these two parts together, $50800 \mathrm{~W}$ or $48 \mathrm{BTU} / \mathrm{s}$ is needed for glass melting and formation.

\subsubsection{Heat Loss with Flue}

As a fact, a great amount of heat is carried away with the exhaust. The flow rates of carbon dioxide and water vapor and the flue temperature are needed to compute the heat loss with the exhaust.

Referring to Equation 3-2, the $\mathrm{CO}_{2}$ flow rate (mole base) is the same as that of the natural gas, which is $0.2133 \times 10^{-3} \mathrm{kmol} / \mathrm{s}$; and the $\mathrm{H}_{2} \mathrm{O}$ vapor flow rate is two times that of the natural gas; that is, $0.4266 \times 10^{-3} \mathrm{kmol} / \mathrm{s}$.

The exhaust temperature is $1800 \mathrm{~K}$, and the ambient temperature is $300 \mathrm{~K}$. Therefore, the heat loss with the exhaust can be evaluated as below:

$$
\begin{gathered}
\Delta \mathrm{h}_{\mathrm{CO} 2}=\mathrm{h}_{\mathrm{CO} 2,1800 \mathrm{~K}}-\mathrm{h}_{\mathrm{CO} 2,300 \mathrm{k}}=88,806 \mathrm{~kJ} / \mathrm{kmol}-9,431 \mathrm{~kJ} / \mathrm{kmol}=79,375 \mathrm{~kJ} / \mathrm{kmol} \\
\Delta \mathrm{h}_{\mathrm{H} 2 \mathrm{O}}=\mathrm{h}_{\mathrm{H} 2 \mathrm{O}, 1800 \mathrm{~K}}-\mathrm{h}_{\mathrm{H} 2 \mathrm{O}, 300 \mathrm{k}}=72,513 \mathrm{~kJ} / \mathrm{kmol}-9,966 \mathrm{~kJ} / \mathrm{kmol}=62,547 \mathrm{~kJ} / \mathrm{kmol} \\
\text { Totally, } \Delta \mathrm{h}_{\text {flue }}=0.2133 \times 10^{-3} \mathrm{kmol} / \mathrm{s} \times 79,375 \mathrm{~kJ} / \mathrm{kmol}+0.4266 \times 10^{-3} \mathrm{kmol} / \mathrm{s} \times 62,547 \\
\mathrm{~kJ} / \mathrm{kmol}=43.613 \mathrm{~kJ} / \mathrm{s}, \text { or } 43613 \mathrm{w}, \text { or } 41.3 \mathrm{BTU} / \mathrm{s} .
\end{gathered}
$$




\subsubsection{Energy Balance Check}

In Section 3.5.1, the total energy input was calculated as $162 \mathrm{BTU} / \mathrm{s}$. This amount should be equal to the summation of the heat for glass melting, the heat loss through the tank surface, and formation, and the heat transported away with the exhaust, with a reasonable error.

Energy input $=$ Energy for glass melting + Heat loss through walls

+ Heat loss with exhaust + error

Thus, the estimation error can be evaluated as

$$
\begin{gathered}
170700 \mathrm{~W}=71850 \mathrm{~W}+50800 \mathrm{~W}+43610 \mathrm{~W}+\text { Error } \\
\text { Error }=3690 \mathrm{~W}
\end{gathered}
$$

This acceptable $2.5 \%$ error is an accumulation caused by the following five aspects:

(1). The total energy input calculation is based on complete, non-disassociation reaction assumption. This causes an over prediction on the available total energy.

(2). The heat loss calculated through tank surfaces assumed all surfaces are perfectly sealed. Actually, hot gas leakage and open channel radiation exist but were not taken into account.

(3), The specific heat of glass is assumed as a constant, which causes an under prediction error.

(4). The energy for the glass formation reaction calculation assumes the reaction occurs at a constant rate over the melting period. It may actually be a function of time.

(5). The flue temperature is expected to be in error. 


\section{Chapter 4 Geometry and Grid Generation}

In order to numerically solve the governing partial differential equations that describe transport processes, approximations to the partial differentials need to be introduced. In finite volume methods, the partial differential equations are reduced to algebraic expressions by integrating the governing equation over discrete sub-domains. The approximate algebraic equations are subsequently solved at these sub-domains within the domain of interest. Therefore, a proper geometry is needed to specify the domain, and the domain needs to be discretized to create these sub-domains. The geometry setup of a batch tank is discussed in Section 4.1, and the grid generation of it is discussed in Section 4.2.

\subsection{Geometry Modeling}

The geometry modeling is the first step in a CFD simulation process. Some geometric details in the real geometry may be simplified to form the geometry of the computational domain, as long as the modeled geometry still captures the flow features. The purpose of geometry creation is to specify the computational domain for proper grid generation; thus the geometry modeling is usually not a direct reflection of the geometry of a real object. Often, when creating geometry, the grid requirement is already taken into consideration.

\subsubsection{Geometry of a Cylindrical Combustor}

Practically, a cylindrical combustor is used for the identification of basic flame features. For example, Don Coe built a cylindrical oxy-fuel combustor and an oxy-fuel firing system in the Combustion Lab at AGA Gas Inc. The diameter of this combustor is 6 feet and the length is 12 feet. Numerically, building up a virtual cylindrical combustor is also necessary, and often, it is efficient because the geometric symmetry of the combustor enables the simulation to be reduced 
to a 2-D problem. In addition, in a real cylindrical combustor, the diameter has to be set big enough to avoid overheating the wall refractory and sensors arranged inside the combustor. When a virtual combustor is constructed up on a computer, this diameter does not have to be as large as that of a real combustor. Figure 4.1 is a schematic of such a cylindrical combustor prepared for flame feature investigation. The length of this combusor is 1.80 meters, the radius is 0.30 meters, and the radius of the exhaust stack is 0.08 meters.

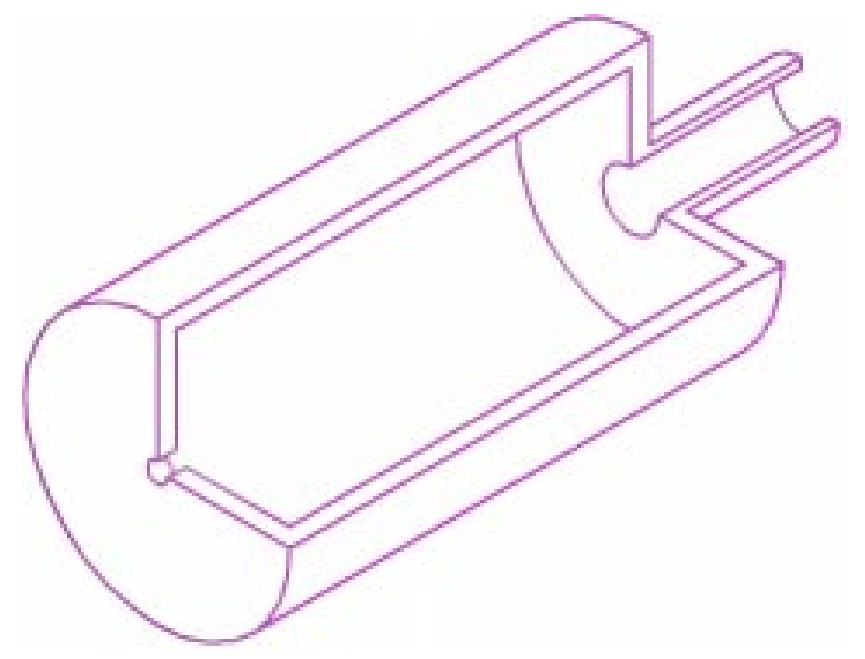

Figure 4.1 A cylindrical oxy-fuel combustor (burner is not shown)

For premixed firing or coaxial diffusion firing, the combustor is geometrically symmetric; the 3-dimensional combustor can be represented using a 2-dimensional plane with an axis of symmetry. Figure 4.2 illustrates the axisymmetric geometry of a cylindrical combustor with a burner.

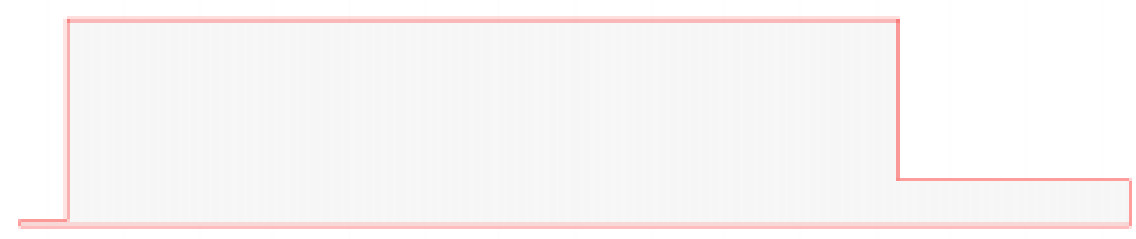

Figure 4.2 Axisymmetric geometry of a cylindrical combustor 


\subsubsection{Geometry of a Batch Tank}

In the hand glass industry, both rectangular and hexagonal shapes are used as the base shape for batch tank design, but rectangular tanks are more popular. Figure 4.3 gives an illustration of a rectangular batch tank and Figure 4.4 illustrates a hexagonal one. With the same melting capacity, they have the same melting area. The hexagonal tank generally requires an exhaust stack on the top of the tank, and it is good for multiple working port situations; the rectangular has an advantage of avoiding overheating the refractories when using oxy-fuel burner(s).

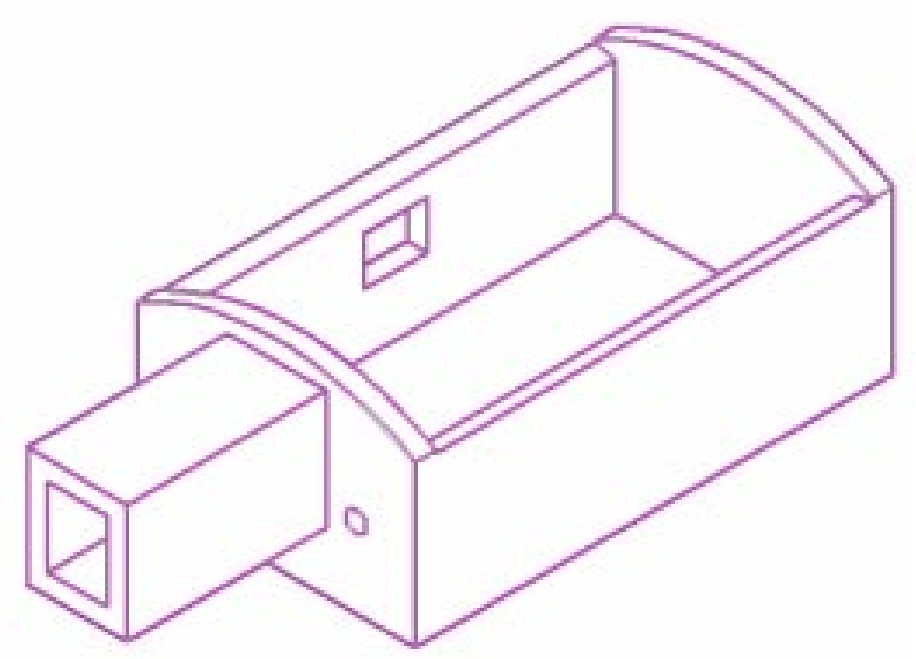

Figure 4.3 Rectangular batch tank (crown removed)

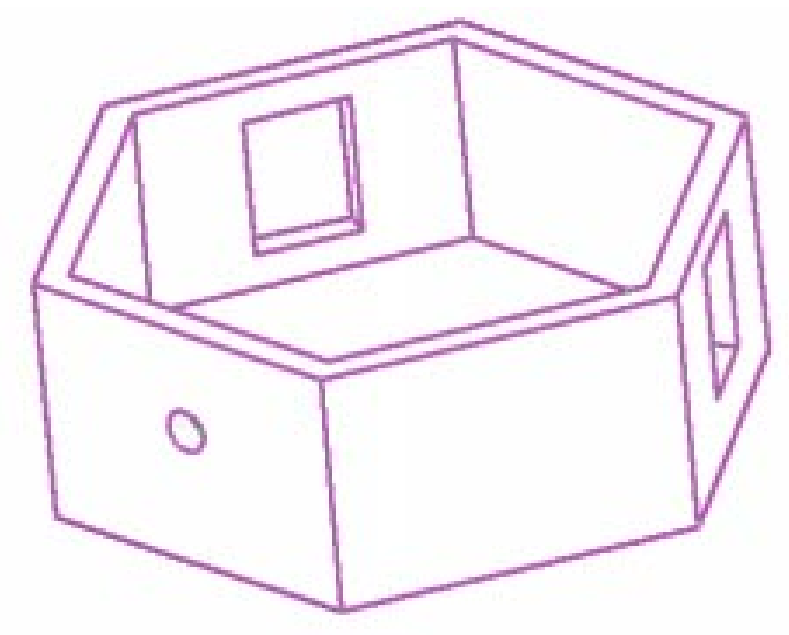

Figure 4.4 Hexagonal batch tank (crown removed) 
Basically, the size of a batch tank depends mainly on the melting capacity of the tank, because the melting capacity requires a certain area for glass melting. For a given capacity and specialized working environment, the length-to-width ratio can be easily determined if flame shape is not a factor. However, in the conversion of an air-fuel tank to an oxy-fuel tank, the tank length, width and the crown height have to be redesigned for energy efficiency enhancement while endeavoring to achieve a longer tank life expectancy. Also, the burner type, burner quantity, and burner placement as well as the stack shape and size are factors for tank geometry design, although the length, width and crown height are primary factors.

The geometry of air-fuel fired batch tanks can be taken as a reference for oxy-fuel batch tank geometry design. On one hand, oxy-fuel tanks may be designed more compact than air-fuel batch tanks, because its combustion chamber can be reduced when most of the nitrogen is removed from the oxidizer supply. On the other hand, the oxy-fuel flame is much hotter than the air-fuel flame, thus the tank length, width, and crown height must not be less than critical values; otherwise, overheating may cause premature failure of refractory. Therefore, at the first stage of geometry design, the geometry is roughly modeled merely based on the glass melting capacity. The proper length, width, and crown height can possibly be best adjusted by simulation.

The computation domain is the region bound by the inner surfaces of the superstructure walls, and the top surface of the glass, as well as the stack inner surfaces. The thickness and the material properties of each wall will be set for heat conduction calculation when specifying boundary conditions. Figure 4.5 shows the geometry of the computation domain for a rectangular tank, which is of most concern for a batch tank.

If a structured grid is required, the physical geometry must be modified to be a gridorientated geometry, which meets the requirements of grid generation and manipulation. Usually, once a physical geometry has been sketched, some of its surfaces have to be divided into several sub-surfaces. All these sub-surfaces together form the geometry needed for grid generation. Figure 4.6 shows the geometry of a similar batch tank, which is oriented for structured grid 
generation. The tank is 1.80 meters long, 1.20 meters wide and 0.60 meters high above the glass level. Its surface, as a whole, consists of 144 sub-surfaces, although the actual batch tank has just 14 distinct surface areas.

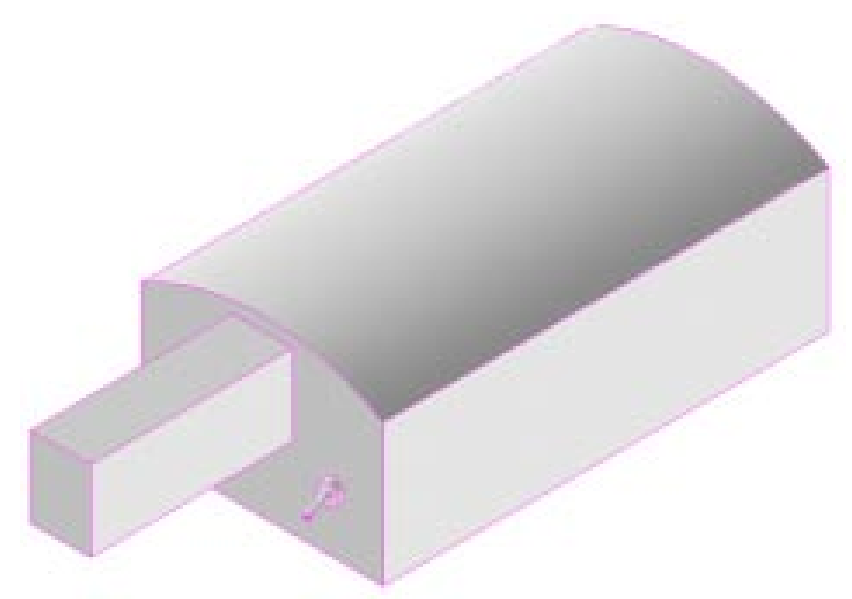

Figure 4.5 Geometry of computation domain for a batch tank

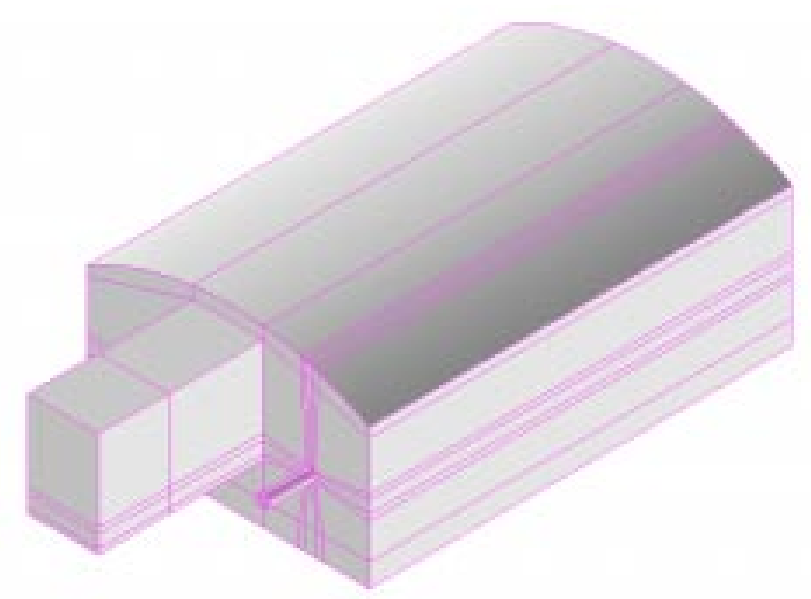

Figure 4.6 Geometry of a batch tank prepared to structured gird generation 


\subsection{Grid Generation}

\subsubsection{General Consideration of Grid Generation}

Tetrahedral, hexahedral, pyramid, or wedge cells or a combination of these cells are acceptable for a three-dimensional problem. When choosing mesh type, the issues of setup time, computational expense, and numerical diffusion should be considered.

The chemical reacting flows in a batch tank involve moderately complex geometry domain. The creation of structured grid (consisting of hexahedral elements) for such domains are time consuming. Setup time for a batch tank geometry is, therefore, one of the major motivations for using unstructured grids employing tetrahedral cells.

A tetrahedral mesh for a batch tank can be created with fewer cells than equivalent mesh consisting of hexahedral elements. This is because a tetrahedral mesh allows cells to be clustered in selected regions of the flow domain, whereas structured hexahedral meshes will generally force cells to be placed in regions where they are not necessarily needed.

Numerical diffusion arises from truncations that are a consequence of representing the fluid flow equations in discrete form; it is involved in all practical numerical schemes for solving fluid flow problem. It is a dominant source of error in three-dimensional situations. The following four points can be made in grid generation so as to keep the numerical diffusion within a finite amount:

- Numerical diffusion is most noticeable when the situation is convection-dominant.

- The second-order discretization scheme can help reduce the effects of numerical diffusion on the solution.

- Refining the mesh will usually reduce the amount of numerical diffusion.

- Numerical diffusion is minimized when the flow is aligned with the mesh. 


\subsubsection{Grid Generation for a Cylindrical Combustor}

The geometry of a cylindrical combustor is simple, thus the structured grid can be used to discretize the computation domain. The computation domain of a cylindrical combustor with a coaxial oxy-fuel burner is shown in Figure 4.7 (For illustration of grid, this particular geometry is not exactly the one used in computation).

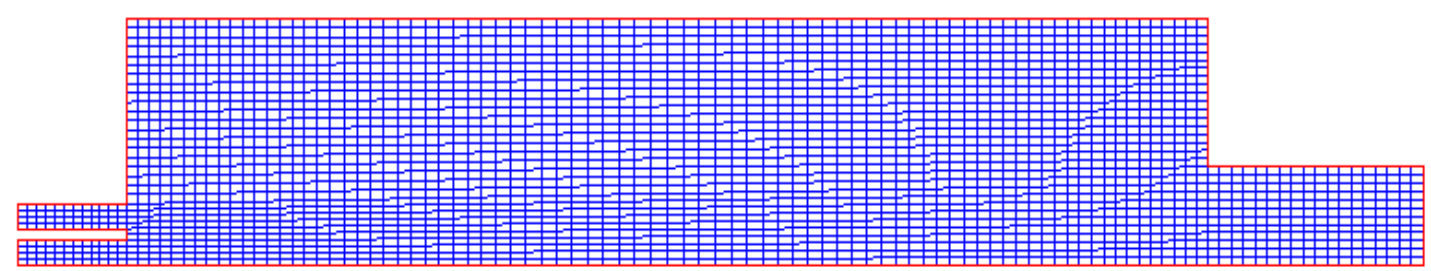

Figure 4.7 Structured grid of 2-D axis-symmetric plane for a cylindrical combustor

\subsubsection{Grid Generation for a Batch Tank}

A batch tank can be meshed with either a structured or an unstructured grid. Take a 2500-pound batch tank as an example, the four-step gird generation process is presented below:

\section{Structure Grid}

1) Setup the geometry oriented for structured grid as shown in Figure 4.6.

2) Mesh each edges with calculated node density.

3) Mesh all surfaces to obtain a surface mesh, as shown in Figure 4.8 (Upper left).

4) Mesh the volume to obtain a structured grid for the whole computational domain. After generation of the 3-D grid, the grid quality can be evaluated by visualization of the internal grid. The internal grid on three orthogonal planes are shown in Figure 4.8, too.

\section{Unstructured Grid}

For the geometry of a batch tank illustrated in Figure 4.5, with $\mathrm{L}=2.2$ meters, $\mathrm{W}=1.2$ meters, and $\mathrm{H}=0.70$ meters above the glass level, this geometry can be meshed with unstructured grid without any manipulations on the surfaces. The four-step meshing process is as stated below: 

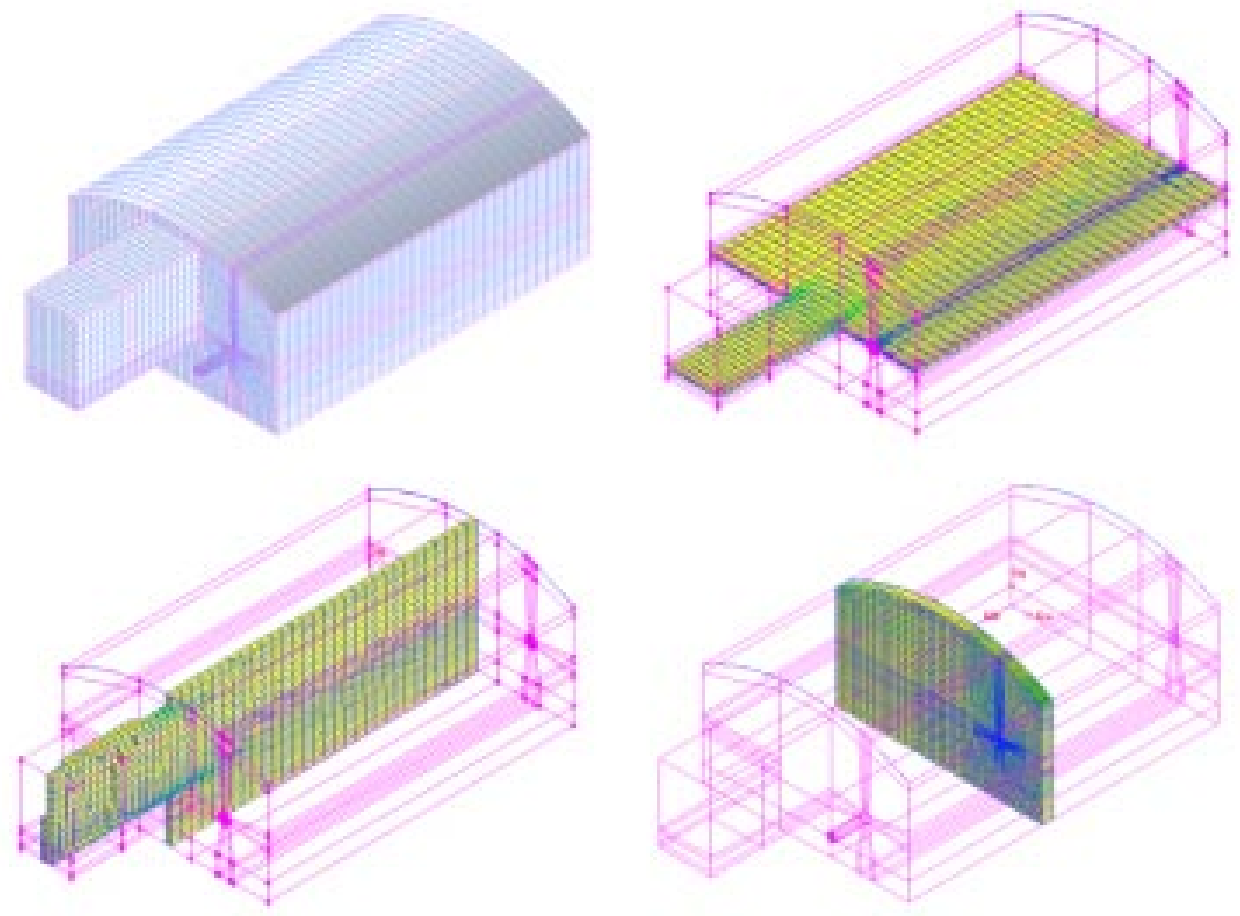

Figure 4.8 Structured grid for a batch tank
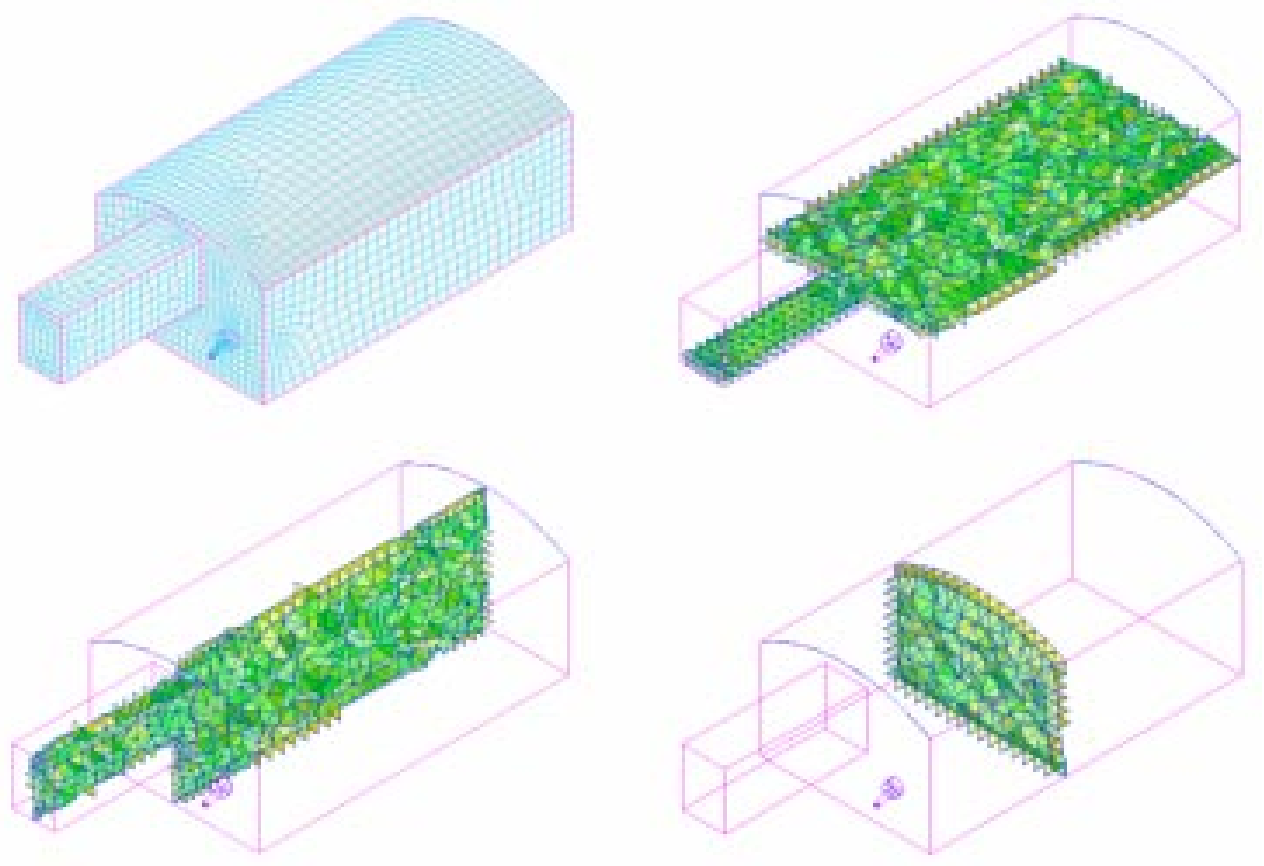

Figure 4.9 Unstructured grid for a batch tank 
1) Setup a physical geometry, as showed in Figure 4.5, which is ready for meshing directly.

2) Mesh each edge with calculated node density.

3) Mesh all surfaces. The generated surface mesh is shown in Figure 4.9 (upper left).

4) Mesh the computational domain with tetrahedral grid. The internal meshes on three orthogonal planes are shown in Figures 4.9, too.

\subsection{Grid Adjustment}

The generated grid for the computational domain may not be as good as expected after one or two simulations; thus it might need to be adjusted for better accuracy or sometimes for convergence. For example, when the grid is generated with low resolution, the computation may lead to a false simulation result or cause a convergence problem. Under such circumstances, the grid definitely needs to be refined. The refinement may be done by overall refinement over the whole domain, such as dividing each sub-domain (finite volume) into $2^{3}$ finer cells. As a result, the grid number increases exponentially and requires more computational efforts. The other way of refinement is based on the simulation results; just refine the grid locally according to the gradient of the interested property, e.g., temperature gradient or velocity gradient. This way results in refinement in the region where fine grid is really needed, and thus improves the computation accuracy with very limited addition of computational cost. Figure 4.10 shows such a grid refinement in two interested regions--the hot flame zone and the layer near the wall. The grid is refined according calculated temperature gradient. Another kind of grid adjustment is grid coercion. For example, this grid adjustment can occur when standard wall function is used for the near wall treatment and the grid adjacent to wall is too fine. But most often, refinement is needed for grid adjustment, because computational cost is always of concern. To save CPU time, an initial grid is usually generated with a reasonable cell number, then refine the grid when necessary. 

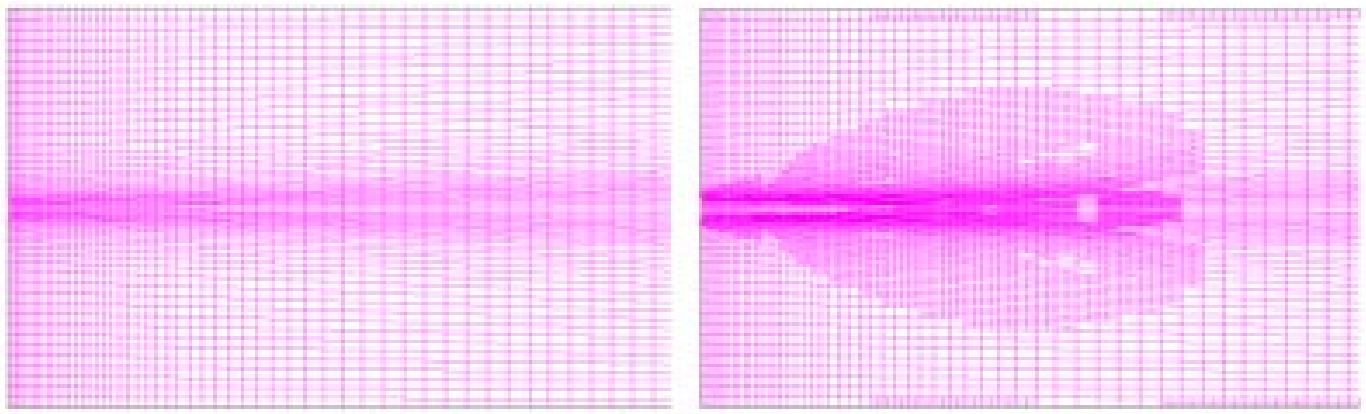

Figure 4.10 Solution based grid adaption. Left: before adaption; Right: after adaption

\begin{abstract}
Numerical uncertainty was checked for all case studies. The grid for cylindrical combustors is ensured to be fine enough. Further refining of grid did not show any significant change in key parameters such as velocity, temperature and species. The grid quality for 3dimensional batch tank was also checked, the edge size of sub-domain (cell) is ensured less than $5 \mathrm{~cm}$ for all case studies, with refining in some sensitive regions such as burner and its vicinity.
\end{abstract}




\section{Chapter 5 Physical and Chemical Models}

Today's CFD codes provide comprehensive modeling capabilities for a wide range of incompressible and compressible, laminar and turbulent fluid flow studies. For modeling the combustion and heat transfer processes in a batch tank, both physical models and chemical transport-reaction models as well as their corresponding governing equations are employed. In this chapter, models for physical processes and models for chemical species transport and reacting flows are identified specifically for oxy-fuel combustion in a batch tank.

\subsection{Basic Physical Models}

The basic physical models for fluid flow and heat transfer in a batch tank include continuity, momentum, and energy equations, as well as equations for buoyancy and swirling flows. Models for turbulence and radiation are so important that they are described in separate sections of this chapter-Sections 5.2 and 5.3, respectively.

\subsubsection{Conservation of Mass}

The general form of the mass conservation equation, or continuity equation, is

$$
\frac{\partial \rho}{\partial t}+\frac{\partial}{\partial x_{i}}\left(\rho u_{i}\right)=S_{m}
$$

where

$$
\begin{array}{lll}
\rho & = & \text { density, } \mathrm{kg} / \mathrm{m}^{3} \\
u_{i} & = & \text { the velocity in the } i \text { direction, } \mathrm{m} / \mathrm{s} \\
S_{m} & = & \text { the source term of mass, } \mathrm{kg} / \mathrm{m}^{3} \mathrm{~s}
\end{array}
$$


Equation 5-1 is valid for incompressible as well as compressible flows. Because the flow in the combustion chamber of a batch tank involves species mixing and reacting, species conservation equations have to be solved. These equations are described in Section 5.4.2.

\subsubsection{Conservation of Momentum}

The reacting fluid in an oxygen-natural gas combustion is a mixture of a certain number of species. Although more than 140 species exist in the combustion, only a small fraction of these species are of the most concern in the modeling of combustion. These significant species include $\mathrm{CH}_{4}, \mathrm{~N}_{2}, \mathrm{O}_{2}, \mathrm{CO}_{2}$, and $\mathrm{H}_{2} \mathrm{O}$. The body force, $F$, acting on species $k$ will contribute to the rate of change of the momentum

$$
F=\rho \sum_{k=1}^{N} Y_{k} f_{k}
$$

in which

$$
\begin{array}{lll}
\rho & = & \text { density, } \mathrm{kg} / \mathrm{m}^{3} \\
Y_{k} & = & \text { the mole fraction of species } k \\
f_{k} & = & \text { the external force per unit mass on species } k \\
\mathrm{~N} & = & \text { the number of species, here } \mathrm{N} \text { equals to } 5 .
\end{array}
$$

Thus, the momentum equation takes the form

$$
\frac{\partial}{\partial t}\left(\rho u_{i}\right)+\frac{\partial}{\partial x_{i}}\left(\rho u_{i} u_{j}\right)=-\frac{\partial p}{\partial x_{i}}+\frac{\partial \tau_{i j}}{\partial x_{j}}+\rho g_{i}+F_{i}
$$

where

$$
\begin{array}{lll}
\rho & = & \text { the density, } \mathrm{kg} / \mathrm{m}^{3} \\
u & = & \text { velocity, } \mathrm{m} / \mathrm{s} \\
p & = & \text { the static pressure, } \mathrm{N} / \mathrm{m}^{2} \\
F_{i} & = & \text { the component of body force in } i \text { direction } \\
g_{i} & = & \text { the acceleration in } i \text { direction, } \mathrm{m} / \mathrm{s}^{2}
\end{array}
$$




$$
\begin{gathered}
\tau_{i j} \quad=\text { the stress tensor which is given by } \\
\tau_{i j}=\left[\mu\left(\frac{\partial u_{i}}{\partial x_{j}}+\frac{\partial u_{j}}{\partial x_{i}}\right)\right]-\frac{2}{3} \mu \frac{\partial u_{l}}{\partial x_{l}} \delta_{i j}
\end{gathered}
$$

with $\quad \mu \quad=\quad$ the viscosity

$$
\delta_{\mathrm{ij}} \quad=\quad \text { the Kronecher delta. }
$$

Here $i, j, l$ are the three orthogonal directions.

\subsubsection{Conservation of Energy}

The energy equation is

$$
\frac{\partial}{\partial t}(\rho E)+\frac{\partial}{\partial x_{i}}\left(u_{i}(\rho E+p)\right)=\frac{\partial}{\partial x_{i}}\left(k_{e f f} \frac{\partial T}{\partial x_{i}}-\sum_{j} h_{j} J_{j}^{\prime}+u_{j}\left(\tau_{i j}\right)_{e f f}\right)+S_{h}
$$

where

$$
\begin{aligned}
& \rho \quad=\text { density, } \mathrm{kg} / \mathrm{m}^{3} \\
& E \quad=\quad h-\frac{p}{\rho}+\frac{u_{i}^{2}}{2}
\end{aligned}
$$

where sensible enthalpy $h$ is defined for incompressible flows as

$$
h=\sum_{\mathrm{j}^{\prime}} m_{j^{\prime}} h_{j^{\prime}}+\frac{p}{\rho}
$$

where $m_{j}$, is the mass fraction of species $j$ ' and

$$
h_{j^{\prime}}=\int_{\mathrm{T}_{\mathrm{ref}}}^{T} c_{p, j} d T
$$

$k_{\text {eff }}=$ the effective conductivity $\left(k+k_{t}\right.$, where $k_{t}$ is the turbulent thermal conductivity, defined according to the turbulence model being used)

$$
J_{j^{\prime}} \quad=\quad \text { the diffusion flux of species } j^{\prime} \text {. }
$$


The first three terms on right hand side of Equation 5-5 represent heat transfer due to conduction, species diffusion, and viscous dissipation, respectively. $S_{h}$ includes the heat of chemical reaction, and any other heat source.

\subsubsection{Buoyancy-Driven Flows}

Because the fluid density varies with temperature, a flow can be induced due to the force of gravity acting on the density variations. The effect of such flows is especially important for the description of the reacting flow introduced using a low momentum burner.

The importance of buoyancy forces in a mixed convection flow can be measured by the ratio of the Grashof number $\left(G_{r}\right)$ and Reynolds numbers $\left(R_{e}\right)$. The Grashof number is defined as

$$
G_{r}=\frac{\text { Buoyancy forces }}{\text { Viscous forces }}=\frac{g \Delta \rho V}{\rho v^{2}}=\frac{\mathrm{g} \beta \Delta \mathrm{TV}}{v^{2}}
$$

where

$$
\begin{array}{lll}
g & = & \text { gravitational acceleration, } \mathrm{m} / \mathrm{s}^{2} \\
\rho & = & \text { density, } \mathrm{kg} / \mathrm{m}^{3} \\
T & = & \text { temperature, } \mathrm{K} \\
\mathrm{V} & = & \text { volume, } \mathrm{m}^{3} \\
v & = & \text { kinetic viscosity, } \mathrm{m}^{2} / \mathrm{s} \\
\beta & = & \text { coefficient of volume expansion, } 1 / \mathrm{K}(\beta=1 / T \text { for ideal gases })
\end{array}
$$

Since $\Delta \rho \approx \rho \beta \Delta T$, it is formally expressed as

$$
G_{r}=\frac{\mathrm{g} \beta \Delta \mathrm{TL}^{3}}{v^{2}}
$$

where $\mathrm{L} \quad=\quad$ the characteristic length, $\mathrm{m}$. 
Therefore, the ratio of the Grashof number $\left(G_{r}\right)$ and Reynolds numbers $\left(R_{e}\right)$ can be expressed as

$$
\frac{G_{r}}{R_{e}^{2}}=\frac{\Delta \rho g L}{\rho v^{2}}
$$

When this ratio approaches or exceeds unity, strong buoyancy contributions to the flow are expected [39].

\subsubsection{Swirling Flows}

In conventional air-fuel firing practice, swirl flows were used to stabilize the air-fuel flame. This method may benefit oxy-fuel too; however, swirl may also cause mixing to occur within the burner tunnel zone, which may impinge on tunnel block material.

The swirling flow is axisymmetric with respect to geometry but still include swirl. In this case, the issue can be solved by modeling the flow in 2D (i.e., solve the axisymmetric problem) and include the prediction of circumferential (or swirl) velocity.

The tangential momentum equation for 2-D swirling flow may be written as

$$
\frac{\partial}{\partial t}(\rho w)+\frac{1}{r} \frac{\partial}{\partial x}(r \rho u w)+\frac{1}{r} \frac{\partial}{\partial r}(r \rho u w)=\frac{1}{r} \frac{\partial}{\partial x}\left[r u \frac{\partial w}{\partial x}\right]+\frac{1}{r^{2}} \frac{\partial}{\partial r}\left[r^{3} u \frac{\partial}{\partial r}\left(\frac{w}{r}\right)\right]-\rho \frac{v w}{r}
$$

where

$$
\begin{array}{lll}
x & = & \text { the axial coordinate } \\
r & = & \text { the radial coordinate } \\
u & = & \text { the axial velocity } \\
v & = & \text { the radial velocity } \\
w & = & \text { the swirl velocity. }
\end{array}
$$




\subsection{Turbulence Model}

\subsubsection{Turbulence of the Flow}

Viscous flows are classified into laminar or turbulent regimes on the basis of their internal flow structure. In the laminar regime, the flow structure is characterized by particle motion in laminae or layers. Flow structure in the turbulent regime is characterized by random, three-dimensional motion of fluid particles superimposed on the mean motion. Whether the flow of combustion gases in a batch tank is laminar or turbulent depends on the properties of the given flow conditions. Considering the flow through a duct such as the fuel or/and oxygen inlets, the Reynolds Number can be used to characterize the flow.

$$
\mathrm{R}_{\mathrm{e}}=\rho \mathrm{VL} / \mu=\mathrm{VL} / \mathrm{V}
$$

where

$$
\begin{array}{lll}
\boldsymbol{\rho} & = & \text { the density of the mixture of fuel-oxygen, } \mathrm{kg} / \mathrm{m}^{3} \\
\boldsymbol{V} & = & \text { the mean velocity of the flow, } \mathrm{m} / \mathrm{s} \\
\boldsymbol{L} & = & \text { the characteristic length of the duct, } \mathrm{m} \\
\boldsymbol{v} & = & \text { the kinetic viscosity, } \mathrm{kg} / \mathrm{m}-\mathrm{s} \\
\boldsymbol{v} & = & \text { the viscosity of the fluid, } \mathrm{m}^{2} / \mathrm{s}
\end{array}
$$

The energy intensity required for the glass melting process is so large that almost all the gaseous flows involved in batch tank are turbulent. These turbulent flows include the flow of fuel and oxygen through the burner inlets, the reacting flow through the combustion chamber, and the exhaust gas flows through the flue outlet. The possible exception is that when a flat flame burner is employed, the flow introduced through the non-circular inlet may be laminar.

Methane $\left(\mathrm{CH}_{4}\right)$, oxygen $\left(\mathrm{O}_{2}\right)$ and nitrogen $\left(\mathrm{N}_{2}\right)$ are involved in the flows through an oxyfuel burner. Their properties and are listed in Table 5.1 for the evaluation of the Reynolds number. 
Table 5.1 Physical properties of $\mathrm{CH}_{4}, \mathrm{O}_{2}$, and $\mathrm{N}_{2}$ [40]

\begin{tabular}{|l|l|l|l|}
\hline at $300 \mathrm{~K}, 1 \mathrm{~atm}$ & $\nu\left(\mathrm{m}^{2} / \mathrm{s}\right)$ & $\mu(\mathrm{kg} / \mathrm{m}-\mathrm{s})$ & $\rho\left(\mathrm{kg} / \mathrm{m}^{3}\right)$ \\
\hline $\mathrm{O}_{2}$ & $15.86 \mathrm{E}-6$ & $20.63 \mathrm{E}-6$ & 1.301 \\
\hline $\mathrm{CH}_{4}$ & $15.60 \mathrm{E}-6$ & $11.20 \mathrm{E}-6$ & 0.714 \\
\hline $\mathrm{N}_{2}$ & $15.63 \mathrm{E}-6$ & $17.84 \mathrm{E}-6$ & 1.142 \\
\hline
\end{tabular}

The Reynolds numbers of the flows through the coaxial inlets can be calculated for given flow velocities. Generally, the Reynolds number is within the range of 5,000 to 50,000. Therefore, the flow through the inlet is fully developed turbulent flow.

\subsubsection{Turbulence Models}

Turbulent flows are characterized by fluctuating velocity fields. The fluctuations are too computationally expensive to simulate directly in practical engineering calculation. Instead, the exact governing equations can be time-averaged, ensemble-averaged, or manipulated to remove the small scales, resulting in equations that are computationally less expensive to solve. However, the modified equations contain additional unknown variables, and thus the turbulence models are needed to determine these variables in terms of known quantities.

Generally, both the Reynolds-averaged approach and the Large Eddy Simulation (LES) approach can be employed to transform the Navier-Stokes equations in such a way that the smallscale turbulent fluctuations do not have to be directly simulated. However, only the Reynoldsaveraged approach is considered for the simulation of the chemical reacting flow in a batch tank based on the following three factors: (1) The mean flow in a batch tank is steady during the melting period; thus, using the Reynolds-averaged approach greatly reduces the computational efforts, (2) Large computer resources are required to resolve the energy-containing turbulent eddies if LES approach is used, (3) the Reynolds-averaged approach has been proven to be suitable for industrial fluid simulations, such as industrial furnaces and boilers, and it works well for glass melting furnaces fired by air-fuel combustion. 
The literature on applications of computational fluid dynamics (CFD) to gaseous fuel fired industrial furnaces shows that the turbulence model of choice is generally one of three twoequation models based on isotropic eddy viscosity concept, and the standard k- $\varepsilon$ model is widely used for air-fuel combustion. In this section, a comparison among these three two-equation based turbulence models is made to find a turbulence model more suitable for oxy-fuel reacting flow. These three models are the standard k- $\varepsilon$ model, the renormalization group (RNG) k- $\varepsilon$ model, and the realizable k- $\varepsilon$ model.

The standard k- $\varepsilon$ model is a semi-empirical model. The model equations are derived from the Reynolds-Average Navier-Stokes (RANS) equations. Its derivation is based on the assumption that the flow is fully turbulent, and the effects of molecular viscosity are negligible. The standard k- $\varepsilon$ model is therefore valid only for fully developed flows. Based on the result of Reynolds Number evaluation, it can be concluded that this model is one option. The standard k- $\varepsilon$ model contains five model constants, which are $\mathrm{C}_{1 \varepsilon}, \mathrm{C}_{2 \varepsilon}, \mathrm{C}_{\mu}, \sigma_{\mathrm{k}}$, and $\sigma_{\varepsilon}$ and their default values are:

$$
\begin{array}{lll}
\mathrm{C}_{1 \varepsilon},=1.44, & \mathrm{C}_{2 \varepsilon},=1.92, & \mathrm{C}_{\mu}=0.09 \\
\sigma_{\mathrm{k}}=1.0, & \sigma_{\varepsilon}=1.3, & \mathrm{P}_{\mathrm{rt}}=0.85
\end{array}
$$

These default values have been determined from experiments with air and water for fundamental turbulent shear flows including homogeneous shear flows and isotropic grid turbulence. They have been found to work fairly well for a wide range of wall-bounded and free shear flows, so these default values of the model constants are the standard ones most widely accepted. But there is no evidence that the standard k- $\varepsilon$ model works accurate enough for oxyfuel reacting flow.

Unlike the standard k- $\varepsilon$ model, the RNG k- $\varepsilon$ model is based on the Reynolds averaging. The RNG-based k- $\varepsilon$ turbulence model is derived from the instantaneous Navier-Stokes equations, using a rigorous mathematical technique called Renormalization Group (RNG) methods. The 
analytical derivation results in a model with constants different from those in the standard $k$ - $\varepsilon$ model, and additional terms in the transport equations for $k$ and $\varepsilon$ [41]. This model provides more universality and rigor, and yields improved predictions for flows with high streamline curvature and high strain rate, low-Reynolds-number and transitional flows, and wall heat and mass transfer. Probably, this model is closer to the reality than the standard k- $\varepsilon$ model for the flow in a batch tank.

The realizable k- $\varepsilon$ model is a relatively recent development; it is good for flows involving rotation and recirculation.

All three turbulence models were assessed in case studies for both cold oxy-fuel mixing and hot oxy-fuel reacting flows, and the assessment is reported in Section 5.2.3.

\subsubsection{Assessment on Turbulence Models}

To determine which one of these three models is best suitable for the simulation of the oxy-fuel combustion and heat transfer phenomena in a batch tank, these models need to be assessed for further use. These three models have been studied based on cold mixing pattern comparison and hot reacting flow simulation.

A coaxial inlet combustor was used to investigate the turbulence of the flow. The center pipe supplies the fuel and the annular pipe supplies the oxidizer (oxygen). The combustion chamber has a radius of 0.30 meters and a length of 1.50 meters. The fuel inlet diameter is 0.020 meters; the fuel inlet pipe thickness is 0.002 meters, and the inner diameter of the annular oxygen pipe diameter is 0.05 meters. The fuel flow velocity is $15 \mathrm{~m} / \mathrm{s}$; and the oxygen flow velocity is $6.7 \mathrm{~m} / \mathrm{s}$. Mixing of fuel and oxygen was studied by focusing on the fluid dynamical aspects of the mixing process in the cylindrical combustor; and comparison on turbulence models was conducted by simulations in which chemical reaction, heat release and transfer were considered.

Temperature distribution in the cylindrical model combustor was obtained by simulation with each of the three two-equation based turbulence models and shown in Figure 5.1. 


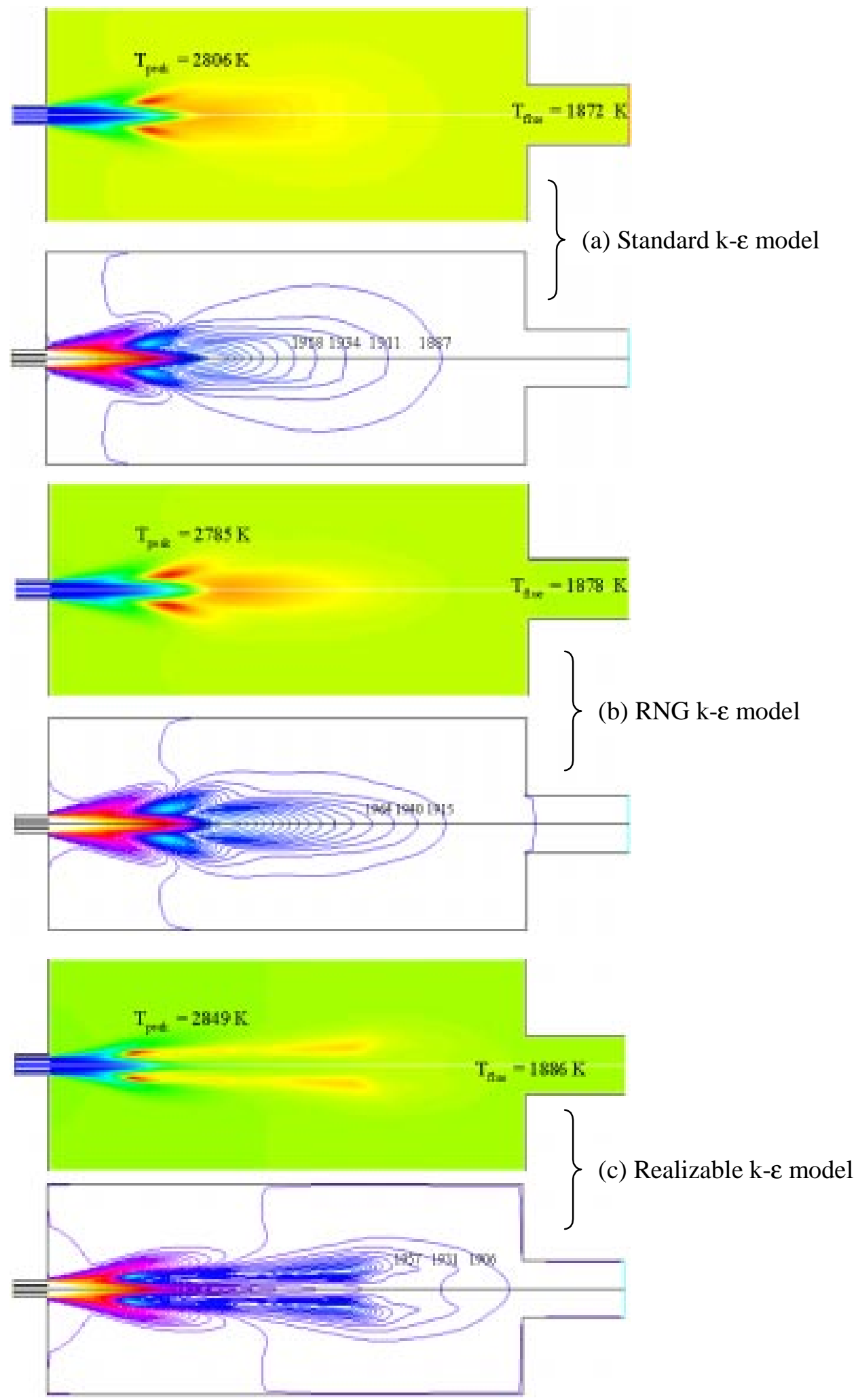

Figure 5.1 Temperature contours of coaxial burner flame using different turbulence models 
The flame shape from the realizable $k-\varepsilon$ model is obviously not fitting the flame profile observed from real firing test. The standard k- $\varepsilon$ model and the RNG k- $\varepsilon$ model are suitable for the oxy-fuel firing with different accuracy. An additional three-dimensional simulation of the firing in a batch tank showed that the standard k- $\varepsilon$ model over predicted the flame temperature. The RNG k- $\varepsilon$ model fits the oxy-fuel firing situation better than the standard k- $\varepsilon$ model, and thus it is chosen for turbulence modeling throughout this research.

\subsection{Radiation Model}

In an oxy-fuel fired batch tank where high temperatures are involved, radiation is usually the dominant mechanism for heat transfer. Calculation of the radiative heat transfer in CFD models is typically handled using "six-flux" models [42]. Therefore, the main issue in the heat transfer model selection is to select an appropriate radiation heat transfer model. Three radiation models are commonly used for combustion issues; they are the Discrete Transfer Radiation Model (DTRM), the P-1 Radiation Model, and the Rosseland Radiation Model.

\subsubsection{The Discrete Transfer Radiation Model (DTRM)}

DTRM is a relatively simple model and increasing the number of rays can ensure its accuracy. It applies to a wide range of optical thickness. Optical thickness of the media is defined as $\alpha \mathrm{L}$, where $\alpha$ is the absorption coefficient and $\mathrm{L}$ is the hydraulic diameter of the combustion chamber. However, DTRM also has three shortcomings; first, because it assumes all surface are diffuse, it means that the reflection of incident radiation at the surface is isotropic with respect to solid angle; second, the scattering is not included; and third, increasing the number of rays to ensure accuracy is CPU-intensive.

\subsubsection{The P-1 Radiation Model}

The P-1 model has several advantages over the DTRM. It is easy to solve with little CPU demand, and the effect of scattering is included in this model so that for combustion applications 
where the optical thickness is large, it works reasonably well. In addition, it can easily be applied to complicated geometries with curvilinear coordinates. The primary disadvantage of the P-1 model is the loss of accuracy; it tends to over predict radiation fluxes from localized heat sources or sinks.

\subsubsection{The Rosseland Radiation Model}

The Rosseland Radiation Model can be derived from the P-1 model equations with some approximations. It has two advantages over the P-1 model; it is faster than the P-1 model and it requires less memory. But this model is valid only when the optical thickness of the medium is greater than 3 .

For certain applications, one radiation model may be more appropriate than the others. However, even for the simulation of the same batch tank, because some of the flow features are functions of the operation parameters (for example, the optical thickness depends on the oxygenfuel supply style), the radiation model may need to be shifted among these three models.

\subsubsection{Calculation for Specifying Radiation Model}

The selection of radiation model depends on the optical thickness of the media in the combustion chamber. Generally, when $\alpha \mathrm{L}>3$, the Rosseland radiation model should be used. When $1<\alpha \mathrm{L}<3$, the P-1 model works better. When $\alpha \mathrm{L}<1$, the DTRM model is appropriate. The L of a typical batch tank is $120 \mathrm{~cm}$ to $150 \mathrm{~cm}$. According to the "mixed-is-burnt" theory, the combustion media in the batch tank can be simplified as a mixture of carbon dioxide and water vapor. The Planck-mean absorption coefficient of water vapor and carbon dioxide at $2000 \mathrm{~K}$ are about $0.01 \mathrm{~cm}^{-1}$ and $0.05 \mathrm{~cm}^{-1}$, respectively [43]. The participating media's absorption coefficient may be linearly approximated using the absorption coefficients of water vapor and carbon dioxide, which yields an estimated media absorption coefficient of $\alpha=0.0233 \mathrm{~cm}^{-1}$. Therefore, the optical thickness is roughly estimated to be in the range of 2.8 3.5. 
Nuray Kayakol [44] of Sisecam Glass Research Center, Istanbul, Turkey, provided two coefficients for oxygen-natural gas combustion in continuous tanks. The absorption coefficient of combustion products $\left(\mathrm{K}_{\mathrm{g}}\right)$ is in the range of $0.1 \sim 0.131 / \mathrm{m}$ without accounting for the effect of soot, while the absorption coefficient of soot $\left(\mathrm{K}_{\mathrm{s}}\right)$ is in the range of $0.58 \sim 2.351 / \mathrm{m}$. He concluded that due to $\mathrm{K}_{\mathrm{s}} \gg>\mathrm{K}_{\mathrm{g}}$, the absorption coefficient of the media can be merely represented by $\mathrm{K}_{\mathrm{s}}$. If so, the calculated optical thickness is in the range of $0.70 \sim 3.52$. This result agrees with the 2.8 3.5 theoretical calculation shown in the previous paragraph. The optical thickness indicates that the P-1 Radiation Model is possibly the most appropriate model, but DTRM model and Rosseland model can not be excluded without further verification.

\subsubsection{Assessment on Radiation Models}

Although the theoretical analysis in Section 5.3.3 suggests that the P-1 radiation model is the most suitable radiation model for oxy-fuel firing, considering the calculation error and the fact that soot contributes much to the absorption coefficient of the participating media, all the three radiation models were studied in simulation. A comparison of the simulated flame profiles is shown in Figure 5.2, and some other predicted quantities are listed in Table 5.2.

The Rosseland Radiation Model is definitely not suitable for oxygen-natural gas firing; obviously, the predicted temperature distribution is false. This model is originally developed for coal combustion situation, in which the amount of particles in the combustion chamber is high and the particulate size is big.

The DTRM model over predicted the flame temperature and the exhaust temperature, as well as the soot formation amount because the optical thickness in the tank much higher than the expected one.

Thus, Rosseland radiation model and DTRM model were excluded, and the P-1 model was selected as the radiation model throughout this research. 

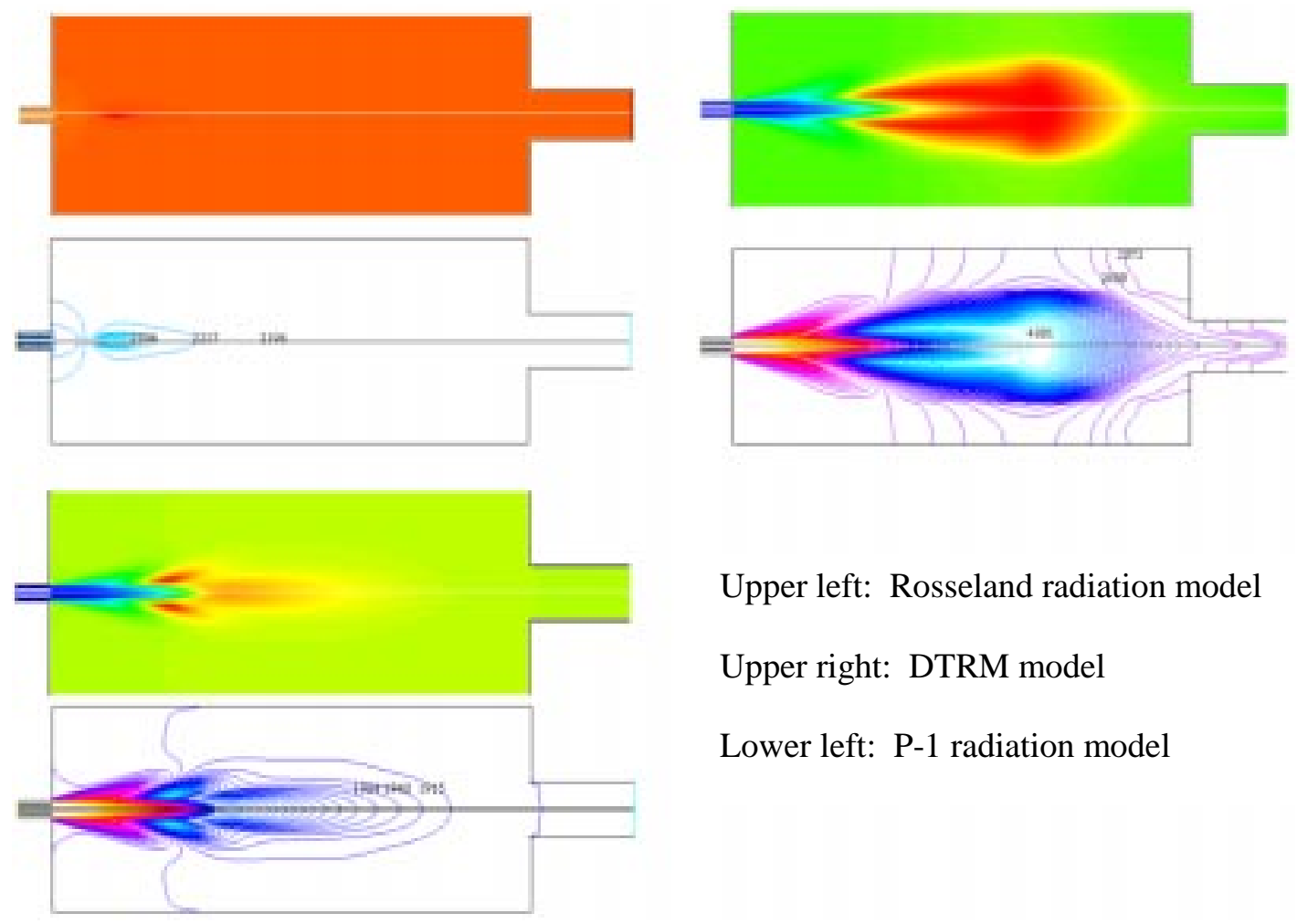

Upper left: Rosseland radiation model

Upper right: DTRM model

Lower left: P-1 radiation model

Figure 5.2 Temperature profiles predicted with three different radiation models

Table 5.2 Assessment Results of Radiation Models

\begin{tabular}{|l|l|l|l|l|c|}
\hline \multirow{2}{*}{$\begin{array}{l}\text { Radiation } \\
\text { Model }\end{array}$} & \multicolumn{2}{|c|}{ Temperature } & \multicolumn{2}{l|}{ Emissions (Wt.\%) } & \multirow{2}{*}{ Flame shape description } \\
\cline { 2 - 5 } & Flame & Exhaust & $\mathrm{NO}_{\mathrm{x}}$ & Soot & \\
\hline P-1 & $2789 \mathrm{~K}$ & $1878 \mathrm{~K}$ & 0.361 & 2.67 & $\mathrm{~L} \approx 1.22 \mathrm{~m}, \mathrm{~W} \approx 0.28 \mathrm{~m}$ \\
\hline DTRM & $4000 \mathrm{~K}$ & $2315 \mathrm{~K}$ & 0.118 & 27.59 & $\mathrm{~L} \approx 1.50 \mathrm{~m}, \mathrm{~W} \approx 0.42 \mathrm{~m}$. \\
\hline Rosseland & $2455 \mathrm{~K}$ & $2197 \mathrm{~K}$ & 0.656 & 1.06 & $\begin{array}{l}\text { Very small flame, homogeneous } \\
\text { temperature distribution in tank }\end{array}$ \\
\hline
\end{tabular}

\subsubsection{Parameters for P-1 Model}

For natural gas-oxygen combustion, there are two coefficients are of most concern in the specification of the P-1 model. One is the absorption coefficient of the participating media and the other is the scattering coefficient of the media. Due to the different designs of the burner structure, the soot formation varies from burner to burner. As a result, there is a big difference in these two coefficients between the high luminosity flame burner and low luminosity flame burner. 
The absorption coefficient of the media depends on the concentration of the water vapor $\left(\mathrm{H}_{2} \mathrm{O}\right)$ and carbon dioxide $\left(\mathrm{CO}_{2}\right)$, and the concentration of soot. The concentration of $\mathrm{H}_{2} \mathrm{O}$ and $\mathrm{CO}_{2}$ in the tank can be calculated but it is impossible to do so for the soot concentration because the overall soot concentration is unknown and its distribution is not homogeneous in combustion space. Rather than setting it as a constant, the absorption coefficient of the media was set as a variable using the Weighted-Sum-of-Gray-Gas Model (WSGGM).

The scattering coefficient, as its name implies, is required if the media contains particles. In the natural gas-oxygen combustion, the media contains soot particles. But soot particles is not treated as coal particles, because the size of soot is smaller than the wavelength of natural gas combustion at high temperature. Therefore, the effect of scattering is small compared with that of absorption. Media containing gas-phase and soot is thus treated as absorbing-emitting media characterized by the use of absorption coefficient of gas-phase plus soot.

Therefore, the scattering coefficient is set as zero, and the absorption coefficient is calculated for soot using the soot volume fraction. This value may be added to the absorption coefficient of gas-phase obtained from weighted-Sum-of-Gray-Gases Model. Without this addition, the radiation from soot particles is neglected, which will lower the flame temperature by about $25-50 \mathrm{~K}$.

\subsection{Chemical Reaction Model}

\subsubsection{Species}

The chemical kinetics of methane combustion are perhaps the most widely researched and most well understood. According to research conducted by Frenkleah, et al [45] in 1992, 149 elementary steps, with 144 reverse reactions, and 33 species are involved in the methane combustion. Considering that the combustion of methane in a batch tank occurs at higher temperatures (above $2000 \mathrm{~K}$ ), the complicated methane combustion mechanism can be reduced to the High-Temperature Simplified Mechanism, which still contains more than 30 chemical 
reactions. In practice, the modeling of so many chemical reactions can not be handled by CFD modeling because of the enormous computational task involved. A common practice hence is to assume a single-step global chemical reaction, which would be

$$
\mathrm{CH}_{4}+2 \mathrm{O}_{2}+\alpha \mathrm{N}_{2} \rightarrow \mathrm{CO}_{2}+2 \mathrm{H}_{2} \mathrm{O}+\alpha \mathrm{N}_{2}
$$

Therefore, $\mathrm{CH}_{4}, \mathrm{O}_{2}, \mathrm{CO}_{2}, \mathrm{H}_{2} \mathrm{O}$, and $\mathrm{N}_{2}$ are all the species when the one-step reaction model is proposed for the species transport of the oxy-fuel combustion in a batch tank. Here $\mathrm{N}_{2}$ is assumed inert because of its negligible contribution to combustion, although it is the source of $\mathrm{NO}_{\mathrm{x}}$ formation.

\subsubsection{Species Transport}

The mixing and transport of these chemical species can be modeled by solving conservation equations describing convection, diffusion, and reaction sources for each component species. The local mass fraction of each species, $m_{i}$, is predicted through the solution of a convection-diffusion equation for the $i$ 'th species.

The general form of the species conservation equation is:

$$
\frac{\partial}{\partial t}\left(\rho m_{i^{\prime}}\right)+\frac{\partial}{\partial x_{i}}\left(\rho u_{i^{\prime}} m_{i^{\prime}}\right)=-\frac{\partial}{\partial x_{i}} J_{i, i^{\prime}}+R_{i^{\prime}}+S_{i^{\prime}}
$$

Where

$$
\begin{aligned}
& \mathrm{R}_{i^{\prime}} \quad=\quad \text { the mass rate of creation or depletion by chemical reaction } \\
& \mathrm{S}_{i^{\prime}} \quad=\quad \text { the mass rate of creation or depletion by addition from the dispersed } \\
& \text { phase plus any other sources } \\
& \mathrm{J}_{i^{\prime}, i} \quad=\quad \text { the diffusion flux of species } i \text {, which arises due to the concentration } \\
& \text { gradient. For turbulent flows, the mass diffusion flux can be calculated as: }
\end{aligned}
$$

$$
J_{i, i^{\prime}}=-\left(\rho D_{i^{\prime}, m}+\frac{\mu_{\mathrm{t}}}{\mathrm{Sc}_{\mathrm{t}}}\right) \frac{\partial m_{i^{\prime}}}{\partial x_{i}}
$$


where

$$
\begin{aligned}
& \mathrm{Sc}_{\mathrm{t}}=\quad \text { the turbulent Schmidt number } \\
& \mu_{\mathrm{t}} / \rho \mathrm{D}_{\mathrm{t}}=\quad \text { a constant } 0.7 \text {, which is good for the situation in a batch tank. }
\end{aligned}
$$

An equation of this form will be solved for $\mathrm{N}-1$ species, where $\mathrm{N}$ is the total number of fluid phase chemical species. For the single-step global chemical reaction model, $\mathrm{N}=5$; therefore, four equations need to be solved.

\subsubsection{Generalized Finite Rate Formulation for Reaction Modeling}

According to the single-step global reaction model, reaction kinetics are ignored by proposing that the reaction is instantaneous and proceeds wherever natural gas and oxygen coexist, to give a mixture of combustion products plus any residual reactants. This is the socalled 'mixed-is-burnt' hypotheses. This assumption is reasonable for modeling many diffusiontype flames where combustion is controlled by the mixing rate. For natural gas-oxygen combustion in a batch tank where mixing is very intensive, the influence of turbulence on the reaction rate should be taken into account by using an appropriate model, e.g. the Magnussen and Hjertager model.

To calculate the source term $R_{i}$, for Equation 5-15, therefore, both the Arrhenius expression and the eddy-dissipation model will be used to calculate the reaction rates. The slowest will be used as the reaction rate and the contribution to the source terms in the species conservation (Equation 5-10) will be calculated from this reaction rate.

Considering premixed oxy-fuel combustion, where methane and oxygen are already homogeneously coexisted, the Arrhenius rate determines the reaction rate. Thus, only this rate needs to be computed using the available methane combustion data.

In most glass melting tanks, diffusion combustion is used and the eddy-dissipation model describes the limiting rate. Therefore, the Arrhenius rate does not have to be calculated. As a result, the source term $R_{i}$, in Equation 5-15 is calculated just from the eddy-dissipation model. 


\subsection{Pollutant Formation Models}

Generally, the primary concerns of the emissions from a batch tank are $\mathrm{NO}_{\mathrm{x}}$ and soot. Other pollutants are normally neglected except, for example, when lead is added for the formation of crystal glassware, the lead pollution has to be treated seriously.

\subsection{1 $\quad \mathrm{NO}_{\mathrm{x}}$ Formation}

As described in Section 3.1, nitrogen does exist in natural gas supply and industrial oxygen supply. In practice, air leakage into tank is also a common phenomenon. If air leakage occurs, the $\mathrm{NO}_{\mathrm{x}}$ emissions worsen. Some glass batch materials contain nitrates, which may emit nitrogen when heated. All these three nitrogen sources should be taken into account in the analysis of $\mathrm{NO}_{\mathrm{x}}$ formation.

$\mathrm{NO}_{\mathrm{x}}$ emission consists of mostly nitric oxide (NO). Less significant are nitrogen oxide $\left(\mathrm{NO}_{2}\right)$ and nitrous oxide $\left(\mathrm{N}_{2} \mathrm{O}\right)$. Therefore, $\mathrm{NO}_{\mathrm{x}}$ modeling is actually $\mathrm{NO}$ formation modeling.

Generally, thermal, prompt, and fuel $\mathrm{NO}_{\mathrm{x}}$ formation as well as $\mathrm{NO}_{\mathrm{x}}$ consumption due to reburning in combustion need to be taken into account for determining $\mathrm{NO}_{\mathrm{x}}$ emissions. The fuel analysis shows that no fuel bound $\mathrm{NO}_{\mathrm{x}}$ source exists in the combustion process; thus, fuel bound $\mathrm{NO}_{\mathrm{x}}$ formation is excluded. Prompt $\mathrm{NO}_{\mathrm{x}}$ tends to form in low temperature, fuel rich conditions and where residence times are short. Batch tanks are stationary combustors operated at high temperature, normally at a fuel lean condition. Hence, the contribution of prompt $\mathrm{NO}_{\mathrm{x}}$ to the total $\mathrm{NO}_{\mathrm{x}}$ emissions is insignificant and thus excluded. As a result, only the thermal NO formation is considered in the $\mathrm{NO}_{\mathrm{x}}$ model for a batch tank.

To predict the thermal $\mathrm{NO}_{\mathrm{x}}$ emission, a transport equation for nitric oxide (NO) concentration should be solved. Because of the rapid reaction rate of thermal $\mathrm{NO}_{\mathrm{x}}$ formation ${ }_{2}$ the $\mathrm{NO}_{\mathrm{x}}$ transport equation is solved based on a given flow field and combustion solution. In other words, $\mathrm{NO}_{\mathrm{x}}$ is post-processed based on the combustion solution. It is thus evident that an accurate combustion solution becomes a prerequisite of $\mathrm{NO}_{\mathrm{x}}$ prediction. Therefore, to be 
realistic, $\mathrm{NO}_{\mathrm{x}}$ variation trends can be accurately predicted using the $\mathrm{NO}_{\mathrm{x}}$ prediction model but the $\mathrm{NO}_{\mathrm{x}}$ quantity itself cannot be pinpointed.

For thermal $\mathrm{NO}_{\mathrm{x}}$ mechanism, only the $\mathrm{NO}$ species transport equation is needed, which has taken into account convection, diffusion, and production of $\mathrm{NO}$ and related species. Equation 5.17 is used for NO formation rate computation.

$$
\rho \frac{\partial Y_{N O}}{\partial t}+\rho u_{i} \frac{\partial Y_{N O}}{\partial x_{i}}=\frac{\partial}{\partial x_{i}}\left(\rho D \frac{\partial Y_{N O}}{\partial x_{i}}\right)+S_{N O}
$$

where

$$
\begin{aligned}
& \mathrm{Y}_{\mathrm{NO}}=\text { the mass fraction of NO } \\
& \mathrm{S}_{\mathrm{NO}}=\quad \text { the source term of species NO }
\end{aligned}
$$

Assume that the nitrogen contents in both the natural gas supply and the oxygen supply are constants, and a positive pressure is always kept during the melting process of a batch tank, Theoretically, the $\mathrm{NO}_{\mathrm{x}}$ emission is just a function of flame temperature $(\mathrm{T})$ and residence time (t), as shown in Equation 5-18.

$$
[\mathrm{NO}]=\mathrm{f}(\mathrm{T}, \mathrm{t})
$$

Therefore, as a principle for reducing the $\mathrm{NO}_{\mathrm{x}}$ emission, both the flame temperature and the residence time should be decreased; however, a compromise has to be made with heat transfer when applying this principle.

\subsubsection{Soot Formation}

\section{(1) Soot formation model}

The prediction of soot formation in combustion is based on two empirical models. In addition, the predicted soot concentration can be included in the soot-radiation interaction when the $\mathrm{P}-1$ radiation model is used. Soot concentration in a combustion system can be predicted using one of the two available models: the single-step Khan and Greeves model [46 ], in which 
the rate of soot formation is predicted; and the two-step Tesner model [47], in which the formation of nuclei particles is predicted and soot formation then predicted on the nuclei. In both models, combustion of the soot (and particle nuclei) is assumed to be governed by the Magnussen combustion rate, which is valid for turbulent flow.

Because the detailed chemistry and physics of soot formation are quite complex and are only approximated in the models, so the results from these models are qualitative indicators rather than accurate quantities.

The one-step model solves a single transport equation for the soot formation:

$$
\frac{\partial}{\partial t}\left(\rho m_{s}\right)+\frac{\partial}{\partial x_{i}}\left(\rho u_{i} m_{s}\right)=\frac{\partial}{\partial x_{i}}\left(\frac{\mu_{t}}{\sigma_{s}} \frac{\partial m_{s}}{\partial x_{i}}\right)+R_{s}
$$

where

$$
\begin{array}{lll}
\rho & = & \text { density, } \mathrm{kg} / \mathrm{m}^{3} \\
\mu_{\mathrm{t}} & = & \text { turbulent viscosity, } \mathrm{kg} / \mathrm{m}-\mathrm{s} \\
m_{S} & = & \text { the mass fraction of soot } \\
\sigma_{S} & = & \text { turbulent Prandtl Number for soot transport } \\
R_{S} & = & \text { net rate of soot generation, } \mathrm{kg} / \mathrm{m}^{3}-\mathrm{s}
\end{array}
$$

$R_{S}$ is the net rate of soot generation, and is the difference between soot formation $R_{S, f}$, and the soot combustion $R_{S, c}$ :

$$
R_{S}=R_{S, f}-R_{S, c}
$$

The rate of formation is given by an empirical expression:

$$
R_{S, f}=C_{S} p_{F} \Phi^{r} \exp (-E / R T)
$$


where

$$
\begin{array}{lll}
\mathrm{C}_{\mathrm{S}} & = & \text { soot formation constant, } \mathrm{kg} / \mathrm{N}-\mathrm{m}-\mathrm{s} \\
\mathrm{p}_{\mathrm{F}} & = & \text { fuel partial pressure, } \mathrm{Pa} \\
\Phi & = & \text { equivalence ratio } \\
\mathrm{r} & = & \text { equivalence ratio exponent } \\
\mathrm{E} / \mathrm{R} & = & \text { activation temperature }(\mathrm{K}) \\
\mathrm{T} & = & \text { temperature }(\mathrm{K})
\end{array}
$$

The rate of soot combustion is the minimum of two rate expressions:

$$
R_{S, c}=\min \left[R_{1}, R_{2}\right]
$$

where

$$
\begin{aligned}
& R_{1}=A m_{S} \rho \varepsilon / k \\
& R_{2}=A \frac{m_{O}}{s_{S}} \frac{m_{S} s_{S}}{m_{S} s_{S}+m_{F} s_{F}} \rho \frac{\varepsilon}{k}
\end{aligned}
$$

where

$$
\begin{array}{lll}
A & = & \text { constant in Magnussen model } \\
m_{O}, m_{F}= & \text { mass fraction of oxygen and fuel } \\
s_{S}, s_{F}= & \text { mass stoichiometries for soot and fuel combustion }
\end{array}
$$

(2) Application of the Model

The soot formation in natural gas combustion is very limited, the conventional oxy-fuel flame is often lack of luminosity. The one-step Khan and Greeves soot formation model may artificially over predict the soot formation amount hence the prediction may not represent real 
physics. This soot formation can not be used for all case studies, it is only used for cases in which significant increasing in soot formation is expected.

\subsection{Summary on Models}

Although the modeling capabilities in a CFD code like FLUENT are comprehensive, the process of selecting a set of appropriate physical models is greatly facilitated when one has a good understanding of the salient features of the flow being studied. In this research, both the physical and chemical models have been tested for their applications in batch tank simulations.

As a result, all the physical and chemical models selected and tested to be appropriate for the study of combustion in a batch tank are listed in Table 5.3.

Table 5.3 Physical Models and Chemical Reaction Models for a Batch Tank

\begin{tabular}{|c|c|}
\hline Item & Selection \\
\hline Space & Axisymmetric 2-D, and 3-D \\
\hline Linearization & Implicit \\
\hline Velocity-Pressure coupling & SIMPLE \\
\hline Time & Steady state \\
\hline Viscous model & RNG standard k- $\varepsilon$ \\
\hline Near wall treatment & Standard wall function \\
\hline Radiation model & $\mathrm{P}-1$ \\
\hline Species model & $\begin{array}{l}\text { Multiple species: } \mathrm{CH}_{4}, \mathrm{O}_{2}, \mathrm{~N}_{2} \\
\text { and } \mathrm{CO}_{2}, \mathrm{H}_{2} \mathrm{O}\end{array}$ \\
\hline Reaction model & Finite rate/eddy dissipation rate \\
\hline $\mathrm{NO}_{\mathrm{x}}$ formation & Thermal $\mathrm{NO}_{\mathrm{x}}$ only \\
\hline Soot Model & $\begin{array}{l}\text { One-step model, with soot- } \\
\text { radiation interaction }\end{array}$ \\
\hline Physical properties & $\begin{array}{c}\text { Composition and temperature } \\
\text { dependent }\end{array}$ \\
\hline Operating pressure & 101330 Pascal \\
\hline Inlet boundary & Velocity \\
\hline Outlet boundary & Pressure \\
\hline Wall boundary & $\begin{array}{l}\text { Static wall, fixed heat flux or } \\
\text { mixed convection and radiation. }\end{array}$ \\
\hline
\end{tabular}




\section{Chapter 6 Boundary Conditions}

Boundary conditions specify the fluid flow and thermal behavior at the boundaries of the physical model for an oxy-fuel batch tank. They are, therefore, critical components in determining appropriate solutions to the governing equations. These boundary conditions must thus be specified appropriately.

Generally, four categories of boundary conditions need to be specified: flow inlet, pressure outlet, wall, and fluid cell zones. They are each described as follows:

(1). Flow inlet. Generally, one to four burners are used in an oxy-fuel batch tank depending on the heat intensity required. For premixed combustion, only one inlet is needed for each burner. For diffusion flame combustion, natural gas and oxygen are introduced into the combustion chamber through separated ducts; therefore, usually two inlets are needed for a coaxial burner and multiple inlets may be needed for a flat flame burner.

(2). Pressure outlet. During the melting period, the feeding port and the working port are closed. Thus, there is just one outlet, which is the exhaust exit. Hence, a pressure outlet boundary condition for the exhaust stack needs to be specified. However, during glassmaking period when workers are gathering glass from the tank through an open working port, then there are two outlets instead of a single outlet.

(3). Wall. One of batch tank's primary features that make it different from a continuous furnace is that its glass melt is static during melting, although actually convection of molten glass does occur. The crown and side walls are both static, and the glass surface can be modeled as a static wall too. Therefore, all walls are static, and the thermal boundary conditions need to be set.

(4). Internal cell zones. It is clear that the internal cell zones of a batch tank are fluid zones. The flow above glass level is a gaseous fluid.

The types of boundary conditions will be specified individually in the following sections. 


\subsection{Inlet Boundary Conditions}

A wide range of boundary conditions can be set to permit flow to enter and to exit the three-dimensional solution domain. To select the most appropriate boundary conditions for the batch tank simulation, the type of conditions and the information needed for each selected type and the turbulence parameters are needed.

\subsubsection{Type of Inlet Boundary Conditions}

Typically there are three options for setting the inlet boundary condition for a batch tank; they are the velocity inlet boundary condition, the pressure inlet boundary condition and the mass flow inlet boundary condition. Either the velocity inlet boundary condition or the pressure inlet boundary condition can be used in this research. The velocity inlet boundary condition is preferred because it defines the velocity and scalar properties of the flow at inlet boundaries. Pressure inlet boundary reflects the industrial operation directly, but it causes variation of the setting of velocity and oxy-fuel ratio.

\subsubsection{Velocity Inlet Boundary Condition Information}

To define the velocity inlet boundary condition for a batch tank, the following information needs to be specified.

(1). Velocity magnitude and direction. One of the primary tasks in this research is to determine the burner direction. In each simulation, the installation position of a burner, that is, the vertical and horizontal angular directions of the burner, are all explicitly defined. Therefore, velocity components do not have to be set; instead, a velocity magnitude is set and the directions of fuel and oxygen flows are perpendicular to the inlet cross section plane.

For oxy-fuel combustion, natural gas consumption can be estimated as $60 \%$ of that in airfuel combustion and the oxygen-fuel ratio is around 2.10. Once the burner is selected, the velocities of the natural gas and the oxygen can be determined as input parameters. For example, 
600 standard cubic feet of natural gas per hour is needed for a 2500 pound-batch tank. Based on this volume flow rate, a velocity magnitude can be calculated for each specific burner.

(2). Temperature. The temperatures of the natural gas, oxygen or premixed oxy-fuel mixture are usually below or at room temperature, so it is generally suitable to set the inlet temperature as the default value of $300 \mathrm{~K}$. If it is preheated, the corresponding temperature can be defined; however, with oxy-fuel combustion, preheating is rarely used because the energy saving is insignificant.

(3). Turbulence parameters. The oxy-fuel flows that enter the tank have been shown to be turbulent. For turbulent flow, boundary values of the turbulent kinetic energy $(\mathrm{k})$ and the turbulence dissipation rate $(\varepsilon)$ are required. The methods for specifying turbulent parameters will be described separately in Section 6.1.3.

(4). Chemical species mass fraction. Concentration of each species in all flow inlets must be defined for handling species transport and chemical reactions. In Section 4.4, the finiterate reaction model was shown to be appropriate, that is, the Arrhenius rate is used for premixed combustion while turbulent mixing rate is used for diffusion flame combustion. No matter whether the mixing rate is or is not the limiting factor of the reaction rate, five species are needed to define the composition and concentration of species in inlet flows when the one step reaction model is used. Natural gas is assumed as a mixture of methane $\left(\mathrm{CH}_{4}\right)$ and nitrogen $\left(\mathrm{N}_{2}\right)$, in which nitrogen takes a percentage of $0.5 \% \sim 1.5 \%$. The oxygen is not $100 \%$ pure, usually the industrial oxygen has a purity range of $92.0 \%$ 99.9\%. The nitrogen does exist in the oxygen supply, although its amount is greatly reduced compared to air-fuel combustion. The combustion products are primarily carbon dioxide and water vapor, which go out through the exhaust outlet. Thus, five species-methane $\left(\mathrm{CH}_{4}\right)$, oxygen $\left(\mathrm{O}_{2}\right)$, nitrogen $\left(\mathrm{N}_{2}\right)$, carbon dioxide $\left(\mathrm{CO}_{2}\right)$, water vapor $\left(\mathrm{H}_{2} \mathrm{O}\right)$ should be defined.

The two step reaction model was also tested for this simulation. With this model, one more species—carbon monoxide $(\mathrm{CO})$ is added. However, the simulation result of this two-step 
model was almost identical to that for the one-step model. Thus, there is no big advantage to use the two-step, six species model instead of the one-step, five species model.

\subsubsection{Turbulence Parameters}

Considering the chemical reactions and the high temperature gradient in a batch tank, kinetic energy $k$ and turbulence dissipation rate $\varepsilon$ can not be set explicitly. Usually, they can be defined by either setting the turbulence intensity $I$ and turbulence length scale $l$, or setting the turbulence intensity $I$ and hydraulic diameter $L_{D}$, or setting the turbulence intensity $I$ and viscosity ratio.

For the chemically reacting flow in a batch tank, the turbulence intensity and the hydraulic diameter are used to determine boundary values of $k$ and $\varepsilon$. This is because once hydraulic diameter is set, the turbulence length scale is implicitly defined. Often the turbulent quantities at the inlet are uncertain and it is a good practice to estimate these quantities. In general, the inlet turbulence intensity and characteristic length depend on the flow details upstream. For batch tanks the upstream flow involves the mixing of natural gas and oxygen, thus the turbulence intensity at inlet might be as large as $10-12 \%$. The characteristic length is used to compute the turbulence length scale for the larger eddies. Since no other scales upstream of the inlet exist, it should be set to the hydraulic diameter of the inlet.

\subsection{Wall Boundary Conditions}

Wall boundary conditions are used to bound fluid and solid regions. The shear stress and heat transfer between the fluid and the wall are computed based on the details in the local flow field. Therefore, the wall boundary conditions are critical components of the simulation of a batch tank. To specify wall boundary conditions appropriately, three assumptions must be made:

(1) No-slip wall. Because the flow is viscous, the no-slip boundary is enforced at walls.

(2) Static wall. All walls of a batch tank are static during melting period. 
(3) Inert wall. No surface reaction occurs in the wall surface, although refractory corrosion does occur slowly over the wall surface.

With these assumptions, only thermal boundary conditions and wall roughness are needed to define the wall boundary. They are described in the following two sections.

\subsubsection{Thermal Boundary Conditions}

The thermal boundary condition at the wall boundaries is needed for heat transfer calculations by solving the energy equation. Theoretically, five types of thermal conditions are available. They are (1) Fixed heat flux, (2) Fixed temperature, (3) Convective heat transfer, (4) Fixed external radiation, and (5) Combined external radiation and convection heat transfer.

To analyze the heat transfer at the wall boundary, a schematic for internal radiation, convection, and conduction, and external convection and radiation is shown in Figure 6.1.

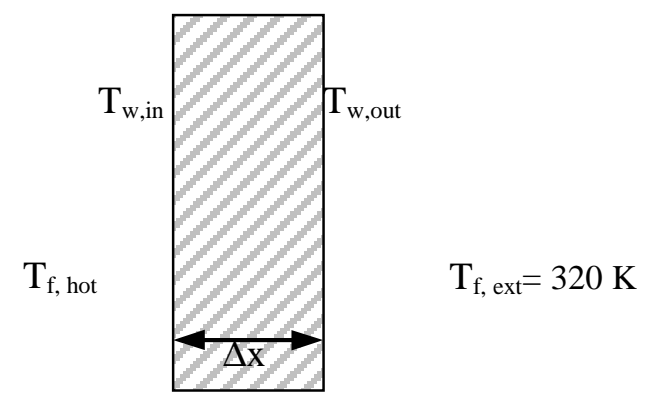

Figure 6.1 Thermal conditions at wall of batch tank

where

$$
\begin{array}{lll}
\mathrm{T}_{\mathrm{f}, \text { hot }} & = & \text { local combustion gas temperature } \\
\mathrm{T}_{\mathrm{w}, \text { in }} & = & \text { inner wall surface temperature } \\
\mathrm{T}_{\mathrm{w}, \text { out }} & = & \text { outer wall surface temperature } \\
\mathrm{T}_{\mathrm{f}, \text { ext }} & = & \text { external air temperature, generally at } 320 \mathrm{~K} \\
\Delta \mathrm{x} & = & \text { wall thickness }
\end{array}
$$

The heat flux $q$ " is the sum of the radiation $q "{ }_{\text {rad }}$ from the hot combustion media to the inner wall surface and the convection $q$ " conv between the hot combustion gas and the wall, as expressed in Equation 6-1. 


$$
q^{\prime \prime}=q^{\prime \prime}{ }_{\text {conv }}+q^{\prime \prime}{ }^{r a d}
$$

where

$$
\begin{aligned}
& q^{\prime \prime}=\quad \text { heat flux (heat transfer to the wall) } \\
& q^{\prime \prime}{ }_{\text {conv }}=\quad h_{f, \text { hot }}\left(T_{w, \text { in }}-T_{f, \text { hot }}\right) \\
& \mathrm{q}^{\prime \prime} \text { rad }=\quad \text { radiative heat flux }=\varepsilon \sigma\left(T^{4}{ }_{w, \text { out }}-T_{f, \text { hot }}^{4}\right)
\end{aligned}
$$

This amount heat flux is transferred through the wall by heat conduction

$$
q^{\prime \prime}=k\left(T_{w, \text { in }}-T_{w, \text { out }}\right) / \Delta x
$$

At outer surface, the heat transfer from the wall surface to surrounding is

$$
q^{\prime \prime}=h_{f, \text { air }}\left(T_{w, \text { air }}-T_{w, \text { out }}\right)+\varepsilon_{e x t} \sigma\left(T_{\text {air }}^{4}-T^{4}{ }_{w, \text { out }}\right)
$$

There are three unknowns in Equations 6-1, 6-2 and 6-3. These unknowns are $T_{w, \text { in }}$, $T_{w, \text { out }}$, and $T_{f, h o t}$. Thus, combined external convection and radiation boundary conditions determine the heat flux across the wall boundary.

However, some knowledge of thermal conditions at the walls of batch tanks has already been gained in batch tank operation. First, the temperature on the inner surface of the wall is in a certain range of $1400^{\circ} \mathrm{C}$ to $1460^{\circ} \mathrm{C}$. The temperature variation among the tank walls is less than $60^{\circ} \mathrm{C}$. Thus, for a wall of given thickness and material properties, the heat flux through the wall can be well estimated.

The batch tank must maintain a certain temperature inside so as to keep the progress of melting. This temperature is required to be above the melting temperature of glass. For example, when melting soda-lime glass, the temperature is required to be around $2660^{\circ} \mathrm{F}\left(1460^{\circ} \mathrm{C}\right)$. The 
refractory with a proper thickness is used as the wall material which ensures the heat conduction through the wall is less than $30 \%$ of the total energy released from combustion chemical reaction.

The outer surface of the refractory radiates heat to the surroundings and a natural convection also occurs at the same time. These two parts of the heat transfer are steady state. Thus, the heat transfer to the surroundings is at a fixed rate. As a result, the thermal boundary does not have to be set as the complicated combined external convection and radiation boundary. Instead, a fix heat flux may work with acceptable accuracy. Table 6.1 lists some commonly used refractory property parameters, which will be used to calculate the heat flux through the walls.

Table 6.1 Wall parameters for heat flux calculation [48]

\begin{tabular}{|l|l|l|l|}
\hline Wall Type & Material Type & $\begin{array}{l}\text { Thickness } \\
\Delta \mathrm{x}(\mathrm{ft})\end{array}$ & $\begin{array}{l}\text { Heat Conductivity } \\
k\left(\mathrm{Btu} / \mathrm{hr} \cdot \mathrm{ft} \cdot{ }^{\circ} \mathrm{F}\right)\end{array}$ \\
\hline Crown & Silica & 0.75 & 0.95 \\
\hline Breast wall & Mullite & 0.75 & 0.95 \\
\hline Side wall & AZS & 1.0 & 0.67 \\
\hline Bottom & Flux Block & 1.25 & 0.82 \\
\hline
\end{tabular}

In a typical batch tank, the temperature difference is about $1350^{\circ} \mathrm{C}$, or $2460^{\circ} \mathrm{F}$. Thus, the heat flux through the walls is computed and listed in Table 6.2.

Table 6.2 Heat flux through walls of a typical batch tank

\begin{tabular}{|l|l|l|l|l|l|}
\hline Wall Type & Material Type & $\begin{array}{l}\text { Thickness } \\
\text { L (feet) }\end{array}$ & $\begin{array}{l}K \\
\left(\text { Btu/hr} \cdot f t \cdot{ }^{\circ} \mathrm{F}\right)\end{array}$ & $\begin{array}{l}\Delta \mathrm{T} \\
\left({ }^{\circ} \mathrm{F}\right)\end{array}$ & $\begin{array}{l}\text { Heat Flux } \\
\left(\mathrm{W} / \mathrm{m}^{2}\right)\end{array}$ \\
\hline Crown & Silica & 0.75 & 0.95 & 2460 & 8980 \\
\hline Breast wall & Mullite & 0.75 & 0.95 & 2460 & 8980 \\
\hline Side wall & AZS & 1.0 & 0.67 & 2460 & 4510 \\
\hline Bottom & Flux Block & 1.25 & 0.82 & 2460 & 4510 \\
\hline
\end{tabular}

In addition, during the melting process, the batch material absorbs heat from the very beginning until it is completely melted. The heat absorbed by the batch material can be calculated using 


$$
q=m C_{p} \Delta T
$$

where

$$
\begin{array}{lll}
m & = & \text { total mass of the batch material in the tank, } \mathrm{kg} \\
C_{p} & = & \text { the thermal capacity of the batch material, } \mathrm{kJ} / \mathrm{kg} \mathrm{K} \\
\Delta T \quad= & \text { the temperature difference between melting stages, } \mathrm{K}
\end{array}
$$

If the whole melting process is divided into several melting stages, a serial $C_{p}$ is needed for each stage. However, $C_{p}$ values at high temperatures are not available. Therefore, the absorbed amount of heat by the batch material is averaged using the $C_{p}$ at the first stage of melting.

\subsubsection{Shear Stress at Wall Boundaries}

When the flow involves walls, turbulent flows in the regions close to the walls are affected by the presence of the walls. First, the mean velocity field is affected through the no-slip condition that has to be satisfied at the wall. Turbulence is also changed by the presence of the wall, but in non-trivial ways. Very close to the wall, turbulence is damped due to the presence of walls.

Wall treatment significantly impacts the fidelity of numerical solutions. Thus, accurate representation of the flow in the near-wall region is a key factor for the successful predictions of wall-bounded turbulent flows. A standard wall function will be used to satisfy this requirement, and it was elaborated on in the turbulence models, analysis presented in Section 5.2.

\subsection{Outlet Boundary Conditions}

Pressure outlet boundary conditions require the specification of a static (gage) pressure at the outlet boundary. The value of static pressure specified is used only while the flow is 
subsonic. For the flow in a batch tank, the overall flow and any local flow under diffusion combustion circumstance are certainly subsonic. Thus, a pressure outlet boundary condition is used to specify the boundary condition at the exhaust exit.

To specify the outlet boundary condition, the following inputs are needed:

Static pressure: as described in Section 6.1.1, the static pressure is positive, but very close to zero. This small static pressure will be maintained by a sensing and automatic controlling system. Engineering practice has already shown that a positive gage pressure of 0.02 in. $\mathrm{H}_{2} \mathrm{O}(5$ pascal) works very well to prevent air leakage into the tank. In this model, the static pressure is set as +5 pascal.

A set of "backflow" conditions are also specified to be used if the flow reverses direction at the pressure outlet boundary during the solution process. If realistic values for backflow quantities are set, then the convergence difficulties will be minimized.

Temperature, chemical species mass fraction and turbulence parameters are needed for specifying the backflow conditions. These values will be used only if flow is pulled in through the outlet.

Because heat transfer involved in this model, the backflow total temperature should be set, the local temperature near the outlet is somewhat higher than the ambient air temperature, it is reasonably to specify the temperature as the average local temperature, for example $323 \mathrm{~K}$.

The turbulence parameters for outlet boundary conditions will need to be set using the methods described in Section 6.1.3.

The chemical species mass fraction can be set the same as that of the ambient air, although it is a little different from the ambient air. Actually much more carbon dioxide and water vapor exist in the adjacent space around the exhaust outlet.

Even when no backflow is expected in the converged solution, realistic values should be always be set to minimize the convergence difficulties in the event that backflow does occur during the calculation. 


\section{Chapter 7 Simulation Process}

In Chapter 4, the geometry modeling and grid generation of both the cylindrical combustor and the oxy-fuel batch tank have been illustrated. In the simulation for batch tank design using CFD tools such as FLUENT by Fluent Inc., the first step is to read the grid file into FLUENT solver. The grid generation described in Chapter 4 is generated using software called GAMBIT provided by Fluent Inc. too. Both the geometry and the grid for all simulations in this research were created using GAMBIT in unit of meters so that the grid was ready for solving using FLUENT without any scaling.

In Chapter 5, both physical and chemical models have been specified for the oxy-fuel combustion. This chapter deals with the simulation process based on the given computation domain and models. Generally, the four main tasks in the simulation process include how to (1) enable the physical models, select material properties, and define boundary conditions for the turbulent flow with chemical species mixing and reaction; (2) initiate and solve the combustion simulation; (3) examine the reacting flow results using graphics; and (4) predict thermal $\mathrm{NO}_{\mathrm{x}}$ emission at exhaust exit.

\subsection{Specification of Models}

\subsubsection{Solving Approach and Domain Dimensionality}

FLUENT provides two categories of solver formulations--the segregated and the coupled. The segregated approach solves the continuity, momentum, energy and species equations sequentially (i.e., segregated from one another), while the coupled approach solves these equations simultaneously (i.e., coupled together). The segregated approach traditionally has been 
for incompressible and mildly compressible flows; it is appropriate for the chemical reacting flow in an oxy-fuel batch tank.

Both two-dimensional and three-dimensional domains are used depending on tasks. A two-dimensional axisymmetric domain is used for the simulation in the cylindrical combustor, in which the domain is axisymmetric about the $\mathrm{x}$-axis (the centerline of the combustor). The twodimensional axisymmetric form of the governing equations is solved instead of the twodimensional Cartesian form. In addition, when swirling flow is exerted to the oxy-fuel burner, Axisymmetric Swirl should be specified so that the swirl component (circumferential component) of velocity is included in the axisymmetric model. The three-dimensional domain is used for tasks other than basic flame feature identification in the model combustor, e.g. burner placement and tank geometry design.

\subsubsection{Energy Equation}

Due to the chemical reacting flow involved in the combustion process, the energy equation (Equation 5-3) described in Chapter 5 needs to be solved; thus, the energy model must be enabled. Once the energy model is enabled, the parameters related to energy or heat transfer can be specified for the calculation of energy.

The thermal properties of all the species including $\mathrm{CH}_{4}, \mathrm{O}_{2}, \mathrm{~N}_{2}, \mathrm{CO}_{2}$, and $\mathrm{H}_{2} \mathrm{O}$ are available from any thermal engineering reference, and they are also stored in FLUENT's library. No modification is necessary for oxy-fuel combustion, and thus the default data are used.

\subsubsection{Viscous Model}

The RNG k- $\varepsilon$ model is selected based on analysis described in Section 5.2. The corresponding model constants are $\mathrm{C}_{\mathrm{mu}}, \mathrm{C}_{1-\varepsilon}, \mathrm{C}_{2-\varepsilon}$ and $\alpha_{0}$. The default values of these constants are used in this model directly. e.g., $\mathrm{C}_{\mathrm{mu}}=0.085, \mathrm{C}_{1-\varepsilon}=1.42, \mathrm{C}_{2-\varepsilon},=1.68$, and $\alpha_{0}=1.0$.

The standard wall function is used for the near-wall treatment for modeling turbulence. 


\subsubsection{Species Model}

Multiple species are involved in the oxy-fuel combustion; thus, the multiple species model enables the calculation of multi-species transport and combustion. The reaction in an oxyfuel batch tank is assumed to be volumetric only; the volumetric reaction model enables the calculation of chemical reacting flow using the finite-rate formulation. The effect of enthalpy transport due to species diffusion in the energy equation is included. Totally, five species are involved in the combustion; the five species are $\mathrm{CH}_{4}, \mathrm{O}_{2}, \mathrm{CO}_{2}, \mathrm{H}_{2} \mathrm{O}$, and $\mathrm{N}_{2}$.

\subsubsection{Radiation}

Radiation heat transfer is dominant in the heat transfer process and it must be included. The optical thickness of the media is less than 3 but bigger than 1; therefore the P-1 model is selected first in this research.

\subsubsection{Pollutants}

$\mathrm{NO}_{\mathrm{x}}$ and soot formations are of most concern in the consideration of pollutant prediction for the performance of a batch tank. In the simulation of $\mathrm{NO}_{\mathrm{x}}$ emission, only the thermal $\mathrm{NO}_{\mathrm{x}}$ is meaningful, other $\mathrm{NO}_{\mathrm{x}}$ formation mechanisms and $\mathrm{NO}_{\mathrm{x}}$ reburning are neglected, as justified in Section 5.5.1. The one-step soot formation model is enabled and the involvement of soot in heat transfer is accounted using the Generalized Soot-Radiation Interaction Model.

\subsection{Materials for Combustion}

\subsubsection{Material Type and Mixture Species}

Basically, the concept of oxy-fuel combustion can be modified from the concept of airfuel combustion; the difference between them is that in oxy-fuel combustion, the $\mathrm{O}_{2}$ mass fraction increased and the $\mathrm{N}_{2}$ mass fraction decreased. Therefore, with adjusted composition the air-fuel mixture model is still appropriate for the oxy-fuel combustion. The material type of the oxy-fuel combustion is the same as long as the nitrogen exists. The mixture species are $\mathrm{CH}_{4}, \mathrm{O}_{2}, \mathrm{CO}_{2}$, $\mathrm{H}_{2} \mathrm{O}$, and $\mathrm{N}_{2}$. 


\subsubsection{Reaction Model}

In premixed combustion, the finite rate reaction model gives the reaction rate. However, in diffusion combustion, the finite-rate/eddy-dissipation model should be used, because the mixing becomes a limiting factor of chemical reaction. Thus, using this model, the Arrhenius rate and the mixing rate are computed simultaneously in each iteration and the smaller of the two used for the next iteration.

\subsubsection{Physical Properties}

The methane-air combustion is the most well-researched combustion known so far; thus, all needed parameters and coefficients of physical properties are available in the gas property and combustion engineering database. FLUENT has loaded such a database and provides users access to use such a database. The tasks in specific applications are to properly use the database. The primary physical properties of species and species mixture, such as density, specific heat, thermal conductivity, viscosity, mass diffusivity, and absorption coefficient are described below.

Because of the temperature gradient, the density $\rho$ of each species is not a constant. The incompressible-ideal-gas law is used to describe the density.

The specific heat $\mathrm{C}_{\mathrm{p}}$ is temperature- and/or composition-dependent. Thus, it is set as a piecewise polynomial function of temperature, and then the mixing law is used to handle the $C_{p}$ of the mixture.

The thermal conductivity $\mathrm{k}$ for each species increases with temperature. For example, the thermal conductivity of $\mathrm{CO}_{2}$ at $300 \mathrm{~K}$ and $1 \mathrm{~atm}$ is $0.016572 \mathrm{~W} / \mathrm{m}{ }^{\circ} \mathrm{C}$, while at $600 \mathrm{~K}$ and $1 \mathrm{~atm}$ it is $0.04311 \mathrm{~W} / \mathrm{m}{ }^{\circ} \mathrm{C}$. Therefore, the thermal conductivity is a function of temperature for each species. The ideal gas law is used to take the temperature's effect into account.

Similar to the thermal conductivity, the viscosity $v$ is also a function of temperature. The ideal gas mixing law is used to set the viscosity of the flow at various temperatures. 
The diffusion coefficients for the species in the mixture are specified using kinetic theory. The kinetic theory parameters for the individual species that comprise the mixture are specified.

The absorption coefficient has to be specified for radiation heat transfer. Due to the high concentration of $\mathrm{CO}_{2}$ and water vapor in the combustion chamber, it is necessary to specify a composition-dependent absorption coefficient, with the local value of a function of the local mass fractions of water vapor and carbon dioxide. The variable-absorption-coefficient model used by FLUENT is the weighted-sum-of-gray-gases model (WSGGM). Basically the overall heat transfer into the computation domain boundaries (glass surface and tank inner surfaces) is of concern; therefore, the wsggm-domain-based model is activated.

The particle emissions from oxy-fuel combustion are primary due to soot formation. The soot formation temperature is believed to be in the range of $1300 \mathrm{~K}$ to $1600 \mathrm{~K}$. However, the oxy-fuel combustion flame temperature or even the overall combustion chamber temperature is generally above $1800 \mathrm{~K}$. This higher temperature limits the soot formation. In addition, fuel lean combustion is generally required for a batch tank. Therefore, the particle emissions from an oxyfuel batch tank are pretty low. Considering the extremely low particle concentration in the combustion chamber, the scattering coefficient may be specified to be a constant very close to zero or simply as zero for the radiation heat transfer.

\subsection{Inputs for Operating Condition}

The operating pressure inside that batch tank is 5 pascal above atmospheric pressure. The reason for maintaining a positive pressure inside the batch tank is to prevent air leakage into tank.

When a low momentum oxy-fuel burner is used to fire a batch tank, the buoyancy may become important to the flame propagation. Under such a situation, the gravitational acceleration effect on the flame propagation should be considered. 


\subsection{Inputs for Boundary Conditions}

The velocity inlet is chosen to specify all inlet boundary conditions. The fuel velocity is explicitly input based on the volume flow rate. For oxygen inlet, the oxygen flow rate is set based on the fuel velocity and oxygen/fuel ratio.

The relationship between fuel velocity and its volume flow rate is

$$
v_{f}=V_{f} / A_{f}
$$

$$
\text { where } \quad \begin{array}{cll}
v_{f} & =\quad \text { the fuel velocity }(\mathrm{m} / \mathrm{s}) \\
V_{f} & =\quad \text { the volume flow rate of fuel }\left(\mathrm{m}^{3} / \mathrm{s}\right)
\end{array}
$$

The relationship between the oxygen velocity and the fuel velocity as well as oxygen/fuel

ratio is

$$
v_{o x y}=\omega v_{f} A_{f} / A_{o x y}
$$

where

$$
\begin{aligned}
& v_{\text {oxy }}=\text { the oxygen velocity, } \mathrm{m} / \mathrm{s} \\
& \omega=\text { oxygen/fuel ratio, in the range of } 1.95 \text { to } 2.20 \\
& A_{\text {oxy }}=\quad \text { the oxygen inlet cross-section area, } \mathrm{m}^{2} \\
& A_{\text {oxy }}=\pi\left(R^{2}-r^{\prime 2}\right) \text { for tube type inlet } \\
& \text { where } \quad R=\text { the oxygen tube inner radius, } \mathrm{m} \\
& r^{\prime}=\text { the outer radius of the fuel inlet, } \mathrm{m}
\end{aligned}
$$




\subsubsection{Input Specification for Inlets}

\section{Fuel inlet}

The following information is needed for fuel inlet:

(1) The fuel velocity. It depends on the volumetric flow rate of the fuel and the fuel inlet cross sectional area.

(2) The fuel temperature.

(3) The specifications of turbulence at fuel inlet. Instead of explicitly specifying both the kinetic energy $\mathrm{k}$ and eddy dissipation rate $\varepsilon$, the turbulence intensity $\mathrm{I}$ and the hydraulic diameter of the inlet are specified.

The turbulence intensity of the flow in the inlet can be calculated using Equation 7-3

$$
I=0.16(\operatorname{Re})^{-\frac{1}{8}}
$$

where $\quad R e$ is Reynolds number, which is

$$
\operatorname{Re}=\frac{\rho u L}{\mu}
$$

$$
\begin{aligned}
& \text { where } \quad \rho=\text { the density of the fluid, } \mathrm{kg} / \mathrm{m}^{3} \\
& \mu=\text { the viscosity of the fluid, } \mathrm{Ns} / \mathrm{m}^{3} \\
& \mathrm{u}=\text { the flow velocity, } \mathrm{m} / \mathrm{s} \\
& \mathrm{L}=\text { the hydraulic diameter of the flow duct, } \mathrm{m}
\end{aligned}
$$

The density $\rho$ and viscosity $\mu$ of the five species are listed in Table 7.1.

Table 7.1 The density and viscosity of oxy-fuel species[49]

\begin{tabular}{|l|c|c|c|c|c|}
\hline at $1 \mathrm{~atm}, 20^{\circ} \mathrm{C}$ & $\mathbf{C H}_{\mathbf{4}}$ & $\mathbf{O}_{\mathbf{2}}$ & $\mathbf{N}_{\mathbf{2}}$ & $\mathbf{C O}_{\mathbf{2}}$ & $\mathbf{H}_{\mathbf{2}} \mathbf{O}$ \\
\hline$\rho\left(\mathrm{kg} / \mathrm{m}^{3}\right)$ & 0.6667 & 1.3354 & 1.1621 & 1.8247 & 0.7492 \\
\hline$\mu\left(\times 10^{-5} \mathrm{~N} \mathrm{~s} / \mathrm{m}^{2}\right)$ & 1.34 & 2.00 & 1.76 & 1.48 & 1.02 \\
\hline
\end{tabular}


(4) The species mass fraction of fuel: the natural gas is not $100 \%$ pure methane since a small amount of nitrogen exists with the fuel supply. The sum of the mass fraction of methane, $m_{f, \text { fuel }}$, and the mass fraction of nitrogen $m_{f, \text { nitro }}$ is unity, as shown in Equation 7-5.

$$
\mathrm{m}_{\mathrm{f}, \text { fuel }}+\mathrm{m}_{\mathrm{f}, \text { nitro }}=1
$$

\section{Oxygen inlet}

Similar information is needed for the oxygen inlet:

(1) the oxygen velocity

(2) the oxygen temperature

(3) the turbulence specification for oxygen inlet

(4) intensity: use Equation 7-3.

(5) hydraulic diameter of the oxygen inlet $\mathrm{L}_{\text {oxy: }}$ :

$$
\mathrm{L}_{\text {oxy }}=2 \sqrt{A_{\text {oxy }} / \pi}
$$

(6) the species mass fraction of oxygen inlet: the industrial oxygen is not $100 \%$ pure $\mathrm{O}_{2}$ since the mass fraction of nitrogen often takes a few percentages.

\subsubsection{Input Specification for Wall Boundary}

As analyzed in Chapter 4, heat flux can be used to specify the thermal boundary condition at the tank surfaces. A negative value of heat flux implies that heat is transferred from the combustion chamber to atmosphere.

Once the heat flux type is selected, the information needed includes values of heat flux and internal emissivity. The value of heat flux is calculated using the method described in Chapter 4. The internal emissivity of the wall is used for radiation heat transfer using the P-1 radiation model; the value of the emissivity of refractory is generally set as 0.93 [38]. 
For accurate thermal wall boundary condition settings, the combined convectionradiation wall boundary should be set for a three-dimensional simulation. The parameters needed are:

The convective heat transfer coefficient: it will be used for the external heat convection calculation. The external convection is in the category of natural convection, this coefficient is estimated in the range of 5 50. To determine a more suitable value, an engineering measurement must be made on-site. David Bivins in PPG Industries Inc. measured such a coefficient for their continuous furnaces and used it in his simulation. But this coefficient for a batch tanks is still uncertain.

Free stream temperature: the external heat-sink temperature in a batch tank shop is around $330 \mathrm{~K}$.

The wall refractory conductivity: as listed in Table 3.3 .

The wall thickness: 9 or 12 inches are the common thickness without counting the thickness of the insulation layer.

External radiation temperature: this temperature has been measured in several glass plant. Without insulation, the outer tank surface temperature is as high as $700 \mathrm{~K}$; with external insulation, the temperature of the outer tank surface still reaches $390 \mathrm{~K}$. In this research, this temperature is not explicitly specified.

Heat generation rate: set as zero for crown and side walls, but non-zero for the glass. A negative value of $40 \%$ of the total energy input is set for glass representing the heat sink (absorbed by glass).

Internal emissivity: set as 0.93 .

External emissivity: set as 0.90 .

\subsubsection{Input Specification for Outlet}

The outlet is already specified as a pressure outlet. The gage pressure is kept at 5 pascal. Similar to the specification of inlet boundary conditions, the turbulence intensity and hydraulic 
diameter are input to specify the turbulence. In actual operation of a batch tank, back flow will not happen, but a virtual back flow may happen in computation; therefore, species for back flow are specified. If a virtual back flow occurs during the computation process, it is assumed that only air is the material in the back flow.

\subsection{Solution Controls}

The equations for flow, energy, turbulence, species, $\mathrm{P} 1, \mathrm{NO}_{\mathrm{x}}$ and soot are enabled. During the computation two sets of common solution parameters (under-relaxation factor and discretization scheme) must be specified to control the computation.

\subsubsection{Under-relaxation Factor}

Under-relaxation factors are used to control the update of computed variables at each iteration. In FLUENT, the default under-relaxation parameters for all variables are set to values that are near optimal for the largest possible number of cases. But it is prudent to adjust the under-relaxation factors during the computation to facilitate convergence.

\subsubsection{Discretization Scheme}

The discretization scheme for the convection terms of each governing equation may be first order or second order, depending on the problem being solved and the grid type. In a batch tank combustion simulation, energy, species, and turbulence equations need to be solved, and the computation domain is meshed using unstructured grid. Therefore, the second-order scheme is required for equations of momentum, energy, kinetic energy $\mathrm{k}$, eddy dissipation rate $\varepsilon$, and species (includes $\mathrm{NO}_{\mathrm{x}}$ ) for better accuracy.

The "standard" scheme is used for pressure; this procedure interpolates the pressure values at the cell faces. The SIMPLE algorithm is used for pressure-velocity coupling; this algorithm uses a relationship between velocity and pressure corrections to enforce mass conservation and to obtain the pressure field. 


\subsection{Convergence Criterion}

The convergence criterion shows the residual value for which the solution of each variable will be considered converged. Values for convergence criterion depend on the variable type. For continuity and velocities, the solving process converges when the residual is less than $1 \times 10^{-3}$, but in this research a more rigorous criterion of less than $1 \times 10^{-5}$ is adopted. To judge if the solution of turbulence is convergent, the convergence of both $\mathrm{k}$ and $\varepsilon$ are also set as $1 \times 10^{-5}$.

In simulations in which chemical reactions are involved, the solution of the energy equation is convergent when the residual reduces to less than $1 \times 10^{-6}$. For all the species, including $\mathrm{CH}_{4}, \mathrm{O}_{2}, \mathrm{CO}_{2}$, and $\mathrm{H}_{2} \mathrm{O}$, the residuals must be less than $1 \times 10^{-6}$. The $\mathrm{NO}_{\mathrm{x}}$ emissions level prediction is post processed based on combustion simulation. The residual is similar to the other species and a convergence criterion of $1 \times 10^{-6}$ is appropriate.

Because the solving for energy and species goes to convergent much slower than that of the continuity, the kinetic energy $\mathrm{k}$ and the eddy dissipation rate $\varepsilon$. Actually when the energy and species solution finally reach their convergence criterion, the residuals of the continuity, the kinetic energy $\mathrm{k}$, and the eddy dissipation rate $\varepsilon$ are already far below $1 \times 10^{-3}$. As a result, the convergence criterion of energy and species are of most concern. When the solutions for them converge, the computation is finished. The convergence criteria for all the variables are listed in Table 7.2.

Table 7.2 Convergence criterion

\begin{tabular}{|l|c|c|}
\hline Variable & Convergence Criterion & Residuals Reached \\
\hline Continuity & $1 \times 10^{-5}$ & $1 \times 10^{-6}$ \\
\hline Velocity $\left(V_{x}, V_{y}, V_{z}\right)$ & $1 \times 10^{-5}$ & $1 \times 10^{-6}$ \\
\hline Energy & $1 \times 10^{-6}$ & $1 \times 10^{-6}$ \\
\hline $\mathbf{K}$ & $1 \times 10^{-5}$ & $1 \times 10^{-6}$ \\
\hline $\boldsymbol{\varepsilon}$ & $1 \times 10^{-5}$ & $1 \times 10^{-6}$ \\
\hline P-1 & $1 \times 10^{-6}$ & $1 \times 10^{-6}$ \\
\hline Species $\left(\mathrm{CH}_{4}\right.$, etc. $)$ & $1 \times 10^{-6}$ & $1 \times 10^{-6}$ \\
\hline NO $_{\mathbf{x}}$ & $1 \times 10^{-6}$ & $1 \times 10^{-6}$ \\
\hline Soot & $1 \times 10^{-5}$ & $1 \times 10^{-5}$ \\
\hline
\end{tabular}




\subsection{A Simulation Example}

To illustrate the simulation process, a simulation example for combustion in a cylindrical combustor is presented.

\subsubsection{Problem description}

Natural gas $\left(99 \% \mathrm{CH}_{4}+1 \% \mathrm{~N}_{2}\right)$ combusts with oxygen $\left(98 \% \mathrm{O}_{2}+2 \% \mathrm{~N}_{2}\right)$ in a cylindrical combustor through a coaxial burner. The gage pressure of the operating pressure is 0.02 inches of water (or 5 pascal) over atmospheric pressure. For a given fuel flow velocity, CFD simulation is used to find the combustion temperature profile and $\mathrm{NO}_{\mathrm{x}}$ emission level.

Dimensions of combustor: length $\mathrm{L}=1.80 \mathrm{~m}$, diameter $\mathrm{D}=0.60 \mathrm{~m}$.

Diameter of fuel inlet: $0.025 \mathrm{~m}$.

Diameter of oxygen inlet: $0.050 \mathrm{~m}$.

\subsubsection{Preparation}

Geometry creation: A x-axisymmetric 2-D geometry is created.

Grid generation: 2-D structured grid generated.

\subsubsection{Simulation process}

Step 1: Read the grid file into FLUENT 5 and check grid.

Step 2: Define models

(1) Solver Selection

Solver: segregated

Space: axisymmetric

Velocity Formulation: absolute

Formulation: Implicit

Time: steady

(2) Energy: enable energy equation

(3) Viscous model

Model: RNG k- $\varepsilon$ model 
Near Wall Treatment: Standard wall functions

(4) Species

Model: multiple species

Reactions: Volumetric reactions

Mixture material: methane-air, five species: $\mathrm{CH}_{4}, \mathrm{O}_{2}, \mathrm{CO}_{2}, \mathrm{H}_{2} \mathrm{O}$ and $\mathrm{N}_{2}$.

(5) Radiation Model

P-1 radiation model.

(6) Pollutant

$\mathrm{NO}_{\mathrm{x}}$ : thermal $\mathrm{NO}_{\mathrm{x}}$ only.

Soot: one-step model, soot-radiation interaction accounted.

\section{Step 3. Define Materials}

(1) Material type: methane-air mixture, $\mathrm{O}_{2}$ and $\mathrm{N}_{2}$ mass fraction in air will be modified in Boundary Conditions setting.

(2) Reaction Model: eddy-dissipation.

(3) Density: incompressible ideal gas law.

(4) $C_{p}$ : mixing law for mixture, piecewise polynomials for each species.

(5) Thermal conductivity k: ideal gas mixing law for mixture (kinetic theory for each species).

(6) Viscosity $v$ : ideal gas mixing law (kinetic theory for each species).

(7) Mass diffusivity: kinetic theory.

(8) Absorption coefficient: wsggm-domain-based.

(9) Scattering coefficient: 0 for lean and stoichiometric combustion

\section{Step 4. Set Operating conditions}

(1) Gage pressure: +5 pascal.

(2) Gravity is neglected at this stage (it is considered for low momentum burner). 


\section{Step 5. Set Boundary conditions}

(1) Velocity fuel inlet

Set the fuel velocity $\mathrm{V}_{\text {fuel }}(\mathrm{m} / \mathrm{s})$.

Set fuel composition: methane mass fraction 0.99 , nitrogen mass fraction 0.01 .

Set turbulence specification: turbulence intensity $I$ and the hydraulic diameter $D_{\text {fuel }}$.

(2) Velocity oxygen inlet

Set the oxygen flow velocity $\mathrm{V}_{\text {oxy }}(\mathrm{m} / \mathrm{s})$.

Set oxidizer composition: oxygen mass fraction 0.98 , nitrogen mass fraction 0.02 .

Set turbulence specification: turbulence intensity $I$ and the hydraulic diameter $D_{\text {oxy }}$.

(3) Walls: heat flux or combined convection-radiation.

If the heat flux is set, an error is expected because of the temperature distribution on a wall is not uniform. The temperature variation may reach 60 100 $\mathrm{K}$, therefore, the error is estimated as $\pm 10 \%$.

\section{Step 6. Solve}

(1) Controls

Under-relaxation: for all equations, using the default under-relaxation factors.

Except for the momentum and soot, set 0.5 for momentum and 0.1 for soot.

Discretization: $2^{\text {nd }}$-order.

Pressure-velocity coupling: SIMPLE.

(2) Initialize: guess temperature is $1800 \mathrm{~K}$.

(3) Set Convergence criterion: use criterions listed in Table 7.2

(4) Solving.

\section{Step 7. Simulation Result Checking}

(1) Graphic Display

(2) Data Analysis 


\section{Chapter 8 Premixed Oxy-Fuel Combustion}

The basic burner features influence the oxy-fuel combustion stability, efficiency, safety, reliability, and emissions; thus the oxy-fuel burner is the heart of the oxy-fuel fired batch tank. Some basic aspects of an oxy-fuel flame, which are dependent on burner features, need to be investigated for the proper use of an oxy-fuel burner in a batch tank. A burner designed with understanding of the mechanism behind the burner behavior will be the key factor in a successful batch tank design.

Burners fall into two categories: diffusion burners and premixed burners. Currently, diffusion burners are commonly used in the glass industry. However, because of the lack of luminosity of an oxy-fuel flame and the difficulty in the measurement of its temperature profile, the flame length, flame volume, temperature profile, and $\mathrm{NO}_{\mathrm{x}}$ emissions have not been systematically characterized yet. It is hard to carry out such research merely by engineering experiments due to economic and technological reasons. Therefore, a burner behavior investigation using CFD methods has great significance for the glass industry. This chapter deals with premixed burners and their flame features while Chapter 9 deals with diffusion burners and their flame features.

While a premixed flame may burn out of control during some engineering experiments or may cause safety problems during actual production, a simulated premixed flame will never "burn" or "explode" in the virtual plant within a computer. This is typically one of the advantages of CFD simulation over engineering experiments. Premixed combustion can be treated as an extreme situation of diffusion combustion—when natural gas and/or oxygen velocity are fast enough, the oxygen and fuel will mix before leaving burner block. Therefore, the 
simulation of premixed combustion does supply some insights even for diffusion burner design, although it is hard to validate such simulations.

\subsection{Oxy-Fuel Mixture}

Premixed combustion means the oxygen and natural gas are already homogeneously mixed before the oxygen fuel mixture enters the combustion chamber through a single oxy-fuel inlet. Because of the high-energy intensity required for glass melting, generally the premixed oxy-fuel burner introduces fuel and oxygen into a combustion chamber under pressure. Flashback is a serious problem for premixed combustion. Thus, the oxy-fuel flow velocity through the burner should be greater than a critical velocity. Cooling of the burner tunnel, as well as the shut-off devices, are required to prevent flashback.

The composition of the premixed fuel-oxygen mixture plays an important role in flame temperature distribution and $\mathrm{NO}_{\mathrm{x}}$ formation. It is dependent on the natural gas composition and the oxygen purity as well as the oxy/fuel ratio. Assume natural gas consists of $m \%$ methane and $(100-m) \%$ nitrogen by weight; and the oxygen consists of $p \%$ oxygen and (100-p)\% nitrogen (by weight); and the required $\mathrm{O}_{2} / \mathrm{CH}_{4}$ mole ratio is $\omega$. Then the composition of the premixed oxy/fuel mixture based on mass fraction can be calculated using the following formulas:

$$
\begin{aligned}
& \mathrm{CH}_{4}: \quad \frac{\mathrm{mp}}{\mathrm{p}+2 \omega \mathrm{m}} \% \\
& \mathrm{O}_{2}: \quad \frac{\omega \mathrm{mp}}{\mathrm{p}+2 \omega \mathrm{m}} \% \\
& N_{2}:\left(100-\frac{(1+2 \omega) m p}{p+2 \omega m}\right) \%
\end{aligned}
$$


For example, if the natural gas contains $99.5 \% \mathrm{CH}_{4}(\mathrm{~m}=99.5)$, the oxygen purity is $98 \%$ $(\mathrm{p}=98)$, and a $\mathrm{O}_{2} / \mathrm{CH}_{4}$ mole ratio $\omega$ of 2.05 is required, then the mixture contains $18.31 \% \mathrm{CH}_{4}$, $75.07 \% \mathrm{O}_{2}$, and $6.62 \% \mathrm{~N}_{2}$.

For a given natural gas supply, if the oxy/fuel ratio is kept at 2.05 , then the composition of the mixture can be calculated using Equations 8-1, 8-2 and 8-3, as listed in Table 8.1.

Table 8.1 Composition of the oxy-fuel mixture at given oxygen purity

\begin{tabular}{|c|c|c|c|c|c|}
\hline $\begin{array}{l}\mathrm{CH}_{4} \text { in NG } \\
\text { (wt. \%) }\end{array}$ & $\begin{array}{l}\mathrm{O}_{2} \text { Purity } \\
\text { (wt. \%) }\end{array}$ & $\begin{array}{l}\mathrm{O}_{2} / \mathrm{CH}_{4} \\
\omega\end{array}$ (molar) & \multicolumn{3}{|c|}{ Composition (wt. \%) } \\
\cline { 4 - 6 } & & & $\mathrm{CH}_{4}$ & $\mathrm{O}_{2}$ & $\mathrm{~N}_{2}$ \\
\hline 99.50 & 92.00 & 2.05 & 18.31 & 75.07 & 6.62 \\
\hline 99.50 & 92.50 & 2.05 & 18.39 & 75.40 & 6.21 \\
\hline 99.50 & 93.00 & 2.05 & 18.47 & 75.74 & 5.79 \\
\hline 99.50 & 93.50 & 2.05 & 18.55 & 76.07 & 5.38 \\
\hline 99.50 & 94.00 & 2.05 & 18.63 & 76.40 & 4.97 \\
\hline 99.50 & 94.50 & 2.05 & 18.71 & 76.73 & 4.56 \\
\hline 99.50 & 95.00 & 2.05 & 18.79 & 77.06 & 4.155 \\
\hline 99.50 & 95.50 & 2.05 & 18.87 & 77.39 & 3.74 \\
\hline 99.50 & 96.00 & 2.05 & 18.95 & 77.71 & 3.34 \\
\hline 99.50 & 96.50 & 2.05 & 19.03 & 78.04 & 2.93 \\
\hline 99.50 & 97.00 & 2.05 & 19.11 & 78.37 & 2.52 \\
\hline 99.50 & 97.50 & 2.05 & 19.19 & 78.69 & 2.12 \\
\hline 99.50 & 98.00 & 2.05 & 19.28 & 79.02 & 1.710 \\
\hline 99.50 & 98.50 & 2.05 & 19.35 & 79.34 & 1.31 \\
\hline 99.50 & 99.00 & 2.05 & 19.43 & 79.67 & 0.90 \\
\hline 99.50 & 99.50 & 2.05 & 19.51 & 79.99 & 0.50 \\
\hline 99.50 & 99.99 & 2.05 & 19.59 & 80.31 & 0.11 \\
\hline
\end{tabular}

\subsection{A Model Combustor}

Because the geometry of a batch tank varies from company to company, it is necessary to investigate the basic flame features in a model combustor. A cylindrical combustor is used for the basic flame feature study for premixed combustion. The geometry and dimension of such a combustor has been described in Chapter 4. Considering most batch tanks used in hand glass industry are those with a capacity less than $4000 \mathrm{lb}$, a $2500 \mathrm{lb}$ batch tank was selected for the case study. Such a tank requires $600 \mathrm{SCFH}$ natural gas as energy input for the melting process. This 
amount of volume flow rate is equivalent to 17 cubic meters per hour or $0.004734 \mathrm{~m}^{3} / \mathrm{s}$. Table 8.2 listed all the inputs required for an energy balance analysis.

Table 8.2 Fuel consumtion rate for a $2500 \mathrm{lb}$. batch tank

\begin{tabular}{|l|c|c|}
\hline \multicolumn{1}{|c|}{ Item } & English Unit & SI Unit \\
\hline Natural gas flow rate & $600 \mathrm{SCFH}$ & $0.004734 \mathrm{~m}^{3} / \mathrm{s}$ \\
\hline Oxy/fuel ratio $\omega$ & 2.05 & 2.05 \\
\hline Oxy-fuel flow rate & $1830 \mathrm{SCFH}$ & $0.01452 \mathrm{~m}^{3} / \mathrm{s}$ \\
\hline
\end{tabular}

Based on this amount of flow rate $F$ of the oxy/fuel mixture, once the inlet diameter $D$ is given, then the flow velocity of the oxy/fuel mixture $V$ can be calculated as $V=F / \pi(D / 2)^{2}$. Then FLUENT is used to simulate the combustion in the model combustor. For 12 designed inlet nozzle diameters, the inlet velocity, the Reynolds number of the flow, the flame length, width and $\mathrm{NO}_{\mathrm{x}}$ emissions obtained from each simulation are listed in Table 8.3. The flame zone is defined as the region within which the $[\mathrm{CO}]$ is over $2000 \mathrm{ppm}$ or $\mathrm{dT} / \mathrm{ds}$ is greater than $5 \mathrm{~K} / \mathrm{cm}$.

Table 8.3 Velocity and flame features

\begin{tabular}{|c|c|c|c|c|c|}
\hline \multirow{2}{*}{$\begin{array}{c}\text { Inlet size } \\
\boldsymbol{D}(\mathrm{m})\end{array}$} & \multirow{2}{*}{$\begin{array}{c}\text { Oxy/Fuel } \\
\text { Velocity }(\mathrm{m} / \mathrm{s})\end{array}$} & \multirow{2}{*}{$\begin{array}{l}\text { Reynolds } \\
\text { number }\end{array}$} & \multicolumn{3}{|c|}{ Flame Features } \\
\hline & & & Length (m) & Width (m) & NO mass fraction \\
\hline 0.0160 & 72.98 & 73460 & 1.03 & 0.46 & $3.18 \times 10^{-4}$ \\
\hline 0.0180 & 57.66 & 65290 & 1.06 & 0.54 & $2.97 \times 10^{-4}$ \\
\hline 0.0200 & 46.71 & 58770 & 1.03 & 0.48 & $3.25 \times 10^{-4}$ \\
\hline 0.0220 & 38.60 & 53420 & 1.03 & 0.51 & $2.92 \times 10^{-4}$ \\
\hline 0.0240 & 32.44 & 48980 & 1.13 & 0.44 & $3.07 \times 10^{-4}$ \\
\hline 0.0256 & 28.50 & 45900 & 1.09 & 0.51 & $2.84 \times 10^{-4}$ \\
\hline 0.0300 & 20.76 & 39180 & 1.10 & 0.46 & $3.00 \times 10^{-4}$ \\
\hline 0.0350 & 15.25 & 33580 & 1.10 & 0.49 & $2.86 \times 10^{-4}$ \\
\hline 0.0450 & 9.23 & 26130 & 1.16 & 0.46 & $2.55 \times 10^{-4}$ \\
\hline 0.0500 & 7.47 & 23500 & 1.13 & 0.40 & $2.48 \times 10^{-4}$ \\
\hline 0.0550 & 6.18 & 21380 & 1.18 & 0.36 & $2.15 \times 10^{-4}$ \\
\hline 0.0600 & 5.19 & 19590 & 1.25 & 0.37 & $1.90 \times 10^{-4}$ \\
\hline
\end{tabular}

\subsection{Profile of Premixed Oxy-Fuel Flame}

In premixed combustion, the oxygen and fuel is already mixed together before entering the combustion chamber, therefore, the flame shape only depends on the turbulence flow velocity 
of the oxy/fuel mixture. The flame shape under given velocities were investigated and a comparison is made in this section.

\subsubsection{Flame Length}

The flame length is somewhat dependent on the velocity of the oxy-fuel mixture. Using the data listed in Table 8.2, the relationship between the oxy-fuel velocity and flame length is shown in Figure 8.1.

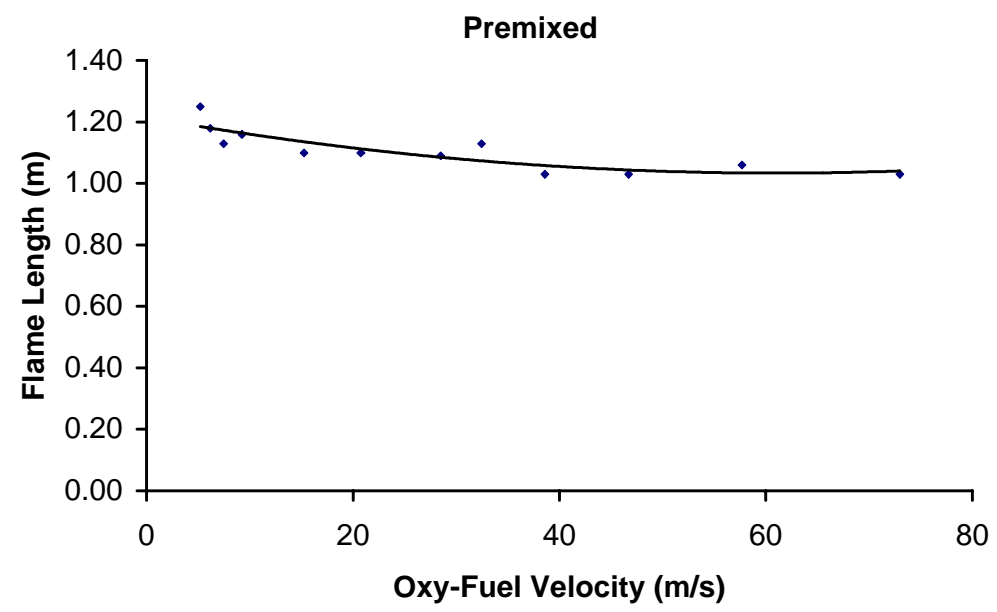

Figure 8.1 Flame length at various oxy-fuel velocities

The flame length decreases slightly with the increasing of the velocity of the oxy/fuel mixture. The flame length is longer than one meter but does not excess 1.30 meters.

\subsubsection{Flame Width}

Based on the data in Table 8.3 the flame width vs. oxy-fuel velocity was plotted. Figure 8.2 shows that higher oxy-fuel velocity contributes to form wider flame, but it seems that the velocity is not necessarily to be set over $20 \mathrm{~m} / \mathrm{s}$. In the range of $20 \sim 80 \mathrm{~m} / \mathrm{s}$, the flame width seems almost stabilized around $0.45 \mathrm{~m} / \mathrm{s}$.

The flame volume can be estimated using the length from Figure 8.1 and the width from 8.2. The flow velocity in the range of $20 \sim 40 \mathrm{~m} / \mathrm{s}$ are desired for bigger flame volume, which contributes to better flame coverage over glass surface. 


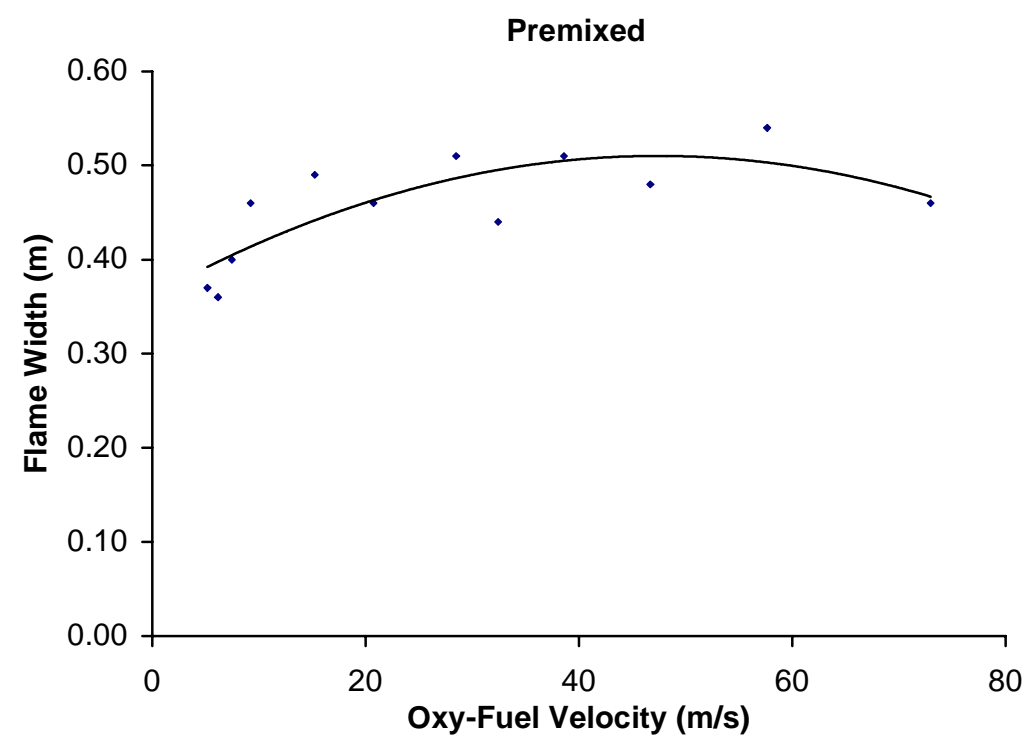

Figure 8.2 Flame radius at various velocities

For example, when the oxy-fuel is introduced into the combustor at $9.2 \mathrm{~m} / \mathrm{s}$, the flame length reaches 1.20 meters, and the flame width is within 0.40 meters. Figure 8.3 shows the temperature profile at such an inlet velocity.

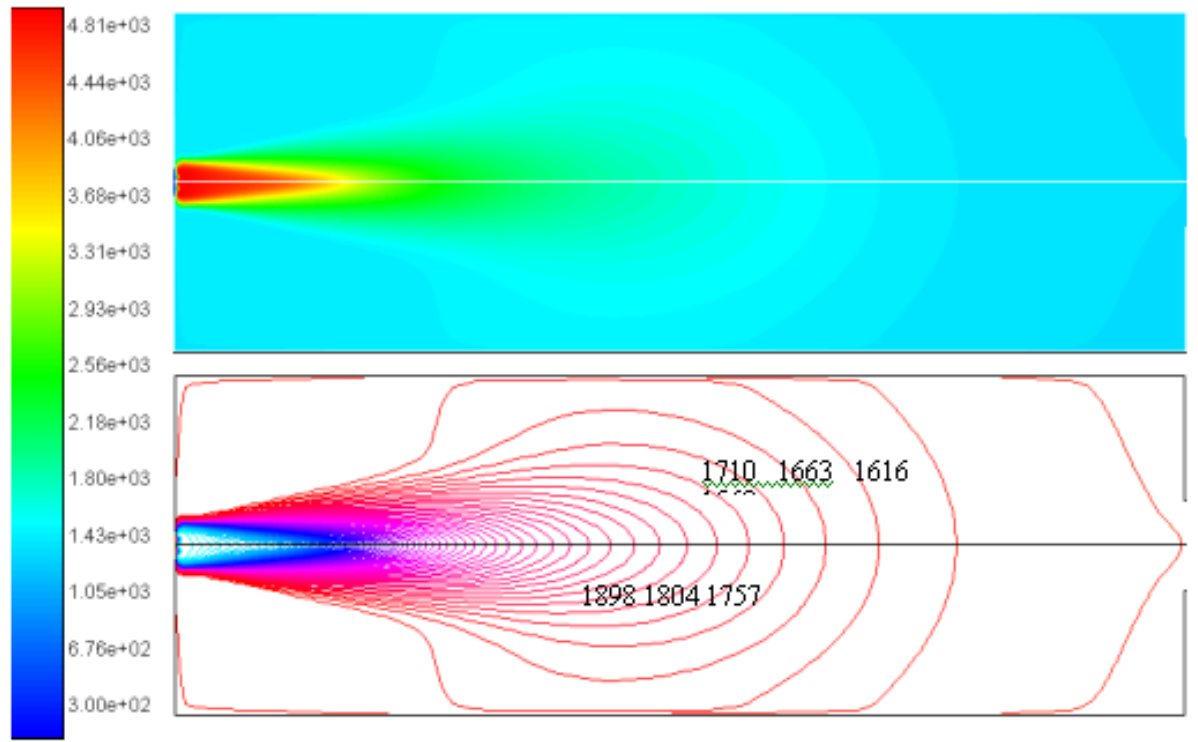

Figure 8.3 Premixed oxy-fuel flame profile when $v=9.2 \mathrm{~m} / \mathrm{s}$ 
The peak temperature in the flame zone is as high as $5000 \mathrm{~K}$, and temperature gradient is sharp in the hot region, which is about 0.40 meters long and 0.20 meter wide. The hot region is close to burner exit, which is potentially harmful to burner tunnel.

\section{4 $\mathrm{NO}_{\mathrm{x}}$ Emissions from Premixed Firing}

Based on the data listed in Table 8.2, the relationship between $\mathrm{NO}_{\mathrm{x}}$ mass fraction in the flue gas and the oxy-fuel velocity was found to be as shown in Figure 8.4.

\section{Premixed}

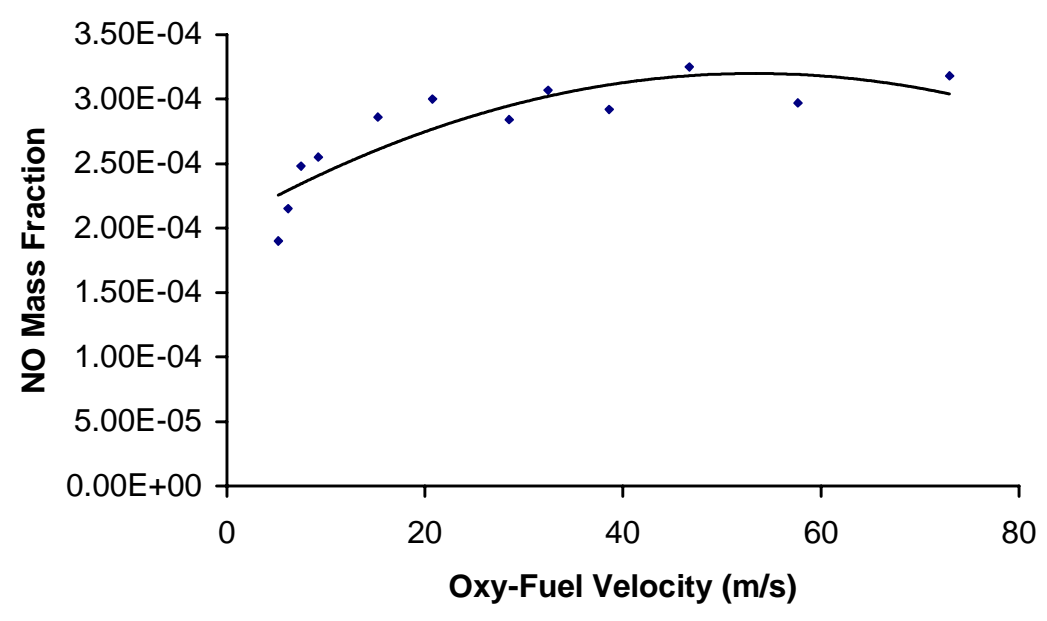

Figure 8.4 NO emissions at various oxy-fuel velocities

$\mathrm{NO}_{\mathrm{x}}$ emissions were found to increase with velocity. The $\mathrm{NO}$ mass fraction in the exhaust is between 0.000250 and 0.000320 . The $\mathrm{NO}_{\mathrm{x}}$ emission level in premixed combustion will be compared with that in diffusion combustion in Chapter 11. 


\section{Chapter 9 Coaxial Oxy-Fuel Burner}

\subsection{Introduction}

A coaxial burner consists of two separated coaxial pipes for fuel and oxygen supplies. The center pipe supplies the fuel and the annular pipe supplies oxygen. This type of burner is widely used in industrial furnaces. Figures 9.1 illustrates the basic structure a coaxial burner.

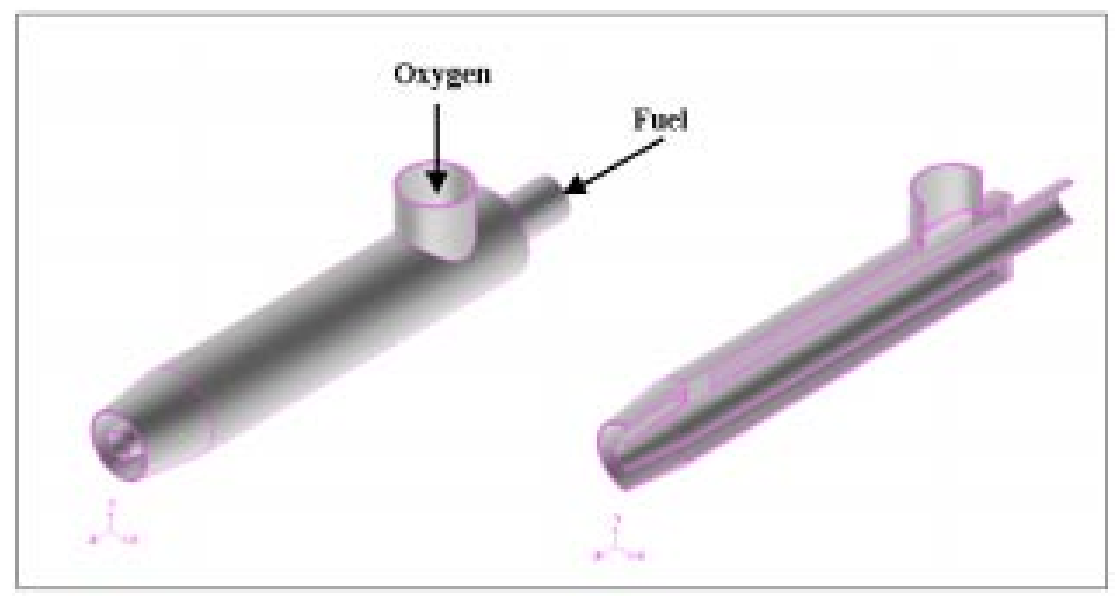

Figure 9.1 Coaxial burner schematic

The flame shape yielded from such a coaxial oxy-fuel burner is usually round, but the flame length, flame width and the flame temperature depend on the details of the burner structure, the flow of the fuel and the flow of the oxygen. The same model combustor as the one used for premixed combustion was used to investigate the basic features of such a coaxial oxy-fuel burner; the only change was that the single oxy-fuel inlet was replaced with the two coaxial inlets.

Both the velocity of the natural gas and the velocity of the oxygen are dominant factors that determine the flame features. In practice, these velocities are limited; they usually are under a certain maximum velocity in order to avoid excessive noise. Generally the flows of natural gas and oxygen through the burner are subsonic, and the Mach number is usually less than 0.3. The 
gas under such a flowing condition can be treated as an incompressible gas, especially when the Mach number is less than 0.2. As a result, all the flow velocities are generally set below $100 \mathrm{~m} / \mathrm{s}$; the only exception in this research is a velocity of $146.5 \mathrm{~m} / \mathrm{s}$ (with Mach number of 0.42 ), which is used for the purpose of comparison.

For each given natural gas flow velocity, a series of oxygen velocities were selected to identify the flame features, such as flame length, maximum flame width, peak temperature of the flame and $\mathrm{NO}_{\mathrm{x}}$ emissions. In this research, the natural gas inlet diameters were set as $1 / 4 \mathrm{inch}, 1 / 2$ inch, $3 / 4$ inch and 1 inch, respectively. Given the same volume flow rate of natural gas, then a series of oxygen velocities were set by adjusting the oxygen inlet diameter on the basis of keeping the oxygen/fuel ratio to be $2.05 \sim 2.1$.

Various fuel nozzle diameters were set for investigation of the mixing and their effects on combustion. Considering the energy requirement for a 2500-pound batch tank, which requires a natural gas volume flow rate of about $600 \mathrm{SCFH}$, the natural gas inlet diameters can be set. The diameters of the five selected nozzles are listed in Table 9.1.

Table 9.1 Coaxial burner's fuel inlet diameters

\begin{tabular}{|l|c|c|c|r|}
\hline \multicolumn{2}{|l|}{ Fuel flow rate } & \multicolumn{2}{|l|}{ Fuel nozzle D } & \multicolumn{1}{l}{$\begin{array}{l}\text { Fuel V } \\
\text { (m/s) }\end{array}$} \\
\hline $\left.\mathbf{( m}^{\mathbf{3}} / \mathbf{h}\right)$ & $\mathbf{( S C F H )}$ & $\mathbf{( m )}$ & $\mathbf{( I n . )}$ & \\
\hline 17.04 & 600 & 0.0064 & $1 / 4$ & 146.50 \\
\cline { 3 - 5 } & & 0.0128 & $1 / 2$ & 36.63 \\
\cline { 3 - 5 } & & 0.0200 & $3 / 4$ & 15.00 \\
\cline { 3 - 5 } & & 0.0256 & 1 & 9.16 \\
\hline
\end{tabular}

The simulation results for these four coaxial burners are presented in the following four sections. The flame edge is defined as the place where temperature gradient is less than $5 \mathrm{~K} / \mathrm{cm}$.

\subsection{Coaxial Burner with a $1 / 4$ inch Fuel Inlet}

The natural gas inlet diameter was first set as $1 / 4$ inch or 0.0064 meters, and then the oxygen velocity was adjusted by using different oxygen inlet diameters. Thus, a series of mixing 
situations were generated. The mixing process determines the flame features. Table 9.2 lists the fuel (natural gas) and oxygen velocities for seven cases and reports the flame features for those seven cases.

Table 9.2 Flame features of coaxial burners with a $1 / 4$ inch fuel inlet

\begin{tabular}{|c|c|c|c|c|c|c|c|c|}
\hline $\begin{array}{l}D_{\text {Fuel }} \\
\text { (m) }\end{array}$ & $\begin{array}{l}V_{\text {Fuel }} \\
\text { (m/s) }\end{array}$ & $\begin{array}{l}\mathrm{D}_{\mathrm{O} 2} \\
(\mathrm{~m})\end{array}$ & $\begin{array}{c}V_{\mathrm{O} 2} \\
(\mathrm{~m} / \mathrm{s})\end{array}$ & \begin{tabular}{|c|}
$\mathbf{V}_{\text {O2 }} / \mathbf{V}_{\text {Fuel }}$ \\
Ratio
\end{tabular} & $\begin{array}{c}\text { Flame } \\
\text { L (m) }\end{array}$ & $\begin{array}{l}\text { Flame } \\
\text { W (m) }\end{array}$ & $\begin{array}{l}\text { Peak } \\
\text { T (K) }\end{array}$ & $\begin{array}{l}\text { NO mass } \\
\text { fraction }\end{array}$ \\
\hline \multirow{12}{*}{$\begin{array}{l}0.0064 \\
\text { (fixed) }\end{array}$} & \multirow{12}{*}{$\begin{array}{l}146.5 \\
\text { (fixed) }\end{array}$} & 0.0128 & 102.60 & 0.700 & 1.27 & 0.44 & 3562 & 0.00111 \\
\hline & & 0.0140 & 81.27 & 0.555 & 1.18 & 0.39 & 3495 & 0.00115 \\
\hline & & 0.0152 & 66.25 & 0.452 & 1.19 & 0.43 & 3450 & 0.00112 \\
\hline & & 0.0164 & 55.27 & 0.377 & 1.18 & 0.44 & 3502 & 0.00112 \\
\hline & & 0.0174 & 48.13 & 0.329 & 1.19 & 0.43 & 3503 & 0.00114 \\
\hline & & 0.0180 & 44.52 & 0.304 & 1.22 & 0.43 & 3578 & 0.00112 \\
\hline & & 0.0200 & 35.10 & 0.240 & 1.23 & 0.45 & 3546 & 0.00107 \\
\hline & & 0.0220 & 28.44 & 0.194 & 1.19 & 0.41 & 3448 & 0.00117 \\
\hline & & 0.0240 & 23.55 & 0.161 & 1.20 & 0.42 & 3527 & 0.00113 \\
\hline & & 0.0300 & 14.67 & 0.100 & 1.13 & 0.40 & 3600 & 0.00118 \\
\hline & & 0.0350 & 10.65 & 0.073 & 1.12 & 0.42 & 3679 & 0.00112 \\
\hline & & 0.0400 & 8.09 & 0.055 & 1.12 & 0.42 & 3739 & 0.00112 \\
\hline
\end{tabular}

D: diameter; V: velocity; L: length; W: width; T: temperature

The oxygen velocities vary from $8.09 \mathrm{~m} / \mathrm{s}$ to $102.60 \mathrm{~m} / \mathrm{s}$, thus yield varied flame lengths, and flame widths and $\mathrm{NO}_{\mathrm{x}}$ emission levels corresponding to each pair of flow velocities of the fuel and the oxygen. Figures 9.2 to 9.3 show the effect of increased oxygen velocities on the flame length, flame width, flame temperature, and $\mathrm{NO}_{\mathrm{x}}$ emission.

Flame coverage is a function of both flame length and flame width. A flame with the proper length and width is an important burner specification for better heat transfer to the glass batch. For the given natural gas velocity of $146.5 \mathrm{~m} / \mathrm{s}$, Figure 9.2 (a) shows that the flame length is around 1.20 meters with respect to varied oxygen velocities, which implies that the flame length governed by the momentum of fuel jet. Figure 9.2 (b) shows the flame width is around 0.42 meters. This result suggests that with a high fuel velocity of $146.5 \mathrm{~m} / \mathrm{s}$, the flame size is not sensitive to oxygen velocity.

$\mathrm{NO}_{\mathrm{x}}$ emissions at various oxygen velocities depend on the flame temperature and flame zone volume. Figure 9.3 shows that the flame temperature is around $3500 \mathrm{~K}$, and the level of 
$\mathrm{NO}_{\mathrm{x}}$ emissions is in the range of 0.00125 to 0.00137 . The differences between $\mathrm{NO}_{\mathrm{x}}$ emissions at different oxygen velocities are less than $8.5 \%$, which are not significant, although there may be an oxygen velocity such as $15.0 \mathrm{~m} / \mathrm{s}$ for which a minimum $\mathrm{NO}_{\mathrm{x}}$ emission occurs.

$$
V_{\text {fuel }}=146.5 \mathrm{~m} / \mathrm{s}
$$

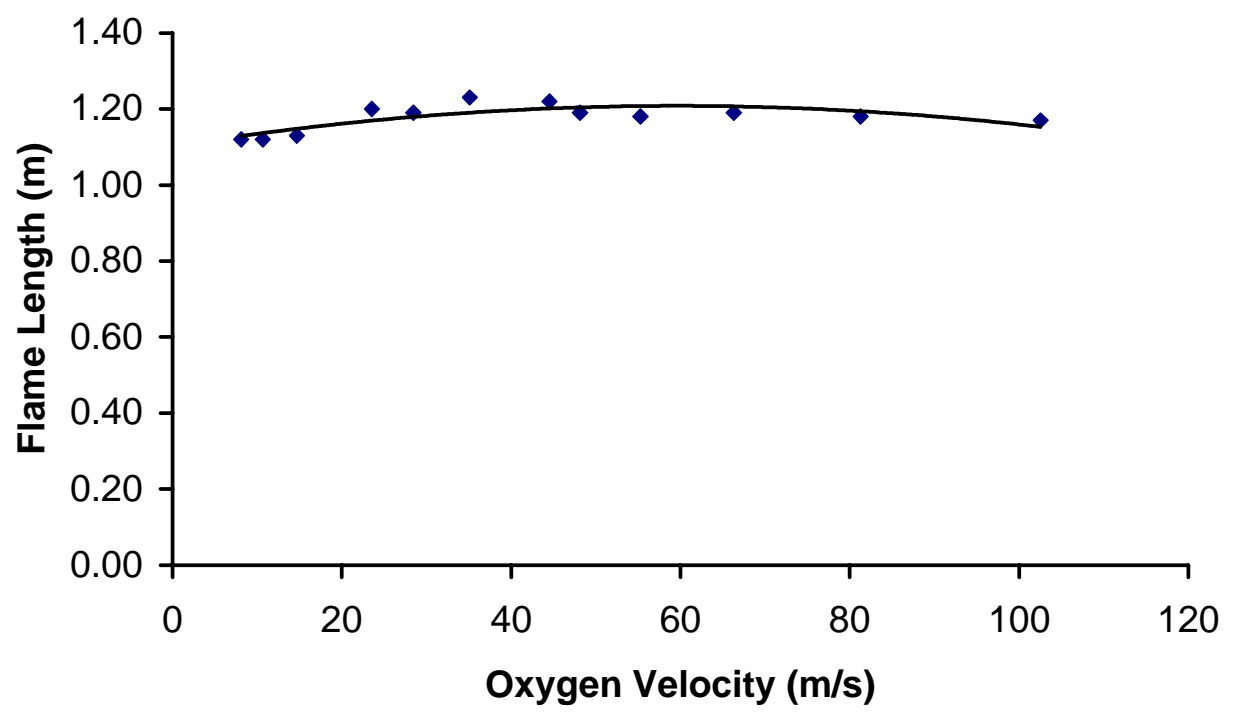

(a)

$$
V_{\text {fuel }}=146.5 \mathrm{~m} / \mathrm{s}
$$

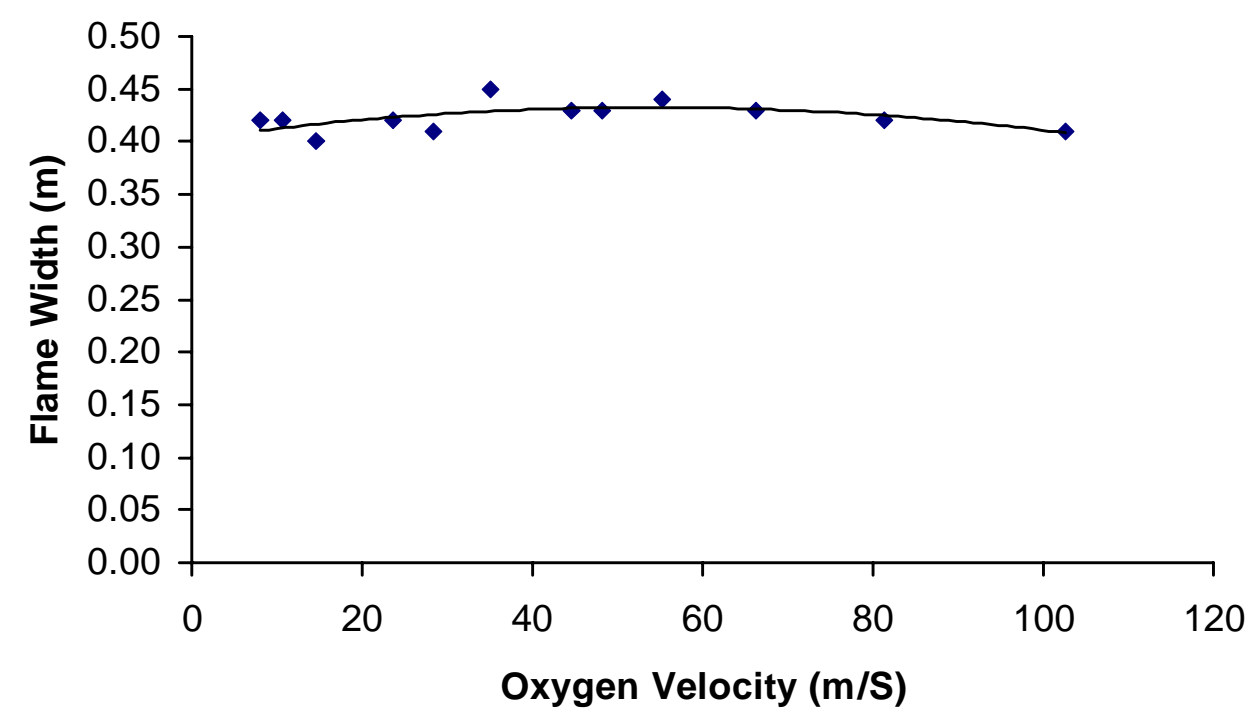

(b)

Figure 9.2 Flame length and flame width of a coaxial burner with $1 / 4$ inch fuel inlet 


$$
V_{\text {fuel }}=146.5 \mathrm{~m} / \mathrm{s}
$$

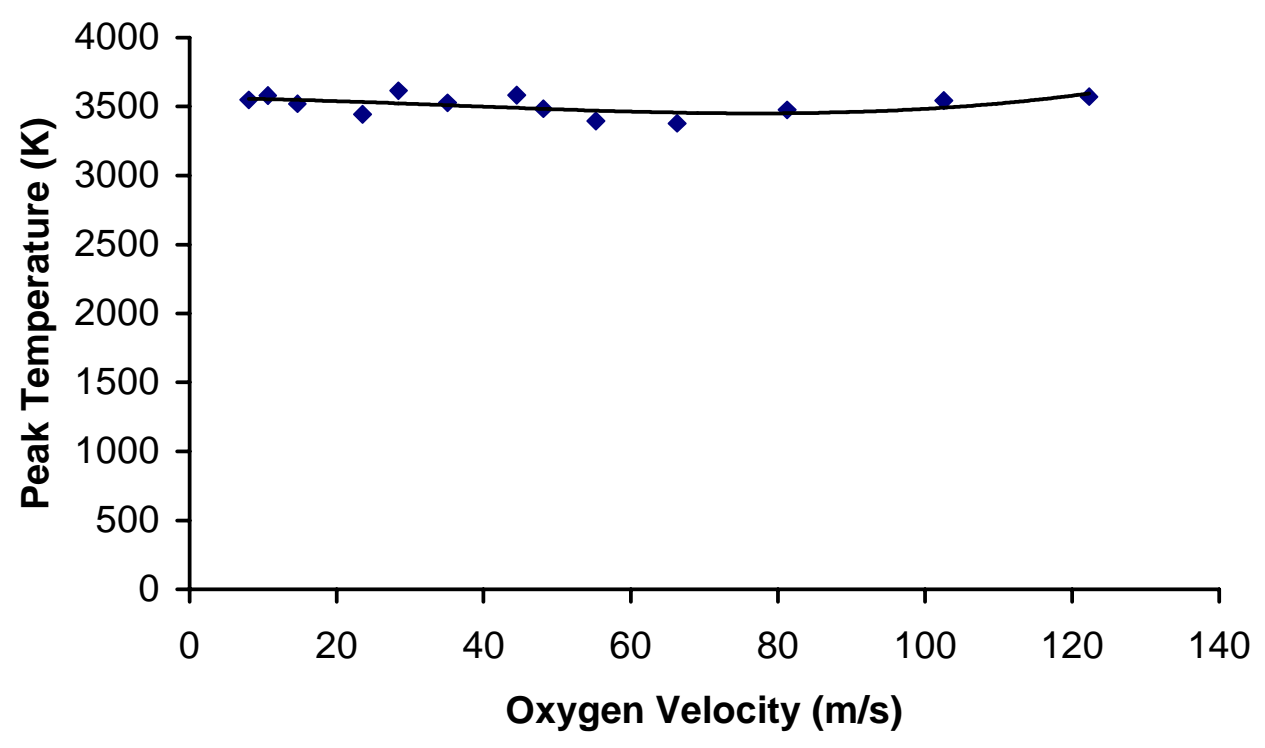

(a)

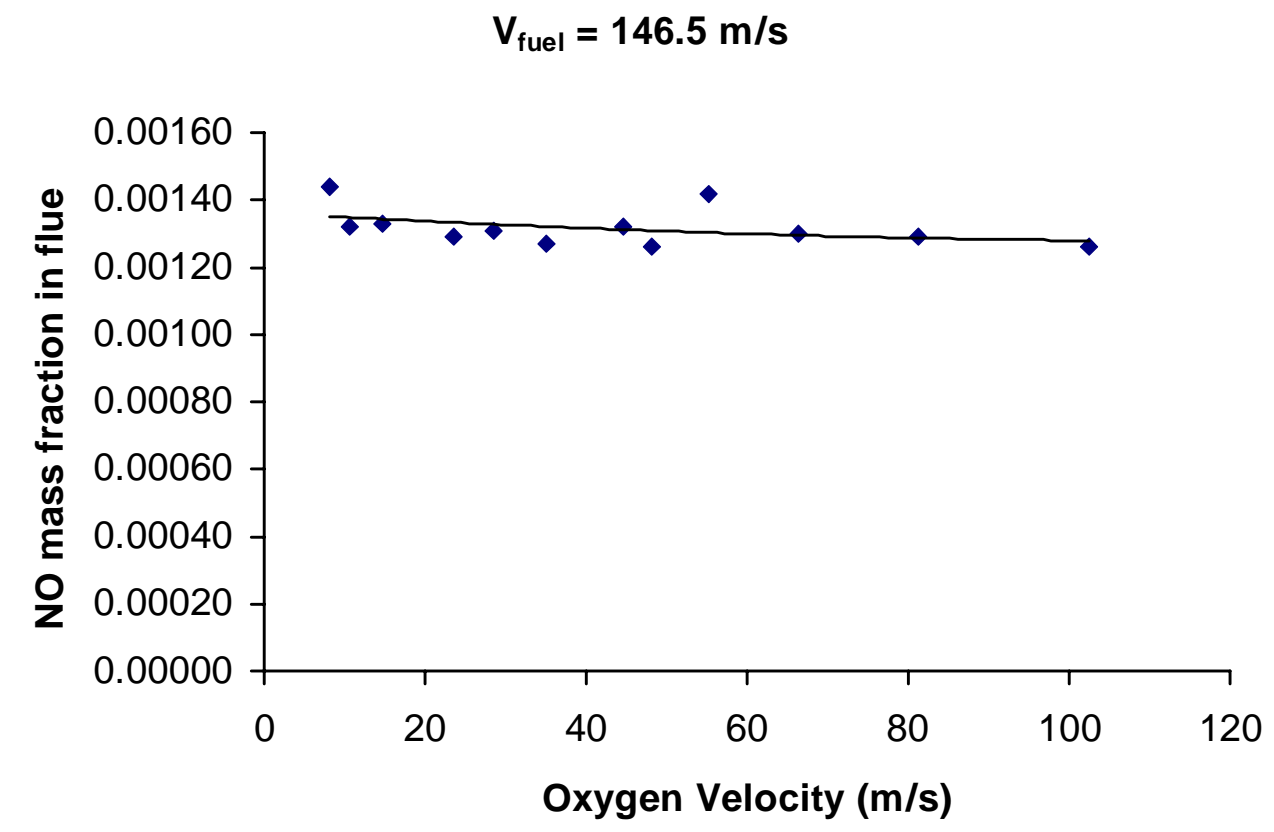

(b)

Figure 9.3 Peak temperature and $\mathrm{NO}_{\mathrm{x}}$ emission of a coaxial burner with $1 / 4$ inch fuel inlet 
If a single burner with its $1 / 4$ inch fuel inlet is used for a 2500 -pound batch tank, it may be too noisy, and hard to operate, and the flame is also too hot. Under a situation where smaller and hotter flame is required, two $1 / 4$ inch burners may be employed at half of the total fuel consumption rate for each burner. Figure 9.4 (a) and (b) show the flames from a $1 / 4$ inch burner with fuel velocity is at $\mathrm{V}=146.5 \mathrm{~m} / \mathrm{s}$. Figure 9.4 (c) and (d) shows the flame features with fuel velocity is at $\mathrm{V}=73.25 \mathrm{~m} / \mathrm{s}$, which yields a lower flame temperature.

(a)

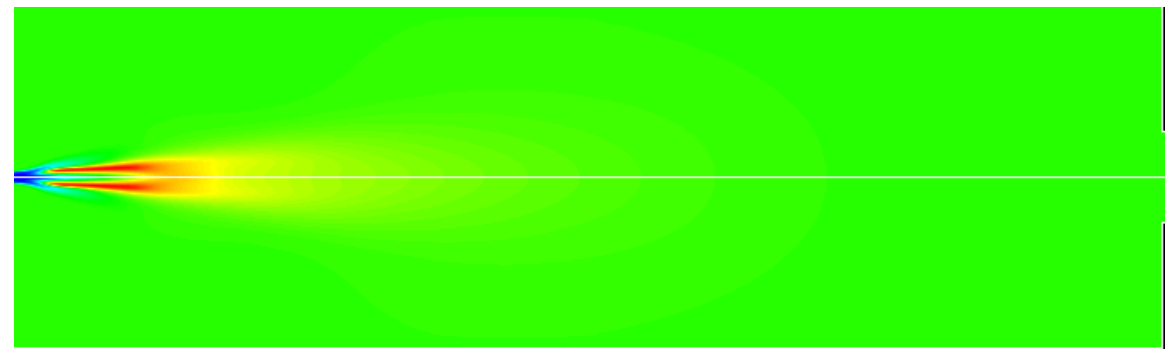

(b)

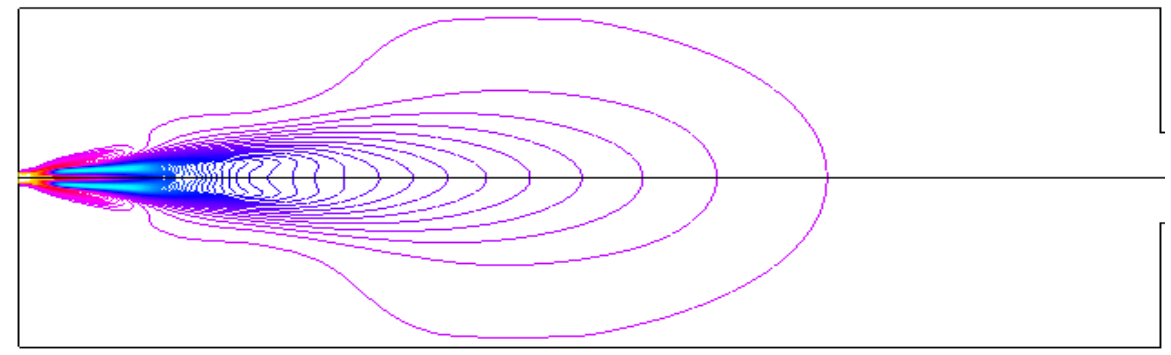

(c)

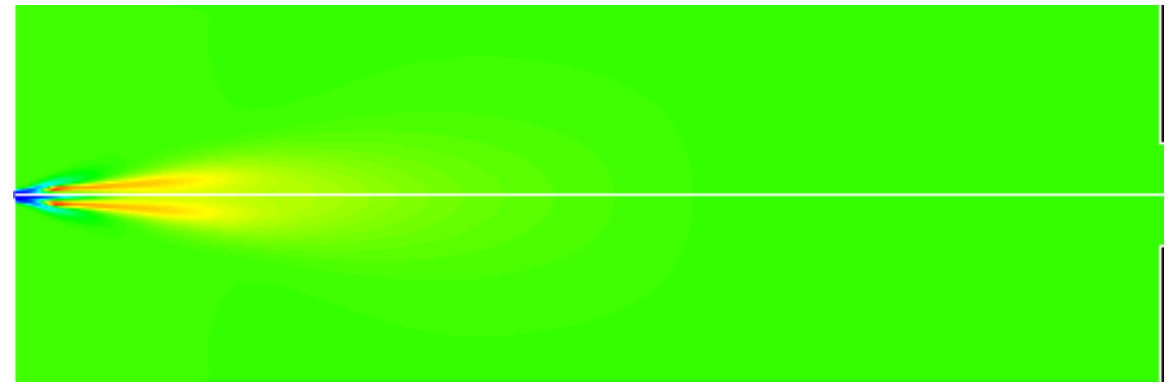

(d)

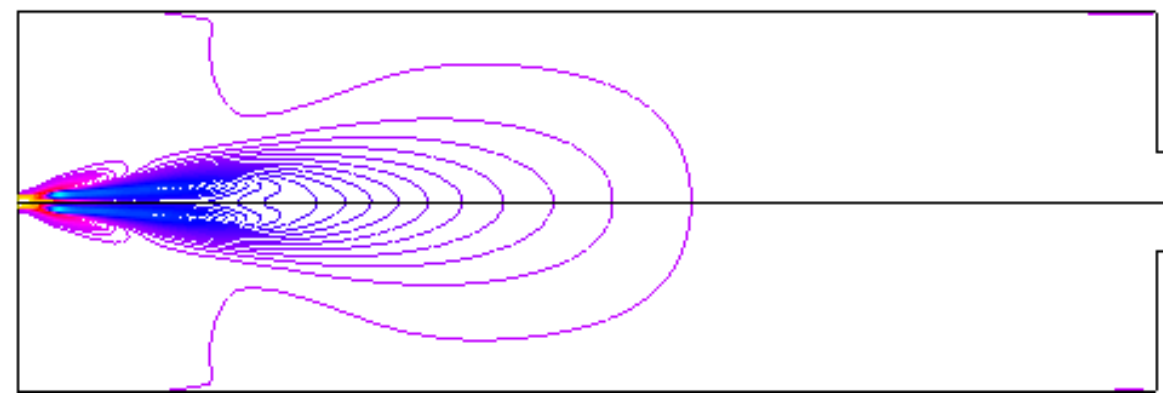

$\begin{array}{ll}\text { (a) and (b) Fuel flow rate }=600 \mathrm{SCFH} & \text { (c) and (d) Fuel flow rate }=300 \mathrm{SCFH}\end{array}$

Figure 9.4 A coaxial burner with $1 / 4$ inch fuel inlet runs at two fuel consumption rates 


\subsection{Coaxial Burner with a $1 / 2$ inch Fuel Inlet}

Compared to the $1 / 4$ inch burner, the $1 / 2$ inch $(0.0128 \mathrm{~m})$ burner introduces natural gas into combustion chamber through a bigger fuel inlet at a much slower velocity-one fourth of the velocity of the $1 / 4$ inch burner. Table 9.3 lists the natural gas velocity, and the varied oxygen velocities, as well as the flame features and $\mathrm{NO}_{\mathrm{x}}$ emission levels observed from a series of simulations.

Table 9.3 Flame features of coaxial burners with a $1 / 2$ inch fuel inlet

\begin{tabular}{|c|c|c|c|c|c|c|c|c|}
\hline $\begin{array}{l}D_{\text {Fuel }} \\
\text { (m) }\end{array}$ & $\begin{array}{l}V_{\text {Fuel }} \\
(\mathrm{m} / \mathrm{s})\end{array}$ & $\begin{array}{l}\mathrm{D}_{\mathrm{O} 2} \\
(\mathrm{~m})\end{array}$ & $\begin{array}{c}V_{\mathrm{O} 2} \\
(\mathrm{~m} / \mathrm{s})\end{array}$ & $\begin{array}{c}\mathbf{V}_{\mathrm{O} 2} / \mathbf{V}_{\text {Fuel }} \\
\text { Ratio }\end{array}$ & \begin{tabular}{|c|} 
Flame \\
L (m)
\end{tabular} & $\begin{array}{l}\text { Flame } \\
W(m)\end{array}$ & $\begin{array}{l}\text { Peak } \\
\text { T (K) }\end{array}$ & $\begin{array}{l}\text { NO mass } \\
\text { fraction }\end{array}$ \\
\hline \multirow{8}{*}{$\begin{array}{l}0.0128 \\
\text { (fixed) }\end{array}$} & \multirow{8}{*}{$\begin{array}{l}36.63 \\
\text { (fixed) }\end{array}$} & 0.0220 & 39.36 & 1.075 & 1.29 & 0.40 & 3434 & 0.00117 \\
\hline & & 0.0228 & 35.40 & 0.967 & 1.33 & 0.37 & 3407 & 0.00115 \\
\hline & & 0.0240 & 30.58 & 0.836 & 1.23 & 0.35 & 3311 & 0.00114 \\
\hline & & 0.0256 & 25.64 & 0.701 & 1.30 & 0.36 & 3221 & 0.00116 \\
\hline & & 0.0280 & 20.32 & 0.555 & 1.30 & 0.36 & 3106 & 0.00116 \\
\hline & & 0.0300 & 17.12 & 0.468 & 1.32 & 0.33 & 2920 & 0.00118 \\
\hline & & 0.0360 & 11.13 & 0.304 & 1.35 & 0.33 & 2838 & 0.00119 \\
\hline & & 0.0440 & 7.11 & 0.194 & 1.26 & 0.33 & 2775 & 0.00117 \\
\hline
\end{tabular}

D: diameter; V: velocity; L: length; W: width, T: temperature

Based on the data shown in Table 9.3, the dependence of flame length, flame width, flame temperature, and $\mathrm{NO}_{\mathrm{x}}$ emissions on oxygen velocities are illustrated in Figures 9.5 and 9.6. Figure 9.5 shows: (a) The flame length is within the range of 1.23 to 1.35 meters; no obvious dependency on oxygen velocity is observed; a lower oxygen velocity tends to form a longer flame because of the delay on the fuel-oxygen mixing. (b) The higher velocity yields a wider flame (lower), which may be due to mass diffusion and oxygen diffusion. Figure 9.6 shows: (a) A higher oxygen velocity yields a higher flame temperature. (b) The $\mathrm{NO}_{\mathrm{x}}$ emission level does not change with oxygen velocities very much (lower).

If a $1 / 2$ inch fuel inlet is set, then it seems that the oxygen velocity can be set within the wide range of 5 to $40 \mathrm{~m} / \mathrm{s}$ depending on the required flame temperature. A lower flame temperature is usually preferred in a batch tank, therefore, a lower oxygen velocity is recommended for a coaxial burner with a $1 \frac{1}{2}$ inch fuel inlet. 


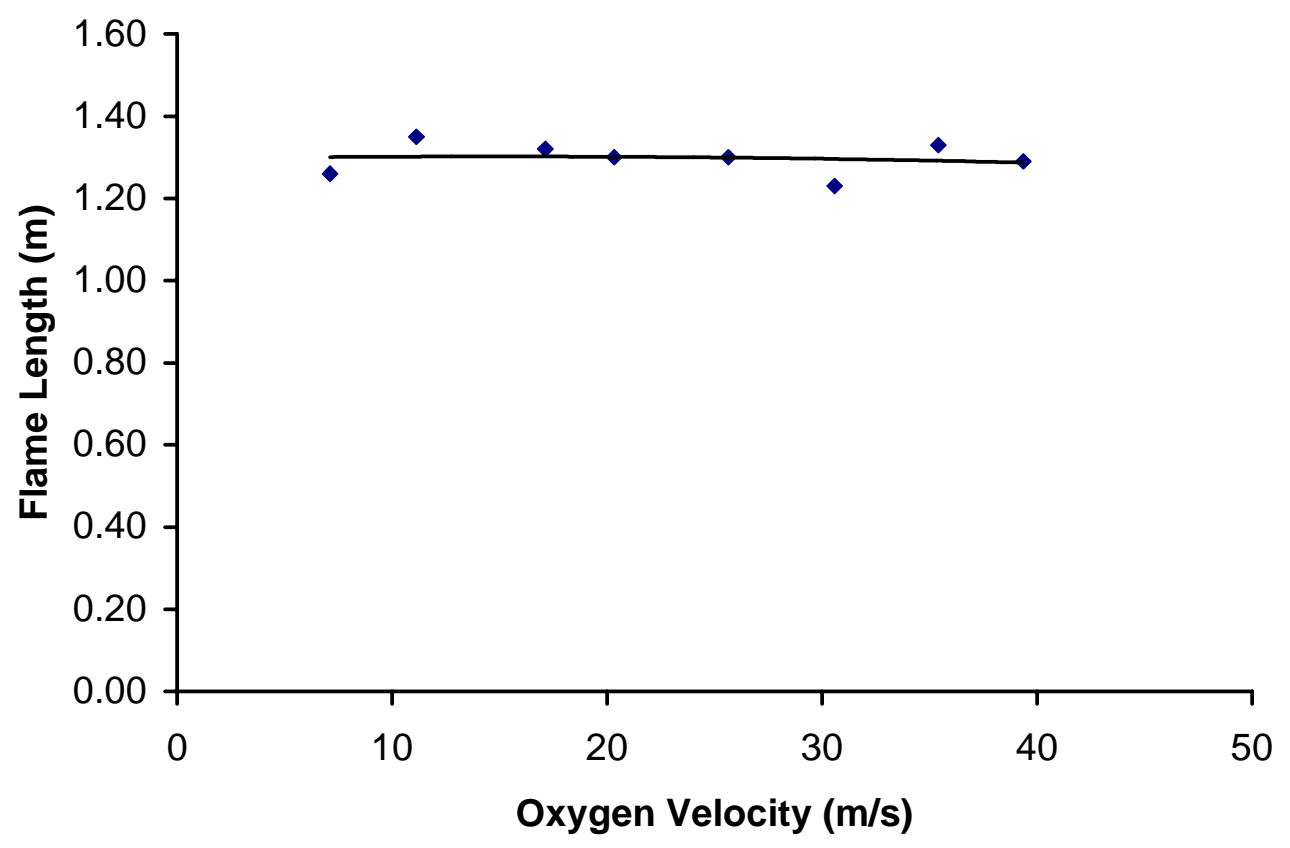

(a)

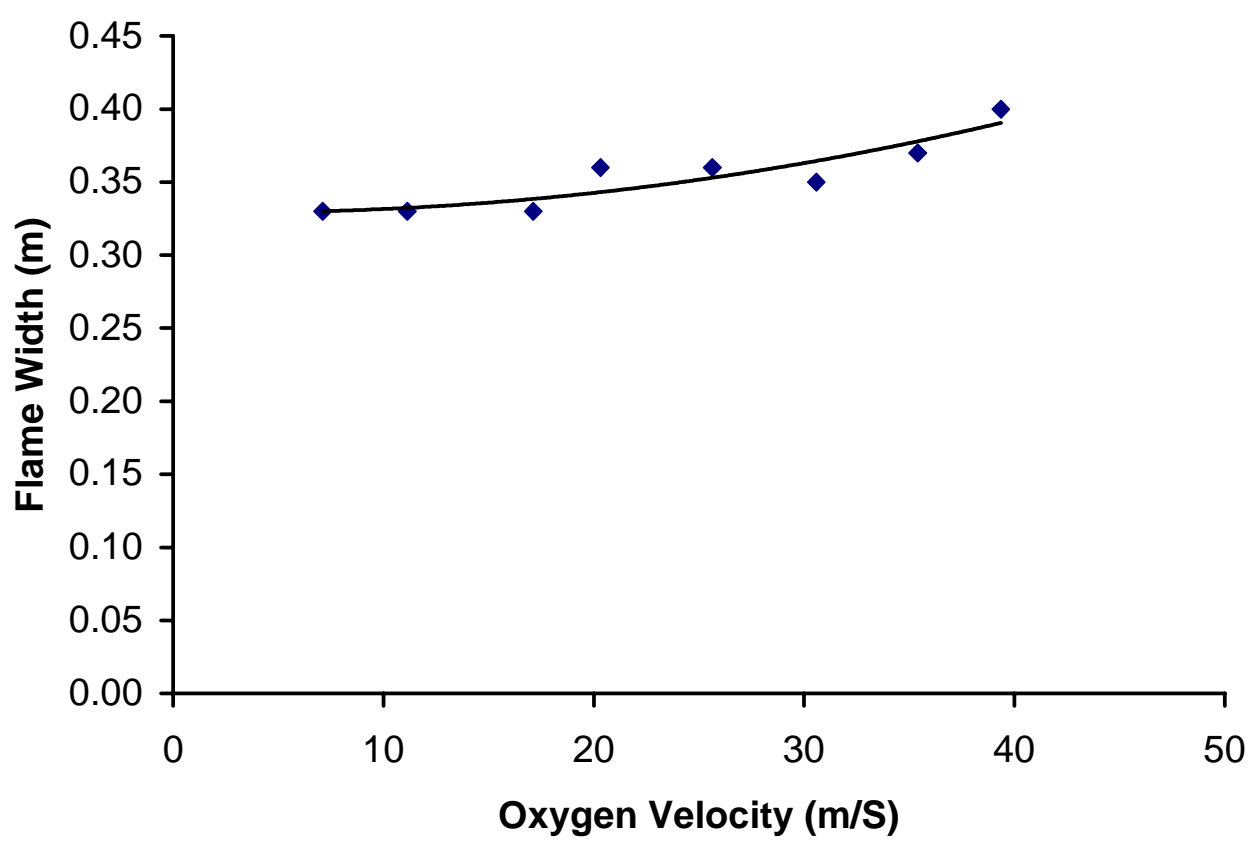

(b)

Figure 9.5 Flame length and flame width of a coaxial burner with $1 / 2$ inch fuel inlet 
$1 / 2$ in. burner, $V_{\text {fuel }}=36.6 \mathrm{~m} / \mathrm{s}$

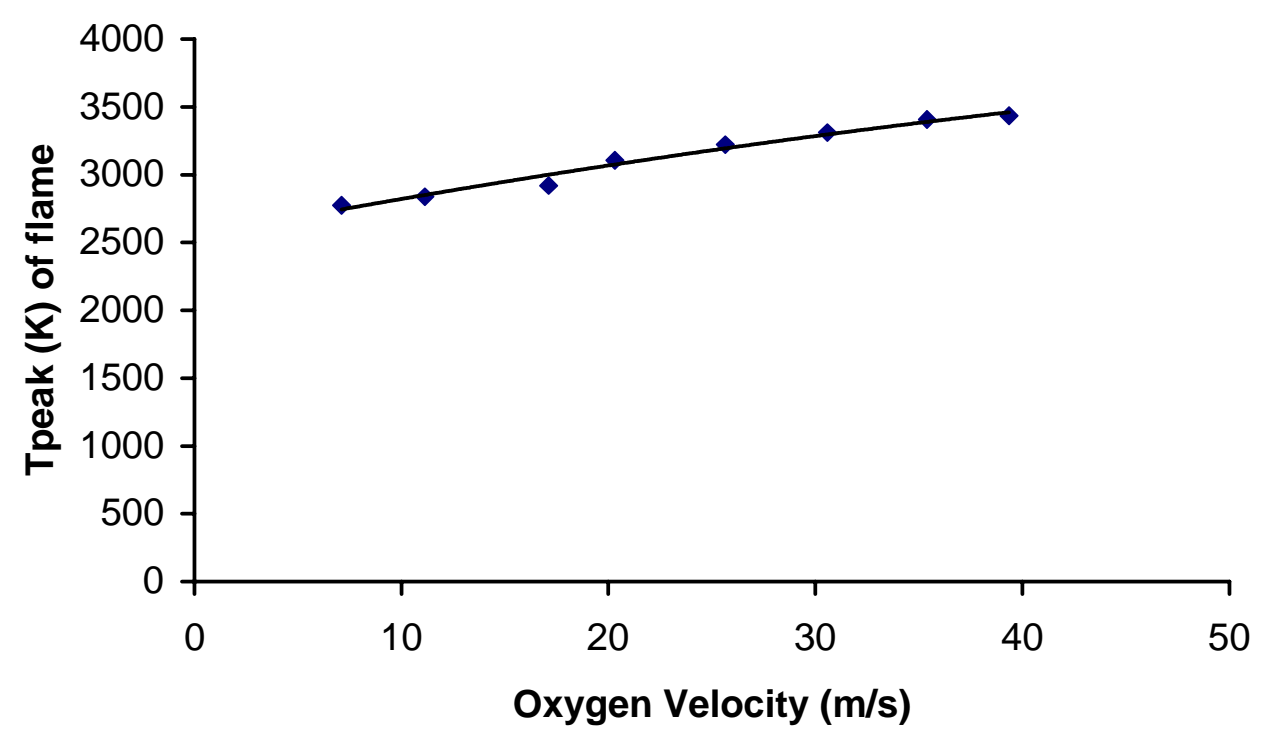

(a)

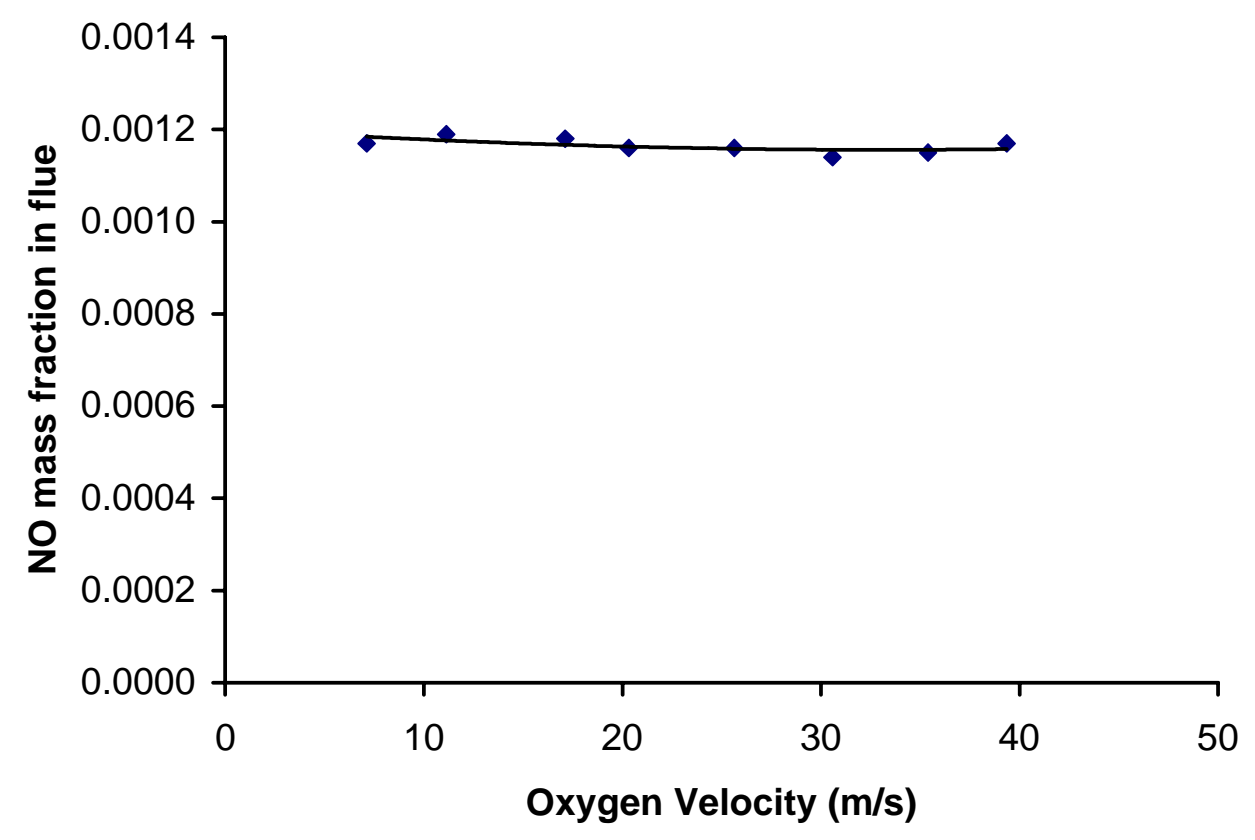

(b)

Figure 9.6 Peak temperature and $\mathrm{NO}_{\mathrm{x}}$ emission of a coaxial burner with $1 / 2$ inch fuel inlet 


\subsection{Coaxial Burner with a $3 / 4$ inch Fuel Inlet}

The natural gas inlet diameter was set as $3 / 4$ inch (or 0.0200 meter), for which the natural gas velocity is $15.0 \mathrm{~m} / \mathrm{s}$. Various velocities of oxygen were obtained by varying the outer oxygen inlet diameter. Table 9.4 lists these tube dimensions and corresponding velocities as well as the simulation results for these seven settings.

Table 9.4 Flame features of coaxial burners with a $3 / 4$ inch fuel inlet

\begin{tabular}{|c|c|c|c|c|c|c|c|c|}
\hline $\begin{array}{l}D_{\text {Fuel }} \\
(\mathrm{m})\end{array}$ & $\begin{array}{l}V_{\text {Fuel }} \\
(\mathrm{m} / \mathrm{s})\end{array}$ & $\begin{array}{l}\mathrm{D}_{\mathrm{O} 2} \\
(\mathrm{~m})\end{array}$ & $\begin{array}{c}V_{\mathrm{O} 2} \\
(\mathrm{~m} / \mathrm{s}) \\
\end{array}$ & $\begin{array}{c}\mathbf{V}_{\text {O22}} / \mathbf{V}_{\text {Fuel }} \\
\text { Ratio } \\
\end{array}$ & $\begin{array}{l}\text { Flame } \\
L(m)\end{array}$ & $\begin{array}{l}\text { Flame } \\
\text { W (m) }\end{array}$ & \begin{tabular}{|l|} 
Peak \\
$T(K)$ \\
\end{tabular} & $\begin{array}{l}\text { NO mass } \\
\text { fraction }\end{array}$ \\
\hline \multirow{8}{*}{$\begin{array}{l}0.0200 \\
\text { (fixed) }\end{array}$} & \multirow{8}{*}{$\begin{array}{c}15.0 \\
\text { (fixed) }\end{array}$} & 0.0320 & 20.20 & \begin{tabular}{|l|}
1.347 \\
\end{tabular} & 1.35 & 0.35 & 3097 & 0.00114 \\
\hline & & 0.0340 & 16.67 & 1.111 & 1.25 & 0.36 & 3044 & 0.00116 \\
\hline & & 0.0360 & 14.06 & 0.937 & 1.29 & 0.38 & 3015 & 0.00117 \\
\hline & & 0.0400 & 10.50 & 0.700 & 1.23 & 0.36 & 3017 & 0.00118 \\
\hline & & 0.0460 & 7.34 & 0.489 & 1.26 & 0.36 & 2757 & 0.00118 \\
\hline & & 0.0500 & 6.00 & 0.400 & 1.23 & 0.35 & 2574 & 0.00123 \\
\hline & & 0.0540 & 5.01 & 0.334 & 1.26 & 0.37 & 2504 & 0.00114 \\
\hline & & 0.0800 & 2.10 & 0.140 & 1.27 & 0.37 & 2459 & 0.00113 \\
\hline
\end{tabular}

D: diameter; V: velocity; L: length; W: width, T: temperature

Figures 9.7 and 9.8 are plotted using the data in Table 9.4. The two figures show various flame features as a function of oxygen velocity.

The $3 / 4$ inch fuel inlet introduces fuel into combustion chamber at a relatively low velocity, the results show that no matter at what velocity the oxygen is introduced into the combustion chamber, the flame have almost the same shape. This indicates that the fuel velocity is the dominant factor for the propagation of flame, oxygen velocity has less effect on flame size. However, the flame temperature increases with oxygen velocity, indicates that the oxygen velocity still strongly affect the mixing rate.

Although the peak temperature of the flame increases with oxygen velocity while the $\mathrm{NO}_{\mathrm{x}}$ emission level does not change with oxygen velocity very much. The reason is that the $\mathrm{NO}_{\mathrm{x}}$ emissions depend on both the flame temperature and the flame volume. 


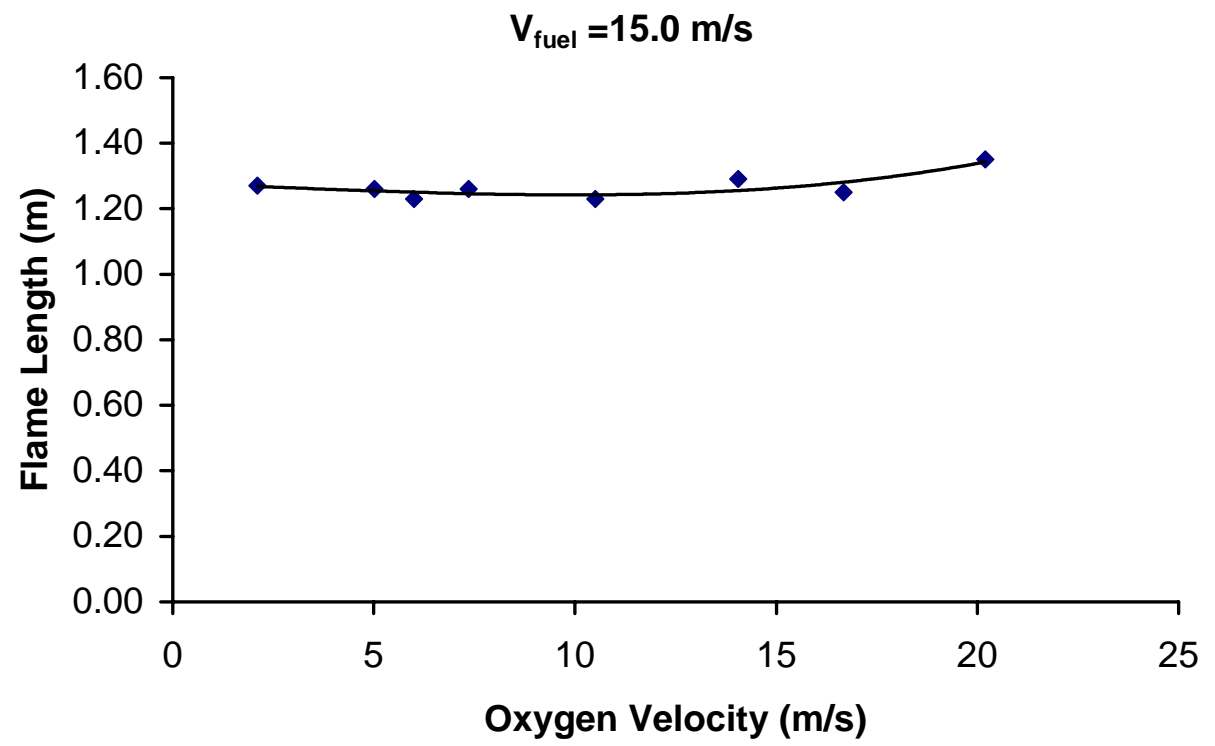

(a)

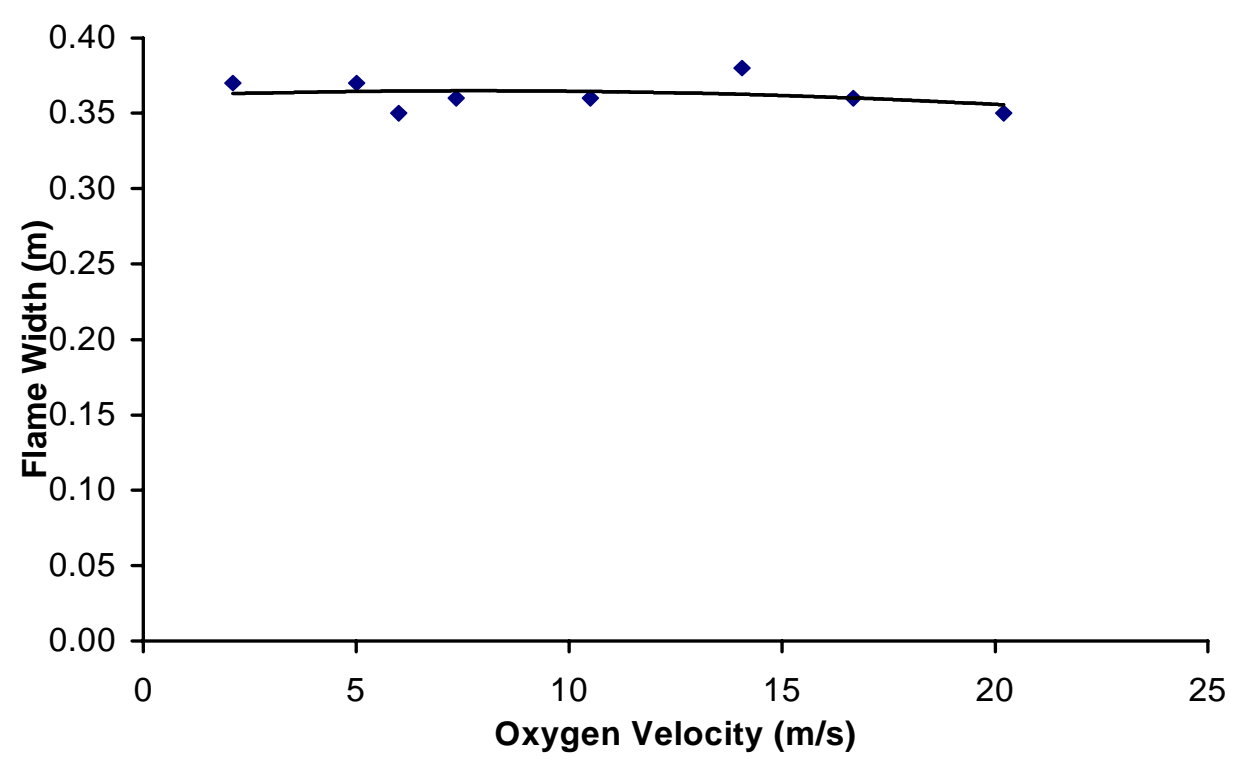

(b)

Figure 9.7 Flame length and flame width of a coaxial burner with $3 / 4$ inch fuel inlet 


$$
V_{\text {fuel }}=15.0 \mathrm{~m} / \mathrm{s}
$$

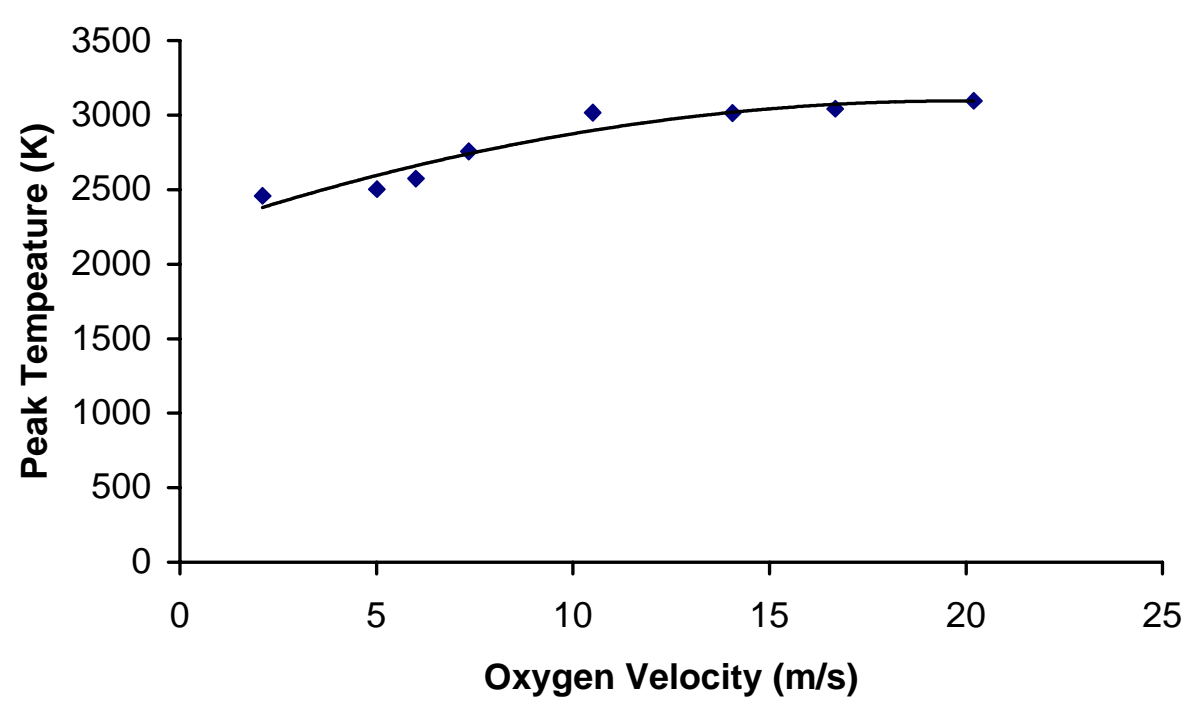

(a)

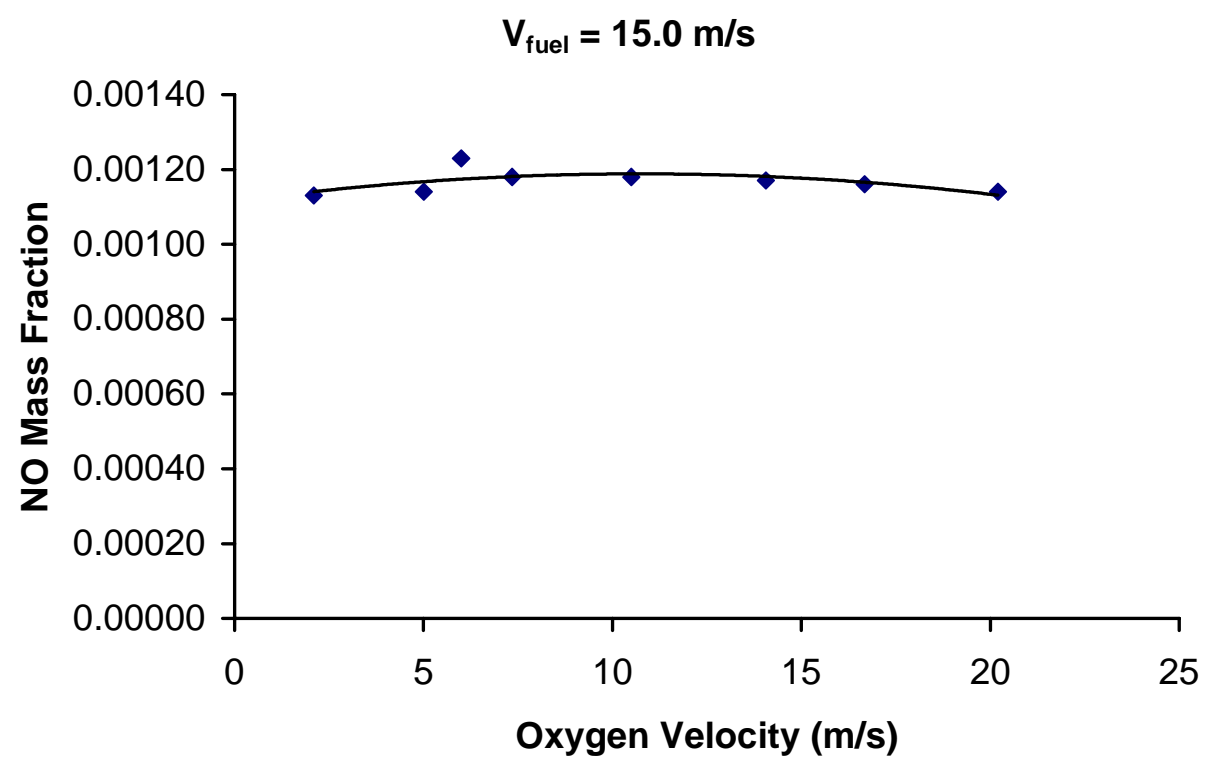

(b)

Figure 9.8 Peak temperature and $\mathrm{NO}_{\mathrm{x}}$ emission of a coaxial burner with $3 / 4$ inch fuel inlet 


\subsection{Coaxial Burner with a 1 inch Fuel Inlet}

The fuel inlet diameter was fixed at 1.0 inch (or $0.0256 \mathrm{~m}$ ), the fuel flow velocity is 9.16 $\mathrm{m} / \mathrm{s}$. The oxygen velocities depend on the oxygen inlet diameter; eight diameters were set and thus eight different oxygen velocities were generated. Table 9.5 lists the sizes of the fuel inlet and the oxygen inlets, and the corresponding simulation results.

Table 9.5 Flame features of coaxial burners with a 1 inch fuel inlet

\begin{tabular}{|c|c|c|c|c|c|c|c|c|}
\hline $\begin{array}{l}D_{\text {Fuel }} \\
(\mathrm{m})\end{array}$ & $\begin{array}{l}V_{\text {Fuel }} \\
(\mathrm{m} / \mathrm{s})\end{array}$ & $\begin{array}{l}\mathrm{D}_{\mathrm{O} 2} \\
(\mathrm{~m})\end{array}$ & $\begin{array}{c}V_{\mathrm{O} 2} \\
(\mathrm{~m} / \mathrm{s})\end{array}$ & $\begin{array}{c}\mathbf{V}_{\mathrm{O} 2} / \mathbf{V}_{\text {Fuel }} \\
\text { Ratio }\end{array}$ & \begin{tabular}{|c|}
$\begin{array}{c}\text { Flame } \\
\mathrm{L}(\mathrm{m})\end{array}$ \\
\end{tabular} & \begin{tabular}{|l|} 
Flame \\
W (m)
\end{tabular} & $\begin{array}{l}\text { Peak } \\
T(K)\end{array}$ & $\begin{array}{l}\text { NO mass } \\
\text { fraction }\end{array}$ \\
\hline \multirow{8}{*}{$\begin{array}{l}0.0256 \\
\text { (fixed) }\end{array}$} & \multirow{8}{*}{$\begin{array}{c}9.16 \\
\text { (fixed) }\end{array}$} & 0.0450 & 9.30 & 1.015 & 1.17 & 0.35 & 2927 & 0.00245 \\
\hline & & 0.0476 & 7.82 & 0.854 & 1.24 & 0.36 & 2980 & 0.00223 \\
\hline & & 0.0500 & 6.83 & 0.746 & 1.26 & 0.39 & 3022 & 0.00231 \\
\hline & & 0.0550 & 5.32 & 0.581 & 1.27 & 0.44 & 3029 & 0.00188 \\
\hline & & 0.0600 & 4.28 & 0.467 & 1.27 & 0.45 & 3022 & 0.00188 \\
\hline & & 0.0700 & 2.97 & 0.324 & 1.31 & 0.47 & 2982 & 0.00174 \\
\hline & & 0.0800 & 2.19 & 0.239 & 1.27 & 0.49 & 2942 & 0.00144 \\
\hline & & 0.1100 & 1.08 & 0.118 & 1.28 & 0.60 & 2845 & 0.00132 \\
\hline
\end{tabular}

D: diameter; V: velocity; L: length; W: width, T: temperature

Figures 9.9 and 9.10 show the flame length, the flame width, and the peak temperature of the flame as well as the $\mathrm{NO}_{\mathrm{x}}$ emission level for the coaxial burner with a $3 / 4$ inch fuel inlet as a function of oxygen velocity.

Figure 9.9 shows that the flame length changes with oxygen velocities slightly; the range of the flame length is between 1.10 meters to 1.30 meters. The oxygen flow velocity has a stronger effect on flame width. Generally, when 1-inch burner is selected for a batch tank, lower oxygen velocity, for example, 50\% less than fuel velocity, will yield a good flame shape.

The peak temperature of the flame decreases with the increasing oxygen velocities. The higher the oxygen velocity, the lower the peak temperature of the flame. This observation provides a principle to manipulate flame temperature according to the application requirements, e.g., to reduce the flame radiation to crown.

But the $\mathrm{NO}_{\mathrm{x}}$ emissions increase with the increasing oxygen velocities is significant, regardless of the decreasing peak temperature. 


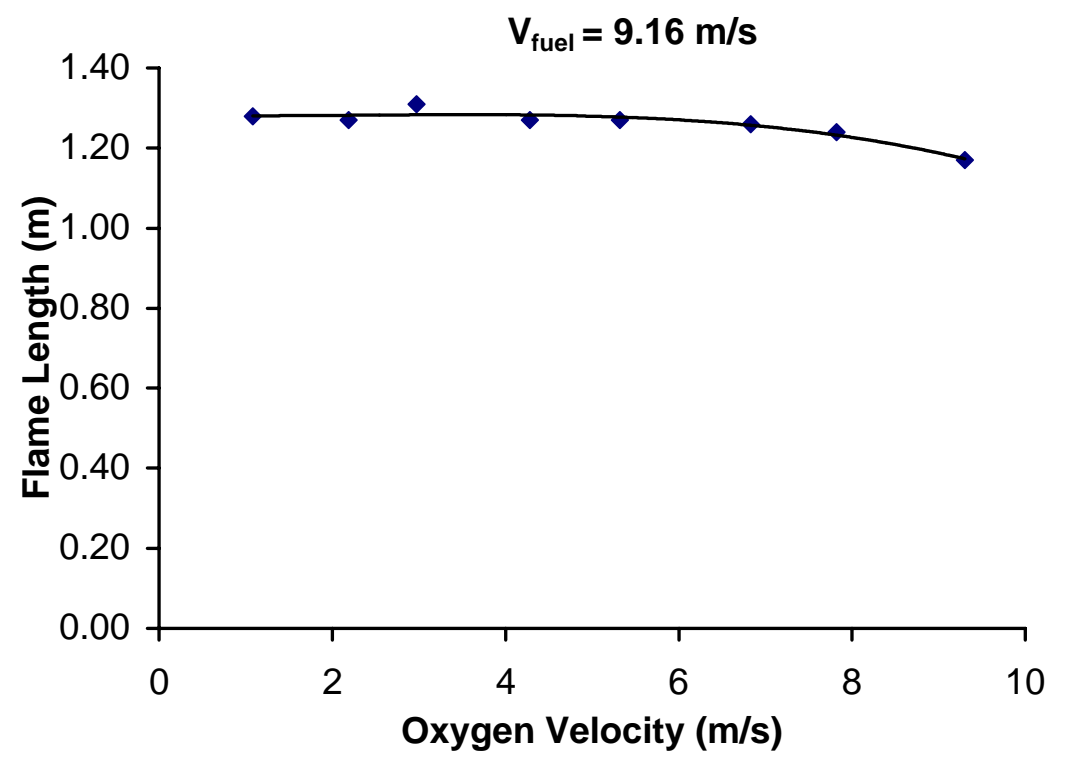

(a)

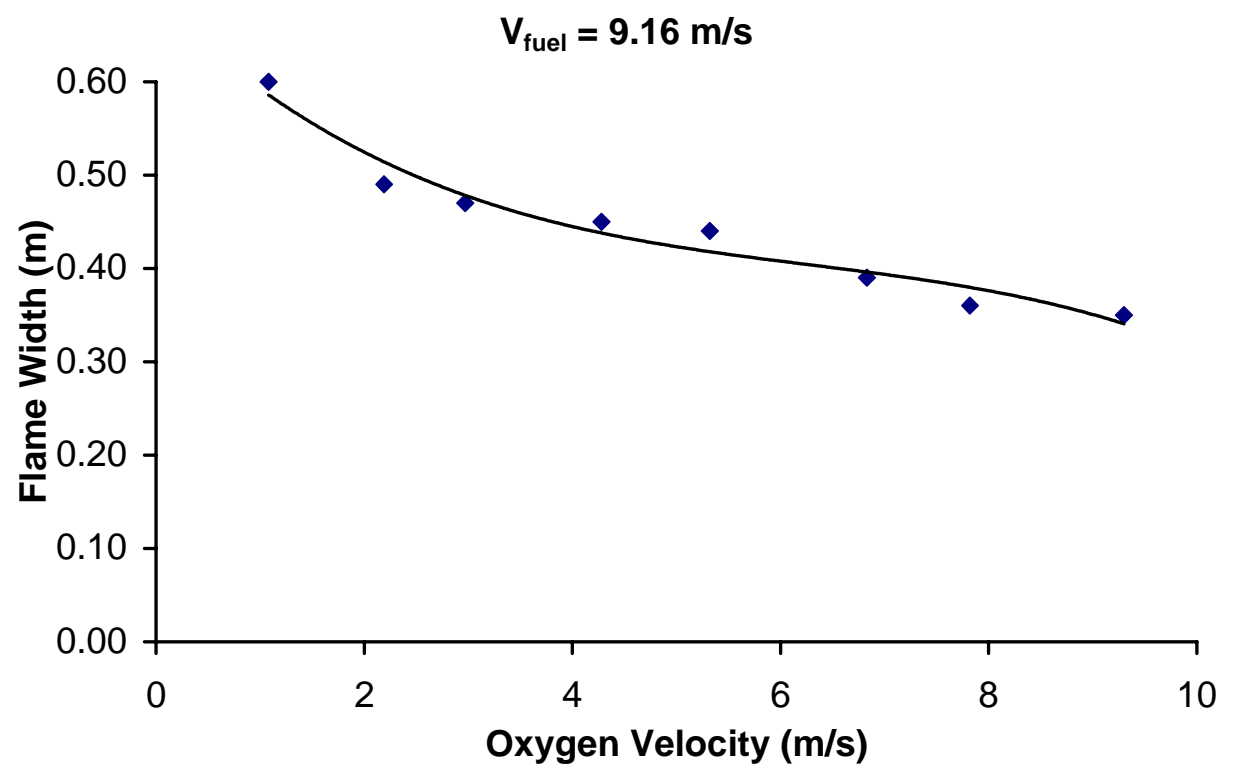

(b)

Figure 9.9 Flame length and flame width of a coaxial burner with 1 inch fuel inlet 


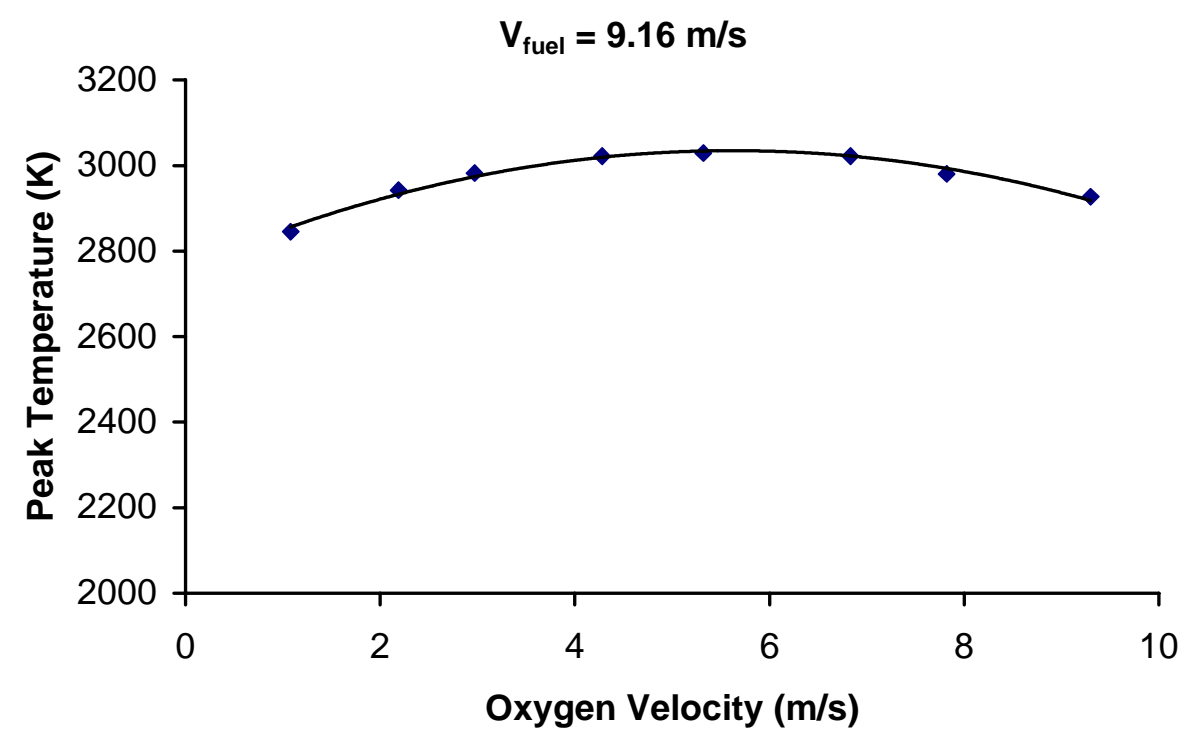

(a)

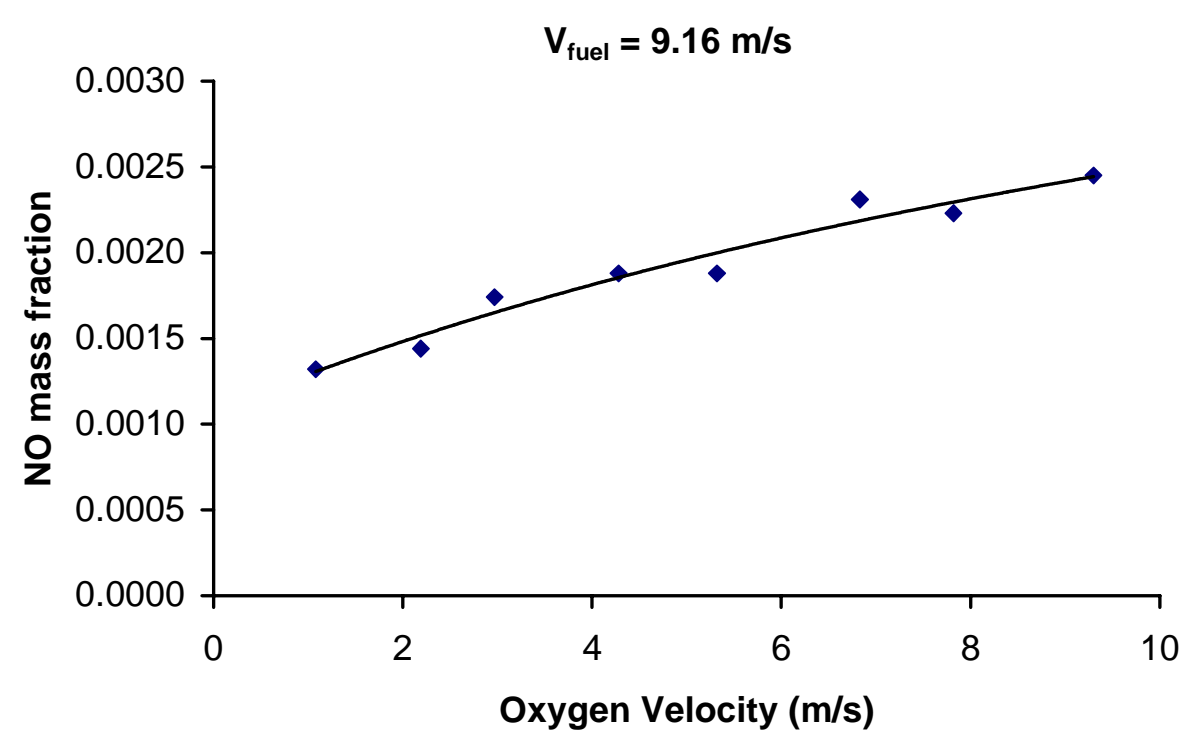

(b)

Figure 9.10 Peak temperature and $\mathrm{NO}_{\mathrm{x}}$ emission of a coaxial burner with 1 inch fuel inlet 
Considering the flame length, the flame width, the flame temperature and $\mathrm{NO}_{\mathrm{x}}$ emissions, oxygen velocity in the range of $4.0 \mathrm{~m} / \mathrm{s}$ to $5.0 \mathrm{~m} / \mathrm{s}$ will match the fuel velocity of $9.16 \mathrm{~m} / \mathrm{s}$. Figure 9.11 shows the flame shape from such a coaxial burner with a 1 inch fuel inlet.
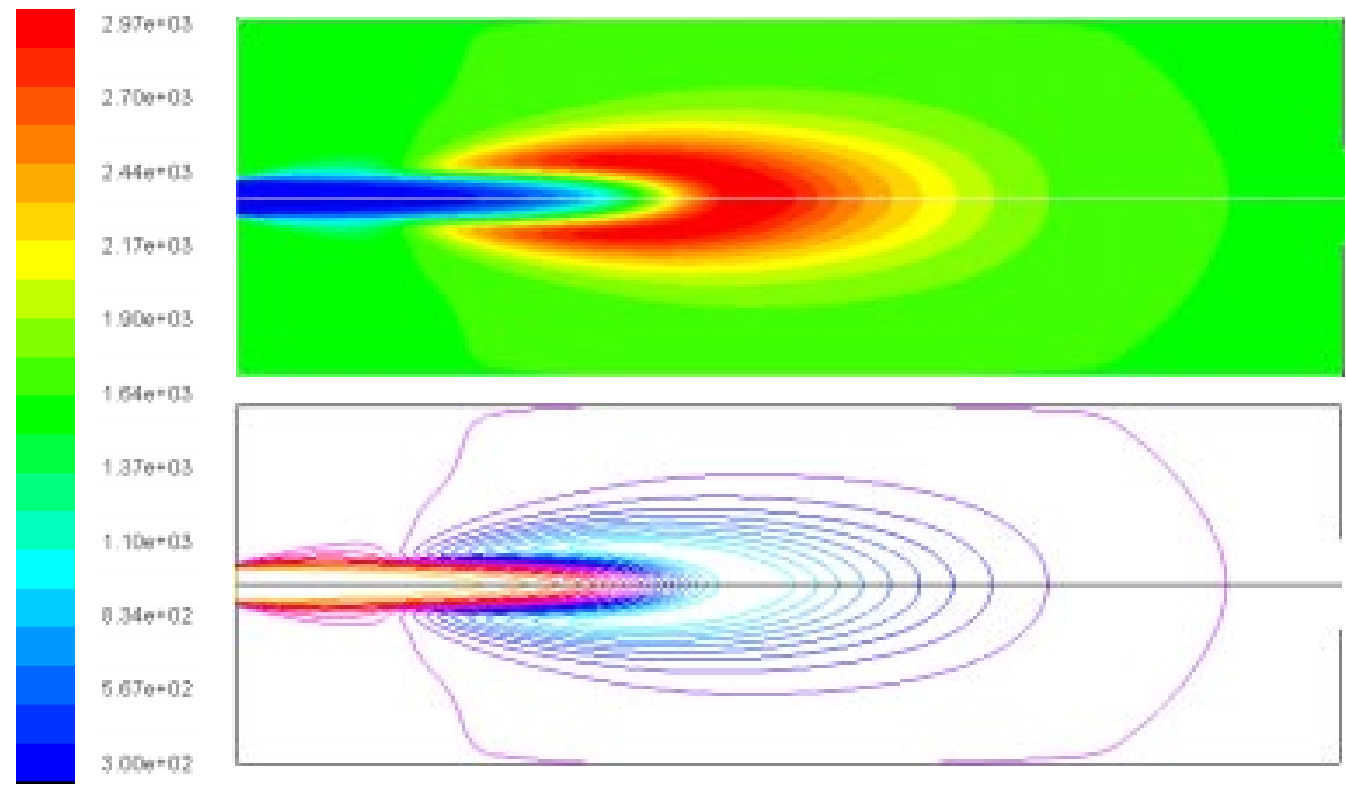

Figure 9.11 Flame shape of a coaxial burner with 1 inch fuel inlet, $V_{\text {oxygen }}=4.2 \mathrm{~m} / \mathrm{s}$

\subsection{Comparison and Summary}

The four different fuel inlet sizes discussed in the previous sections can be compared each other to find the general trends of the fuel velocity effects on flame features. Figure 9.12 is a comparison of the flame profile among all the four fuel inlet sizes. Figure 9.13 is a comparison of wall temperature distributions on the side wall of the cylindrical combustor. Six conclusions can be summarized from such comparisons.

First, the higher fuel velocity tends to yield higher flame peak temperature. When the fuel velocity is $146.5 \mathrm{~m} / \mathrm{s}$, the peak temperature of the flame can be over $3600 \mathrm{~K}$, while a low fuel velocity of $9.2 \mathrm{~m} / \mathrm{s}$ yield a flame with peak temperature less than $3000 \mathrm{~K}$. The temperature difference due to fuel velocity difference is significant. The reason is that, the higher fuel velocity the bigger shear stress between the fuel flow and oxygen flow. The shear stress drives 
the mixing process to occur in a shorter time period, which creates a scenario close to premixed combustion.
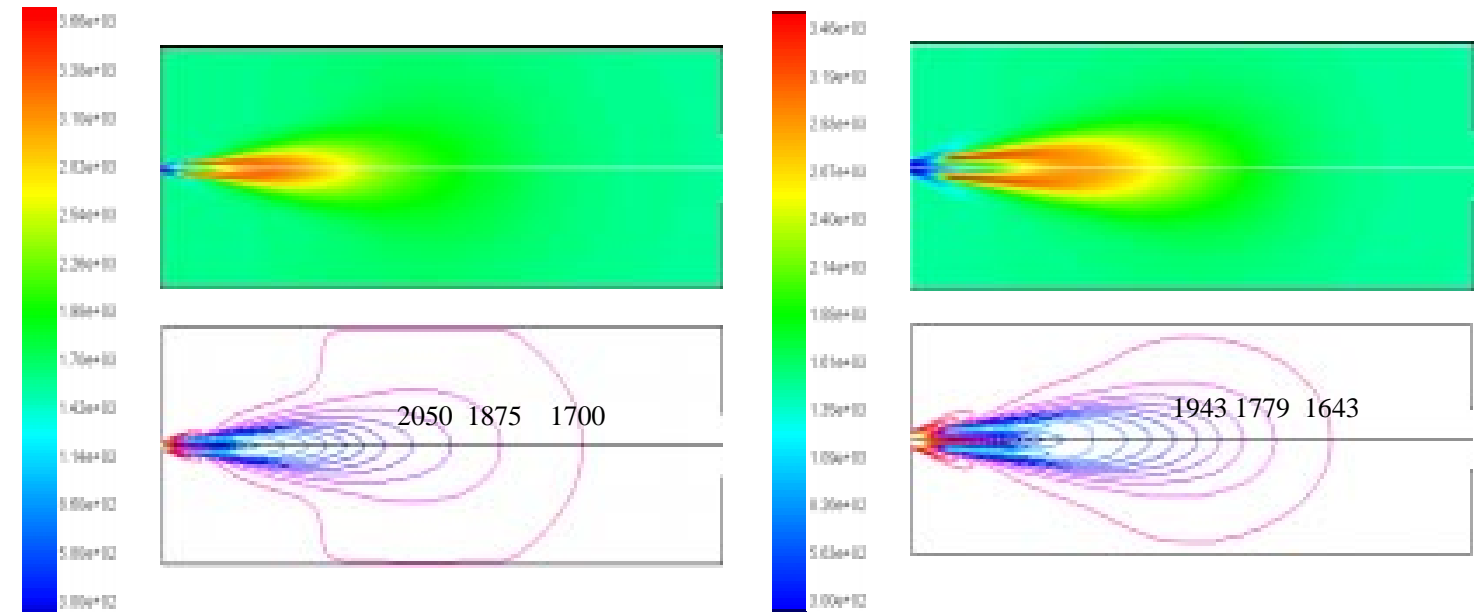

(a) $1 / 4$ inch fuel inlet

(b) $1 / 2$ inch fuel inlet
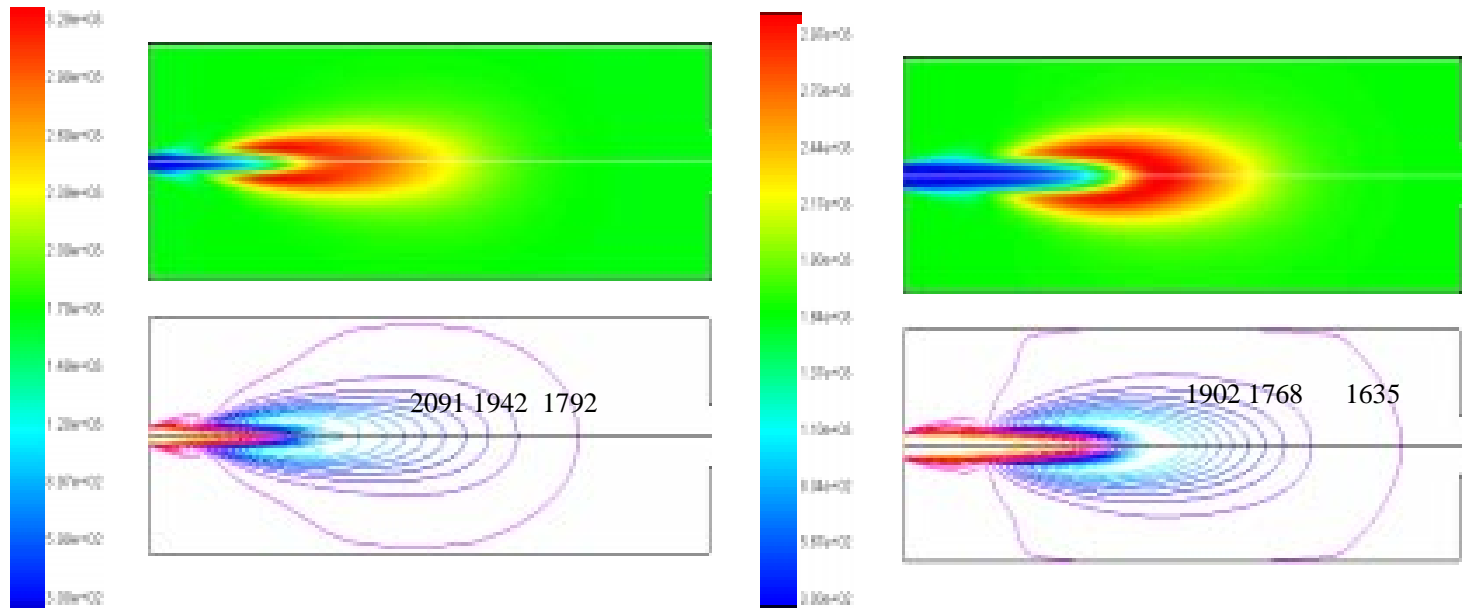

(c) $3 / 4$ inch fuel inlet

(d) 1 inch fuel inlet

Figure 9.12 Flame profile comparison among burners with $1 / 4,1 / 2,3 / 4$, and 1 inch fuel inlet

Second, the higher the fuel velocity, the smaller the flame size. This provides a flexibility of burner selection for batch tank operation. When a batch tank has very limited size, a smaller flame may serve better. When the melting capacity of a batch tank is over 2000 pounds, a coaxial burner with fuel inlet size of 1 inch is probably the choice. 


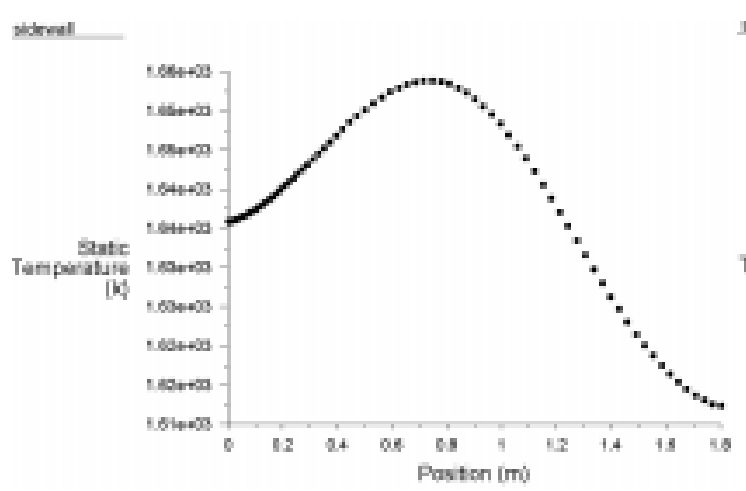

(a) $1 / 4$ inch fuel inlet

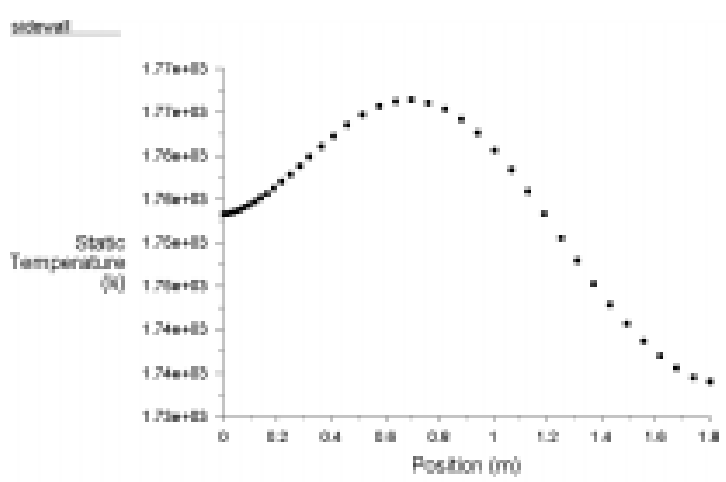

(c) $3 / 4$ inch fuel inlet

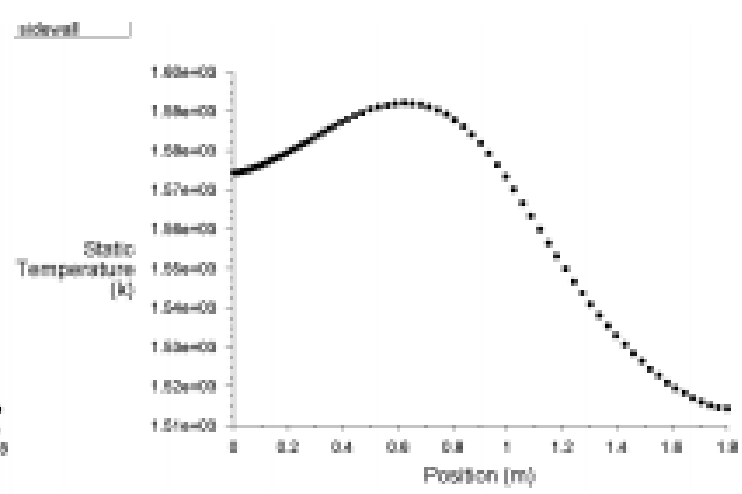

(b) $1 / 2$ inch fuel inlet

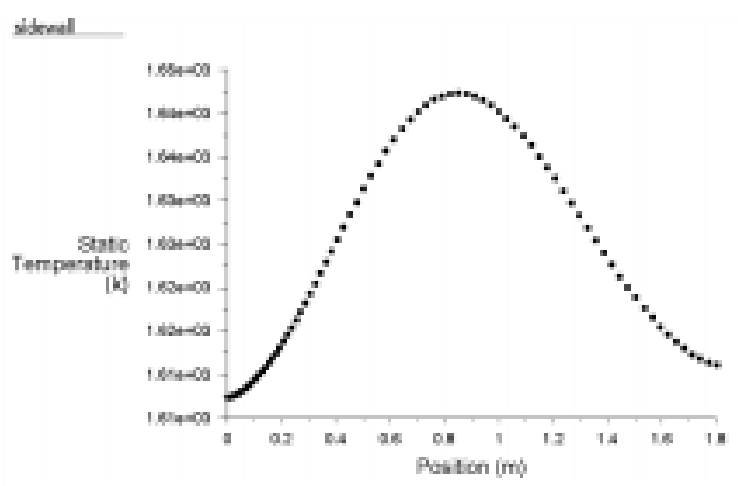

(d) 1 inch fuel inlet

Figure 9.13 Wall temperature distribution along axial direction

Third, the larger the fuel inlet size, the further the hot zone of the flame moves away from the burner tip. This feature makes the cooling of the burner more efficient, since the burner block is expected to be cooled by the inlet flows without additional cooling.

Fourth, the $\mathrm{NO}_{\mathrm{x}}$ emission levels from coaxial burners are almost all at the same level, although the emission levels does increases slightly with fuel velocity.

Fifth, for each of the four given fuel inlets and the corresponding fuel velocities, there is a range of oxygen velocities to match these given fuel velocities. Usually the oxygen velocity 
should be $50 \%$ less than the fuel velocity for good burner performance, e.g., lower flame temperature, larger flame size, and lower $\mathrm{NO}_{\mathrm{x}}$ emissions.

Sixth, the temperature on the side wall is non-uniform, both temperature of the hot spot and the position of the hot spot vary with fuel velocity as well as oxygen velocity.

Soot formation model has been used in coaxial burner behavior study. However, the model may not represent the real physics very well. The temperature prediction with soot formation and that without soot formation should be compared. A better soot formation model is expected to improve the prediction accuracy. 


\section{Chapter 10 Flat Flame Burners}

\subsection{Introduction to Flat Flame}

High flame temperature, lack of luminosity, and limited flame coverage are the primary disadvantages of the round flame produced by a coaxial burner. A round flame usually results in less heat transfer to the batch material or glass melt, as well as overheating of the glass surface and the superstructure refractory. To enhance heat transfer to the glass while avoiding overheating of the superstructure refractory, the following three flame features should be specified. First, increase the flame coverage over the glass; second, manipulate the mixing of the fuel and oxygen to form a certain amount of soot so as to increase the luminosity of the flame, which will reduce the peak temperature and enhance heat transfer via soot radiation; third, adjust the direction of fuel and oxygen flow at the inlet to abate the effect of buoyancy when buoyancy is important. A flat flame does have these three required features and thus has been used in some

continuous furnaces. As described in Chapter 2, BOC's introduced Flat Jet ${ }^{\mathrm{TM}}$ burner to glass industry in 1993 [23]. Today, flat flame has been used in some continuous furnaces, but rarely used in batch tanks.

\subsection{Inlet Arrangement}

To form a flat flame, fuel and oxygen inlets are alternatively arranged in narrow orifices. This results in a horizontally wider but vertically thinner flame. Figure 10.1 illustrates a simple example of an alternately arranged alignment of two fuel inlets and three oxygen inlets. The central inlet and the far outside inlet on both sides are oxygen inlets; the other two inlets are fuel inlets. The mixing of fuel and oxygen is delayed due to the structure of the separated fuel and 
oxygen inlets. Therefore, the flame is expected to have higher luminosity due to soot formation in the combustion process.

There are two primary concerns related to the application of a flat flame for a batch tank. One concern is that the flame width may be over-sized, and thus cause side wall refractory corrosion. The other concern is that the very low momentum of the flat flame burner may result in the buoyancy force playing an important role in flame deformation — the buoyancy force drives the flame toward the crown.

In this research, two efforts are made for flat flame application in batch tanks. The first effort is to better understand the necessary inlet flow features for achieving a flat flame formation. The second effort is to study the buoyancy issue based on a better understanding of the aerodynamics of the fuel and oxygen flows.

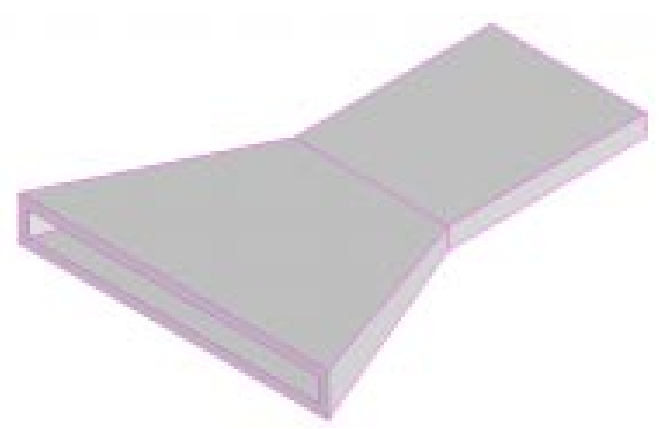

(a) Flat flame burner inlet and block

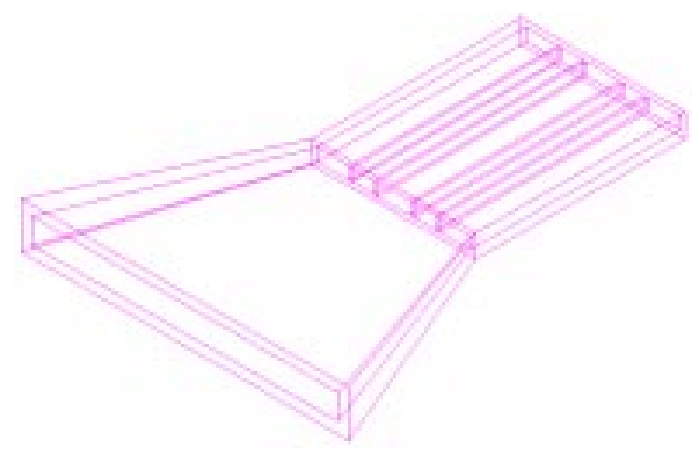

(c) 3-D prospective view

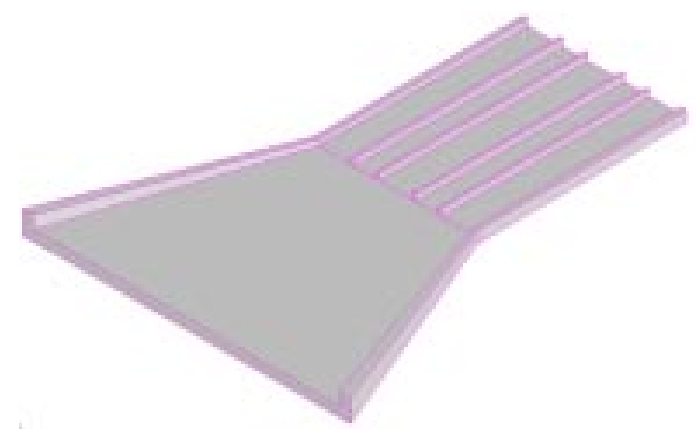

(b) inlet structure (cut view)

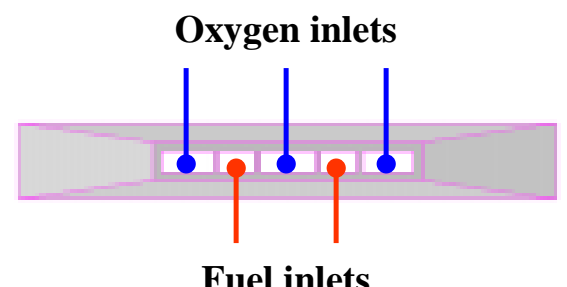

(d) Fuel-oxygen inlet arrangement

Figure 10.1 Fuel and oxygen inlets of a flat flame burner 


\subsection{Flat Flame Profile}

In a flat flame burner design, the fuel and oxygen inlets are aligned alternately to create alternative fuel rich and fuel lean regions. This kind of inlet arrangement has advantages over coaxial burners in flame temperature and flame shape control, as well as soot formation enhancement. One of the prerequisites is that the flows of fuel and oxygen are with low turbulence, otherwise the burner flame will propagate too much in the vertical direction. Based on the simulation results of coaxial burners presented in Chapter 9, the upper limit of the flow velocities of the fuel and the oxygen is set at $10 \mathrm{~m} / \mathrm{s}$. The disadvantage of flat flame is that the flame is formed at low fuel and oxygen velocities, in which buoyancy plays a role in the propagation of the flame. The buoyancy tends to drive the flame upward to the crown of the batch tank; thus, the magnitude and direction of fuel and oxygen inlet velocities, and the tank crown height are design parameters in addition to the inlet dimension and structure.

Three-dimensional simulations were conducted to investigate the flat flame burner behavior. The burner was installed in a batch tank with a capacity of 2500 pounds. Figure 10.2 shows the temperature distribution in the batch tank with a fuel velocity of $10.7 \mathrm{~m} / \mathrm{s}$, and Figure 10.3 shows the corresponding hot zone profile of the flat flame, which has a length of 1.21 meters, a width of 0.53 meters and a thickness of 0.24 meters.

One of the most significant features of the flat flame is that its peak flame temperature is in the range of $2300 \sim 2500 \mathrm{~K}$, which is much lower than the peak flame temperature of its counterpart coaxial burner.

When the fuel and oxygen velocities are set at around $10 \mathrm{~m} / \mathrm{s}$, buoyancy has no significant effect on the flame propagation. The flame length, width, and thickness can be tuned by burner inlet design. 


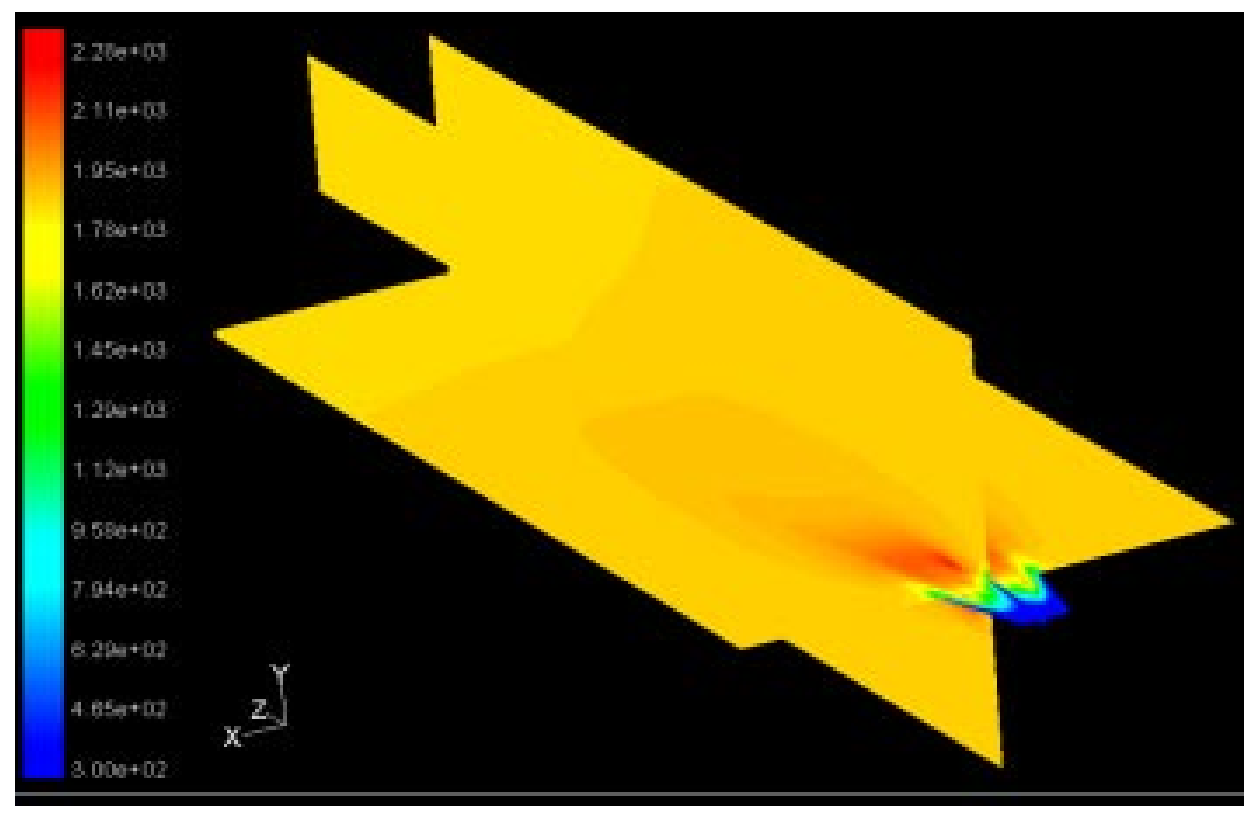

Figure 10.2 Temperature contour on two orthogonal planes

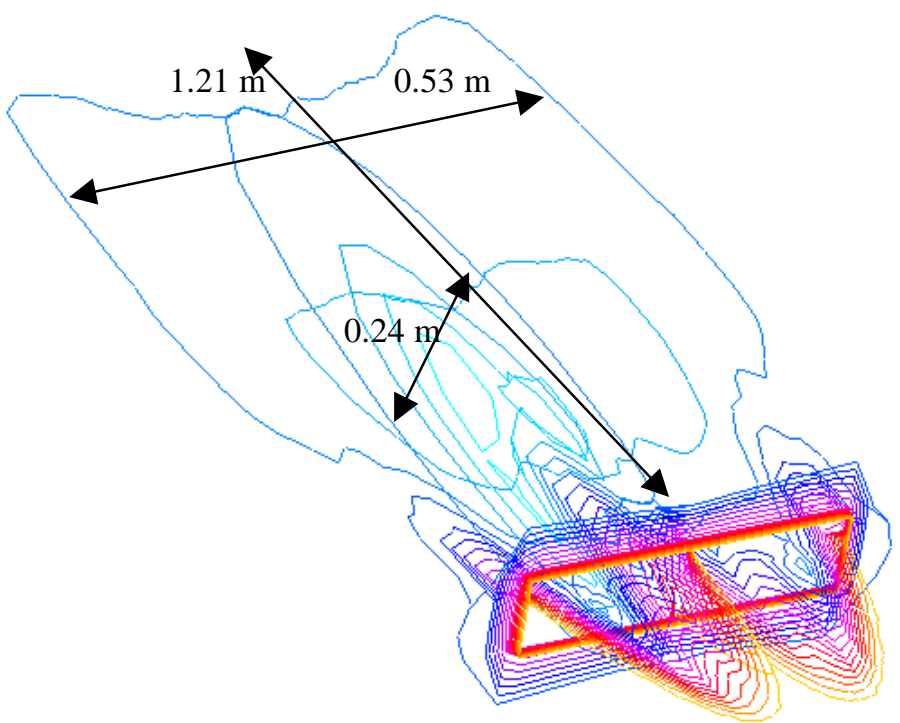

Figure 10.3 Hot zone profile of flat flame 


\subsection{Flat Flame Shape Manipulation}

The flat flame temperature is much lower than that of a coaxial burner flame. The flame temperature is around $2400 \mathrm{~K}$, which does not need further control. Instead, flame shape is of most concern in design. Lower fuel and oxygen velocities tend to form longer and wider flames, but buoyancy may be significant when the flow velocities of the fuel and the oxygen are low. The flame length, width, and thickness can be iteratively optimized through simulations.

For example, to form a longer and wider flame, and meanwhile to figure out if the flame propagation is sensitive to buoyancy, a low flow velocity of $5.0 \mathrm{~m} / \mathrm{s}$ was set. Figures 10.4 to 10.6 show the temperature distribution inside a batch tank with such a flat flame burner.

Figure 10.4 shows that the flame is long and wide, and the length is almost perfect for a 2500-lb tank. Figure 10.5 shows the temperature contours on a series of slices parallel to the end walls. The flame is long and wide and does not impinge on the side walls, nor on the crown or the glass surface. Figure 10.6 shows that the buoyancy does drive the flame upward toward the crown, but the flame does not reach the crown.

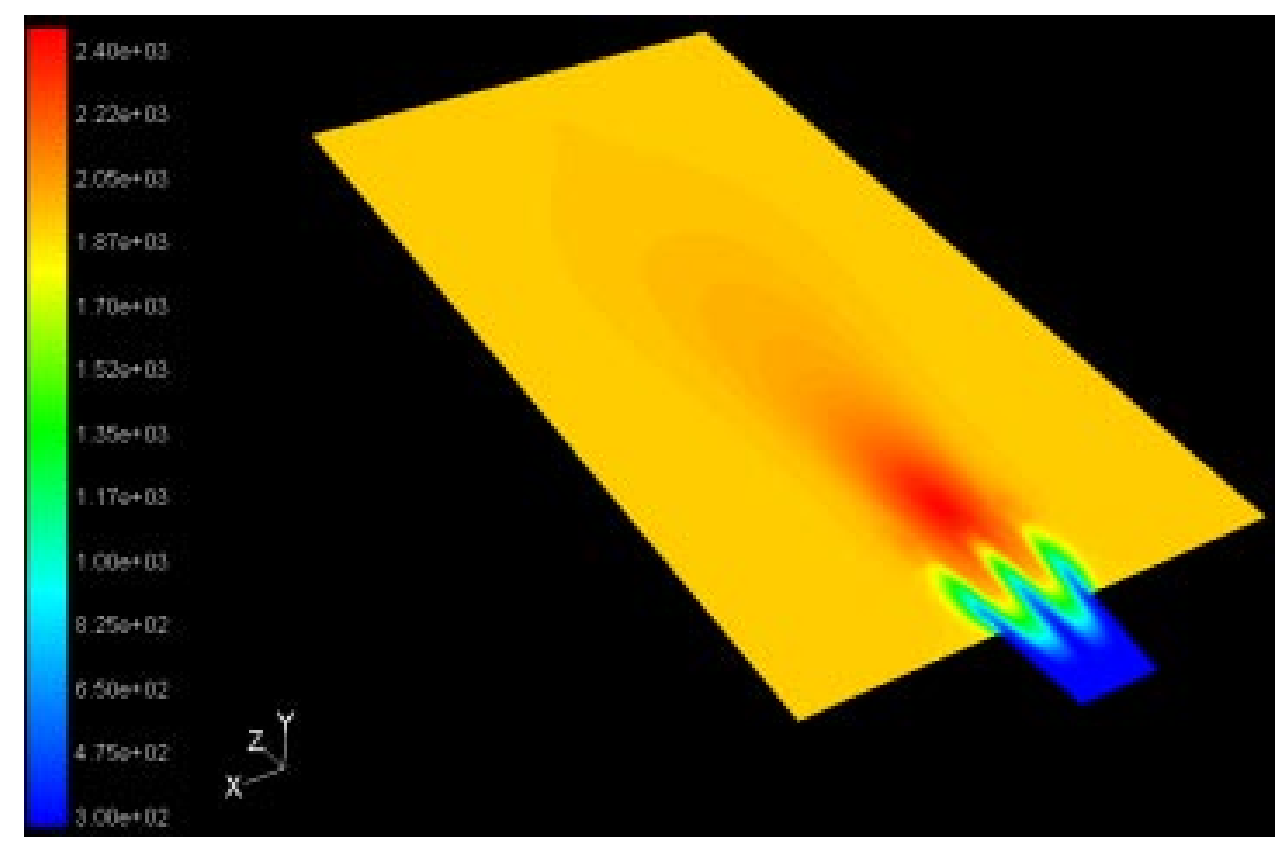

Figure 10.4 Flat flame temperature contour in tank, $V_{\text {fuel }}=5.0 \mathrm{~m} / \mathrm{s}$ 


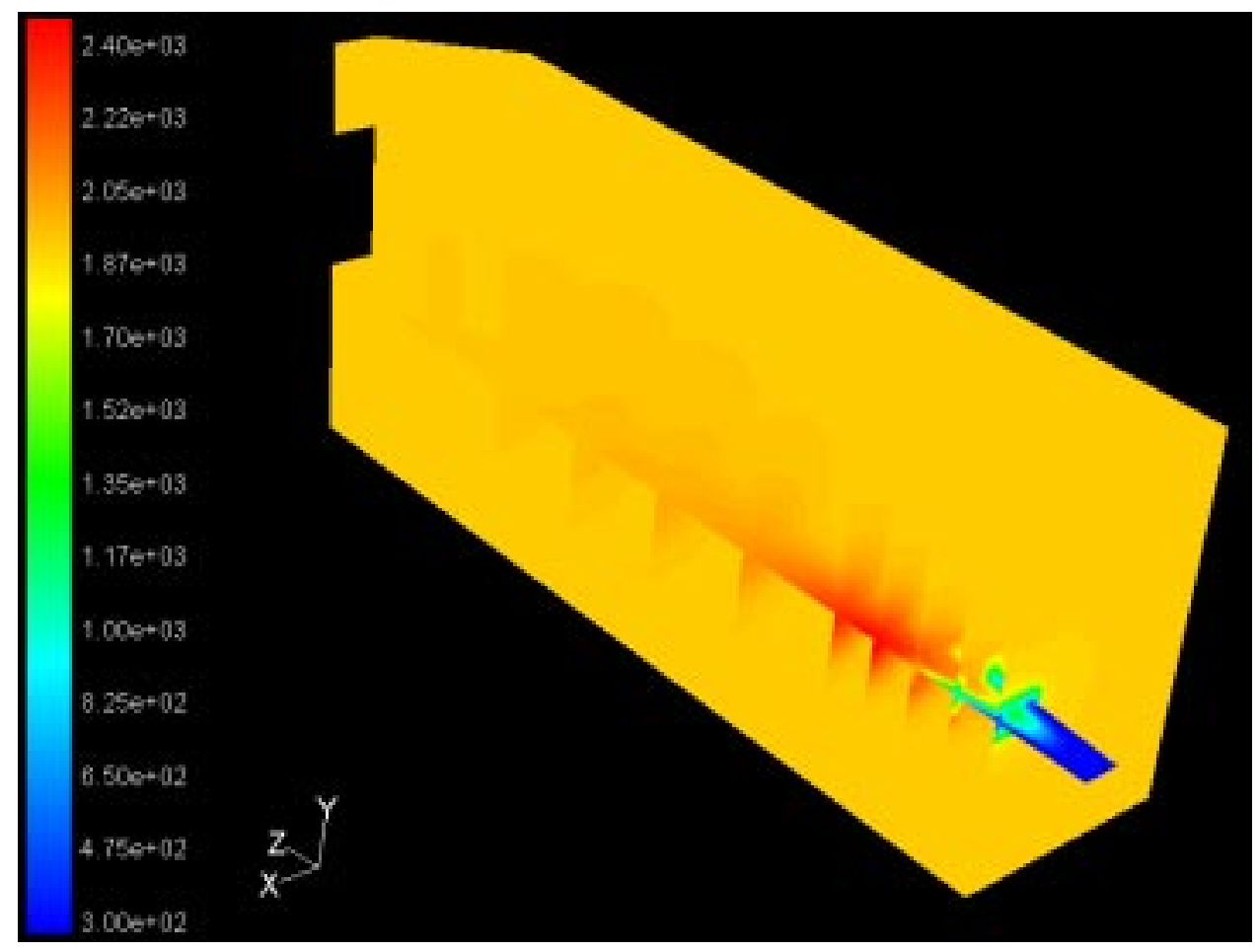

Figure 10.5 Flat flame profile and temperature distribution in tank, $V_{\text {fuel }}=5.0 \mathrm{~m} / \mathrm{s}$

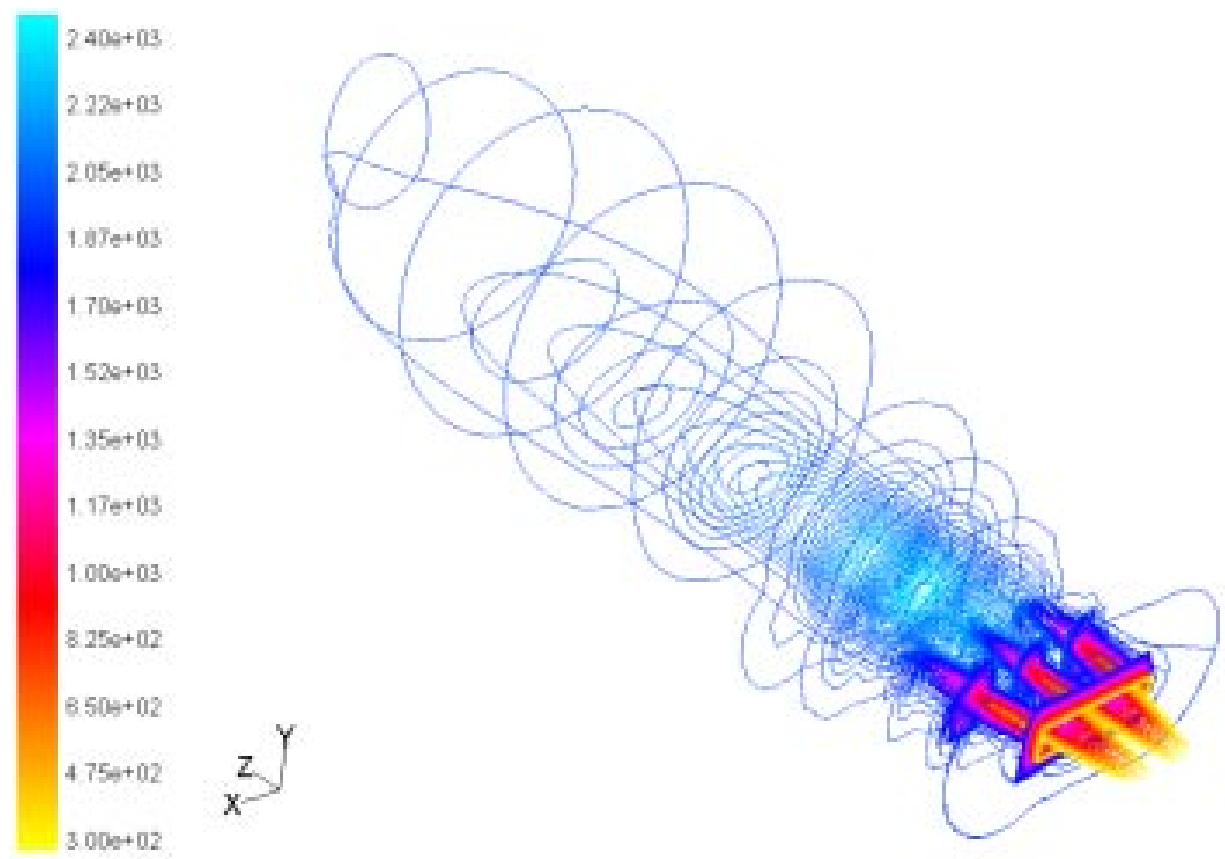

Figure 10.6 Temperature distribution in tank, $\mathrm{V}_{\text {fuel }}=5.0 \mathrm{~m} / \mathrm{s}$ 


\section{Chapter 11 Burner Placement and Batch Tank Design}

\subsection{Introduction}

The investigation on burner and flame profiles presented in Chapters 8, 9, and 10 provide a basic understanding and a guide for burner selection for a specific batch tank. The following six step procedure is recommended for the design of a batch tank, including its burner selection and placement.

First, calculate the melting area for the batch tank. This calculation is based on the melting capacity required for a specific glass production.

Second, select the length and width for the batch tank. Usually the length/width ratio is dependent on the available space in the shop. Increasing this ratio will mean more refractory materials are required to build the tank and a correspondingly larger heat loss through the tank walls. However, a larger length/width ratio will extend the tank life expectancy and the resident time of the oxy/fuel in the tank. Therefore, if there are no floor space restrictions, then the length/width ratio can be tentatively set at around 1.5 .

Third, determine the energy requirement for the batch tank.

Fourth, select the number of burners according the melting capacity. If the melting capacity is less than 2000 pounds, then a single coaxial burner is recommended; if the melting capacity is more than 2000 pounds but less than 4000 pounds, either coaxial burner or flat flame burner is recommended. For batch tanks with capacity beyond 4000 pounds, flat flame burners are preferred.

Fifth, simulate the firing with the settings and selections in previous four steps using CFD tools. This simulation will settle any concern on (1) burner type, number, placement; (2) batch tank geometry; and (3) temperature distribution and recirculation in the batch tank. 
Sixth, finalize the batch tank design by iterative adjustments and simulations.

\subsection{Burner Placement and Tank Design Aspects}

Figure 11.1 shows the design of a batch tank as well as the positions for two burners placements in this tank. The tank length $\mathrm{L}$, width $\mathrm{W}$, and its superstructure height $\mathrm{H}$ are tentatively designed by empirical data based on the understanding gained from air-fuel firing. These three parameters will be later adjusted by the simulation results.
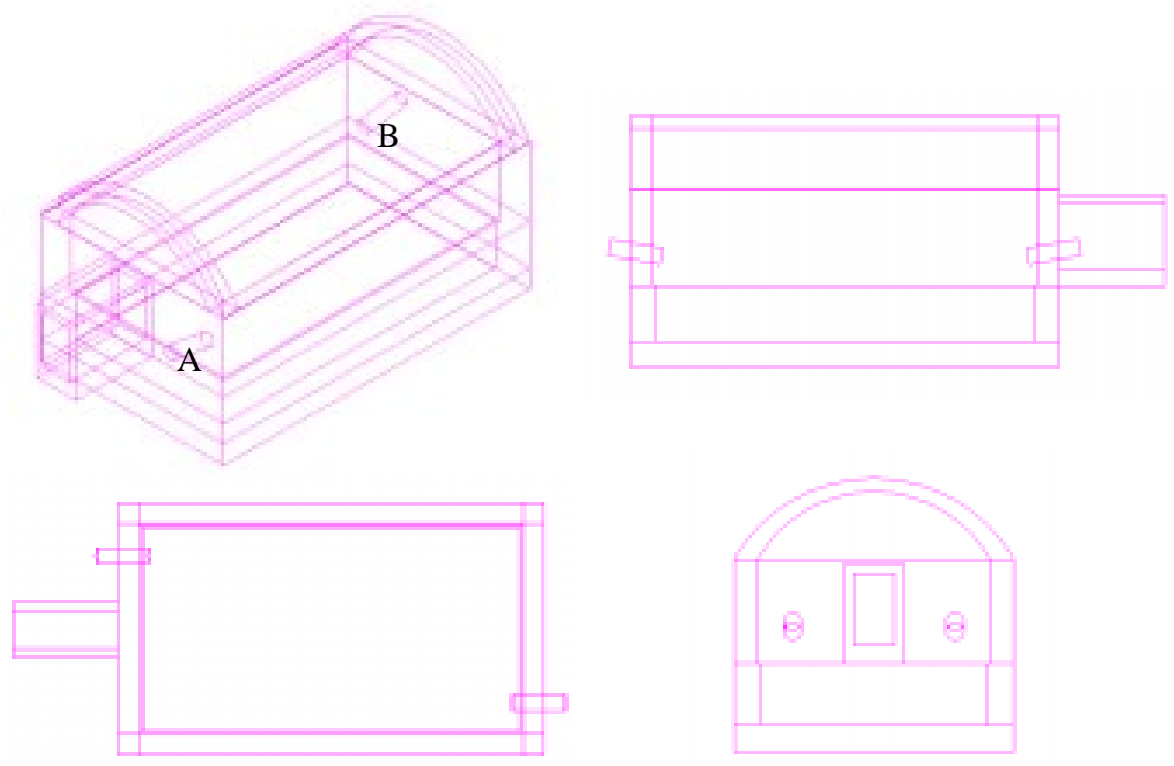

Figure 11.1 Schematic of burner placement in a batch tank

Because most small and medium size batch tanks are less than 6 feet wide, the burner (no matter what type) is recommended to be installed in either end and not in the two side walls. For a single burner, position A or B is optional but Position A is recommended; for two burners, position A and position B are the option. The vertical distance above glass surface $h_{1}$ and the vertical distance below the crown $\mathrm{h}_{2}$ of positions $\mathrm{A}$ and/or $\mathrm{B}$ are design parameters. The burner will be directed vertically downward to glass surface a few degrees if the fuel velocity is low. 
This angle $\alpha$ is a design parameter. The burner will also be directed a few degrees horizontally toward the center of the tank to avoid overheating the nearby side wall. This angle $\beta$ is another design parameter.

These four batch tank design parameters, $\mathrm{h}_{1}, \mathrm{~h}_{2}, \alpha$ and $\beta$, as well as the batch tank length L, width $\mathrm{W}$, superstructure height $\mathrm{H}$, will be determined and optimized by simulation.

\subsection{Simulation for Burner Placement and Tank Design}

As an example of iterative design, a single coaxial burner with a $1 / 2$ inch fuel inlet is installed on the end wall of a batch tank. The length and width as well as the superstructure height of the tank are 1.80 meters, 1.20 meters, and 0.70 meters, respectively. The burner is 0.30 meters above the glass surface. The other burner and operating conditions are listed in Table 11.1.

Table 11.1 Parameters of burner and tank and operating condition

\begin{tabular}{|l|l|l|}
\hline \multicolumn{1}{|c|}{ Item } & \multicolumn{1}{c|}{ Information } & Description \\
\hline Melting capacity & 2500 pounds & $\mathrm{C}($ pound $)$ \\
\hline Energy requirement & 600 SCFH fuel & $\mathrm{Q}(\mathrm{SCFH})$ \\
\hline Tank length & 1.80 meters & $\mathrm{L}(\mathrm{m})$ \\
\hline Tank width & 1.20 meters & $\mathrm{W}(\mathrm{m})$ \\
\hline Superstructure height & 0.70 meters & $\mathrm{H}(\mathrm{m})$ \\
\hline Burner type & coaxial & \\
\hline Fuel inlet diameter & 0.0128 meters $(1 / 2$ inch $)$ & $\mathrm{D}_{\mathrm{F}}(\mathrm{m})$ \\
\hline Oxygen inlet diameter & 0.0 & $\mathrm{D}_{\mathrm{O}}(\mathrm{m})$ \\
\hline Burner position & 0.30 meters above glass & $\mathrm{h}_{1}(\mathrm{~m})$ \\
\hline Vertical angle & 0 & $\alpha($ degree $)$ \\
\hline Horizontal angle & $0,7.5,9.5,12,14,15$ & $\beta($ degree $)$ \\
\hline
\end{tabular}

It is found that when using coaxial burners with fuel inlet diameter less than 1 inch, and the burner is set 0.30 meters above the glass level, the vertical angle could be set as zero. Figure 11.2 shows that the vertical distance $\mathrm{h}_{1}$ is a little short and has caused overheating on glass surface. When this distance is increased to 0.40 meters (16 inches), the overheating disappeared. 
In a glass melting batch tank, tank operation engineers observed premature failures of refractory on refractory wall which is on the burner side. This phenomenon is due to the parallel burner alignment. To solve this problem, the burner needs to be directed a certain angle toward center of the tank, but the value of the angle needs to be determined. Three-dimensional simulations are used to identify the proper angle value.
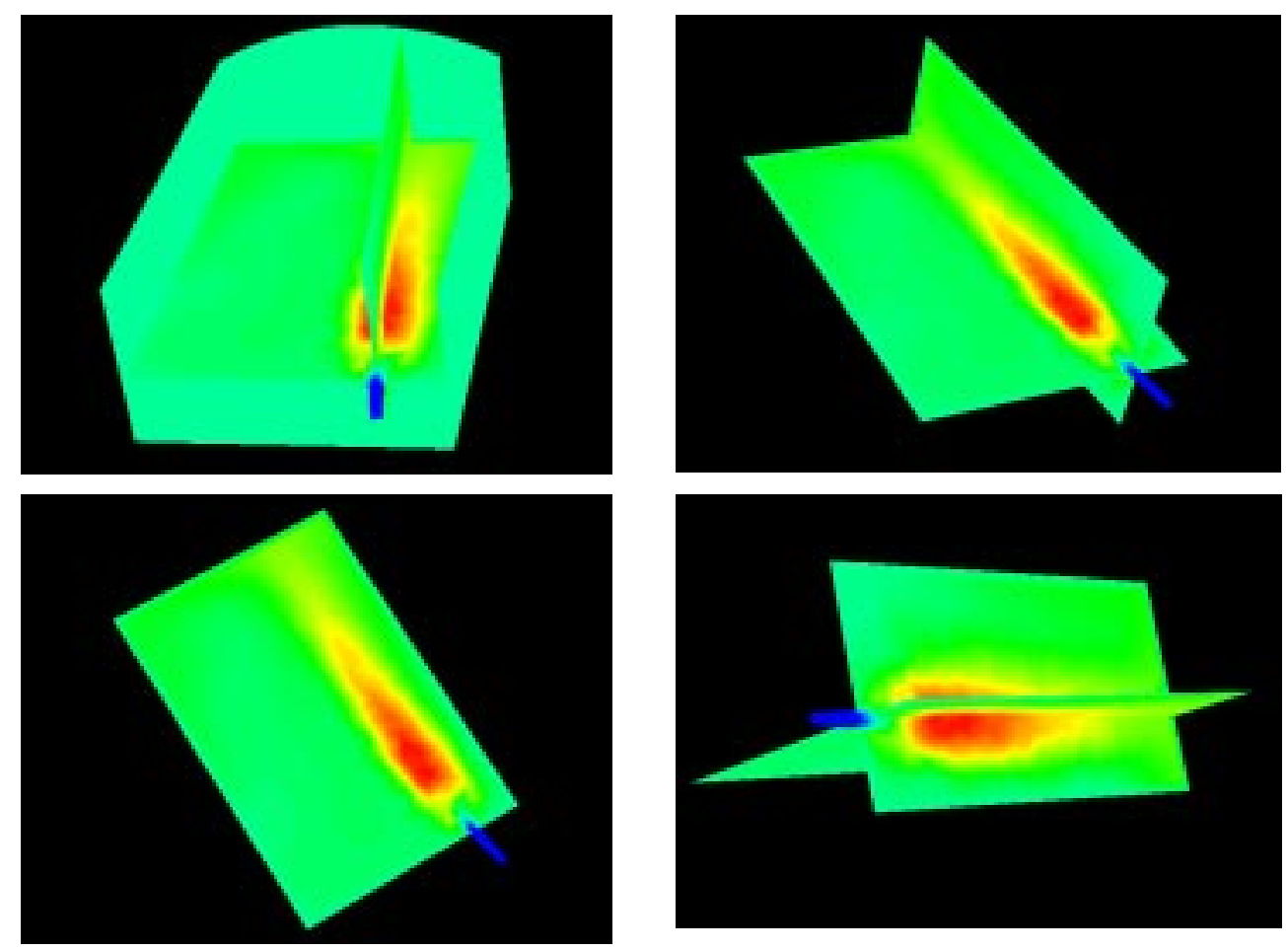

Figure 11.2 Temperature contour with $\beta=7.5^{\circ}$

First, the parallel installation was tested. The results indicated that the flame reached the side wall, which explained why the premature failure of refractory occurred in the nearby sidewall. Then an angle $\beta$ of 7.5 degree was proposed to direct the burner. The result shown that the angle $\beta$ was not big enough and the batch tank length was also too short. As a result, the angle was doubled to 15 degree, which proved to be over adjusted. The circulation of flow made the flame reached the other side of the tank. The right angle is therefore in the range of 7.5 to 15 
degree. In the simulation for burner direction determination, it was also found that the tank length $\mathrm{L}$ was not big enough. Thus the tank length was extended to 2.0 meters. After the tank length $\mathrm{L}$ was extended and the horizontal angle $\beta$ was changed, the iterative simulation found the right angle $\beta$ to be 14 degree for this specific batch tank with the specified coaxial burner. Figure 11.3 shows that the flame is well away from both side walls.
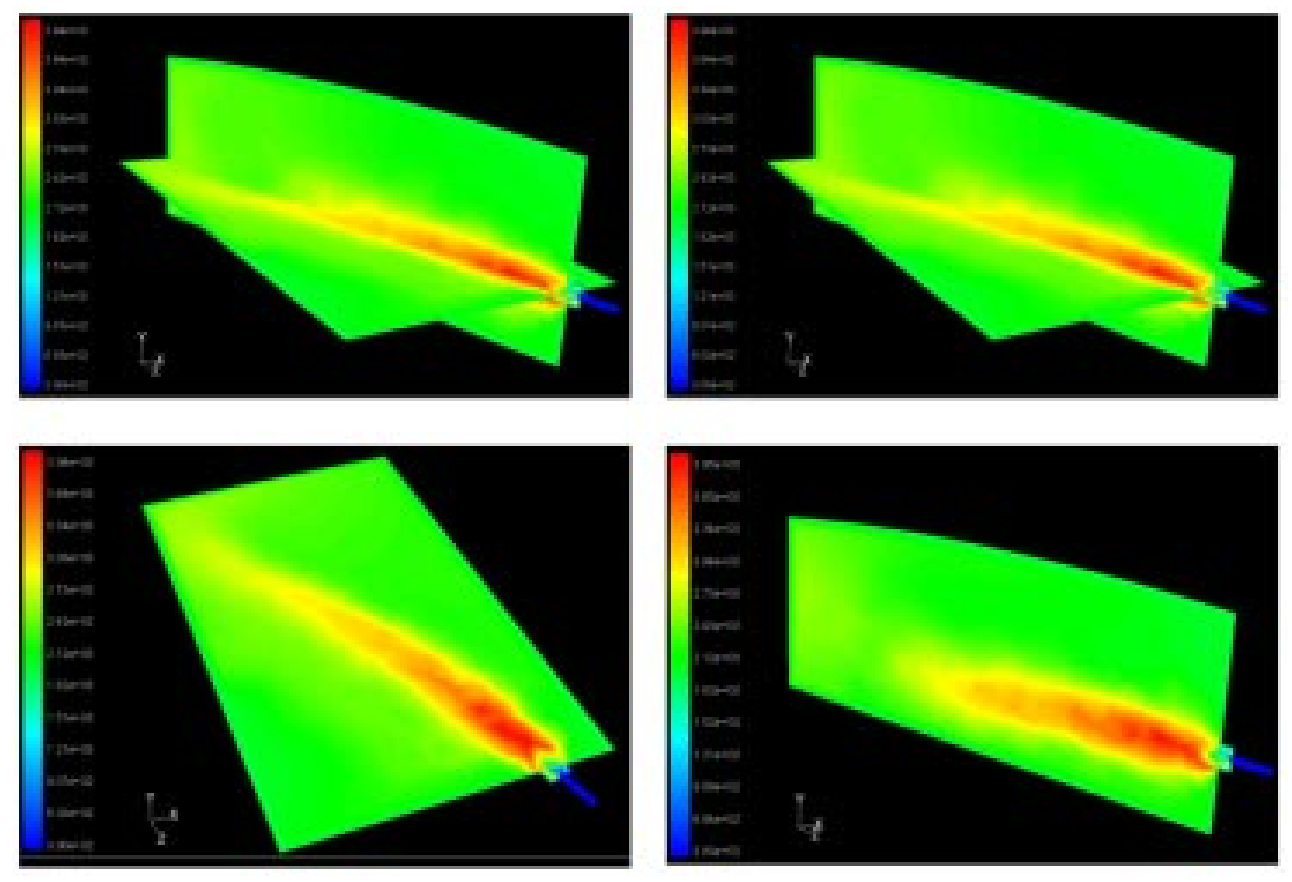

Figure 11.3 Temperature contour for extended tank and redirected burner

This procedure for horizontal angle $\beta$ determination is essential for any situation in which the batch tank geometry and/or the burner type or size are changed.

Other design parameters, such as the tank length $\mathrm{L}$, tank width $\mathrm{W}$, tank height $\mathrm{H}$, burner number, burner installation position and burner jet direction, etc., can be determined using the similar procedure. 


\subsection{Conclusions}

The oxy-fuel burner for a batch tank can be initially selected based on flame simulation results.

The vertical distance between the burner and the glass surface $h_{1}$ is found to be in the range of 0.30 to 0.40 meters. A distance of 0.40 meters is commonly recommended for coaxial burners; and a distance of 0.35 meters is recommended for flat flame burners.

The vertical burner angle $\alpha$ can be set as zero for coaxial burners. This angle $\alpha$ for flat flame burner is non-zero; the proper angle $\alpha$ needs to be determined by simulation for each application. The horizontal angle $\beta$ for any diffusion burner (no matter coaxial burner or flat flame burner) is one of the key factors in burner placement.

Finally, iterative 3-D simulations for those design parameters $\alpha, \beta, \mathrm{h}_{1}, \mathrm{~h}_{2}, \mathrm{~L}, \mathrm{~W}$, and $\mathrm{H}$ finalize the design of a batch tank with burner selection and placement. 


\section{Chapter 12 Summary, Contributions and Future Work}

This chapter is a summary of the research results and conclusions obtained in this research. Relevant details of these results and conclusions are in previous chapters. Some figures from previous chapters are repeated in this chapter.

Contributions of this research and future work that may be extended from this research are also presented in this chapter.

\subsection{Summary}

\subsubsection{Objective}

The six main objectives of this research include (1) Identification of the main design aspects for an oxy-fuel batch tank; (2) Modeling of the physical and chemical processes for the oxy-fuel firing in a batch tank; (3) Identification of the operating and boundary conditions which will be utilized in simulation; (4) Simulation of the oxy-fuel firing in a model combustor to identify the basic flame features for a premixed burner, a coaxial burner and a flat flame burner;

(5) Simulation of the burner placement in a batch tank, involving both tank geometry optimization and burner-tank compatibility; and (6) Identification of the factors for controlling $\mathrm{NO}_{\mathrm{x}}$ formation.

\subsubsection{Approaches}

The primary approach for performing this research is to use computational fluid dynamics (CFD) modeling and simulation. Theoretical analyses and engineering measurements were used to define the models and to validate the simulation results. 


\subsubsection{Results}

\section{$\underline{\text { Identification of Batch Tank Design Aspects }}$}

An on-site investigation of an existing batch tank provides first-hand knowledge of the existing operations and the potential for batch tank design enhancement. For example, local overheating on tank superstructure might be observed. Also the further control of $\mathrm{NO}_{\mathrm{x}}$ emissions from a batch tank is still a challenge. In order to enhance the design of correct batch tanks, the oxy-fuel burner and its flame features, the placement of the oxy-fuel burner in a batch tank, and the geometry features of an oxy-fuel batch tank were specified as the primary design aspects for this research. Flame features include the flame profile and the flame temperature as well as the $\mathrm{NO}_{\mathrm{x}}$ emission level. Burner placement includes the position for installation of a burner in a batch tank and the direction of the burner, i.e., the vertical and horizontal angles for burner alignment. Batch tank geometry design includes the length, the width, the superstructure height, and the burner-tank compatibility.

\section{Modeling}

Geometry Model: A cylindrical combustor can be used to investigate the basic flame features. The geometry of an air-fuel fired batch tank can be taken as a reference for an oxy-fuel batch tank geometry design. The tank geometry as initial modeled can possibly be best adjusted by simulation.

Turbulence Model: The simulation of air-fuel combustion for a batch tank is simulated with the standard k- $\varepsilon$ model. The results indicate that the standard k- $\varepsilon$ model is good for an airfuel tank. When this turbulence model is applied to oxy-fuel firing, the accuracy precision seems reduced. The RNG k- $\varepsilon$ model however significantly increases the accuracy of computation. 
Radiation Model: The selection of a radiation model depends on the optical thickness ( $\alpha \mathrm{L}$, where $\alpha$ is the absorption coefficient and $\mathrm{L}$ is the diameter of the combustion chamber) of the media in the combustion chamber. Generally, when $\alpha \mathrm{L}>3$, the Rosseland radiation model should be used. When $1<\alpha \mathrm{L}<3$, the P-1 model works better. When $\alpha \mathrm{L}<1$, only the DTRM model is appropriate. The calculated optical thickness in a typical batch tank indicated that the P1 model meet the requirement; and the P-1 model is verified to be the most appropriate radiation model for an oxy-fuel fired batch tank.

Chemical Reaction Model: The finite rate is used for methane-oxygen combustion. Both the Arrhenius rate and the turbulent mixing rate need to be calculated simultaneously, although only the smallest is taken to determine the combustion rate. The one-step (5 species) global reaction and two-step ( 7 species) model were both tested, and the difference in simulation results found to be insignificant. Therefore, the one-step global reaction model is used for finite rate calculation. For premixed oxy-fuel combustion, the Arrhenius rate is directly used in the species transport equation; for diffusion flame combustion, the mixing rate is calculated using the eddydissipation reaction model and used in the species transport equation.

$\mathrm{NO}_{\mathrm{x}}$ Formation Model: Thermal $\mathrm{NO}_{\mathrm{x}}$ is dominant in the combustion of natural gas and industrial oxygen. The $\mathrm{NO}_{\mathrm{x}}$ emissions level prediction actually is a post processing calculation based on the oxy-fuel combustion simulation. The prediction has qualitative significance for both burner and tank design as well as tank performance evaluation, but the prediction can not be quantitatively interpreted as an absolute value of $\mathrm{NO}_{\mathrm{x}}$ emission.

Soot Formation Model: Comparison between the one-step soot formation model and the two-step soot formation model shows that the one step soot formation model is appropriate for oxy-fuel combustion in a batch tank. The soot's contribution to heat transfer has been taken into account by using a general soot-radiation interaction model. 


\section{Simulation for Flame from Premixed Burners}

For premixed combustion, a cylindrical model combustor with diameter of 0.6 meters and length of 1.80 meters is used for flame profile identification. The relationship between the oxyfuel velocities and flame length, flame width, and $\mathrm{NO}_{\mathrm{x}}$ mass fraction in the exhaust are shown in Figure 12.1. Note: Figure 12.1 is a repeat of Figures 8.1, 8.2 and 8.4. The results portrayed in this figure indicate that slower oxy-fuel velocities tend to form longer flame. The mass fraction of $\mathrm{NO}_{\mathrm{x}}$ in the exhaust was found to be proportional to the oxy-fuel velocity as shown in the third graph in Figure 12.1.

\section{$\underline{\text { Simulation for Flame from Coaxial Burners }}$}

Both the velocities of the natural gas and the oxygen are dominant factors that determine the flame features of a diffusion flame. In this research, $1 / 4$ inch, $1 / 2$ inch, $3 / 4$ inch and 1 inch inlets for natural gas were studied, based on the same volume flow rate of natural gas; thus, four different natural gas velocities were set. Then for each natural gas velocity, a set of oxygen velocities was achieved by adjusting the oxygen inlet diameters. For all coaxial burners, the natural gas consists of $99 \% \mathrm{CH}_{4}$ and $1 \% \mathrm{~N}_{2}$; the oxygen consists of $98 \% \mathrm{O}_{2}$ and $2 \% \mathrm{~N}_{2}$.

\section{(1) Coaxial burners with a 1/4 inch fuel inlet}

The natural gas inlet diameter was first set as $1 / 4$ inch or 0.0064 meters, and then the oxygen velocity was adjusted by using different oxygen inlet diameters. The fuel velocity is fixed at $146.50 \mathrm{~m} / \mathrm{s}$, and oxygen velocities varied from $8.10 \mathrm{~m} / \mathrm{s}$ to $102.6 \mathrm{~m} / \mathrm{s}$.

Figure 12.2 shows the flame length and the flame width at various oxygen velocities. It seems the flame profiles are very alike. Figure 12.3 shows the peak temperature of the flame and the $\mathrm{NO}_{\mathrm{x}}$ emission. Note: Figure 12.2 is a repeat of Figures 9.2, and Figure 12.3 is a repeat of Figure 9.3, respectively. There is a variation in the peak temperature of the flames, but all are around $3500 \mathrm{~K}$, which is pretty high. The $\mathrm{NO}_{\mathrm{x}}$ emissions at various oxygen velocities depend on 
the flame temperature and flame zone volume, The mass fraction of NOx in the exhaust is at around 0.00130 , and because of the small variation in flame size and flame temperature, the variation of $\mathrm{NO}_{\mathrm{x}}$ emissions is within $10 \%$.

\section{(2) Coaxial burners with a $1 / 2$ inch fuel inlet}

Compared to the $1 / 4$ inch burner, the $1 / 2$ inch $(0.0128 \mathrm{~m})$ burner introduces natural gas into combustion chamber through the burner for the same supply pressure at a much slower velocityone fourth the velocity of the $1 / 4$ inch burner.

Figure 12.4 shows the flame length and flame width of a coaxial burner with $1 / 2$ inch fuel inlet, which introduces the fuel into the combustor at $36.5 \mathrm{~m} / \mathrm{s}$. Note: Figure 12.4 is a repeat of Figures 9.5. The flame lengths are around 1.30 meters; the flame width increases with the oxygen velocity.

Figure 12.5 shows the peak temperature and the $\mathrm{NO}_{\mathrm{x}}$ emissions of burners with a $1 \frac{1}{2}$ inch fuel inlet. Note: Figure 12.5 is a repeat of Figures 9.6. The peak temperature increases with oxygen velocity. The mass fraction of $\mathrm{NO}_{\mathrm{x}}$ in the exhaust seems to be very stable; and it is lower than that from coaxial burners with a $1 / 4$ inch fuel inlet.

\section{(3) Coaxial burners with a $3 / 4$ inch fuel inlet}

The natural gas inlet diameter was set as 0.0200 meters (around 3/4 inch), for which the natural gas velocity is $15.0 \mathrm{~m} / \mathrm{s}$. Various velocities of the oxygen were obtained by adjusting the annular oxygen inlet diameter from 0.040 to 0.11 meters.

Figure 12.6 shows the flame profile as a function of oxygen velocity. Note: Figure 12.6 is a repeat of Figures 9.7. It seems that the oxygen velocity has very limited effect on flame length and flame width for the given natural gas velocity of $15.0 \mathrm{~m} / \mathrm{s}$.

Figure 12.7 shows the peak temperature of flame and the $\mathrm{NO}_{\mathrm{x}}$ emissions from coaxial burners with a $3 / 4$ inch diameter fuel inlet. Note: Figure 12.7 is a repeat of Figures 9.8. The peak 
temperature of the flame increases with oxygen velocity, indicating that the faster the mixing the higher the temperature. Compared to burners with a $1 / 4$ or $1 / 2$ inch diameter fuel inlet, the flame temperature is lower. The $\mathrm{NO}_{\mathrm{x}}$ emission seems to be insensitive to the oxygen velocity, and the absolute value is about the same as that from a coaxial burners with a $1 / 2$ inch fuel inlet.

\section{(4) Coaxial burners with a 1 inch fuel inlet}

The natural gas velocity from a 1 inch diameter inlet is relatively low, being only 9.16 $\mathrm{m} / \mathrm{s}$. For this fixed natural gas velocity, nine oxygen velocities were set to form a series of mixing patterns and flames.

Figure 12.8 shows that when the oxygen velocity is in the range of 2.0 to $4.0 \mathrm{~m} / \mathrm{s}$, both the flame length and flame width contribute to form a larger flame coverage. Note: Figure 12.8 is a repeat of Figures 9.9. Figure 12.9 shows that a lower oxygen velocity also contributes to a lower $\mathrm{NO}_{\mathrm{x}}$ emission.

\section{(5) Fuel Velocity vs. Flame Features}

Fuel inlet diameters of $1 / 4,1 / 2,3 / 4$ and 1 inch are used in coaxial burners while keeping the volume flow rate of the fuel the same. These burners introduce fuel into the combustor at very different flow velocities, which are $146.5 \mathrm{~m} / \mathrm{s}, 36.5 \mathrm{~m} / \mathrm{s}, 15.0 \mathrm{~m} /$, and $9.16 \mathrm{~m} / \mathrm{s}$, respectively. The influence of fuel inlet size on the flame features is shown in Figure 12.10. Note: Figure 12.10 is a repeat of Figures 9.11. 

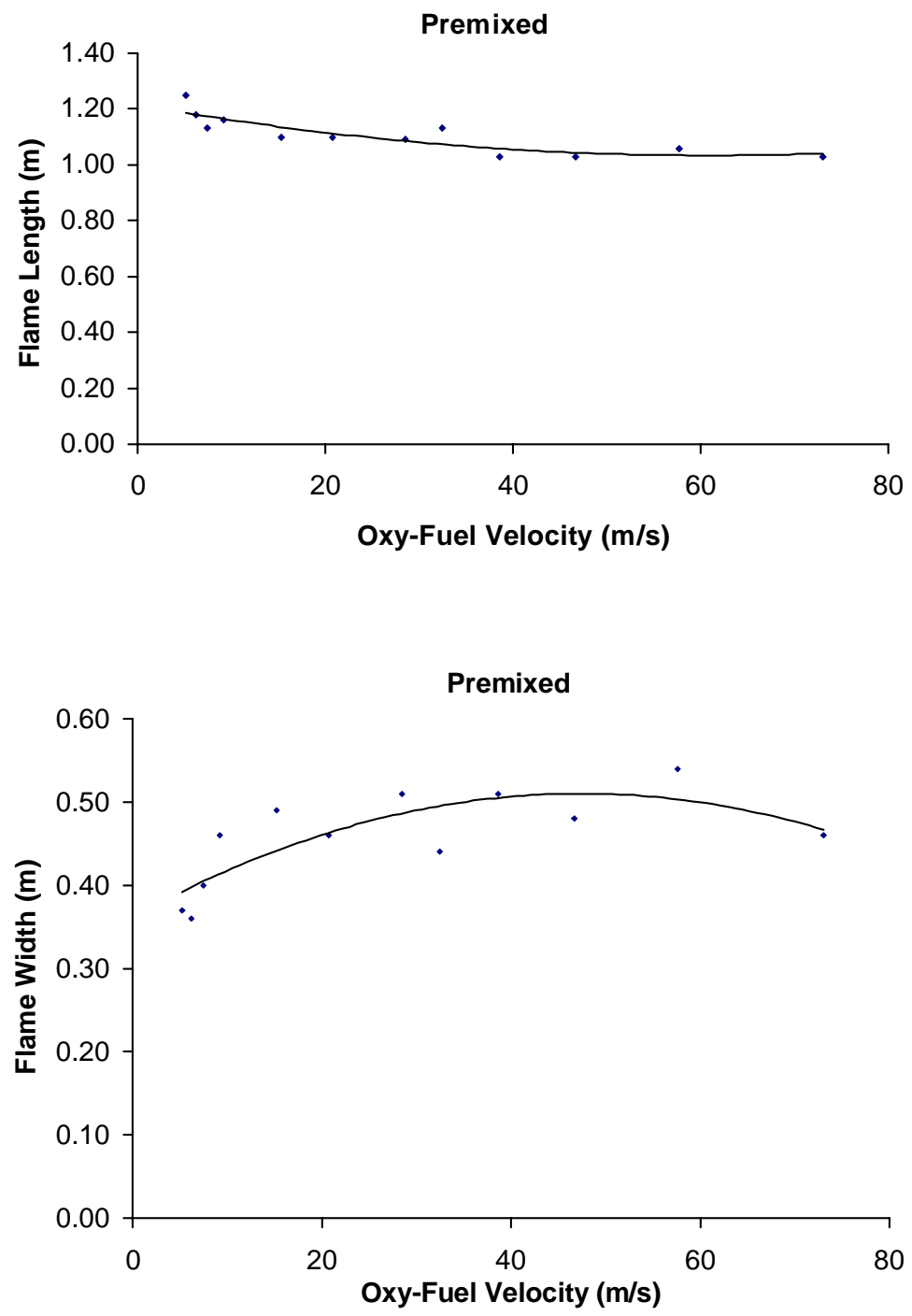

Premixed

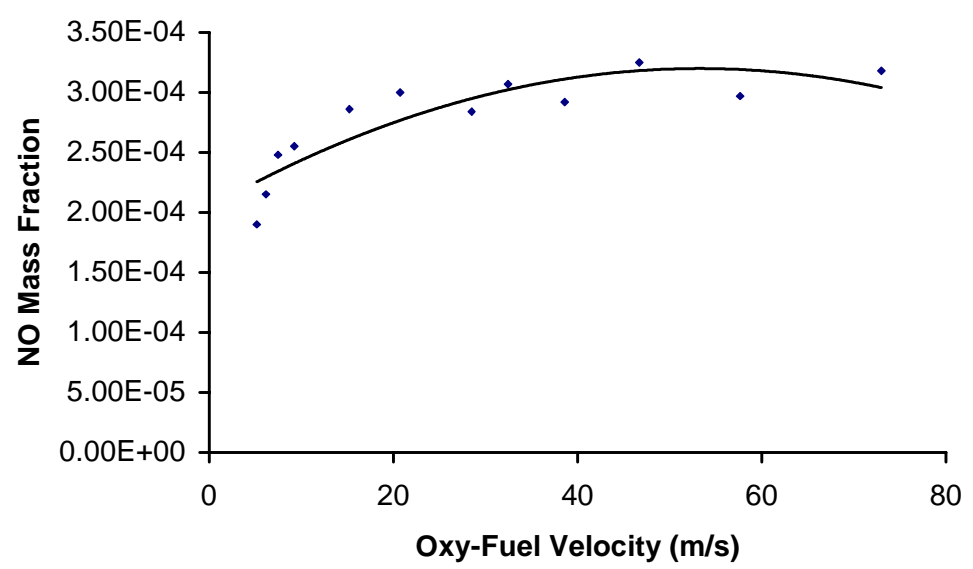

Figure 12.1 Premixed flame profile and $\mathrm{NO}_{\mathrm{x}}$ emission 


$$
V_{\text {fuel }}=146.5 \mathrm{~m} / \mathrm{s}
$$

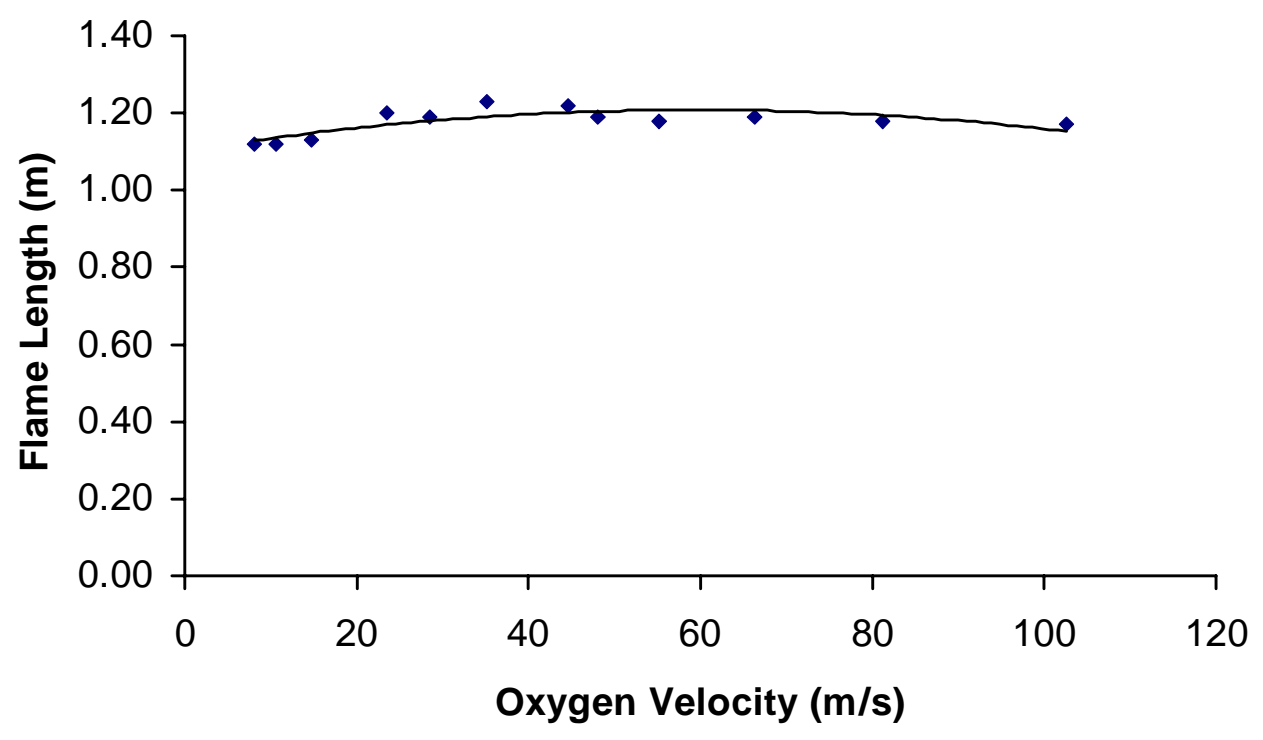

$$
V_{\text {fuel }}=146.5 \mathrm{~m} / \mathrm{s}
$$

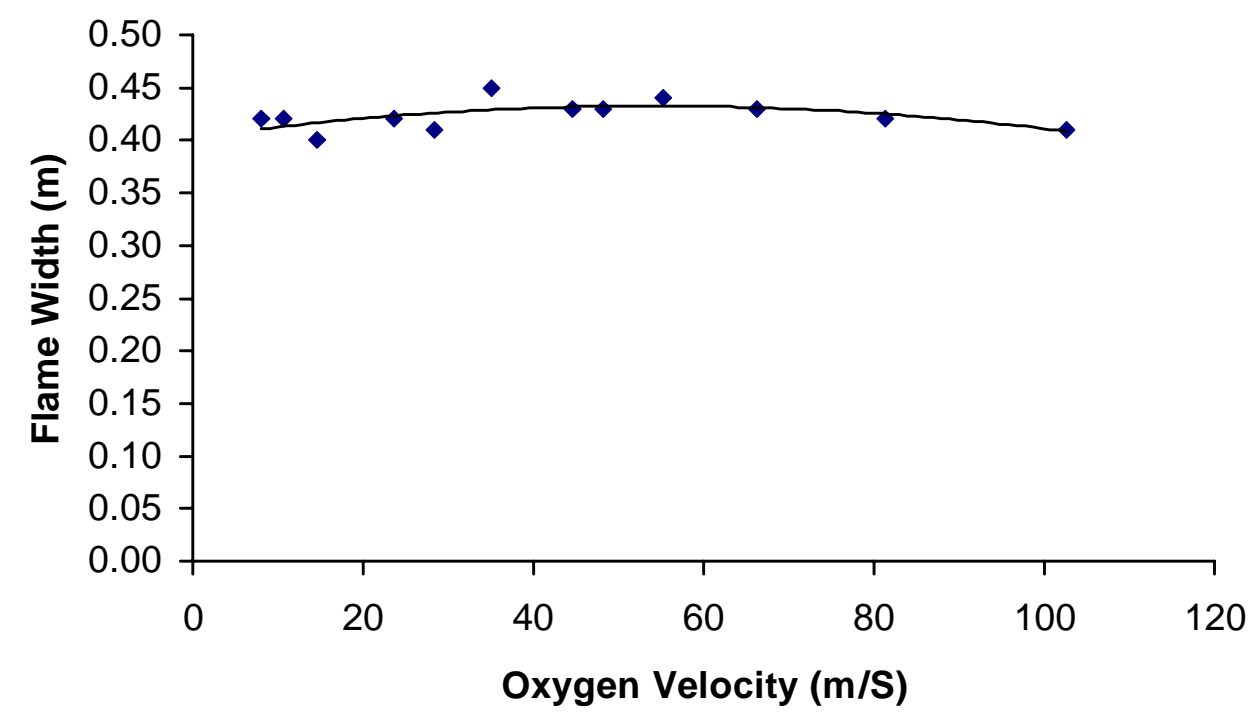

Figure 12.2 Flame length and flame width of a coaxial burner with $1 / 4$ inch fuel inlet 


$$
V_{\text {fuel }}=146.5 \mathrm{~m} / \mathrm{s}
$$

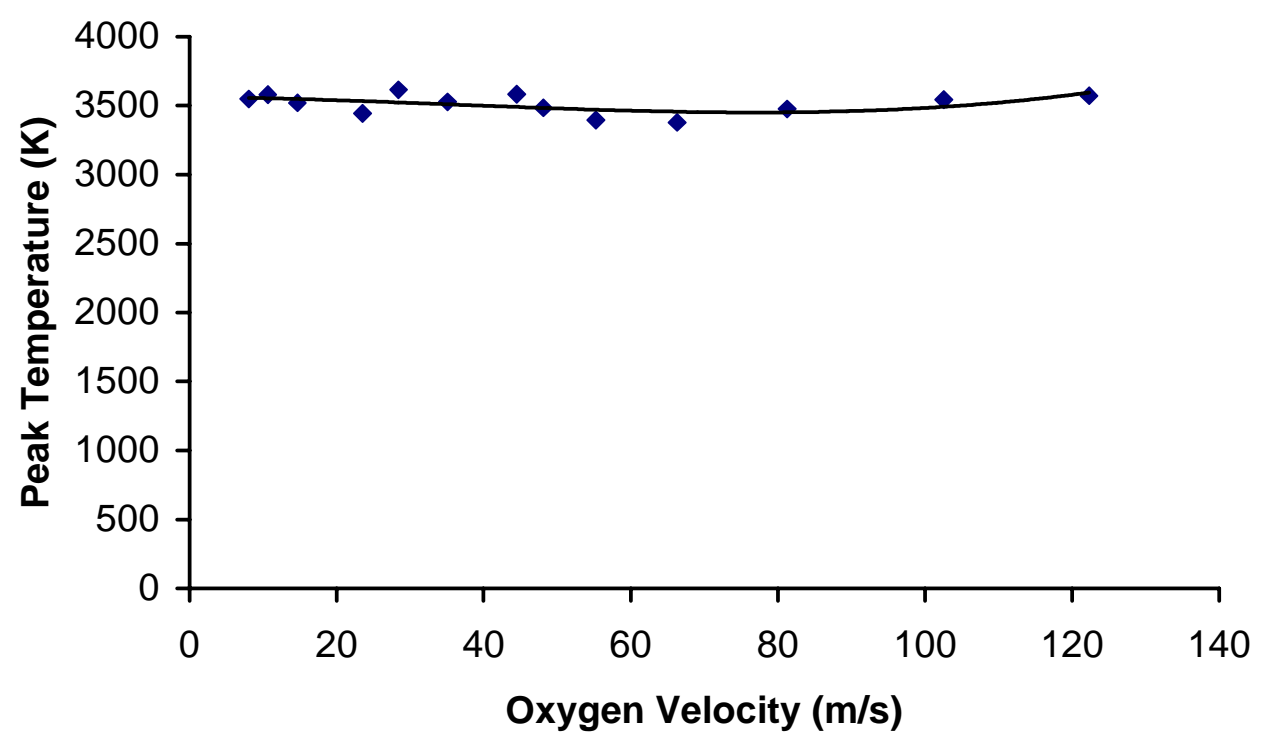

$V_{\text {fuel }}=146.5 \mathrm{~m} / \mathrm{s}$

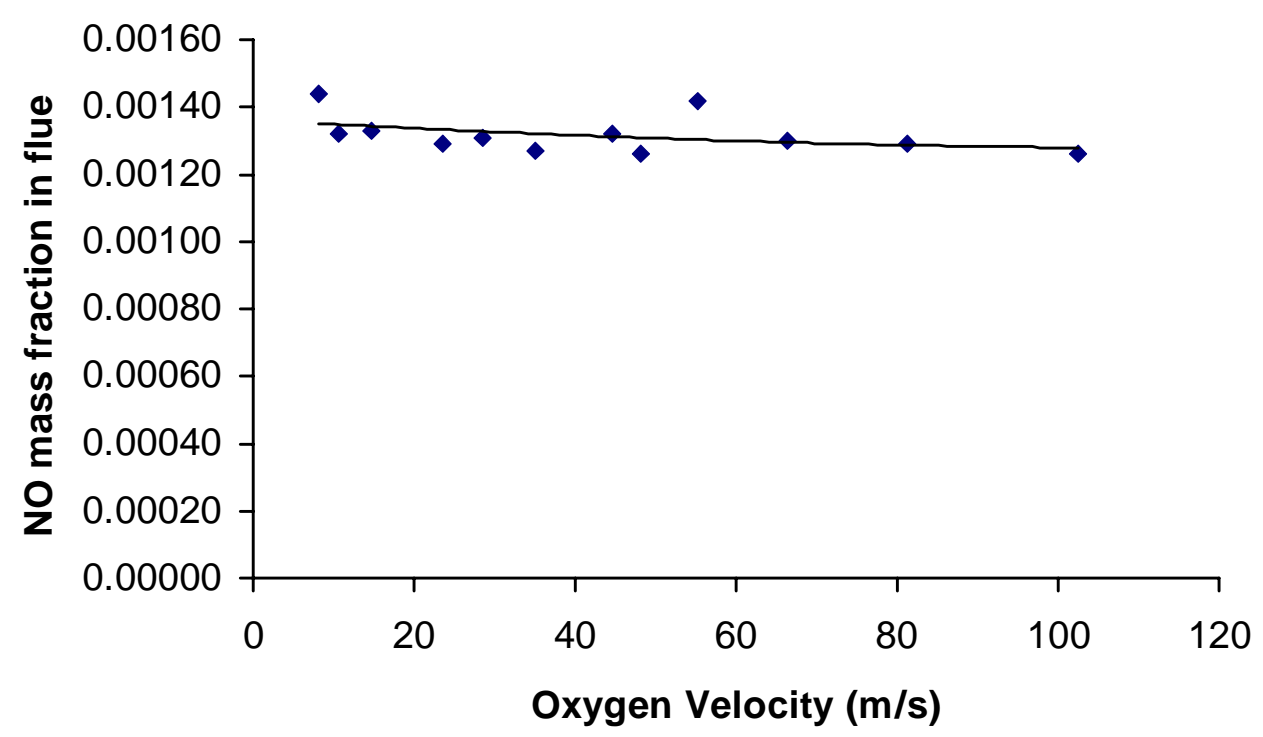

Figure 12.3 Peak temperature and $\mathrm{NO}_{\mathrm{x}}$ emission of a coaxial burner with $1 / 4$ inch fuel inlet 


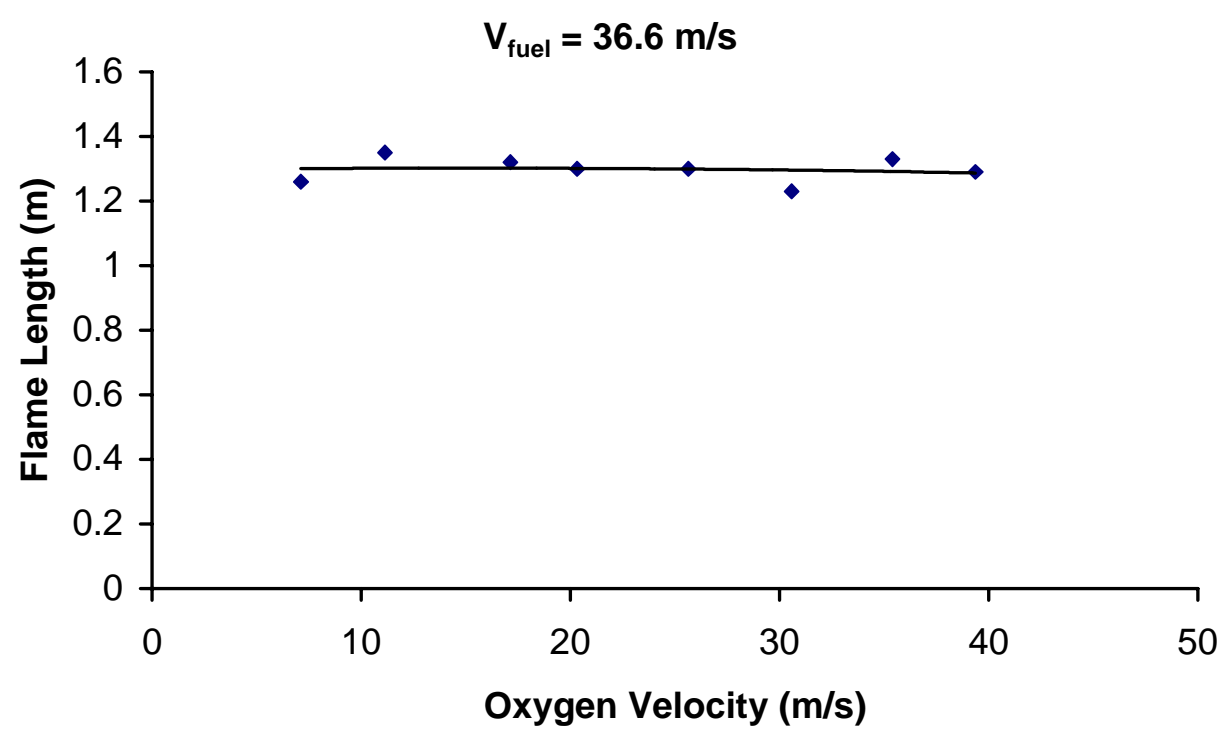

(a)

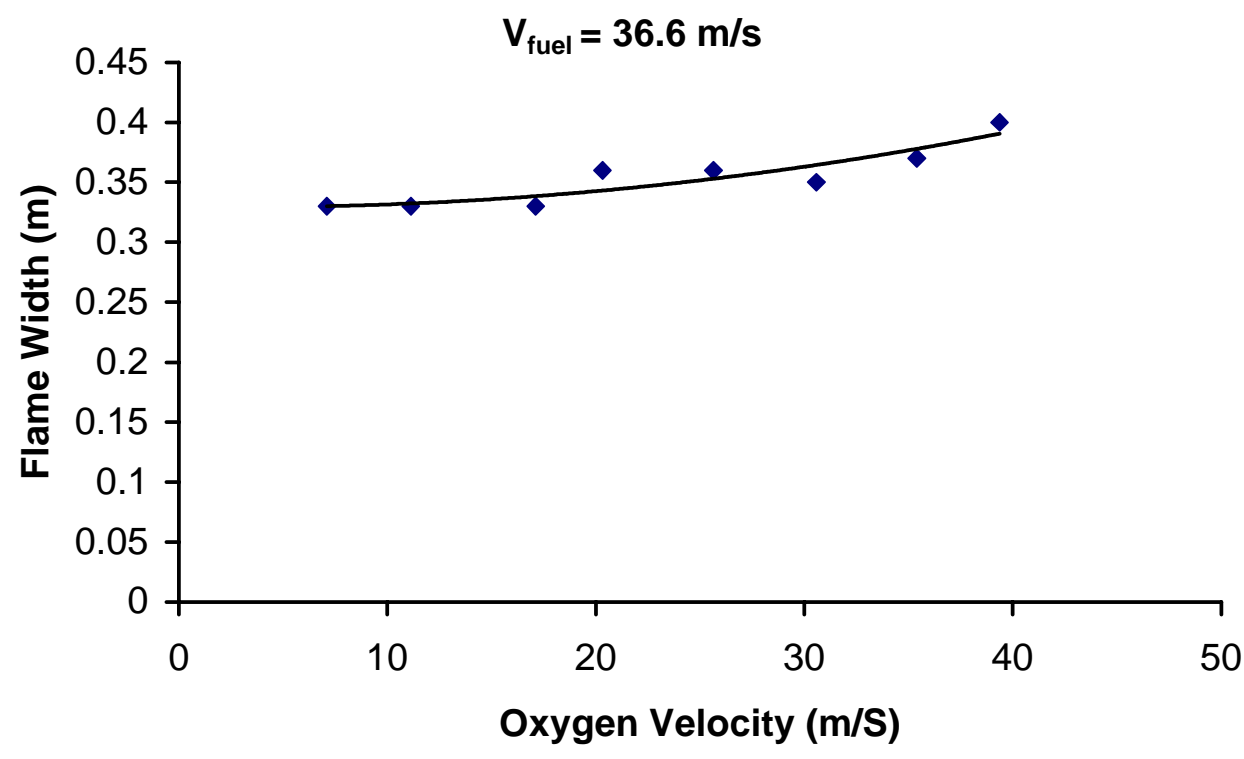

(b)

Figure 12.4 Flame length and flame width of a coaxial burner with $1 / 2$ inch fuel inlet 

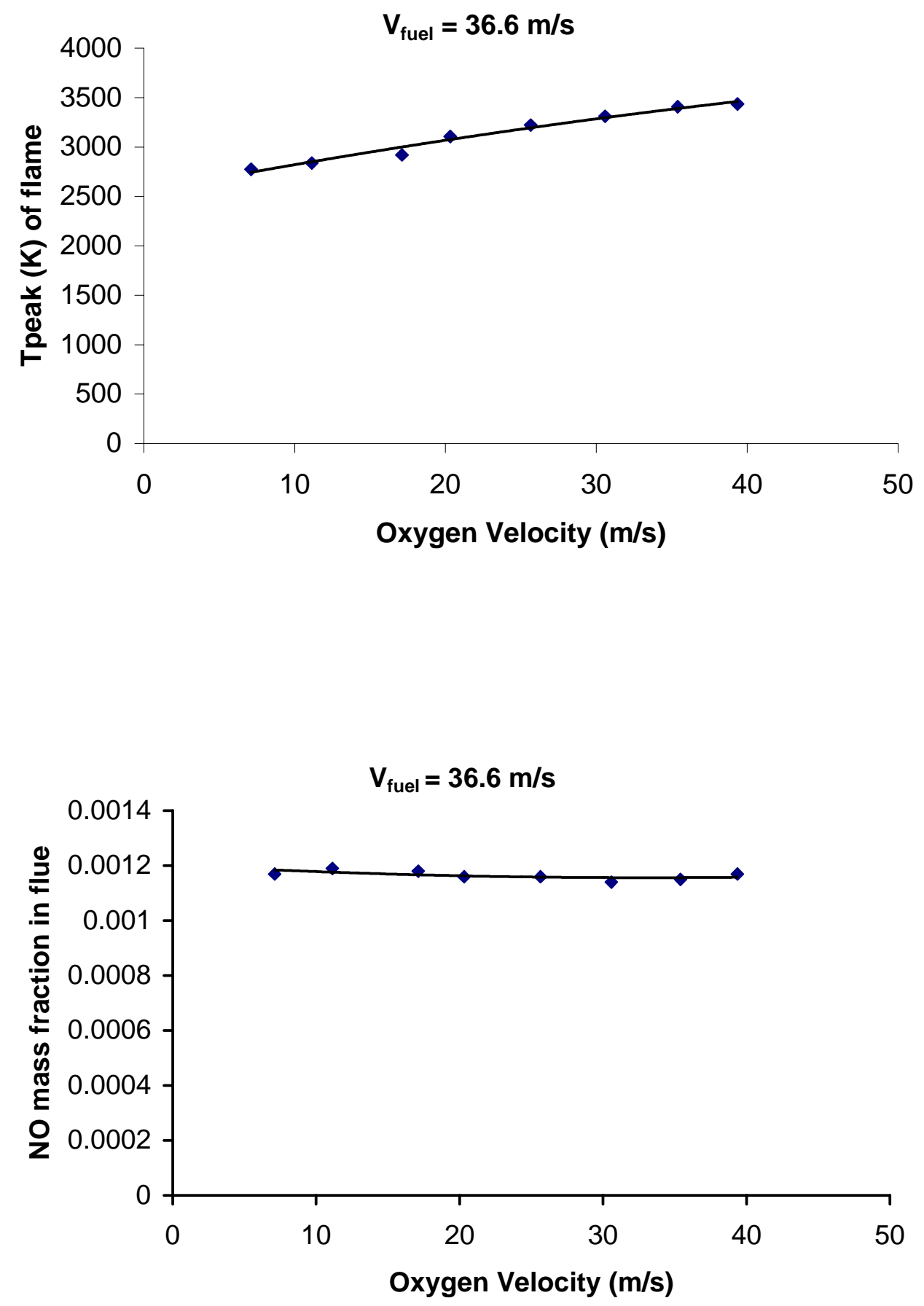

Figure 12.5 Peak temperature and $\mathrm{NO}_{\mathrm{x}}$ emission of a coaxial burner with $1 / 2$ inch fuel inlet 


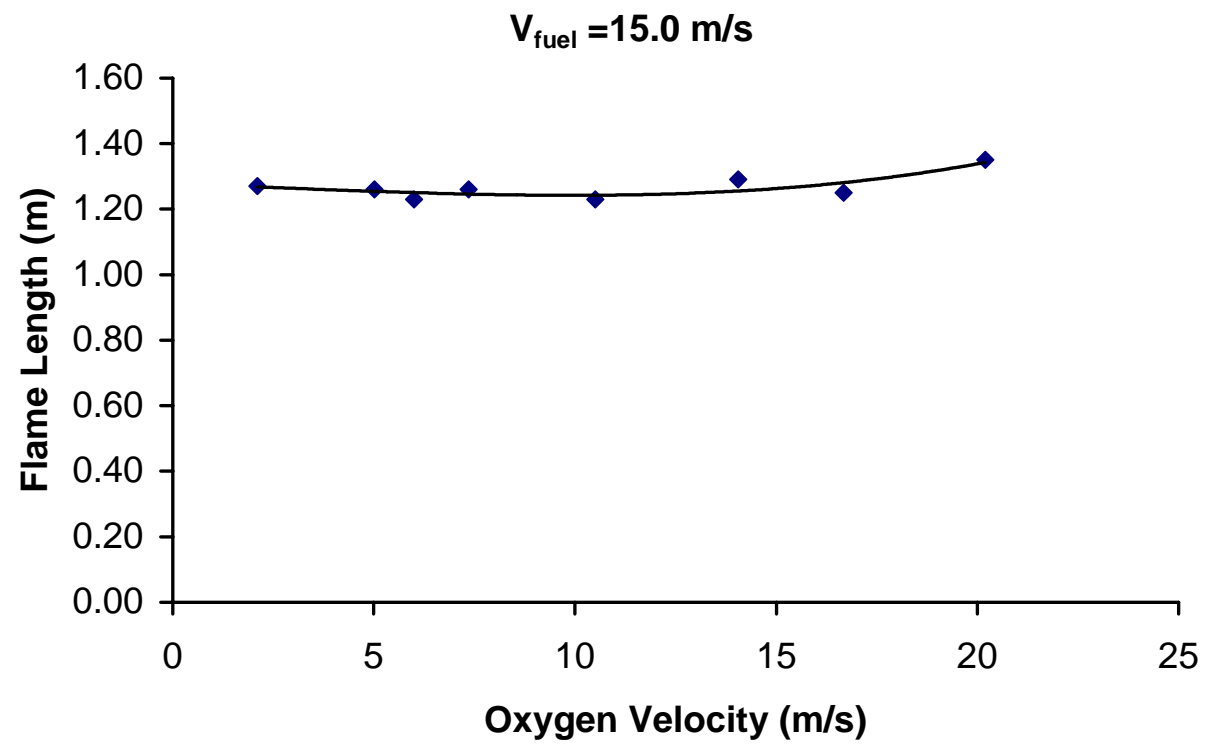

(a)

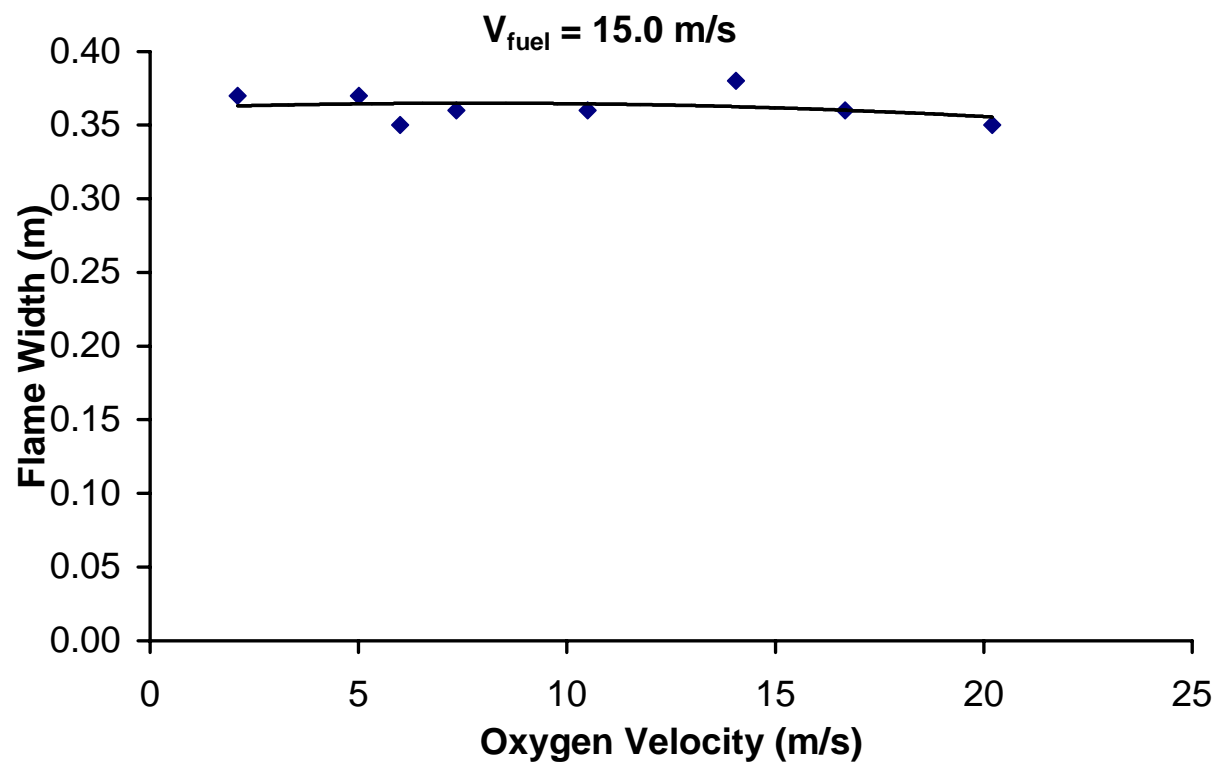

(b)

Figure 12.6 Flame length and flame width of a coaxial burner with $3 / 4$ inch fuel inlet 


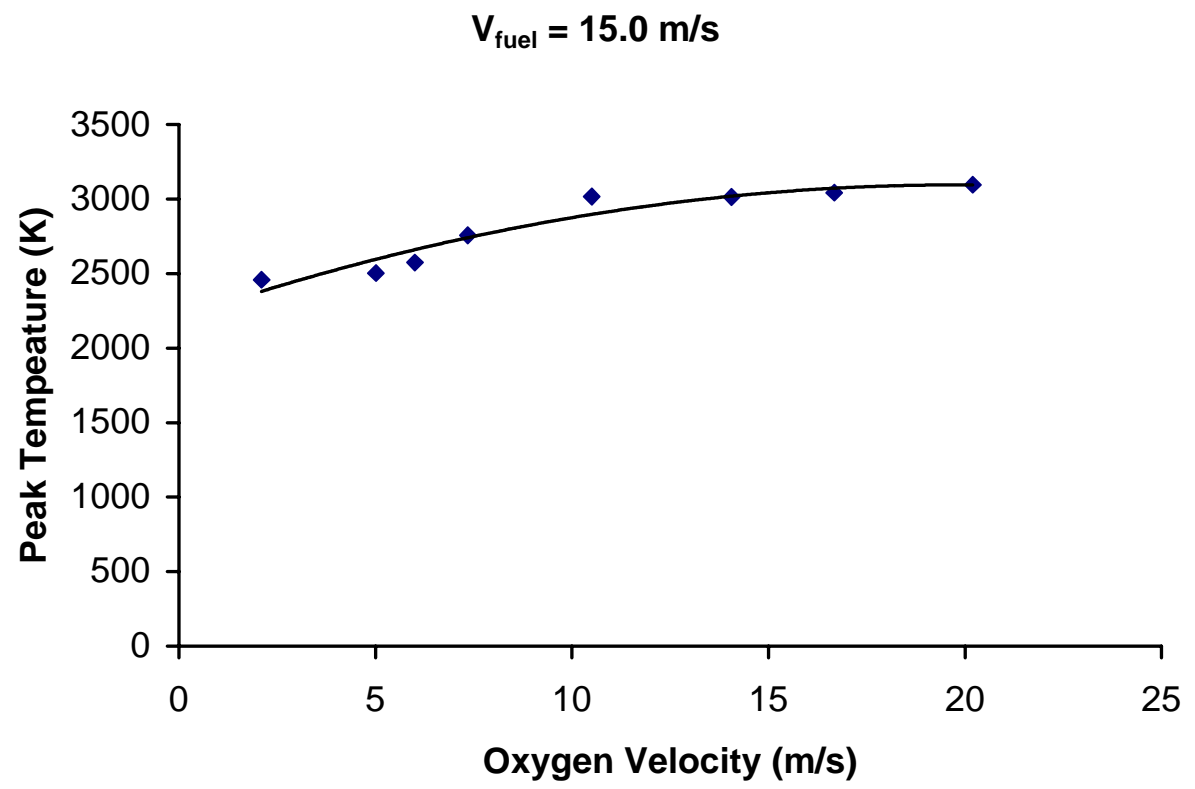

(a)

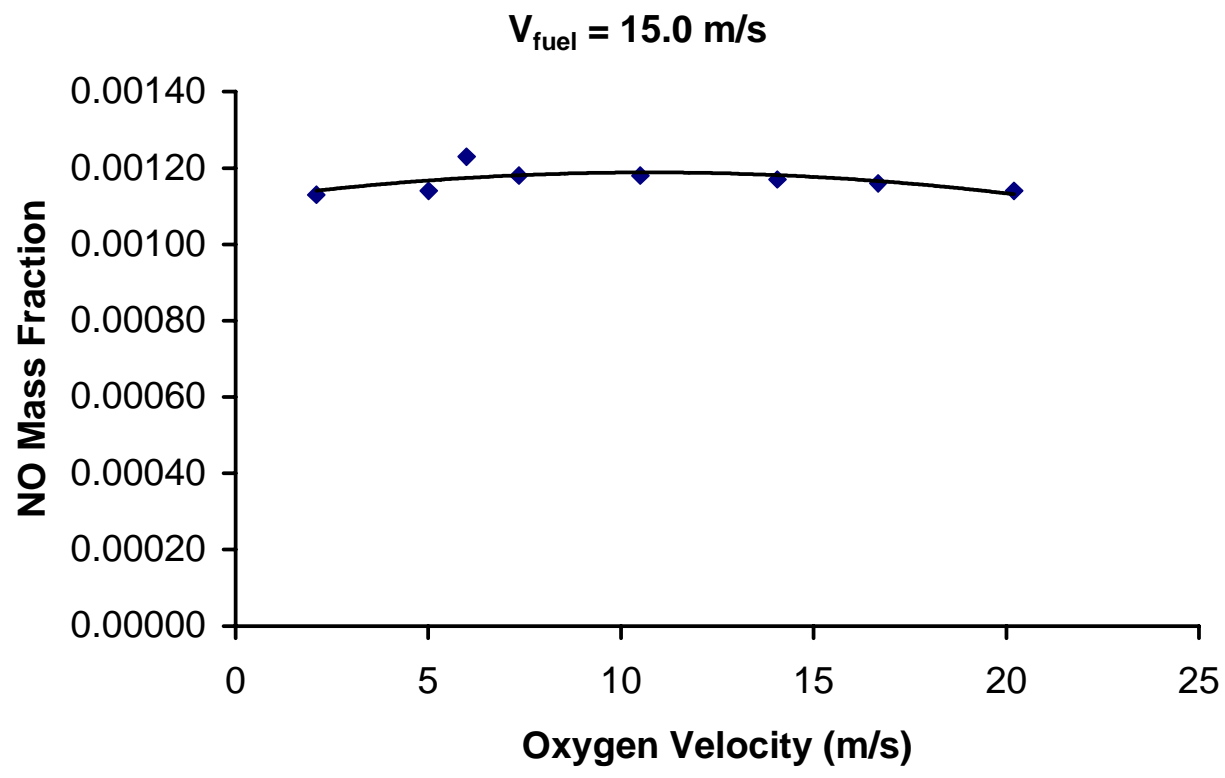

(b)

Figure 12.7 Peak temperature and $\mathrm{NO}_{\mathrm{x}}$ emission of a coaxial burner with $3 / 4$ inch fuel inlet 


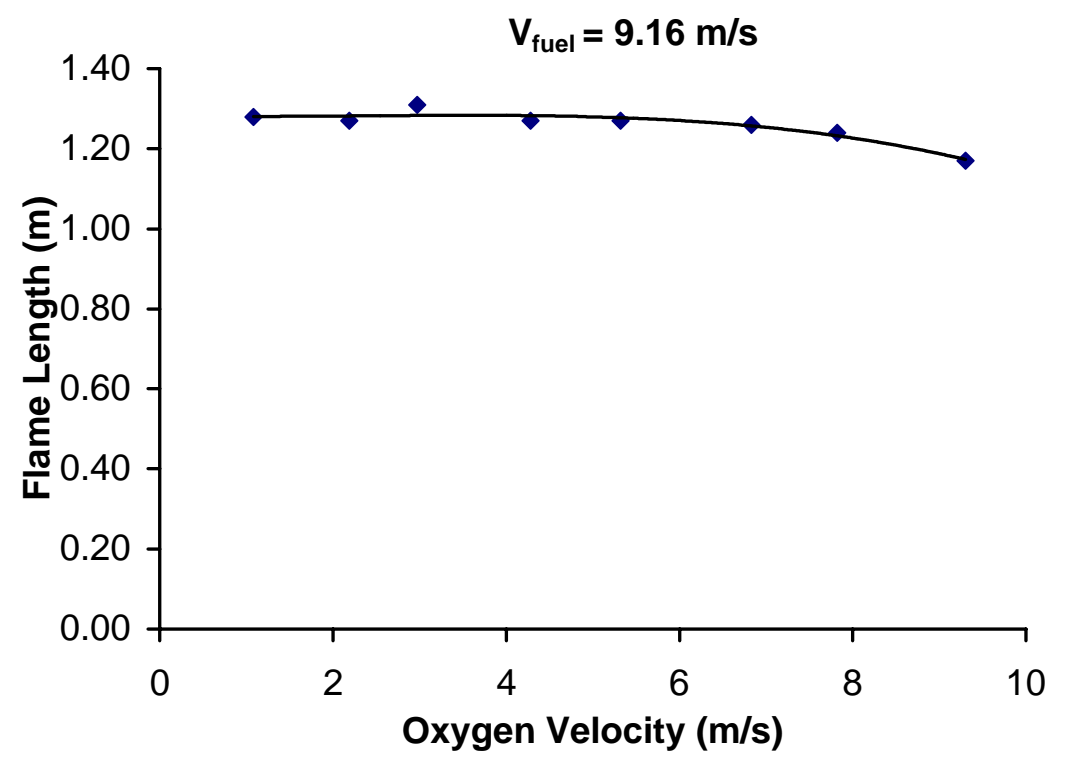

(a)

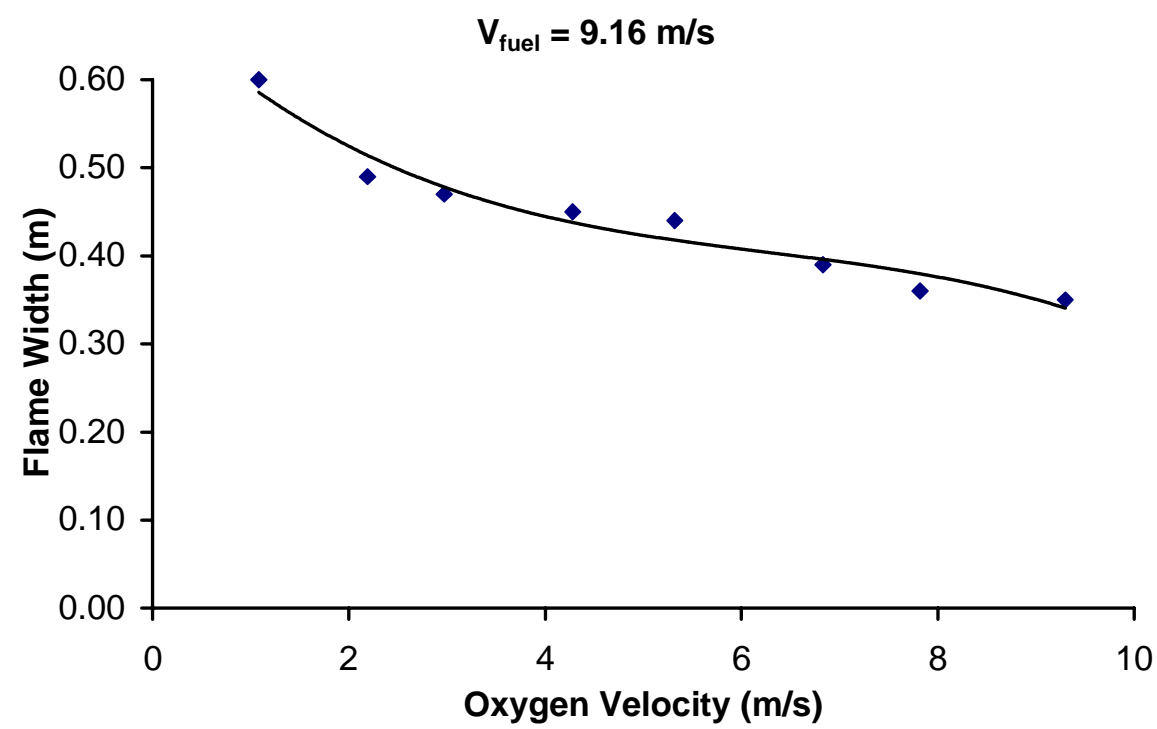

(b)

Figure 12.8 Flame length and flame width of a coaxial burner with 1 inch fuel inlet 


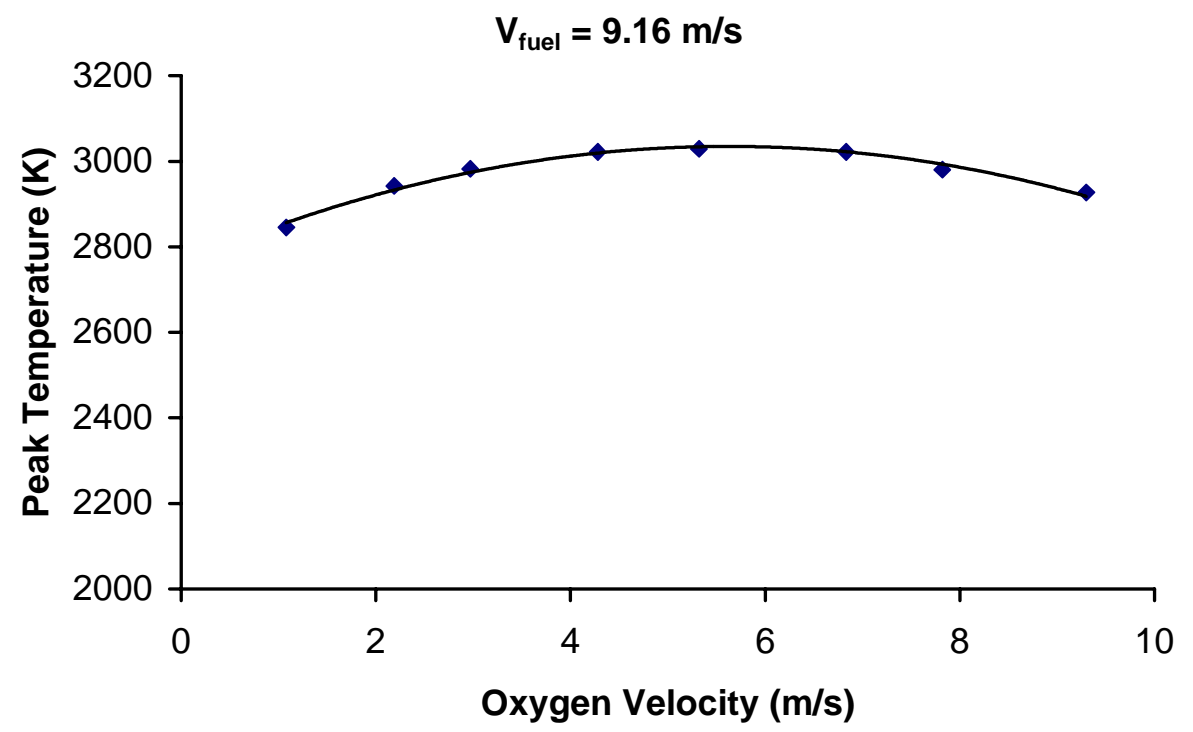

(a)

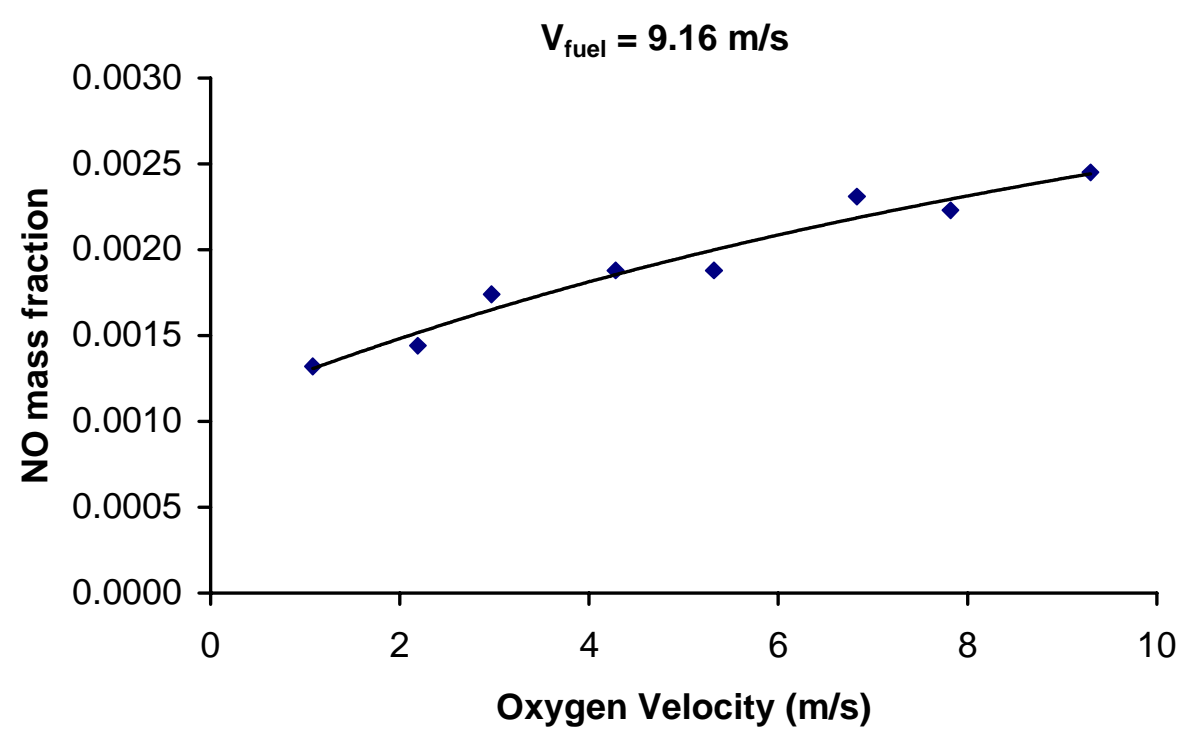

(b)

Figure 12.9 Peak temperature and $\mathrm{NO}_{\mathrm{x}}$ emission of a coaxial burner with 1 inch fuel inlet 

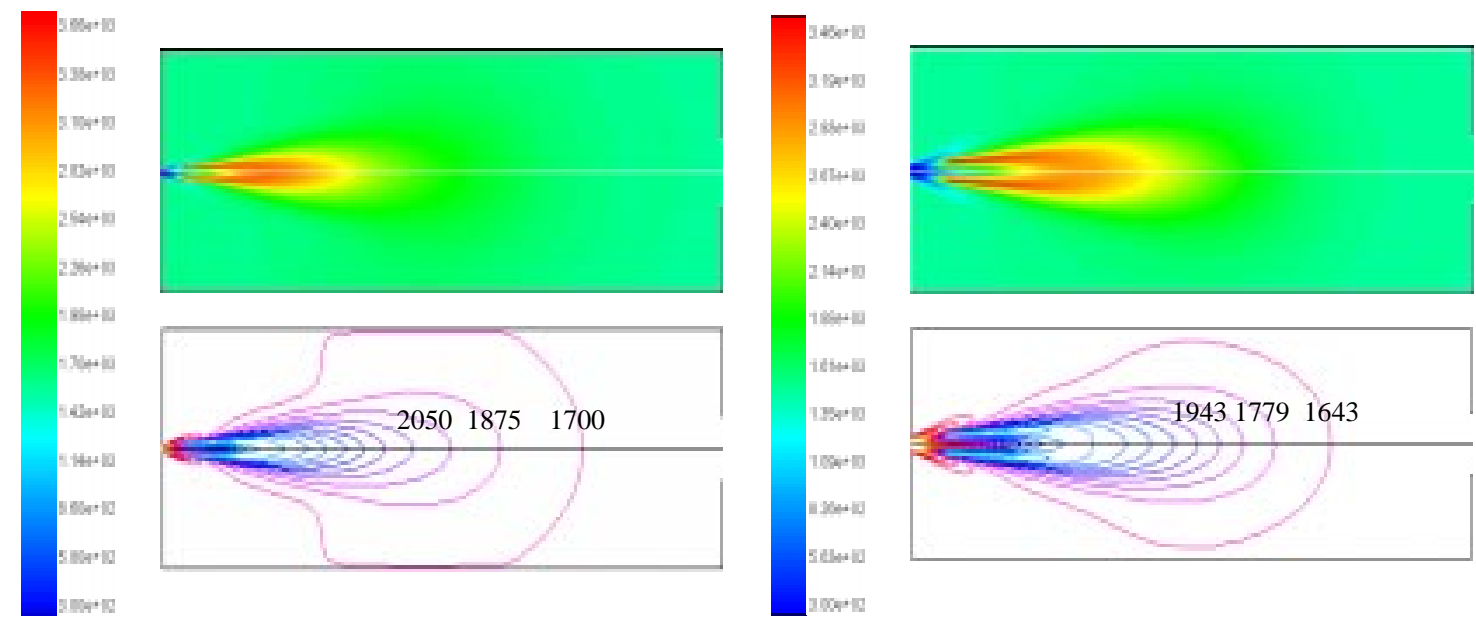

(a) $1 / 4$ inch fuel inlet

(b) $1 / 2$ inch fuel inlet
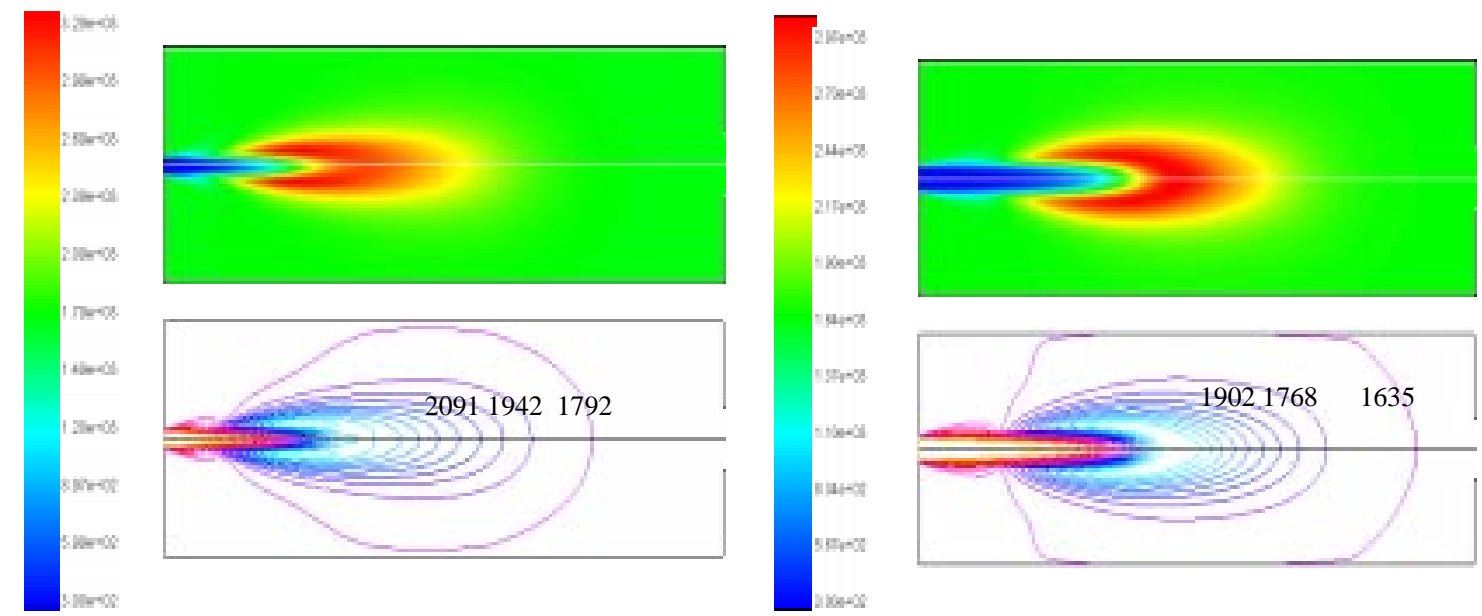

(c) $3 / 4$ inch fuel inlet

(d) 1 inch fuel inlet

Figure 12.10 Fuel velocity vs. flame profile 


\section{Simulation of Flat Flame Profile}

A flat flame has a larger flame coverage over the glass surface and will have a higher flame luminosity. Therefore, a flat flame has a higher heat transfer to the glass and less possibility of overheating the superstructure refractory. The flat flame's hot zone shape is shown in Figure 12.11. Note Figure 12.11 is a repeat of Figure 10.3. More details about flat flame features are presented in Chapter 10, refer Figures 10.1 to 10.5.

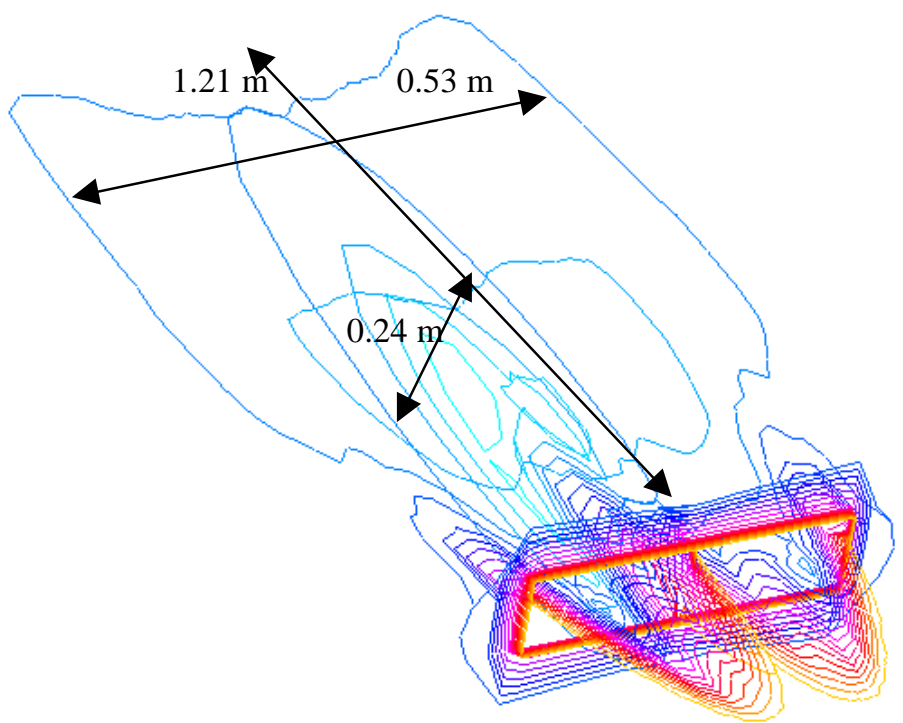

Figure 12.11 Flat flame geometry

Lower velocities for the fuel flow and oxygen flow are required for a flat flame formation. With the velocities less than $10 \mathrm{~m} / \mathrm{s}$, the effect of buoyancy on flame propagation can not be neglected. A vertical pitch angle $\alpha$ downward is needed. In this research, an angle $\alpha$ of 6 degree for a $600 \mathrm{SCFH}$ flat flame burner was able to successfully counteracted the buoyancy of the flame propagation. 


\section{$\underline{\text { Simulation of Burner Placement versus Tank Geometry }}$}

Based on the obtained flame features, a series of simulations for burner placement versus tank geometry were conducted using 3-dimensional simulations.

The simulation for burner placement was conducted for two purposes. First, to prevent the overheating on refractory caused by flame contact and second, to put the flame in a proper position for better heat transfer to the glass. For a typical batch tank with a $2500 \mathrm{lb}$. capacity, a single burner is used and the proper horizontal angle $\beta$ for the burner placement is between $9 \sim 15^{\circ}$.

The simulation for tank geometry concentrates on two parameters: length and crown height. The tank width is not as significant as the tank length and the crown height, because the proper burner placement solves the width design.

For $\mathrm{NO}_{\mathrm{x}}$ emissions control, both a fuel rich and a fuel lean combustion were simulated. Both the fuel rich and the fuel lean combustion tend to lower the $\mathrm{NO}_{\mathrm{x}}$ emissions. However, the fuel rich combustion results in higher soot emission, e.g., $0.2 \%$ in the flue. In addition, most hand glassmaking processes need excess oxygen to enable the metallic reaction for coloring. Therefore, fuel lean combustion is required. Fuel lean combustion results in a lower flame temperature, which reduces the thermal $\mathrm{NO}_{\mathrm{x}}$ formation.

\subsection{Contributions}

This research utilized the method of the CFD modeling and simulation to explore design enhancements for a batch tank for the hand glass industry. With the results and procedures developed in this research, a batch tank design engineer may take today's CFD technology as a common design tool to enhance the batch tank design. The analyses and simulation verification

confirmed the identified models for the physical and chemical processes in oxy-fuel firing. Those models such as the turbulence model, the radiation model, the chemical reaction model, the soot 
formation and soot-radiation interaction model, and the $\mathrm{NO}_{\mathrm{x}}$ formation model are now recommended for oxy-fuel batch tank design engineers for the purpose of their future use.

This research studied the behavior of oxy-fuel firing for a premixed burner. This provided some insights on oxy-fuel firing which are hard to gain from real engineering tests because of safety. For example, the $\mathrm{NO}_{\mathrm{x}}$ emissions from premixed combustion was found to be much lower than the $\mathrm{NO}_{\mathrm{x}}$ emission from diffusion combustion. This leads to an exploration of a potential way of controlling $\mathrm{NO}_{\mathrm{x}}$ emissions.

To meet the most application needs for the hand glass industry, the commonly used coaxial burner was systematically studied. In a batch tank, the fuel inlet diameter is usually less than 1 inch. Research on four sizes of fuel inlet $(1 / 4,1 / 2,3 / 4$, and 1 inch inlets) was conducted. The effect of fuel velocity and oxygen velocity on burner behavior, such as flame size, flame temperature and $\mathrm{NO}_{\mathrm{x}}$ emissions were identified. The understanding of coaxial oxy-fuel burner behavior obtained provides a guide for the selection of an oxy-fuel burner for a given batch tank to meet the required melting capacity, melting temperature, and the $\mathrm{NO}_{\mathrm{x}}$ emission regulation.

The flat flame burner has been used in continuous glass melting furnaces while the traditional coaxial oxy-fuel burner is still the main choice for a batch tank. Thus, the study of a flat flame burner specifically for a batch tank was also conducted in this research. The flat flame has a larger flame coverage over the glass surface which will increase the melting efficiency; the thinner vertical flame thickness and lower flame temperature will extend the life expectancy of the batch tank.

The placement of oxy-fuel burner in a batch tank in terms of its location and direction was investigated as an effort aimed at extending the life expectancy of the batch tank. The horizontal yaw angle of the burner direction was found to be a very important design aspect in burner installation. For example, for a typical batch tank with $2500 \mathrm{lb}$. melting capacity, an angle of 14 degrees away from the side wall of the batch tank was found appropriate. Other parameters 
for burner placement such as the vertical distance above the glass surface and the vertical pitch angle of the burner direction were studied too.

Finally, iterative simulations optimized the burner placement versus the tank geometry, and the burner-tank compatibility was checked. The temperature distribution within the designed batch tank also provides information for other design concerns such as the location of the batch feeding port and the location of the glass melt gathering port.

\subsection{Future Work}

High luminosity flames are preferred for oxy-fuel firing in a batch tank. The modeling of soot formation is the most important aspect of combustion modeling for prediction of high luminosity firing. Further study on both the modeling and simulation of soot formation as well as soot-radiation interaction will improve the prediction accuracy of high luminosity flames.

Size limitations for a batch tank might prevent the flat flame burner block structure from fitting its usual installation position. An asymmetric burner block be may needed for the proper use of the flat flame burner in a batch tank to avoid the possible overheating of the refractory. 


\section{REFERENCES}

[1] James P. Shaffer, Ashok Saxena, Stephen D. Antolovich, Thomas H. Sanders, Jr., and Steven B. Warner, The Science and Design of Engineering Materials, second edition, McGraw Hill, Boston, 1999.

[2] Glass Dictionary, www.glassonline.com/dictionary/index.HTML

[3] Mike Nelson, "Oxy-Fuel in North America", Workshop Proceedings of Oxy-Fuel Issues for Glassmaking in the 90's, DOE/Conf-970292, February 27, 1997. pp217-227.

[4] Robert Moore, "Glass Contact/Superstructure Refractories for Oxy-Fuel Melters”, Workshop Proceedings of Oxy-Fuel for Glassmaking in the 90's, DOE/Conf-970292, February 27, 1997. pp263-280.

[5] Stephen R. Turns, An Introduction to Combustion-Concepts and Applications, McGraw Hill, Inc., New York, 1996. pp480-488.

[6] Anthony J. Gallo, "How to Better Understand $\mathrm{NO}_{\mathrm{x}}$ Requirements", Glass Industry, November 1994. pp16-22.

[7] “Glass Industry Solutions”, Gas Research Institute Digest, Chicargo, IL, 1998.

[8] William J. Snyder, Frederic N. Steigman, and Abilio Tasca, "Several Factors are Fueling the Movement in Oxygen Firing Conversion”, Glass Industry, March 1994. pp14-19.

[9] "Switch to Oxy-fuel Gives GE More Glass Capacity (Conversion to 92\% oxy-fuel lowers plant emissions)", Glass Industry, May 1998. pp24-25.

[10] Daniel Wishnick and Andrew Mclver, "Burner Technologies Are Improved for Glassmaking", Glass Researcher, vol.8, 1998. p18.

[11] John Brown, "Path to the First Large Glass Container Oxy-fuel Furnace in the United States", Glass Researcher, Vol. 8, 1998. pp16-17. 
[12] Ronald W. Schreoder, "Development of Oxy-Fuel Technology in the Glass Industry", Glass Researcher, volume 8, 1998. pp1-4.

[13] "Pilkington LOF Fires Up Oxy-Fuel Glass Manufacturing Line", (news) Glass Researcher, vol. 8, 1998. p18.

[14] Greg Prusia, "Flat Flame Burners Well-Suited to Oxy-Fuel Glass Melting", Glass Researcher, vol. 8, 1998. p11.

[15] Roberto Ruiz, Steve Wayman, Benjamin Jurcik, Louis Philippe, and Jean-Yves Iatrides, “Oxy-Fuel Furnace Design Considerations”, Glass industry, May 1995. pp10-23.

[16] Erik Muysenberg, “TNO--Glass Technology”, Workshop Proceedings of Oxy-Fuel Issues for Glassmaking in the 90's, DOE/Conf-970292, February 27, 1997. pp254-261.

[17] Ronny Eriksson, Don Coe, Rudiger Eichler, "Measurement and Control of $\mathrm{NO}_{\mathrm{x}}$ in OxygenFired Glass Furnaces”. 52nd Conference on Glass Problems held at the University of Illinois at Urbana-Champaign November $12 \& 13,1991$.

[18] John Brown, "Future Oxygen Needs for the Glass Industry". Workshop Proceedings of OxyFuel Issues for Glassmaking in the 90's, DOE/Conf-970292, February 27, 1997. pp51-53.

[19] Geoffrey Hintz, “Oxygen Supply Systems_-VPSA/PSA Plants”, Workshop Proceedings of Oxy-Fuel Issues for Glassmaking in the 90's, DOE/Conf-970292, February 27, 1997. pp916.

[20] Rakesh Govind, "Chemical Absorption of Oxygen", Workshop Proceedings of Oxy-Fuel Issues for Glassmaking in the 90's, DOE/Conf-970292, February 27, 1997. pp17-26.

[21] Jack Machnis, "Paramagnetic Oxygen Separation", Workshop Proceedings of Oxy-Fuel Issues for Glassmaking in the 90's, DOE/Conf-970292, February 27, 1997. p27-32.

[22] P. J. Mohr and D. B. Wishnick, Combustiontec. Inc., "100\% Oxygen-Fuel Firing of Glass Melting Furnaces-Case History", draft paper.

[23] Mechanical Engineering, November 1998. p63.

[24] Henry Halem, Glass Notes-a reference for the glass artist. Franklin Mills Press, 1999. 
[25] R. R. McConnel \& R. E. Goodson, "Modeling of Glass Furnaces Design for Improved Energy Efficiency”. Glass Technology, vol.20, 1979. pp100-106

[26] H. Mase and K. Oda, "Mathematical Model of Glass Tank Furnace with Batch Melting Process", Journal of Non-crystal Solids, vol. 38-39, 1980. pp807-812.

[27] F. Simonis, H. De Waal, and R. C. G. Beerkens, "Influence of Furnace Design and Operation Parameters on the Residence Time Distribution of Glass Tanks, Predicted by Computer Simulation", XIV International Congress on Glass, New Delhi, 1986, Part III, pp118-27.

[28] M. G. Carvalho, P. Oliveila, and V. Semiao, “A-Three-Dimensional Numerical Modeling of an Industrial Glass Furnace”, J. Inst.Energy, 09/1988. pp143-56.

[29] M.G Carvalho and M. Nogueira, "Model-Based Evaluation of Oxy-Fuel Glass Melting Furnace Performance", Ceramics Engineering and Science Proceedings of the $199556^{\text {th }}$ Conference on Glass Problems, Oct. 24-25, 1995. Vol.17 no.2, 1996, Urbana, IL, USA. pp121-131.

[30] D. Shamp, O. Marvin et al, "Oxy-Fuel Furnace Design Optimization Using Coupled Combustion/Glass Bath Numerical Simulation", $59^{\text {th }}$ Conference on Glass Problems, Columbus, OH, Oct. 27-28, 1998. pp23-36.

[31] OIT Times Newsletter, US DOE, Office of Industrial Technologies, 1999.

[32] Benjamin Jurcik, Jr., and Carol Schnepper "Geometric Considerations for Modeling Oxyfuel Glass Tanks”. Glass Industry, April 1996. pp28-30.

[33] FLUENT Website, http://www.fluent.com/solutions/glass/index.htm

[34] O.M.G.C. Op den Camp, E.G.J. Peters, and V.O. Aume, "Mathematical Modeling of Forehearths", 59 $9^{\text {th }}$ Conference on Glass Problems, October 27-28, 1998. Columbus, OH. pp133-142

[35] E. N. Tiratsoo, Natural Gas, 1972. 
[36] Gary L. Borman and Kenneth W. Ragland, Combustion Engineering, McGraw-Hill, 1998, p29.

[37] Michael J. Moran and Howard N. Shapiro, Fundamentals of Engineering Thermodynamics, $3^{\text {rd }}$ edition, John Wiley \& Sons, Inc. New York, 1995. pp822 827.

[38] North American Combustion Handbook. Vol.I: Combustion, Fuels, Stoichiometry, Heat Transfer, Fluid Flow. Third edition, North American Mfg. Co., Cleveland, OH, 1986.

[39] Yunus A. Cengel, Heat Transfer--A Practical Approach, McGraw Hill, 1999.

[40] J. P. Holman, Heat Transfer, $8^{\text {th }}$ edtion, McGraw-Hill, 1997. p647-648.

[41] FLUENT 5, User's Guide, Vol. 5.

[42] J.M. Rhine and R.J. Tucker, Modeling of Gas-Fired Furnaces and Boilers and Other Industrial Heating Processes. McGraw-Hill, 1991.

[43] Michael F. Modest, Radiative Heat Transfer, McGraw Hill, 1993. pp370, Figure 9.18.

[44] Correspondence with Dr. Nuray Kayakol at Sisecam Glass Research Center, Istanbul, Turkey.

[45] M. Frenklach, H. Wang, and M. J. Rabnowitz, "Optimization and Analysis of Larger Chemical Kinetic Mechanism Using the Solution Mapping Method-Combustion of Methane," Progress in Energy and Combustion Science, 18: 47-73 (1992).

[46] I.M. Khan and G. Greeves. "A Method for Calculating the Formation and Combustion of Soot in Diesel Engines", Heat Transfer in Flames, chapter 25. Scripta, Washington DC, 1974.

[47] P. A. Tesnes, T. D. Snegiriova, and V. g. Knorre. "Kinetics of Dispersed Carbon Formation”. Combust. Flame, 17:253-260, 1971.

[48] Eugene A. Avallone and Theodore Baumeister III, Mark's Standard Handbook for Mechanical Engineers, ninth edition, McGraw Hill, 1986.

[49] Frank M. White, Fluid Mechanics, fourth edition, McGraw Hill, Boston, 1999. 